IRINEU DE BRITO JUNIOR

LOCALIZAÇÃO DE DEPÓSITOS DE SUPRIMENTOS DE ALÍVIO PARA RESPOSTA A DESASTRES ATRAVÉS DE PROGRAMAÇÃO LINEAR ESTOCÁSTICA E ANÁLISE DE DECISÃO COM MÚLTIPLOS CRITÉRIOS

SÃO PAULO

2015 
IRINEU DE BRITO JUNIOR

\section{LOCALIZAÇÃO DE DEPÓSITOS DE SUPRIMENTOS DE ALÍVIO PARA RESPOSTA A DESASTRES ATRAVÉS DE PROGRAMAÇÃO LINEAR ESTOCÁSTICA E ANÁLISE DE DECISÃO COM MÚLTIPLOS CRITÉRIOS}

Tese de doutorado apresentada à Escola Politécnica da Universidade de São Paulo para obtenção do título de Doutor em Ciências.

Área de concentração:

Engenharia de Produção

Orientador: Professor Livre Docente Hugo T. Y. Yoshizaki

Coorientadora: Professora Doutora Adriana Leiras

SÃO PAULO 
Este exemplar foi revisado e corrigido em relação à versão original, sob responsabilidade única do autor e com a anuência do orientador.

São Paulo, 21 de maio de 2015

Assinatura do auto

Assinatura do orientador

\section{Catalogação-na-publicação}

Brito Junior, Irineu de

Localização de depósitos de suprimentos de alívio para resposta a desastres através de programação linear estocástica e análise de decisão com múltiplos critérios / I. Brito Junior -- versão corr. -- São Paulo, 2015.

$233 \mathrm{p}$.

Tese (Doutorado) - Escola Politécnica da Universidade de São Paulo. Departamento de Engenharia de Produção.

1.Logística 2.Desastres ambientais 3.Programação estocástica 4.Tomada de decisão 5.Operações humanitárias I. Universidade de São Paulo. Escola Politécnica. Departamento de Engenharia de Produção II.t. 


\section{AGRADECIMENTOS}

Aos meus orientadores Hugo e Adriana, que além do auxílio na elaboração deste trabalho, foram companheiros de pesquisas e lutaram para o início dos estudos sobre Logística Humanitária na Universidade de São Paulo. Ao Paulo por mostrar as oportunidades de pesquisa sobre o assunto fora do Brasil e pela oportunidade em Lugano.

Aos professores Miriam e André pelas sugestões produtivas que muito auxiliaram a elaboração desta pesquisa.

Ao pessoal da Defesa Civil do estado de São Paulo, especialmente Homero, Kamada, Cintia, Paulo Henrique, Araújo Monteiro e Ornelas pelas discussões produtivas, informações operacionais e avaliações que contribuíram muito para a elaboração e pelos resultados deste trabalho.

Aos companheiros de turma e pessoal do Cislog Everton, Celso, Flávio, Joice, Otávio, Tábata e Luísa pelas discussões e sugestões que promoveram a melhoria do trabalho. A Fabi por todo apoio durante esses anos.

Flávia, Sebastian, Gloria e Sara pela recepção em Lugano e pelas discussões e opiniões que promoveram a visualização de outros pontos de vista e realidades.

A Capes pelo suporte financeiro em Lugano e ao Centro Paula Souza por permitir a realização deste trabalho.

Aos meus pais, Irineu e Eneida e meus irmãos, Maurício e Fábio pelas palavras de apoio e pelo suporte em São Paulo.

A Helenice e Aline que tiveram a paciência e compreensão pelos momentos de ausência não cabe agradecer, mas compartilhar este trabalho. 


\section{RESUMO}

Com o aumento do número de desastres e consequente incremento no número de pessoas vitimadas, a preparação para esses eventos é uma necessidade das sociedades modernas. Neste sentido, o planejamento das operações logísticas para atendimento as situações de emergências é uma atividade recente e pouco explorada na produção acadêmica. O objetivo deste trabalho é estabelecer uma metodologia para definir locais para o pré-posicionamento de materiais utilizados no socorro a populações afetadas por desastres através de um modelo de otimização estocástica de dois estágios e análise de decisão multicritério e que considerem parâmetros quantitativos e qualitativos. Com base nos custos de transporte e do não atendimento a demanda, e utilizando informações como mapeamentos de riscos; custos de transporte; histórico de ocorrências de desastres; cobertura geográfica; compras de materiais; capacidades de depósitos e de transporte, um modelo estocástico de programação linear minimiza os custos operacionais para abastecimento às vítimas. Uma análise detalhada sobre como atribuir penalidades para demanda não atendida também é apresentada. Devido à incerteza quanto a severidade de um desastre e a influência da mídia nas fases pós-desastres estes parâmetros são representados na forma de cenários. O resultado do modelo estocástico mostra a quantidade de locais e quais localidades minimizam o custo operacional. Após a obtenção desse resultado, uma nova etapa é utilizada para decisão de escolha do local, com a aplicação de modelo de decisão multicritério que considere, além dos valores obtidos pela modelagem, critérios subjetivos característicos a operações humanitárias. Os resultados finais mostram que modelos estocásticos promovem resultados mais confiáveis que os determinísticos, especialmente, em situações nas quais materiais disponíveis não podem atender toda a demanda e que a consideração de critérios qualitativos e quantitativos proporciona uma decisão mais robusta em operações humanitárias.

Palavras-chave: Logística de operações humanitárias. Localização de instalações. Modelo estocástico de programação linear. Modelo de decisão multicritério. Suprimentos de alívio. 


\begin{abstract}
The increase in disasters and the consequent increase in the number of victims make it highly necessary to prepare for these events in modern societies. Logistics operations planning to meet emergencies is a recent activity and little explored in academic production. Our aim is to establish a method to locate pre-positioned materials used in disaster relief through a two-stage stochastic optimization model and a multi-criteria decision analysis that consider quantitative and qualitative parameters. Based on transportation and unattended demand costs, and using information such as risk mapping, transportation costs, historical occurrences of disasters, coverage, materials purchase, warehouses and transport capacities, a stochastic linear programming model minimizes the operating costs to supply the victims. A detailed analysis on how to assign penalties for unmet demand is also presented. Due to the uncertainty of the disasters severity and the influence of the media in phases after disasters, these parameters are represented as scenarios. The result of the stochastic model shows the quantity and the locations that minimize the operational cost. After this result, a new phase is applied for site selection, with the application of multi-criteria decision analysis that consider the values provided by the model and subjective criteria characteristic of humanitarian operations. The final results show that stochastic models promote more reliable results than deterministic ones, especially in situations in which the materials available cannot meet all the demand and that the consideration of qualitative and quantitative criteria provides better decisions in humanitarian operations.
\end{abstract}

Key words: Humanitarian logistics. Facility location. Stochastic optimization. Multicriteria decision analysis. Relief supply. 


\section{LISTA DE ILUSTRAÇÕES}

Figura 1 - Estrutura da metodologia de pesquisa. …………...........................23

Figura 2 - Tópicos abordados e sequenciamento da revisão literária. ......................26

Figura 3 - Impacto de um desastre em uma sociedade. .......................................28

Figura 4 - Relação entre evento e desastre. …………….................................29

Figura 5 - Classificação de desastres naturais (principais e subtipos)......................30

Figura 6 - Tipos de operações humanitárias. ………………………………......33

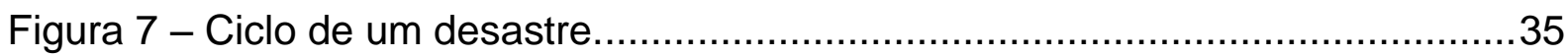

Figura 8 - Exemplo de estrutura de uma cadeia de suprimentos empresarial. .........40

Figura 9 - Estrutura de uma cadeia de suprimentos de assistência humanitária. .....42

Figura 10 - Nível de dificuldade da operação de resposta. .....................................45

Figura 11 - Fluxo de materiais conforme a fase do desastre. ..................................50

Figura 12 - Classificação dos problemas de localização multicritério.........................79

Figura 13 - Integração MCDA e programação linear...........................................8

Figura 14 - Metodologia para a análise de decisão multicritério................................82

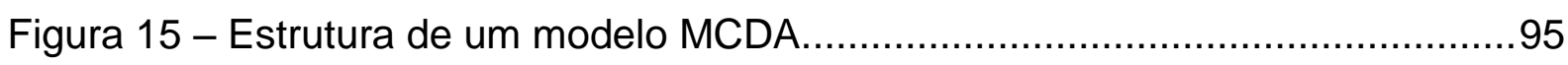

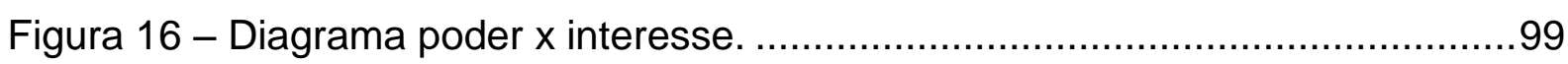

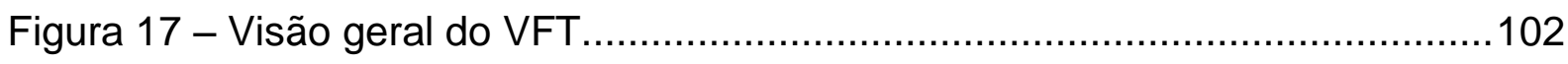

Figura 18 - Localização das cidades e dos locais candidatos (depósitos). .............112

Figura 19 - Estrutura do modelo...............................................................114

Figura 20 - Total de faltas e depósitos abertos em função da penalidade. ............143

Figura 21 - VSS e EVPI em função das penalidades. ........................................145

Figura 22 - Curva de ótimo e subótimos........................................................149

Figura 23 - Resultados da modelagem e próximas etapas. ................................156

Figura 24 - Diagrama poder $\mathrm{x}$ interesse elaborado. ..........................................160 
Figura 25 - Árvore de valor para a seleção do depósito. ……………………......163

Figura 26 - Fluxo atual do processo de modelagem.........................................166

Figura 27 - Função de valor para o atributo custo. ..............................................169

Figura 28 - Função de valor para o atributo distância em relação à REDEC. ........170

Figura 29 - Função de valor para o atributo salubridade do depósito.....................172

Figura 30 - Pesos normalizados dos atributos ...............................................173

Figura 31 - Resultados para o subcritério Gestão. …………………………....176

Figura 32 - Resultados para o subcritério Infraestrutura. ....................................176

Figura 33 - Resultados para os subcritérios Custos, Gestão e Infraestrutura. .......177

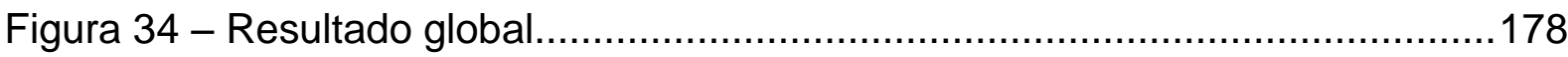

Figura 35 - Resultado global X variação do peso do atributo Custo.......................179

Figura 36 - Resultado global X variação do peso do atributo Infraestrutura...........180

Figura 37 - Resultado global X variação do peso do atributo Gestão......................181

Figura 38 - Resultados para o subcritério Gestão com alteração do local da coordenadoria.

Figura 39 - Resultado global com alteração do local da coordenadoria. .................182

Figura 40 - Resultados para os subcritérios Custos, Gestão e Infraestrutura. .......183

Figura 41 - Resultado global com alteração da função de valor de Custos. 184 


\section{LISTA DE TABELAS}

Tabela 2.1 - Exemplos de desastres por modo de inicio........................................31

Tabela 2.2 - Características de desastres naturais e emergências complexas.........32

Tabela 2.3 - Requisitos de logística durantes as etapas de um desastre. ................36

Tabela 2.4 - Níveis de planejamento das decisões em logística humanitária. ...........44

Tabela 2.5 - Estratégias Logísticas X Desastres.................................................46

Tabela 3.1 - Avaliação do desempenho de modelos estocásticos.............................63

Tabela 3.2 - Critérios utilizados para penalidades...................................................72

Tabela 3.3 - Critérios de localização conforme a fase do desastre. ...........................85

Tabela 3.4 - Classificação dos modelos aplicados à fase de resposta......................91

Tabela 4.1 - Probabilidades dos cenários. ......................................................123

Tabela 4.2 - Tempo de sobrevivência humana...................................................130

Tabela 4.3 - Estimativa da população afetada por desastres e demanda total. ......133

Tabela 4.4 - Resumo das necessidades de materiais.........................................135

Tabela 5.1 - Tempos e detalhes da execução....................................................140

Tabela 5.2 - Alteração do tempo de execução em função de M. ............................141

Tabela 5.3 - Resultados do modelo determinístico............................................146

Tabela 5.4 - Resultados do modelo estocástico.................................................146

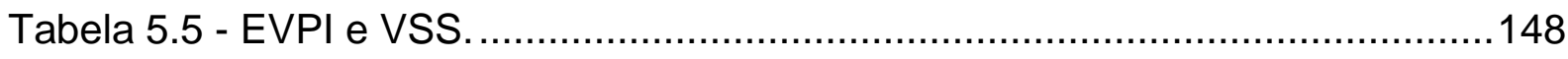

Tabela 5.6 - Resumo de faltas de materiais. .................................................151

Tabela 5.7 - Média, mediana e média aparada das probabilidades. ......................152

Tabela 5.8 - Alterações dos resultados em função das probabilidades...................153

Tabela 5.9 - Alterações dos resultados devido a ruptura em SP.........................155

Tabela 6.1 - Resultados da avaliação das alternativas pelos stakeholders. ...........174 


\section{LISTA DE ABREVIATURAS E SIGLAS}

AFT Alternative Focused Thinking ou Pensamento Baseado em Alternativas.

AHP Analytic Hierarchy Process ou Análise Hierárquica de Processos.

CD Centro de distribuição.

DAH Heurística da decomposição e atribuição.

EM-DAT The OFDA/CRED International Disaster Database.

EVPI Expected Value of Perfect Information ou Valor Esperado da Informação Perfeita.

FEMA Federal Emergency Management Agency

IBGE Instituto Brasileiro de Geografia e Estatística.

IFRC International Federation of Red Cross and Red Crescent Societies ou Cruz Vermelha Internacional.

INPE Instituto Nacional de Pesquisas Espaciais.

IPT Instituto de Pesquisas Tecnológicas do Estado de São Paulo.

ISDR United Nations International Strategy for Disaster Reduction ou Estratégia Internacional para Redução de Desastres das Nações Unidas.

MACBETH Measuring Attractiveness by a Categorical Based Evaluation Techniqueé.

MAUT Multiattribute Utility Theory ou Teoria da Utilidade Multiatributo.

MAVT Multiattribute Value Theory ou Teoria de Valor Multiatributo.

MCDA Multi-criteria Decision Analysis ou Metodologia Multicritério de Apoio à Decisão.

MCDM Multi-criteria Decision Making ou Métodos Multicritérios de Tomada de Decisão.

MCNDP Problema de máxima cobertura multiproduto com dois objetivos.

MSF Médecins Sans Frontières ou Médicos Sem Fronteiras. 
NUDEC Núcleo Comunitário de Defesa Civil

REDEC Coordenador Regional de Defesa Civil

SEADE Fundação Sistema Estadual de Análise de Dados.

SIG Sistema de Informações Geográficas.

SODA Strategic Options Development Analysis ou Desenvolvimento e Análise de Opções Estratégicas.

UNHCR United Nations High Commissioner for Refugees ou Auto Comissariado das Nações Unidas para os Refugiados.

VFT Value Focused Thinking ou Pensamento Baseado em Valores.

VSS Valor da Solução Estocástica.

WFP World Food Programme. 


\section{SUMÁRIO}

RESUMO

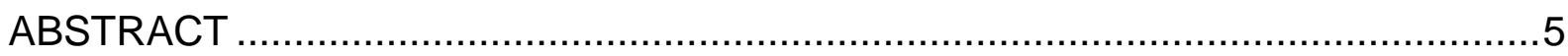

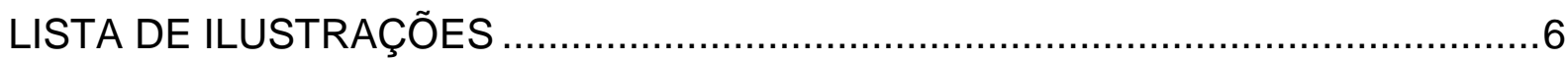

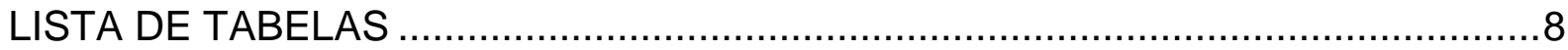

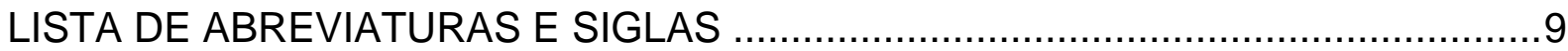

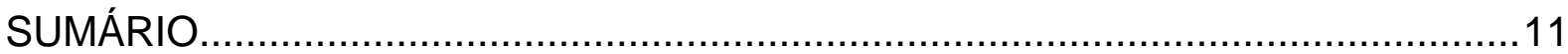

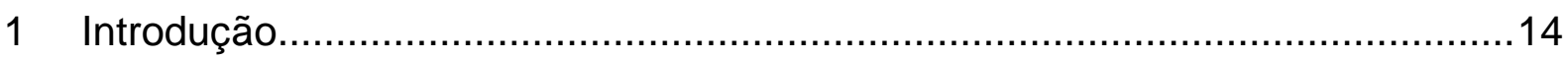

1.1 A relevância do tema e a interface com a logística ....................................17

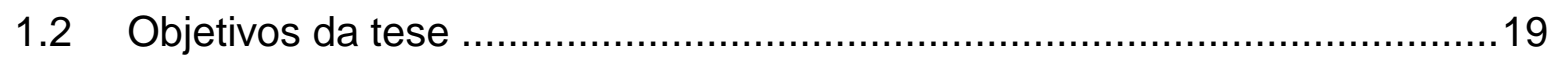

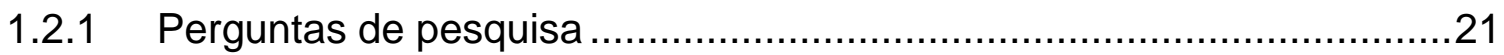

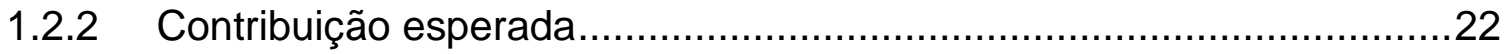

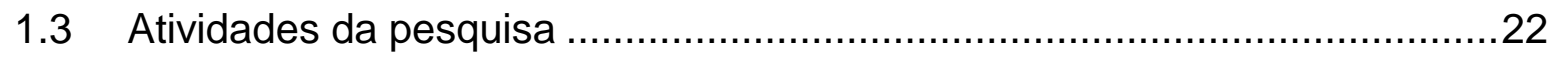

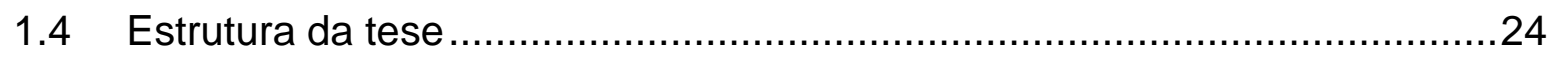

2 Revisão da literatura sobre operações humanitárias ..........................................26

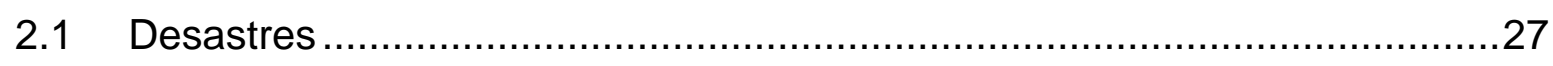

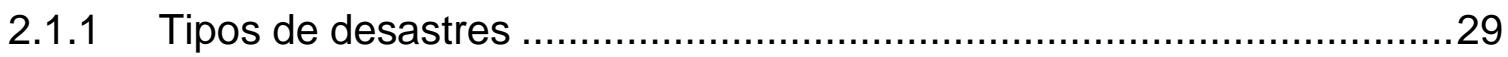

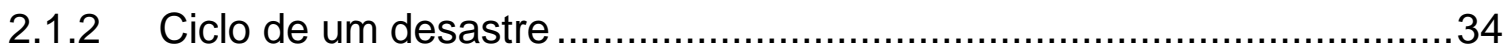

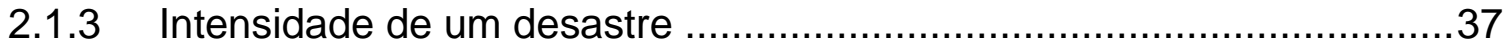

2.1.4 A influência da mídia em um desastre ................................................38

2.2 Cadeia de suprimentos empresarial e cadeia de suprimentos humanitária 39

2.2.1 Cadeia de suprimentos empresarial ................................................ 40

2.2.2 Cadeia de suprimentos humanitária …............................................. 40

2.3 Logística de operações humanitárias......................................................

2.3.1 Níveis de planejamento da logística humanitária ................................44

2.3.2 As estratégias logísticas e os tipos de desastres ................................4

2.3.3 Gerenciamento da fase de resposta a um desastre .............................49

3 Revisão da literatura sobre modelos estocásticos e multicritério aplicados a

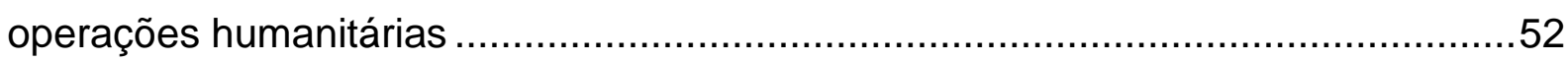

3.1 Modelos de localização de instalações ..................................................52

3.2 Modelos de localização de instalações de operações humanitárias ............54

3.3 Localização de instalações utilizando otimização estocástica .....................60 
3.3.1 Desempenho da solução estocástica

3.3.2 Localização de instalações humanitárias utilizando otimização estocástica.

3.3.3 Outras aplicações de otimização estocástica em logística de operações humanitárias 67

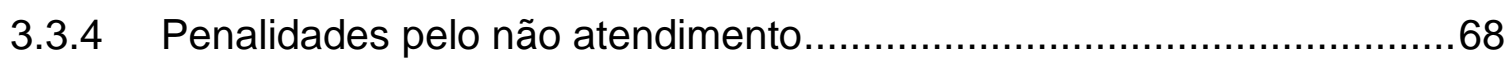

3.3.5 Estabelecimento de probabilidades para cenários ...............................72

3.4 Métodos multicritérios de tomada de decisão …….................................73

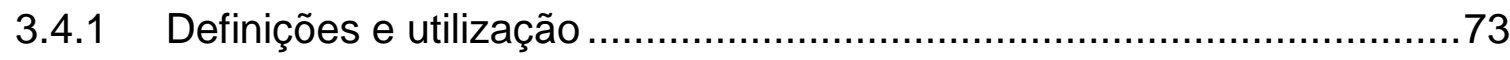

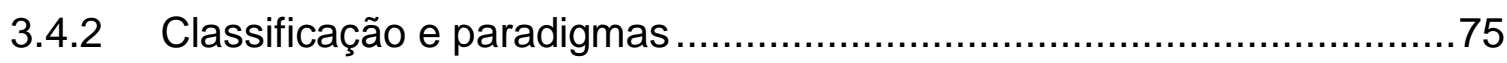

3.4.3 Métodos multicritérios de tomada de decisão aplicados à localização de

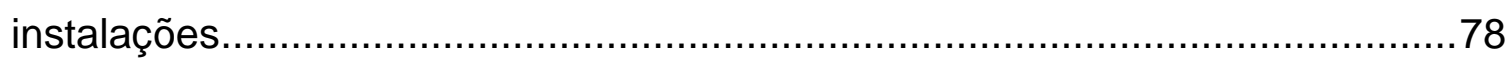

3.4.4 Métodos multicritérios de tomada de decisão aplicados à localização de

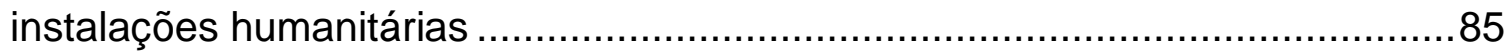

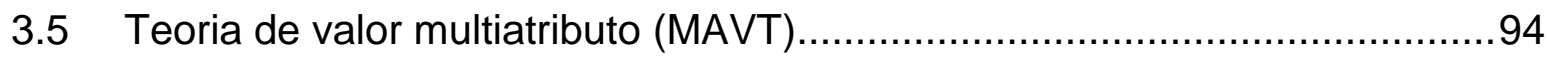

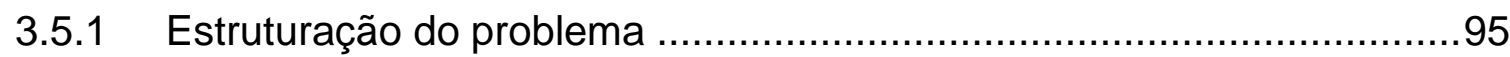

3.5.2 Estruturação do processo decisório.................................................100

3.5.3 Avaliação das alternativas de decisão .............................................105

4 Modelo de programação estocástica ............................................................110

4.1 Descrição do problema ................................................................110

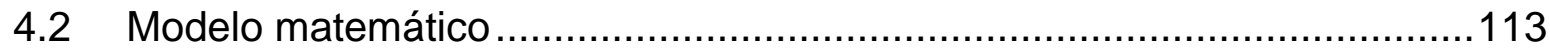

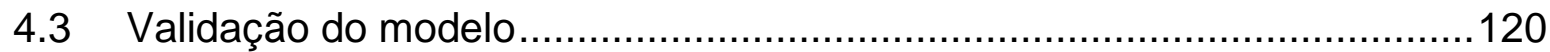

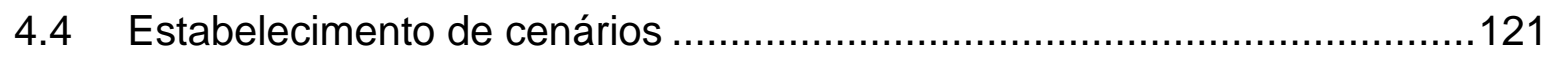

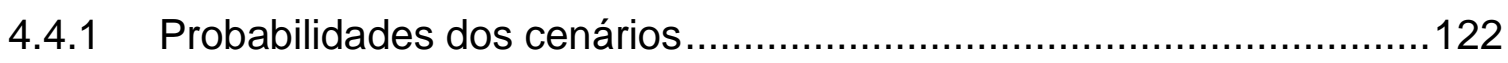

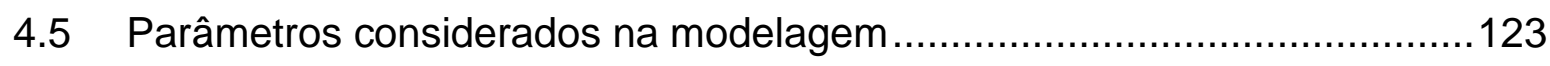

4.5.1 Parâmetros de primeiro estágio (não dependentes de cenários) …....123

4.5.2 Parâmetros de segundo estágio (dependentes de cenários) …...........126

4.5.3 Parâmetros de segundo estágio (não dependentes de cenários) .......138

5 Resultados do Modelo Estocástico e Análise .................................................140

5.1 Resultados computacionais: operação do modelo ……….......................140

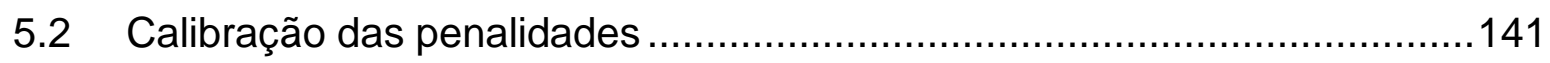

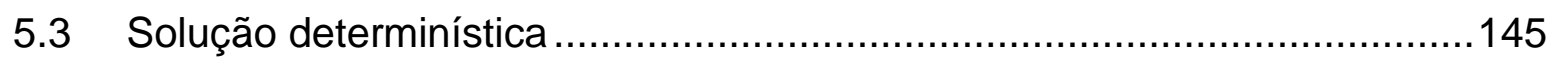

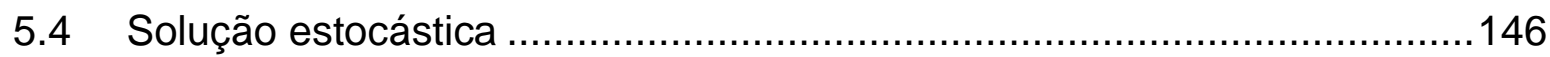


5.5 Desempenho das soluções determinística e estocástica .........................147

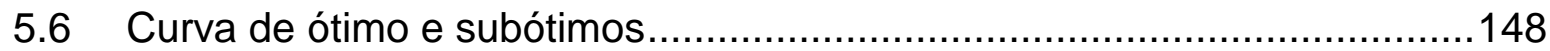

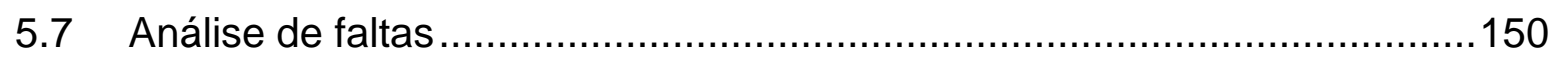

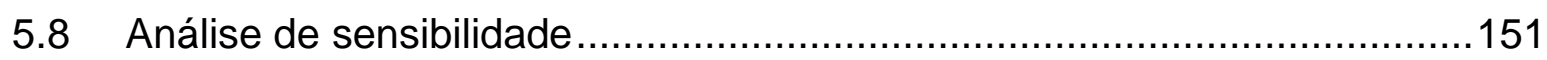

5.8.1 Diferentes probabilidades dos cenários.........................................152

5.8.2 Mudanças nos critérios de atribuição de penalidades. .......................153

5.8.3 Variação do parâmetro $A_{i}$ causando rupturas nos arcos de transporte154

5.9 Conclusões sobre os resultados do modelo............................................155

6 Aplicação do Modelo de Decisão Multicritério …….......................................158

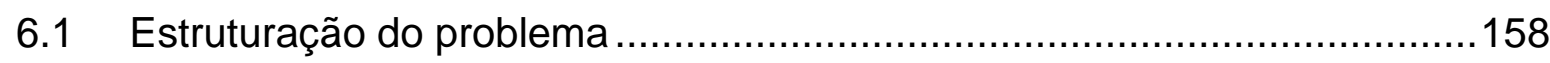

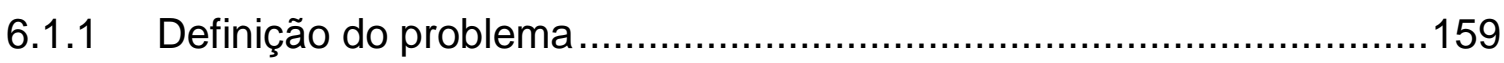

6.1.2 Participantes na decisão (stakeholders) ……….............................159

6.2 Estruturação do processo decisório ...................................................161

6.2.1 Estruturação das árvores de valor ................................................162

6.2.2 Definição dos atributos ..........................................................163

6.2.3 Identificação e criação das alternativas ............................................166

6.3 Avaliação das alternativas de decisão .................................................167

6.3.1 Obtenção das funções de valor ...................................................167

6.3.2 Obtenção dos pesos dos atributos ………………………...........173

6.3.3 Avaliação do desempenho das alternativas ....................................173

6.3.4 Agregação das performances parciais das alternativas ......................174

6.3.5 Obtenção do desempenho global ...............................................175

6.3.6 Análise de sensibilidade e robustez dos resultados ...........................178

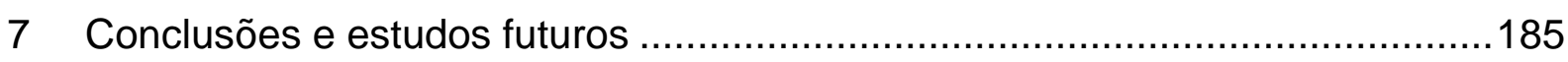

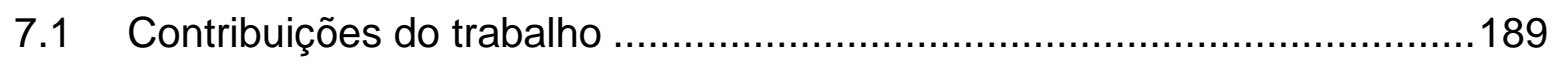

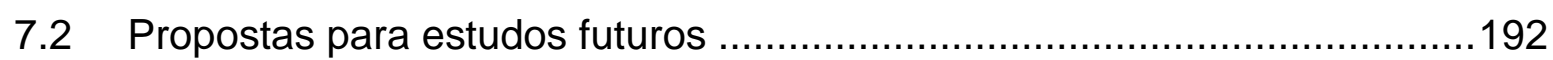

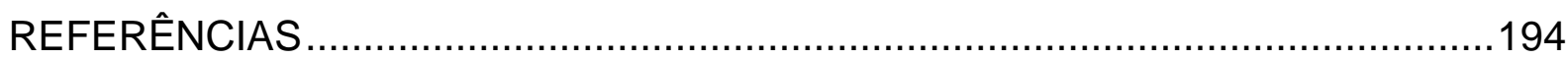

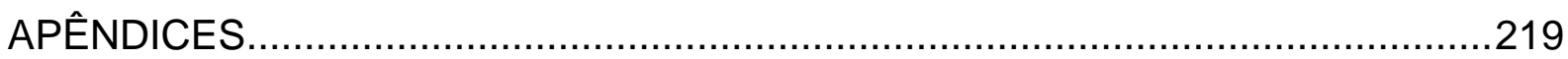




\section{Introdução}

Inundações, tempestades, terremotos, tsunamis, deslizamentos de terra, secas, conflitos, campos de refugiados e outras situações emergenciais denominadas desastres fazem parte do cotidiano em nossas vidas e estão aumentando. O assunto ganha destaque devido ao aumento acentuado do número de pessoas afetadas por desastres naturais (enchentes, furacões, terremotos, maremotos); desastres provocados pelo homem (conflitos, atentados terroristas e guerras); e o crescente aumento dos prejuízos econômicos, o que tem demandado maiores esforços dos Estados e de organizações de ajuda humanitária (GUHA-SAPIR et al., 2011).

Diversos episódios recentes de grande magnitude têm demonstrado a vulnerabilidade das sociedades atuais, evidenciando a necessidade de um tratamento logístico diferenciado para estes eventos. Como exemplo, pode-se citar o tsunami e o terremoto no Oceano Índico em 2004; os frequentes furacões no Caribe e América do Norte; os terremotos no Paquistão em 2005, na China em 2008, no Haiti e no Chile em 2010, na Nova Zelândia; e a série de desastres em Tōhoku, no Japão, em 2011 e nas Filipinas em 2013. No Brasil, ocorreram inundações no Vale do Itajaí (SC) em 2008, no Nordeste em 2009, e em São Luiz do Paraitinga (SP) no início de 2010; catastróficos deslizamentos na região serrana do Rio de Janeiro em 2011; alagamentos e deslizamentos no Espirito Santo e Minas Gerais no final de 2013 e no início de 2014 em Itaóca (SP).

A natureza incerta de tais acontecimentos, em adição ao grande número de vítimas, faz com que a logística de operações humanitárias apresente um aspecto crítico na gestão de desastres e operações de socorro, e representa uma das principais alavancas para alcançar melhorias em termos de custos, tempo e qualidade (BLECKEN, 2010). A mobilização ágil e eficaz de recursos é essencial para auxílio as pessoas em situação de vulnerabilidade a desastres. A escassez de materiais ou uma gestão ineficiente de recursos pode comprometer a resposta da emergência, 
resultando em um aumento no sofrimento das vítimas (HOLGUÍN-VERAS et al., 2013). Por isso, é importante desenvolver estratégias de preparação e resposta.

Van Wassenhove (2006) traça uma definição para operações humanitárias como sendo os processos e sistemas envolvidos na mobilização das pessoas, recursos, habilidades e conhecimento para ajudar pessoas vulneráveis afetadas por um desastre. Apte (2009), em uma visão mais abrangente, não restrita somente a fase de resposta a um desastre, e elaborada a partir de conceitos de organizações humanitárias, como WFP (World Food Programme) e MSF (Médicos Sem Fronteiras), definiu logística humanitária como "o processo de planejamento, implementação e controle da eficiência, do custo-benefício, do transporte e armazenagem de materiais, assim como o fluxo de informações, do ponto de origem ao ponto de consumo com o objetivo de atendimento as necessidades do beneficiário final".

Assim, o tema Logística de Operações Humanitárias apresenta diferenças intrínsecas em relação aos sistemas logísticos empresariais desenvolvidos e aperfeiçoados nas últimas décadas e apresentados por Ballou (2006). Muitas operações de gestão de crises humanitárias ainda têm seus modelos de gestão baseados em princípios das organizações militares e de governo, fundamentados na filosofia "just in case", devido, até mesmo, à falta de um planejamento prévio e alternativas de abastecimento para períodos de crise humanitária. Atualmente, cadeias de suprimentos empresariais consideram este tipo de filosofia como uma abordagem ultrapassada (NATARAJARATHINAM; CAPAR; NARAYANAN, 2009). Diversos estudos, sob uma ótica global, vêm sendo desenvolvidos demonstrando a importância da logística de operações humanitárias para as nações (THOMAS, 2004; BEAMON; KOTLEBA, 2006; VAN WASSENHOVE, 2006), entretanto a realidade dessas operações logísticas ainda é pouco compreendida (HOLGUÍNVERAS et al., 2014).

Previsões estimam que, ao longo dos próximos 50 anos, os desastres naturais e os provocados pelo homem irão aumentar cinco vezes em número e severidade (THOMAS; KOPCZAK, 2005). Independentemente das causas naturais ou antropogênicas, artigos científicos em periódicos de grande impacto mostram 
alteração no padrão de chuvas ocorridas no planeta, fazendo com que regiões secas registrem menos precipitações, tornando-se ainda mais áridas e áreas propensas a inundações aumentem seus índices de chuvas (MARVEL; BONFILS, 2013). Também são mostradas maior ocorrência de extremos climáticos e consequente elevação da quantidade de desastres naturais no Brasil (SAMPAIO, 2014), assim como, o aumento da frequência de tempestades no sudeste do Brasil, em decorrência do aquecimento global (MARENGO; VALVERDE; OBREGON, 2013), (PINTO JR.; PINTO; FERRO, 2013). Este quadro faz com que medidas de preparação para desastres se tornem necessárias, dentre elas o pré-posicionamento de materiais para atendimento a emergências. A importância deste préposicionamento de suprimentos de alívio foi demonstrada quando o furacão Katrina devastou New Orleans em 2005. A falta de materiais estocados e a demora na chegada destes suprimentos prejudicaram ainda mais o socorro às vítimas. Problemas com legislação e dificuldades na definição de autoridade e responsabilidades (governo estadual $X$ governo federal) provocaram lentidão na resposta (HOLGUÍN-VERAS et al,. 2007).

Suprimentos de alívio são elementos básicos para que as pessoas afetadas tenham acesso a alimentos e produtos para sua higiene nos primeiros momentos após a ocorrência de um desastre. A agilidade e prontidão na distribuição desses itens são necessárias, principalmente, nas primeiras 72 horas após o evento (golden 72 hours), para que as equipes de socorro iniciem as atividades e os desabrigados e desalojados consigam, dessa forma, se estabilizar para início da normalização de suas vidas (FIEDRICH; GEHBAUER; RICKERS, 2000), (BRASIL, 2007). Também estão incluídos os materiais necessários para as equipes de socorro, busca e salvamento (resposta) atuarem logo após o evento.

No Brasil, o tema começou a ser estudado pela comunidade científica somente na última década. Marcelino (2007) apresenta conceitos básicos e estudos sobre desastres naturais ocorridos no Brasil. Estudos específicos sobre logística de operações humanitárias tiveram seu início no país em função, principalmente, dos eventos ocorridos no estado de Santa Catarina em 2008 e conduzidos por grupos de pesquisadores da região, como o trabalho de Nogueira; Gonçalves e Novaes (2008), 
propondo indicadores de desempenho para Logística Humanitária; e de Nogueira e Gonçalves (2010), que aplicou uma metodologia de auxílio a tomada de decisão para localização de uma central para recebimento de materiais. Giannotti (2010) também realizou estudos sobre a aplicação de um Sistema de Informações Geográficas (SIG) como suporte e apoio a logística humanitária de um banco de alimentos. Barbosa et al. (2010) utilizaram um sistema de apoio a decisão e SIG na localização de suprimentos de alívio para atendimento a desastres ocorridos no Vale do Paraíba Paulista. Bertazzo et al. (2013) avaliaram as publicações realizadas sobre o assunto no Brasil e observaram que encontram-se concentradas em revistas não-científicas e anais de congressos, além de detectarem a necessidade de publicações em periódicos com elevado fator de impacto.

\subsection{A relevância do tema e a interface com a logística}

Imediatamente após o evento sísmico da Ásia em 2004, durante uma conferência das Nações Unidas sobre as doações, um embaixador europeu afirmou: "Nós não precisamos de uma conferência de doadores, precisamos de uma conferência de logística" (SHANE; BONNER, 2005). Um relatório publicado pelo Instituto Fritz, uma organização sem fins lucrativos que atua com a logística específica de resposta a desastres, indicou que muitas organizações de ajuda envolvidas no tsunami de 2005, na Ásia, não possuíam conhecimento nem tecnologia em logística para atuarem em desastre de grande porte (THOMAS; KOPCZAK, 2005).

Essas afirmações sobre as dificuldades encontradas para abastecimento de materiais ou para permitir que as doações chegassem ao destino evidenciam a necessidade de um tratamento logístico diferenciado para atendimento à população afetada. A coordenação de múltiplas agências de ajuda, Estados, forças militares e fornecedores locais e regionais, todos com suas próprias maneiras e estruturas operacionais pode ser muito desafiadora (LONG; WOOD, 1995). A deficiência nessa 
coordenação e no fluxo de informação ao longo da rede, muitas vezes, leva a dificuldades e, até mesmo, a conflitos durante a distribuição ao usuário final (MURRAY, 2005). Portanto, o período em que as organizações de ajuda estão se preparando para uma eventual ocorrência é também o momento em que podem desenvolver plataformas de colaboração e estabelecer bases confiáveis para o fluxo de informações em casos de desastres.

Essa necessidade de cooperação entre instituições e Estados é cada vez mais necessária em função do aumento na proporção dos desastres. A citação da IFRC (2009) resume bem esta necessidade:

\footnotetext{
"O impacto da mudança climática e o aumento da frequência de emergências complexas significa que a escala global de desafios humanitários excede a capacidade máxima de enfrentamento de qualquer Estado, indivíduo ou organização humanitária." (tradução nossa).
}

O assunto também passou a ser relevante para algumas empresas, que possuem programas sociais ou de ajuda humanitária, como os tradicionais operadores logísticos DHL e TNT, que iniciaram a participação e apoio em operações de socorro a desastres, estabelecendo parcerias com a Organização das Nações Unidas (ONU) (KOVÁCS; SPENS, 2007). Outro exemplo foi a participação ativa de empresas de transporte durante as operações de resposta ao tsunami de Tōhoku, no Japão, em 2011, quando a capacidade governamental não era capaz de realizar o pleno atendimento e foram firmados acordos de cooperação com a Japanese Trucking Association (JTA) para transporte de suprimentos dos locais não atingidos para as áreas afetadas pelo desastre. (HOLGUÍN-VERAS et al., 2014). A participação de empresas privadas é conveniente ao setor, pois proporciona, além dos recursos, 0 aprimoramento das tecnologias logísticas utilizadas.

Uma análise simplificada sobre o assunto, apenas para avaliação das ordens de grandeza, pode ser realizada por meio do cruzamento de informações acadêmicas e organismos internacionais de ajuda. Essa análise mostra que, por exemplo, durante o ano de 2008, na África subsaariana, uma região onde o índice de pobreza é de $51 \%$, o montante da ajuda recebida foi de US\$39 bilhões, o que corresponde a 
US\$47 para cada habitante (ROSSI, 2011). Dados do WFP (WFP, 2011) mostram que o custo de alimentos para a região é de US\$390 por tonelada. Levando em consideração essas informações, é possível concluir que, com o valor de ajuda, pode-se fornecer diariamente $330 \mathrm{~g}$ de alimentos para cada habitante na região, 0 que corresponde a $60 \%$ da quantidade diária ideal de alimento para uma pessoa (550g), segundo o WFP. Entretanto, ainda segundo Rossi (2011), devido a fatores como corrupção, diferenças nos critérios da distribuição (não equidade) e logística, parte dessa ajuda não chega a seu destino.

Dificuldades logísticas também ocorreram localmente. Em 2010, o município de São Luiz do Paraitinga, no Vale do Paraíba Paulista, foi afetado por uma inundação de grandes proporções, deixando mais de 5.000 desabrigados e desalojados no local. Devido à inexistência de local específico, durante a operação de resposta ao desastre, foi necessário a adaptação de instalações de um batalhão da Policia Militar para as operações de triagem e armazenagem de materiais (KAWASAKI et al., 2012). Esse evento originou a necessidade de um estudo para localização e instalação de um depósito para suprimentos de alivio na região e motivou interações e troca de informações com a Defesa Civil do estado de São Paulo para a geração de estudos sobre localização para a instalação de um depósito.

Os tópicos anteriormente abordados mostram a relevância do assunto e justificam a necessidade de aprofundamento dos estudos na área de logística de operações humanitárias, especialmente na localização de depósitos de suprimentos de alívio.

\subsection{Objetivos da tese}

O objetivo desta tese é a proposição de uma metodologia para localização de instalações para armazenagem de suprimentos de alívio em uma fase de preparação para um eventual desastre, levando em consideração critérios quantitativos e qualitativos para a tomada de decisão. Uma aplicação foi realizada 
na Defesa Civil do estado de São Paulo para a localização de um depósito de suprimentos de alivio na região do Vale do Paraíba Paulista e essa metodologia proposta pode ser utilizada para situações semelhantes em outras regiões e localidades.

A metodologia contempla a utilização de otimização estocástica e, em sequência, a análise multicriterial tornando a tomada de decisão, suportada por dois métodos, mais robusta do que a tomada de decisão por um dos métodos individualmente. Pode ser caracterizado como um trabalho multimetodológico (MINGERS; ROSENHEAD, 2004) com metodologias aplicadas em série (POLLACK, 2009).

Neste trabalho pode-se aplicar a definição de Rosenhead et al. (1972), que entende robustez como a flexibilidade contida numa decisão e que a mantém em condições quase ótimas em diferentes cenários, o que a torna apropriada para sua tomada sob condições de incerteza, ou ainda o conceito de Mulvey et al. (1995), em que é relacionada a robustez com a capacidade de execução sob diferentes cenários.

Para atingir esse objetivo foram consideradas as seguintes etapas parciais:

- Inicialmente um modelo de programação estocástica de localização foi desenvolvido para proposição de locais com base na minimização de custos. Para a implementação desse modelo:

$\checkmark$ Cenários são propostos de acordo com a intensidade do desastre, influência de mídia e a quantidade de doações enviadas pela população.

$\checkmark$ A demanda de suprimentos de ajuda humanitária é definida segundo conceitos internacionalmente estabelecidos, por meio de dados históricos dos organismos de ajuda e, também, com base nos mapeamentos de riscos realizados pelos municípios.

$\checkmark$ Penalidades pelo não atendimento à demanda são avaliadas e estabelecidas. 
$\checkmark$ Parâmetros como custos e capacidade de transporte, capacidade de armazenagem, além de características específicas do segmento humanitário, como rupturas em acessos, cobertura de atendimento e compras emergenciais são considerados.

- A escolha de localidades para pré-posicionamento de estoques pode conter critérios subjetivos e não quantificáveis. Após o modelo apresentar locais para estabelecimento de armazéns de suprimentos de alívio, um método multicritério (MCDA - Multi-criteria Decision Analysis) é aplicado para apoiar a decisão de escolha do local.

Para a tomada de decisão em operações humanitárias o critério custo é considerado, especialmente, na fase de preparação a um desastre, pois as instituições possuem orçamentos e necessitam de sua otimização, todavia deixa de ser prioritário nas operações de resposta a um desastre, pois nessa fase, apesar da preocupação com os custos, atendimento e salvamento (minimização de sofrimento) passam a ser prioritários (PAIVA, 2012).

\subsubsection{Perguntas de pesquisa}

A principal pergunta a ser respondida pela pesquisa é:

- Onde localizar instalações para armazenagem de suprimentos de alívio ao longo de uma cadeia de suprimentos humanitária?

Para responder a principal pergunta alguns questionamentos secundários devem também ser avaliados pela pesquisa:

- Quais os cenários possíveis para um desastre em uma determinada região?

- Qual a demanda esperada para suprimentos de alívio?

- Como penalizar a falta de um suprimento? 
- Quais critérios influenciam a decisão de localização?

- A solução é flexível de tal forma que situações não previstas também podem ser atendidas?

\subsubsection{Contribuição esperada}

$\mathrm{Na}$ avaliação da literatura sobre logística de operações humanitárias nenhuma publicação, utilizando Modelos Estocásticos de Localização e, posteriormente, Métodos Multicritério para Tomada de Decisão, foi encontrada, assim como a atribuição de penalidades pelo não atendimento é parâmetro muito utilizado nos processos de modelagem, porém sua obtenção é pouco detalhada na literatura. Nesse contexto, esta tese procura contribuir ao fornecer uma metodologia mais robusta para apoio na tomada de decisão sobre localização em logística de operações humanitárias, assim como na inserção de novos parâmetros e seus respectivos critérios nesse processo de modelagem. Também são apresentadas contribuições específicas a logística de operações humanitárias como um método para atribuição de penalidades pelo não atendimento da demanda, alocação de produtos que possam ser adquiridos mediante contratos previamente negociados; além do estabelecimento de restrições para avaliação das capacidades de transporte e de atividades de armazenagem quando eventos humanitários venham a ocorrer. Adicionalmente, como resultado observado, uma análise sobre a estratégia de Defesa Civil brasileira e da infraestrutura atual para respostas a desastres é efetuada.

\subsection{Atividades da pesquisa}


Conforme a tipologia estabelecida por Filippini, apud Nakano, 2009, o método de pesquisa utilizado é o de Modelagem, com a utilização de técnicas de pesquisa operacional para descrever o funcionamento de um sistema.

A pesquisa pode ser assim descrita (Figura 1):

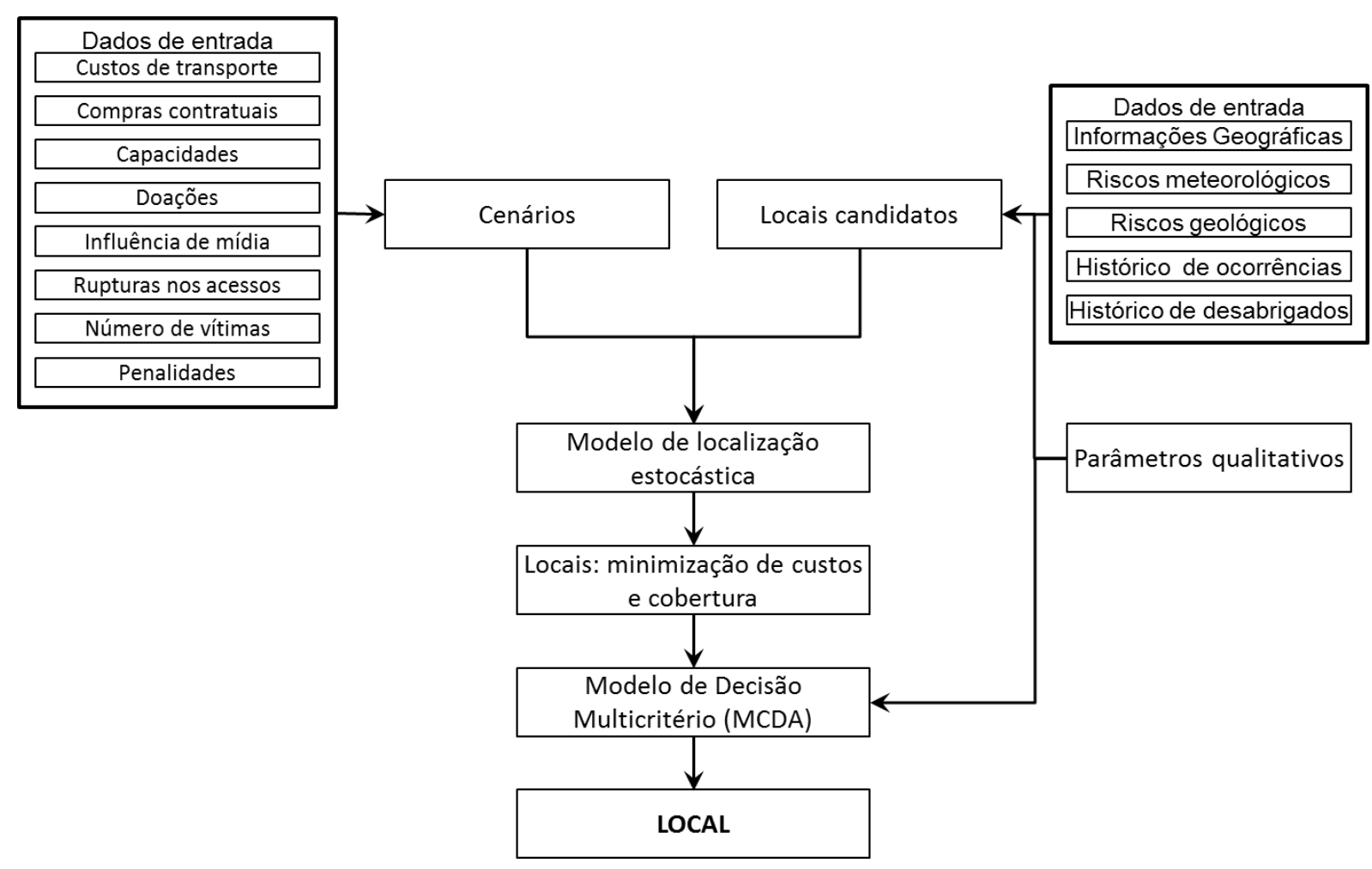

Figura 1 - Estrutura da metodologia de pesquisa.

Para estabelecimento dos cenários utilizados no modelo estocástico, parâmetros como: demanda com base no número estimado de vítimas; custo de transporte e possíveis rupturas nos acessos; aquisição de materiais; penalidades pelo não atendimento; doações realizadas pela população influenciada principalmente pela divulgação de mídia; capacidades de processamento e armazenagem de materiais; e fatores específicos de peso e volume dos materiais são utilizados e abordados pelos cenários estabelecidos.

Os dados de entrada para determinação de locais candidatos são obtidos a partir do histórico de ocorrências, informações geográficas, meteorológicas e geológicas. Estas informações foram obtidas junto a Defesa Civil do estado de São Paulo e, 
também institutos de pesquisa como IPT e INPE e foram utilizadas para definir regiões com potencial para receber um depósito de suprimentos de alívio (candidatas) e para a solução do modelo estocástico. O modelo é, então, aplicado e os locais são sugeridos.

Reuniões e entrevistas com os tomadores de decisão foram realizadas em dois momentos. Nas discussões preliminares, no início do processo (2011 e 2012), para definição dos locais candidatos; e na análise de decisão (em 2014) foram realizados 5 encontros, totalizando aproximadamente 9 horas. Mediante as informações produzidas nesses encontros, ferramentas multicritério para tomada de decisão (MCDA) foram aplicadas para a escolha do local definitivo, refinando o resultado do modelo quantitativo e inserindo critérios subjetivos no processo decisório. Também foram realizadas avaliações de especialistas (9) para estabelecimento de cenários, utilizando ferramentas via web para criação e resposta de questionários.

\subsection{Estrutura da tese}

Esta tese possui a seguinte estrutura:

Capitulo 1. Introdução: refere-se à motivação e objetivos deste trabalho.

Capitulo 2. Revisão da literatura sobre operações humanitárias: aborda os conceitos teóricos sobre desastres e a logística de operações humanitárias, que foram utilizados para a confecção desta tese e apresenta o estado da arte sobre o assunto.

Capitulo 3. Revisão da literatura sobre modelos estocásticos e multicritério aplicados a operações humanitárias: complementa o capítulo anterior abordando os conceitos sobre modelos de localização, otimização estocástica e metodologia multicritério no processo de tomada de decisão. 
Capitulo 4. Modelo de programação estocástica: apresenta o modelo e define a determinação e metodologia de cálculo dos parâmetros necessários para a execução.

Capitulo 5. Resultados do Modelo Estocástico e Análise: apresenta os resultados obtidos pelo modelo no processo de modelagem e análises e conclusões preliminares, principalmente, sobre as capacidades da Defesa Civil.

Capítulo 6. Aplicação do Modelo de Decisão Multicritério: descreve o processo e apresenta os resultados obtidos na aplicação do modelo multicritério, considerando os diversos tomadores de decisão.

Capítulo 7. Conclusões e estudos futuros: apresenta uma análise dos resultados obtidos pelo trabalho.

Referências bibliográficas e apêndices complementam este trabalho. 


\section{Revisão da literatura sobre operações humanitárias}

A revisão de literatura nesta tese foi dividida em dois capítulos. A primeira parte (Cap. 2 Revisão da literatura sobre operações humanitárias) visa estabelecer uma fundamentação teórica sobre desastres e a logística de operações humanitárias que é o objeto de melhoria deste trabalho. A segunda parte (Cap. 3 Revisão da literatura sobre modelos estocásticos e multicritério aplicados a operações humanitárias) aborda os modelos utilizados para otimização e tomada de decisão). A

Figura 2 ilustra os assuntos abordados e a sequência adotada na criação de uma plataforma conceitual para o desenvolvimento da tese.

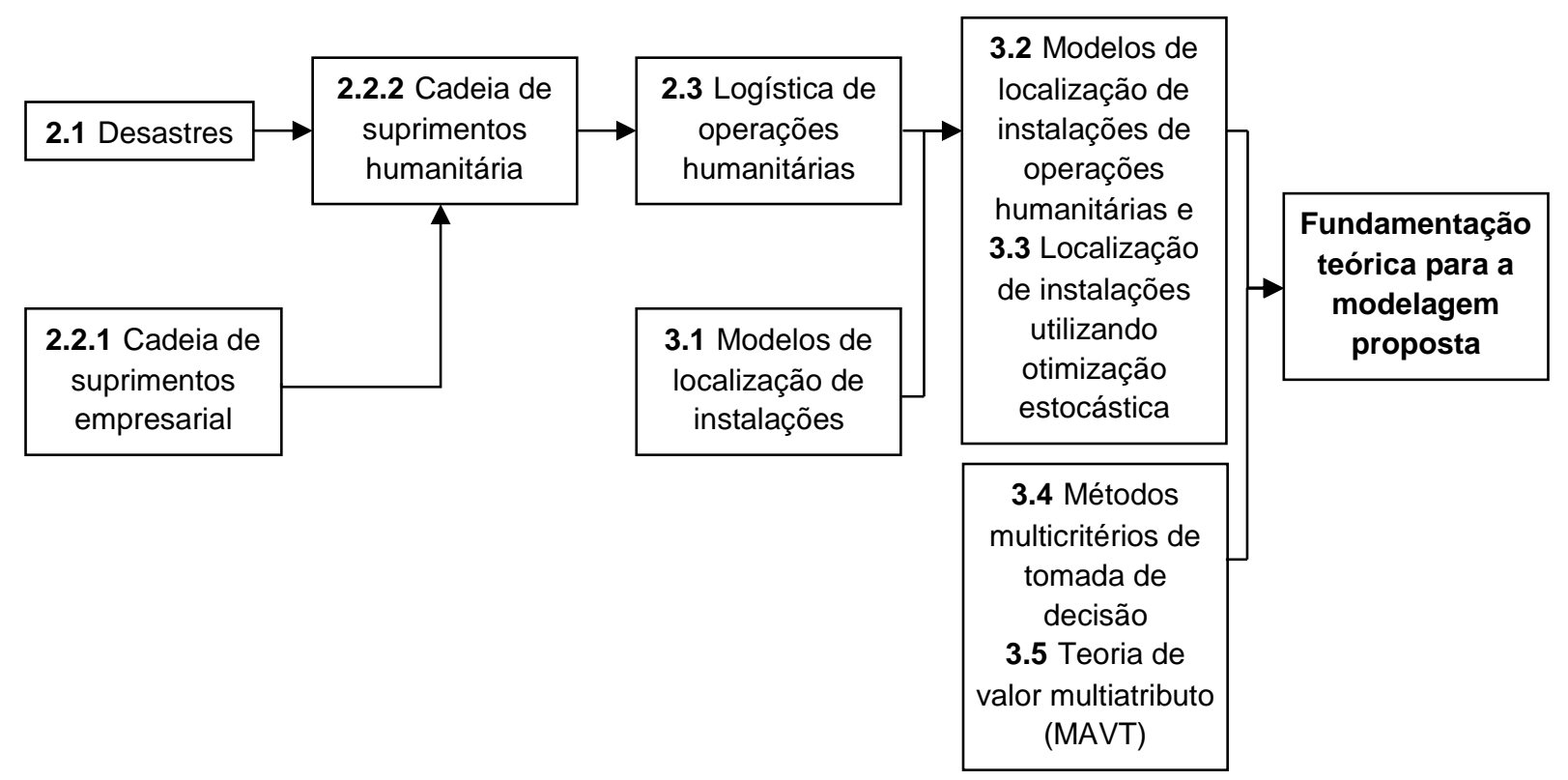

Figura 2 - Tópicos abordados e sequenciamento da revisão literária.

Além destes assuntos, outros tópicos e técnicas aplicáveis a logística de operações humanitárias complementam a abordagem ao longo destes capítulos com o objetivo de conceituar e estabelecer possibilidades de continuidade deste trabalho. 


\subsection{Desastres}

Segundo a Federação Internacional da Cruz Vermelha (IFRC, 2008), desastre significa "uma ruptura grave do funcionamento da sociedade, que representa uma ameaça significativa e generalizada para a vida humana, saúde, propriedade ou ao meio ambiente. Decorrem de acidentes, naturais ou da atividade humana. Podem ocorrer de repente ou como resultado de processos de longo prazo".

Outra definição é dada pelo ISDR - Estratégia Internacional para Redução de Desastres da Organização das Nações Unidas (United Nations International Strategy for Disaster Reduction) (UN/ISDR, 2009), que considera desastre "uma interrupção grave do funcionamento de uma comunidade ou sociedade, causando um grande número de mortes, perdas materiais e impactos econômicos e ambientais que excedem a capacidade da comunidade ou sociedade afetada de resolver a situação usando seus próprios recursos" (tradução nossa).

Sob uma ótica sociológica, o desastre é um evento incerto e ocorre quando um agente provoca danos físicos e sociais que comprometem o funcionamento de uma comunidade, expressando, diante dos efeitos, suas vulnerabilidades sociais (PERRY; QUARANTELLI, 2005). Quando uma sociedade é atingida a qualidade de vida de sua população, a atividade econômica e a estabilidade social são afetadas. A maneira como essa sociedade reage a esse evento definirá seu padrão de vida posterior. A Figura 3, ilustra o impacto de um desastre no padrão de vida de uma sociedade. 


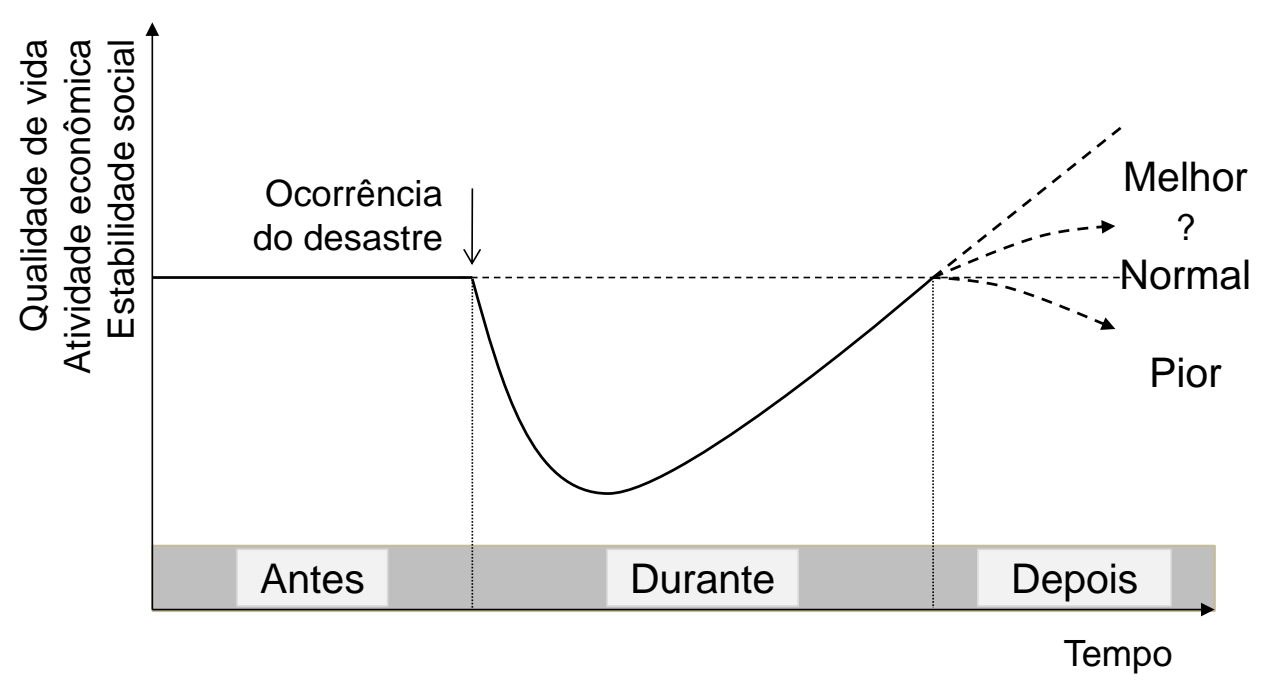

Figura 3 - Impacto de um desastre em uma sociedade. Fonte: adaptado de Tobin e Montz (1997) e Marcelino (2007).

Nesse aspecto, o conceito de vulnerabilidade pode ser entendido como o grau que uma pessoa ou uma comunidade é susceptível de ser atingida por um desastre (VALENCIO et al., 2009). A vulnerabilidade a desastres naturais está relacionada ao nível de desenvolvimento e a qualidade ambiental de uma sociedade. Pessoas de menor renda, em desvantagem social ou ainda em situação de miséria (CHAKRAVARTY, 2014), especialmente, em países em desenvolvimento, são as mais impactadas por um desastre. Devido às dificuldades desses grupos de se adaptarem ao pós-desastre ou de se refazerem dos danos, a ajuda humanitária torna-se importante (NOLZ; SEMET; DOERNER, 2011).

O conceito de perigo refere-se à possibilidade de um evento, fenômeno ou atividade humana ocorrer em determinado local provocando morte ou ferimentos em pessoas, danos materiais, rupturas socioeconômicas ou degradação ambiental (TOMINAGA; SANTORO; AMARAL, 2009) (UN/ISDR, 2009).

Desastres ocorrem quando condições de perigo e vulnerabilidade convergem. A Figura 4 mostra essa relação. Por exemplo, uma tempestade severa pode ser considerada apenas um evento natural se não atingir áreas ocupadas. Caso atinja um local habitado pode gerar situação potencial de perigo a pessoas e bens (MARCELINO, 2007). 


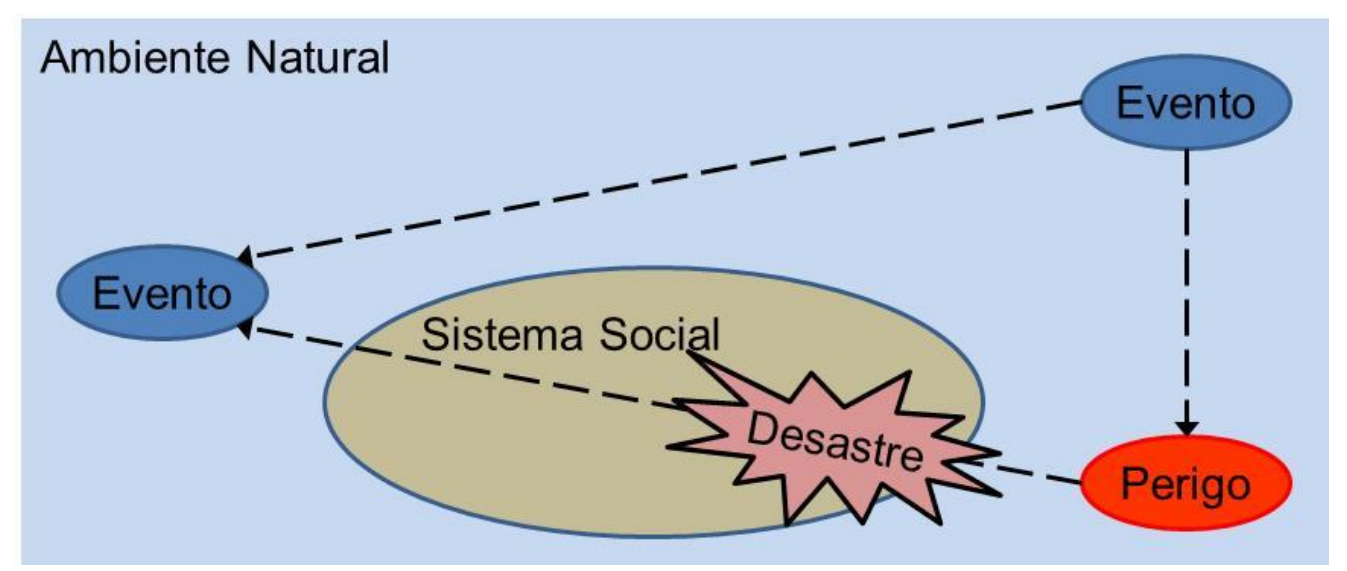

Figura 4 - Relação entre evento e desastre. Fonte: Marcelino (2007).

Os conceitos de vulnerabilidade e perigo originam a possibilidade em se ter consequências prejudiciais ou danosas e dão origem ao conceito de risco $(R)$, que pode ser representado como uma função do perigo $(\mathrm{P})$; vulnerabilidade $(\mathrm{V})$; e do dano potencial (DP) (TOMINAGA; SANTORO; AMARAL, 2009).

O dano potencial, segundo IFRC (2000) e Duran, Gutierrez e Keskinocak (2011), é quanto uma situação de perigo é capaz de danificar um sistema social. Este conceito varia conforme o tipo de desastre e influencia a velocidade de envio de suprimentos na fase de resposta e o tipo de material a ser suprido.

\subsubsection{Tipos de desastres}

Dentro dos conceitos de desastres, a IFRC os divide conforme a origem, podendo ser naturais ou provocados pelo homem (antropogênicos), também conhecidos por tecnológicos ou emergências complexas. (IFRC, 2011). 
Um desastre natural ocorre quando um fenômeno natural modifica a superfície terrestre e atinge locais habitados, provocando danos materiais e humanos (AMARAL; GUTJAHR, 2011). São fenômenos físicos também causados por eventos de início rápido ou lento. A base de dados EM-DAT (EM-DAT, 2012) divide o grupo de desastres naturais em subgrupos, tipos e subtipos, conforme a Figura 5:

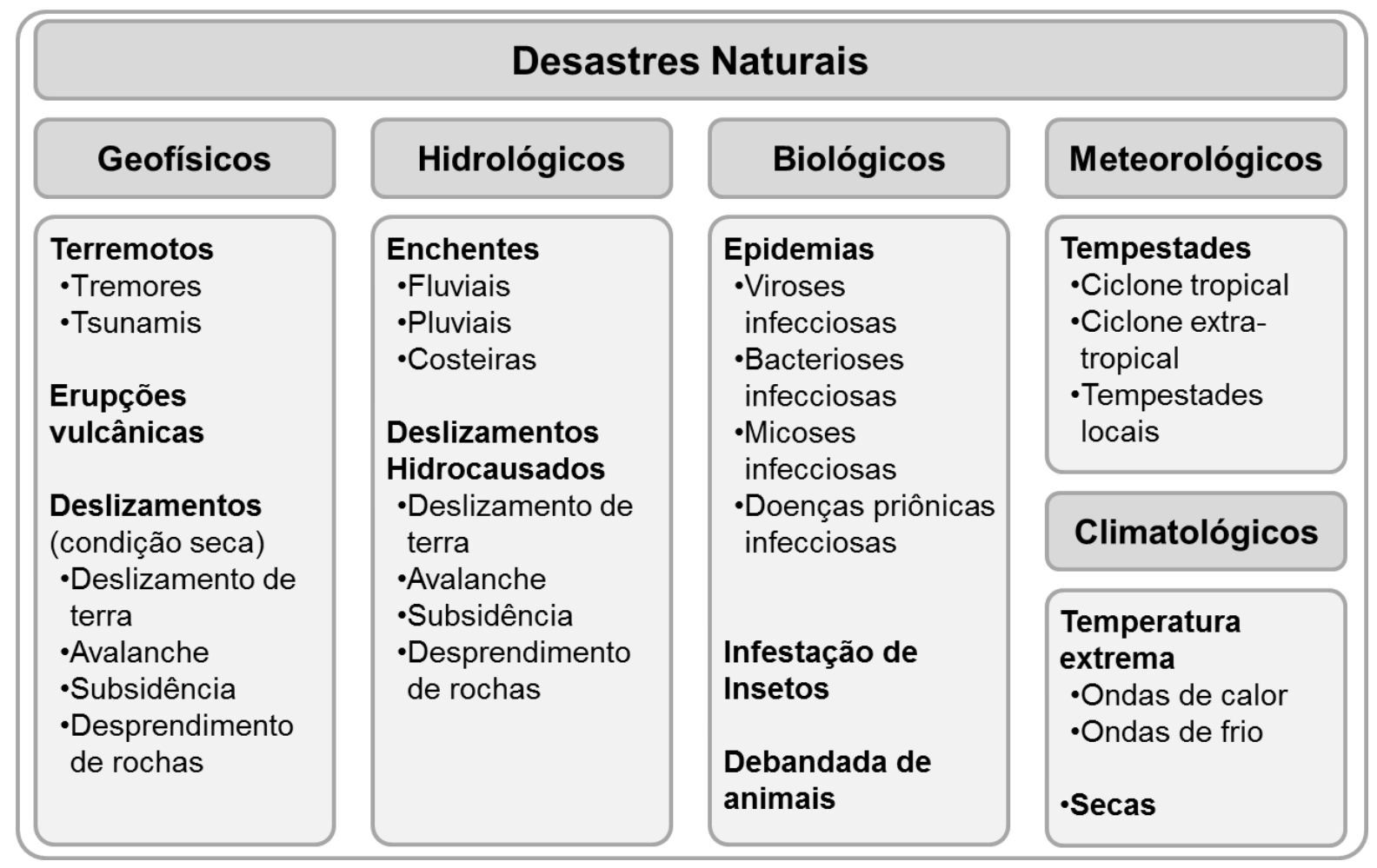

Figura 5 - Classificação de desastres naturais (principais e subtipos). Fonte: EM-DAT (2012).

Desastres de origem humana, tecnológicos ou ainda emergências complexas, são acidentes de origem química ou nuclear, conflitos sociais, terrorismo, fome, deslocamentos populacionais, acidentes industriais e acidentes de transporte. São eventos causados por seres humanos, de natureza voluntária ou não, também denominados de antropogênicos. Ocorrem em assentamentos humanos ou na trajetória entre eles. Estão inclusos neste tipo de evento a degradação ambiental, a poluição e acidentes ambientais (IFRC, 2011) (EM-DAT, 2012).

A diferença entre os desastres naturais e os antropogênicos é que enquanto os desastres naturais resultam da fraqueza física ou estrutural de uma sociedade que 
não conseguiu prevenir ou absorver os efeitos dos eventos naturais, os antropogênicos resultam de uma fraqueza da sociedade que falha na regulamentação de atividades, na acomodação de interesses, ou ainda na aceitação e convivência pacífica entre grupos (ABDALA-BERTRAND, 2000).

Van Wassenhove (2006) define uma abordagem para agrupamento dos desastres conforme o modo de início que pode ser súbito ou lento. Eventos súbitos impactam uma sociedade abruptamente e exigem uma resposta rápida e coordenada, enquanto os desastres de início lento requerem um processo mais longo de abastecimento da população afetada. Esta abordagem mostra características fundamentais para a logística de operações humanitárias, proporcionando um melhor entendimento do modo de funcionamento da cadeia de suprimentos humanitária, pois o modo de início define a detecção de necessidades, os tipos de materiais necessários e a forma de abastecimento. Na Tabela 2.1, essa classificação é exemplificada.

Tabela 2.1 - Exemplos de desastres por modo de inicio.

\begin{tabular}{lcc} 
& Natural & Antropogênico \\
\hline \multirow{3}{*}{ Início súbito } & Terremoto & Ataque terrorista \\
& Furacão & Golpe de estado \\
& Tornados & Acidente químico \\
\hline Início lento & Fome & Crise política \\
& Seca & Crise de refugiados \\
& Miséria & \\
\hline
\end{tabular}

Outra abordagem para a classificação de desastres é a de Baldini et al. (2012), em que são também inseridas características como a capacidade de previsão de um desastre, seu impacto potencial e a extensão geográfica dos danos provocados por esse desastre. Apte (2009) também ressalta a importância da extensão geográfica de um desastre, classificando tais eventos em localizados ou dispersos. Estas características influenciam a atuação logística, particularmente, dos eventos de 
baixa previsibilidade $\mathrm{e}$ de alto impacto e extensão, pois requerem um posicionamento estratégico pré-evento que pode influenciar toda a fase de resposta. A Tabela 2.2, ilustra essa classificação para os tipos de desastres que possuem grande repercussão:

Tabela 2.2 - Características de desastres naturais e emergências complexas.

\begin{tabular}{|c|c|c|c|c|}
\hline $\begin{array}{l}\text { Tipo de } \\
\text { desastre }\end{array}$ & $\begin{array}{c}\text { Natural / } \\
\text { antropogênico }\end{array}$ & $\begin{array}{c}\text { Capacidade de } \\
\text { Previsão }\end{array}$ & $\begin{array}{l}\text { Impacto } \\
\text { Potencial }\end{array}$ & $\begin{array}{l}\text { Extensão } \\
\text { Geográfica }\end{array}$ \\
\hline Terremoto & Natural & Baixa & Alto & $\begin{array}{l}\text { Dispersa } \\
\text { (nacional) }\end{array}$ \\
\hline Tsunami & Natural & Baixa & Alto & $\begin{array}{l}\text { Dispersa } \\
\text { (multinacional) }\end{array}$ \\
\hline $\begin{array}{l}\text { Tempestade / } \\
\text { Furacão }\end{array}$ & Natural & Média & Médio/Alto & $\begin{array}{l}\text { Dispersa } \\
\text { (nacional) }\end{array}$ \\
\hline $\begin{array}{l}\text { Erupção } \\
\text { Vulcânica }\end{array}$ & Natural & Média & Alto & Dispersa \\
\hline Pandemias & Ambos & Baixa & Alto & $\begin{array}{l}\text { Dispersa } \\
\text { (global) }\end{array}$ \\
\hline Ataque terrorista & Antropogênico & Média & Médio & Local \\
\hline $\begin{array}{l}\text { Acidente de } \\
\text { Transporte }\end{array}$ & Antropogênico & Baixa & Médio & Local \\
\hline Conflito armado & Antropogênico & Média & Alto & $\begin{array}{l}\text { Dispersa } \\
\text { (multinacional) }\end{array}$ \\
\hline $\begin{array}{l}\text { Deslizamento de } \\
\text { terra }\end{array}$ & Natural & Média & Baixo & Local \\
\hline Avalanche & Natural & Média & Baixo & Local \\
\hline $\begin{array}{l}\text { Acidente } \\
\text { químico }\end{array}$ & Antropogênico & Baixa & Médio & Local \\
\hline Acidente nuclear & Antropogênico & Baixa & Alto & $\begin{array}{l}\text { Dispersa } \\
\text { (multinacional) }\end{array}$ \\
\hline
\end{tabular}

Fonte: Adaptado de Apte (2009) e Baldini et al. (2012).

Desastres de início súbito requerem um esforço logístico maior em termos operacionais e de custos devido a necessidade de resposta rápida às áreas devastadas (COZZOLINO, 2012). De um desastre, outros podem ser decorrentes, como, tais como, a cólera após o terremoto do Haiti, em 2010, ou a sequência de desastres observado em Tōhoku, no Japão, em 2011 (HOUGUìN-VERAS, 2012). 
Diferentes tipos de desastres devem ser gerenciados de maneiras diferentes. Um desastre de início súbito possui uma logística diferenciada de desastres de início lento. A gestão das necessidades e agilidade no abastecimento de uma região devastada por um terremoto é diferente das de um campo de refugiados. A localização do desastre também gera modelo de gestão diferenciado, especialmente, quando ocorrem em regiões de baixo desenvolvimento humano (KOVÁCS; SPENS, 2007).

Swann; Ganesan e Keskinocak (2009) dividiram os desastres de acordo com a abordagem operacional e, consequentemente, o modelo de resposta a ser adotado, complementando a abordagem de Van Wassenhove (2006), separando as operações humanitárias em atividades de socorro a desastres e em apoio ao desenvolvimento humano de determinado local (Figura 6). Também inserem o componente de previsibilidade de um desastre.

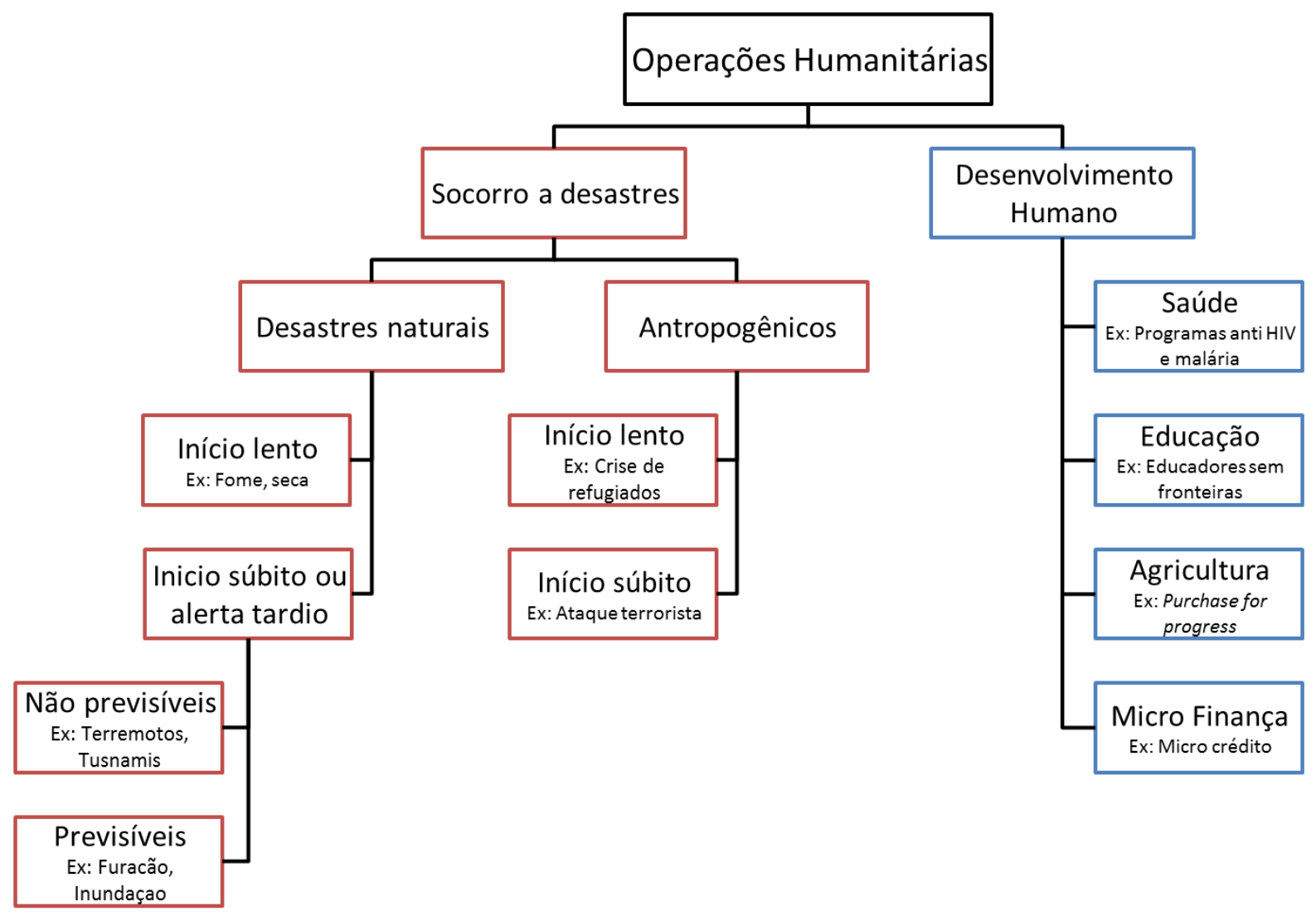

Figura 6 - Tipos de operações humanitárias.

Fonte: Swann; Ganesan e Keskinocak (2009) 
Souza (2012) também diferenciou a logística humanitária em relação a sua aplicação em eventos de início rápido ou lento, destacando que em desastres de início rápido, assim como em serviços emergenciais, a prontidão da resposta significa a diferença entre a vida e a morte das pessoas, analisando a logística de operações humanitárias, de acordo com a fase do desastre. Destaca o papel da Defesa Civil neste tipo de desastre, especialmente, no Brasil.

\subsubsection{Ciclo de um desastre}

Desastres possuem o que pode ser chamado de um ciclo de ocorrência (FEMA, 2012). Este ciclo envolve uma série de fases de gerenciamento que incluem estratégias para mitigar riscos, preparar-se, responder e recuperar-se de situações de emergência e seus efeitos. Essas fases não são estáticas e, muitas vezes, estão conectadas, assim como podem se sobrepor.

Alguns trabalhos adotam 10 fases para um desastre (emergência; restauração; reconstrução; desenvolvimento nacional; prevenção; mitigação; preparação; alerta; ameaça; e impacto) (CARTER, 2008). De acordo com o ISDR (UN/ISDR, 2002) até 2002, segundo as Nações Unidas, as atividades de gerenciamento de desastres podiam ser categorizadas em cinco fases genéricas: previsão; alerta; socorro; reabilitação; e reconstrução. Esse conceito, então, focado somente na ocorrência física do desastre, foi alterado e reduzido para quatro fases, incorporando uma fase anterior ao alerta sobre o desastre (quando uma comunidade procura minimizar seus efeitos) e, também, as três últimas fases foram simplificadas, reduzidas para duas, pois estão associadas com o esforço pós-desastre, que envolve as atividades de resposta e recuperação. Neste trabalho, esse conceito utilizado pela FEMA e UN/ISDR é adotado. A Figura 7 ilustra as fases: 


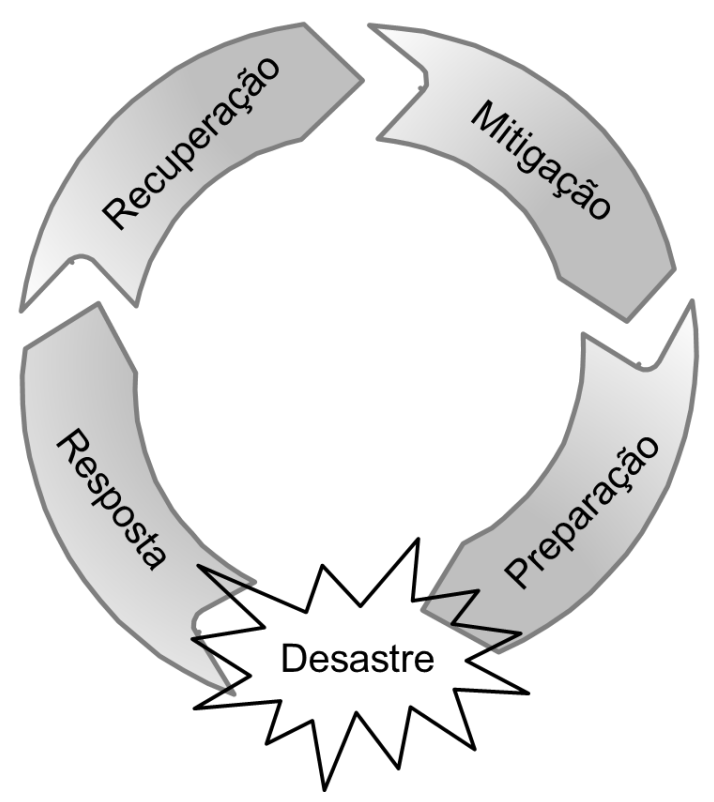

Figura 7 - Ciclo de um desastre.

Fonte: FEMA (2012).

Estas fases podem ser assim descritas (FEMA, 2012):

- Mitigação: atividades que eliminem ou reduzam a probabilidade de ocorrência ou os efeitos de um desastre, inclusive leis e códigos que reduzam a vulnerabilidade da população. Se não puderem evitar desastres, podem, pelo menos, reduzir o impacto negativo. Por exemplo, reforços no telhado irão reduzir danos causados por vendavais; evitar construções em várzeas reduz a chance de residências inundadas.

- Preparação: basicamente, significa pôr em prática mecanismos para combater fatores que a sociedade não foi capaz de mitigar (TOMASINI; VAN WASSENHOVE, 2009b). Planejar como reagir quando um desastre venha a ocorrer e disponibilizar recursos necessários para a eficácia da resposta. Essas atividades ajudam a salvar vidas e minimizar os danos, preparando as pessoas para que respondam apropriadamente quando uma emergência é iminente. Para responder corretamente uma comunidade deve ter um plano de resposta, pessoal treinado e os recursos para essa resposta. 
- Resposta (ou durante o desastre): é o ato do atendimento à emergência. Abrange o período durante e imediatamente após o desastre. Durante esta fase, é prestada assistência às vítimas do evento e tenta-se reduzir a probabilidade de danos maiores. As primeiras 72 horas são críticas para o socorro às vítimas (SALMERÓN; APTE, 2010), pois após esse tempo uma comunidade passa a encontrar dificuldades para sobreviver por seus próprios meios.

- Recuperação: é a última fase do ciclo de vida de gerenciamento de desastres. A sociedade afetada, apoiada pelo estado e por instituições, procura restabelecer a normalidade. Vigora até que todos os sistemas retomem a operação normal ou quase normal. No curto prazo de recuperação restaurase sistemas vitais. No longo prazo, a recuperação pode durar meses ou anos, até que a área do desastre retome à sua condição anterior ou ainda uma situação melhor.

Quando a abordagem ocorre em Logística das Operações Humanitárias, o principal foco são as fases de preparação e resposta (TOMASINI; VAN WASSENHOVE, 2009b).

O ciclo de desastre é evidente em desastres de início súbito. Em desastres de início lento as fases não se encontram bem definidas e, por vezes, sobrepõem-se, dificultando uma análise das características das necessidades logísticas. Howden (2009) caracterizou os requisitos de logística durantes as etapas de um desastre de início súbito e Kessler (2013) complementou o estudo comparando com os desastres de início lento. A Tabela 2.3 apresenta essas características. 
Tabela 2.3 - Requisitos de logística durantes as etapas de um desastre.

\begin{tabular}{|c|c|c|c|c|c|}
\hline \multirow[b]{2}{*}{ Fase } & \multicolumn{4}{|c|}{ Início súbito } & \multirow{2}{*}{$\begin{array}{l}\text { Início lento } \\
\text { Auxílio ao } \\
\text { desenvolvimento }\end{array}$} \\
\hline & Mitigação & Preparação & Resposta & Recuperação & \\
\hline Duração & $\begin{array}{l}\text { Longo prazo e } \\
\text { contínuo }\end{array}$ & $\begin{array}{l}\text { Longo prazo e } \\
\text { contínuo }\end{array}$ & Dias ou meses & $\begin{array}{l}\text { Meses ou } \\
\text { anos }\end{array}$ & $\begin{array}{l}\text { Longo prazo e } \\
\text { contínuo }\end{array}$ \\
\hline $\begin{array}{l}\text { Volume de } \\
\text { transporte }\end{array}$ & Baixo & Baixo & Alto & Médio & Moderado \\
\hline $\begin{array}{l}\text { Tipos de } \\
\text { suprimento } \\
\text { s }\end{array}$ & Variados & $\begin{array}{l}\text { Kits para } \\
\text { atendimento } \\
\text { às } \\
\text { necessidades } \\
\text { básicas }\end{array}$ & $\begin{array}{l}\text { Alimentos, } \\
\text { suprimentos } \\
\text { médicos, } \\
\text { água, higiene, } \\
\text { abrigos, kits } \\
\text { domésticos, } \\
\text { etc }\end{array}$ & $\begin{array}{l}\text { Variam } \\
\text { conforme o } \\
\text { tipo de } \\
\text { desastre } \\
\text { (material de } \\
\text { reconstrução } \\
\text { ou meios de } \\
\text { subsistência) }\end{array}$ & $\begin{array}{l}\text { Amplo gama de } \\
\text { produtos e } \\
\text { desenvolvimento } \\
\text { de tecnologia }\end{array}$ \\
\hline Urgência & Baixa & Baixa & $\begin{array}{l}\text { Alta: lead time } \\
\text { dos materiais } \\
\text { pode } \\
\text { comprometer } \\
\text { a operação }\end{array}$ & $\begin{array}{l}\text { Média: } \\
\text { pressão de } \\
\text { governos e } \\
\text { doadores }\end{array}$ & Moderada \\
\hline $\begin{array}{l}\text { Fontes de } \\
\text { suprimento }\end{array}$ & $\begin{array}{l}\text { Local ou não } \\
\text { local }\end{array}$ & Local & Não local & $\begin{array}{l}\text { Local ou não } \\
\text { local }\end{array}$ & Local ou não local \\
\hline
\end{tabular}

Fonte: Adaptado de Howden (2009) e Kessler (2013).

\subsubsection{Intensidade de um desastre}

A magnitude e a extensão que um desastre pode alcançar definem as necessidades de materiais de alívio, equipes de resgate e, consequentemente, a logística de operações. A Defesa Civil (BRASIL, 2007) classifica a intensidade de um desastre em quatro níveis. Conforme Castro (1999), Tominaga; Santoro e Amaral (2009) e CEPED-SC (2010) a intensidade de um desastre pode ser assim classificada:

Nível I - pequeno porte, quando os danos provocados pelo desastre são facilmente suportáveis e superados pelas próprias comunidades afetadas. 
Nível II - médio porte, apesar de prejuízos significativos, a própria comunidade supera os danos e prejuízos provocados pelo desastre através de uma mobilização e utilizando seus próprios recursos, sem a necessidade de auxílio externo.

Nível III - grande porte, quando a comunidade local necessita complementar os recursos locais com auxílio externo para poder superar os danos e prejuízos provocados pelo desastre.

Nível IV - muito grande porte, quando os efeitos provocados pelo desastre são de tamanho montante que mesmo comunidades participativas, bem informadas, preparadas e facilmente mobilizáveis não superam os danos e prejuízos. Esta intensidade também pode ser denominada catástrofe (PERRY; QUARANTELLI, 2005), pois a maioria/toda comunidade é afetada, tornando impossível para os desabrigados irem para residências de amigos ou familiares. A rotina é interrompida e a maioria das instalações e bases operacionais das organizações de emergência também é impactada. Além disso, as autoridades locais são incapazes de realizar suas funções durante as fases de resposta e recuperação. Somente com auxílio externo a comunidade supera os danos e prejuízos em tempo aceitável.

Outra abordagem apresentada pela entidade de resseguros Munich $\mathrm{Re}$ (NATCATSERVICE, 2011) classifica a intensidade em sete níveis, desdobrando o evento catástrofe em quatro, entretanto neste trabalho seguiremos a Defesa Civil brasileira.

Desastres também são mensurados, especialmente a divulgação por parte da mídia, em função do número de óbitos. Este valor também é utilizado para comparação entre desastres (ALBALA-BERTRAND, 2000).

\subsubsection{A influência da mídia em um desastre}


A mídia exerce um papel fundamental na fase de resposta a um desastre, principalmente na mobilização de voluntários e doações, e especialmente em desastres naturais, onde as pessoas estão dispostas a doar, quando comparado aos desastres antropogênicos (ZAGEFKA et al., 2011), porém, muitas vezes, a mídia, em sua visão empresarial, escolhe com cuidado os assuntos que geram repercussão e audiência e, consequentemente, mais lucrativos conforme o local (CORONEL, 2010). Nessa situação necessidades mais elevadas e mais urgentes passam despercebidas quando a mídia deixa de expô-las devido às manchetes concorrentes. Outro aspecto é que crises e emergências não ocorrem de forma linear, podendo acontecer simultaneamente e competir por tempo e atenção da mídia (ARNOLD, 2011).

\subsection{Cadeia de suprimentos empresarial e cadeia de suprimentos humanitária}

Para a avaliação dos modelos de localização em logística de operações humanitárias, é relevante a compreensão das diferenças entre as cadeias de suprimentos empresarial (ou comercial) e humanitária. Modelos de localização fartamente encontrados na literatura são focados no abastecimento da cadeia de suprimentos comerciais, entretanto a cadeia de suprimentos humanitária difere da cadeia de suprimentos comercial, pois possui características próprias adaptadas a sua especificidade (BEAMON; KOTLEBA, 2006). A utilização e a aplicação de modelos matemáticos para decisões estratégicas de localização em cadeias de suprimentos empresariais ocorrem há longa data, enquanto na cadeia humanitária essa aplicação teve seu crescimento acadêmico somente no século XXI (PERES et al., 2012). 


\subsubsection{Cadeia de suprimentos empresarial}

$\mathrm{Na}$ cadeia de suprimentos comercial existe a conversão das matérias primas em produtos acabados. As etapas produtivas agregam valor ao consumidor final, e abrangem desde a aquisição de matérias-primas, produção, até a entrega ao consumidor final. As instalações, em geral, não estão em um mesmo local requerendo, assim, atividades logísticas de transporte, armazenagem, controle de estoques e abastecimento que se realizam ao longo dessa cadeia num processo repetitivo e contínuo (BALLOU, 2006). Blanco e Goentzel (2006) inserem também os fluxos de materiais, financeiros e de informações ao longo dessa cadeia de suprimentos, destacando a importância do fluxo de informações que deve ocorrer em todos os sentidos. Na Figura 8, é possível visualizar uma representação de cadeia de suprimentos empresarial desde os fornecedores até o consumidor final, assim como os fluxos de materiais, financeiro e de informações:

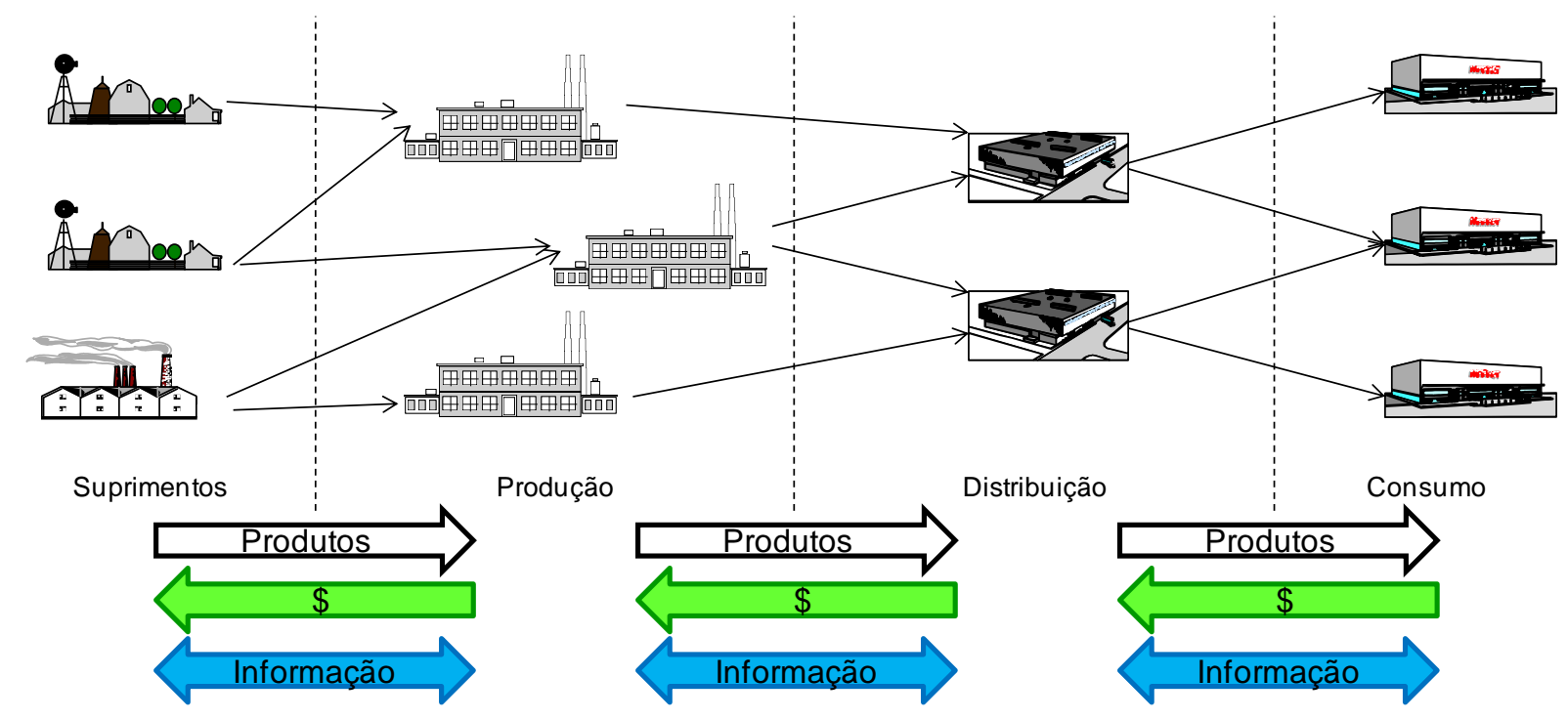

Figura 8 - Exemplo de estrutura de uma cadeia de suprimentos empresarial. Fonte: Adaptado de Beamon (2006), Ballou (2006) e Blanco e Goentzel (2006)

\subsubsection{Cadeia de suprimentos humanitária}


Thomas e Kopczak (2005) e Van Wassenhove (2006) descrevem a existência de diferenças entre as cadeias de suprimentos comercial e humanitária em termos de seus objetivos estratégicos, características da demanda, dos clientes e fatores ambientais de operação. As características que trazem complexidade e desafios únicos para o projeto da cadeia humanitária são:

- Imprevisibilidade da demanda;

- Demanda súbita, ocorrendo em grandes quantidades e com prazos curtos para uma ampla variedade de suprimentos;

- Altos riscos associados com a distribuição adequada e oportuna, devendo observar o conceito de equidade nesta distribuição (SWANN; GANESAN; KESKINOCAK, 2009);

- Falta de recursos (oferta, pessoas, tecnologia, capacidade de transporte e dinheiro);

- Instalações (facilidades) permanentes e/ou temporárias ao longo da cadeia.

$\mathrm{Na}$ cadeia de suprimentos humanitária, os suprimentos obtidos a partir de doadores e/ou fornecedores seguem, inicialmente, a estoques pré-posicionados. Em geral, os suprimentos são transportados de vários locais para uma central de distribuição, normalmente em instalações permanentes, localizadas em pontos estratégicos (NOGUEIRA; GONÇALVES; NOVAES, 2008), podendo este ponto ser próximo ao local do evento ou em outras regiões mais estáveis e seguras. Estes depósitos são abastecidos durante a fase de preparação de um desastre. A partir desses depósitos, durante a fase de respostas, os suprimentos são transportados até outro centro de distribuição localizado próximo ao evento, instalado para o atendimento. Neste centro de distribuição, os suprimentos são separados, classificados e transferidos para centros de distribuição locais, conforme as necessidades. Finalmente, os suprimentos de auxílio humanitário são entregues aos beneficiários. Banomyong e Sopadang (2010) afirmam que pode demorar até quatro meses para a ajuda chegar aos destinatários em uma área de crise, mesmo em caso de uma cadeia de suprimentos humanitária estruturada. 
Alguns suprimentos são adquiridos de fontes locais devido à proximidade ou para manter a atividade econômica da localidade (PAHO, 2001). A aquisição de suprimentos locais deve ser avaliada para não causar desabastecimento no mercado e consequente aumento de preços. Estes materiais são também enviados para os centros de distribuição locais, ou diretamente distribuídos aos beneficiários, conforme Figura 9. A distribuição de materiais (última milha) é a etapa mais desafiadora na logística de operações humanitárias (HOLGUíN-VERAS et al., 2014).

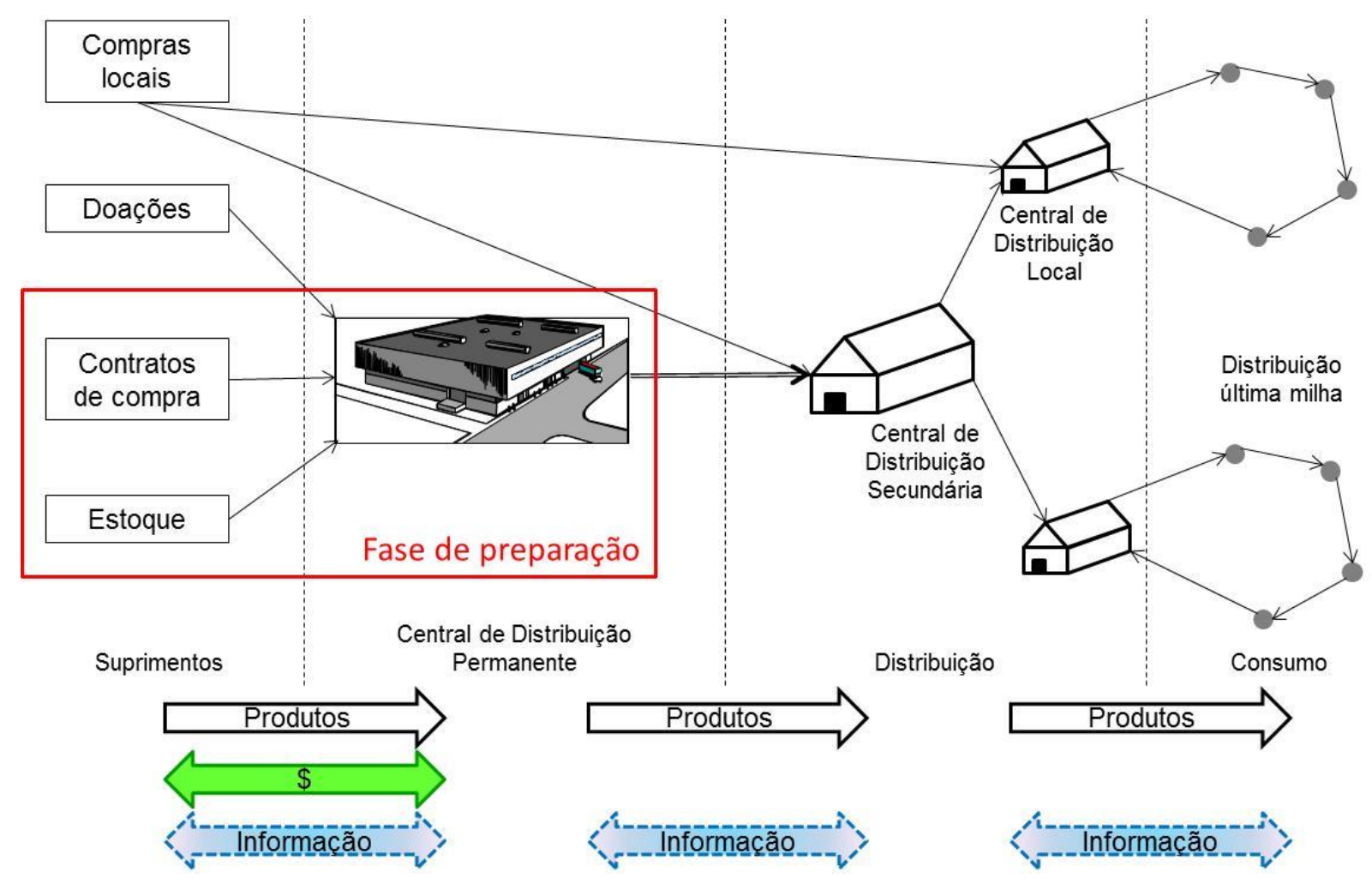

Figura 9 - Estrutura de uma cadeia de suprimentos de assistência humanitária.

Fonte: Adaptado de Ballou (2006), Blanco e Goentzel (2006) e Nogueira; Gonçalves e Novaes (2008).

Ausente, na definição de logística humanitária, é a noção de lucro, um aspecto marcante do setor comercial. Em vez de lucro, as organizações humanitárias objetivam um equilíbrio entre velocidade e custos em sua cadeia de suprimentos. $O$ fluxo de informações é pouco estruturado devido à característica de um desastre que destrói serviços e infraestrutura existentes, inclusive sistemas de comunicação, e pode comprometer a coordenação das ações e deteç̧ão de demanda de materiais na fase de resposta. 
Uma característica importante na avaliação de uma cadeia de suprimentos humanitária é a resiliência. De acordo com os conceitos da física, é a propriedade de que são dotados alguns materiais, de acumular energia quando exigidos ou submetidos a estresse sem ocorrer ruptura. Numa cadeia de suprimentos empresarial, resiliência pode ser entendida como a capacidade para responder a um infortúnio e restaurar o processo normal de abastecimento (RICE; CANIATO, 2003). Em operações humanitárias, a estrutura logística (depósitos, vias ou veículos) pode ser vulnerável e deixar de existir repentinamente (RATICK; MEACHAM; AOYAMA, 2008).

\subsection{Logística de operações humanitárias}

Segundo a Federação Internacional da Cruz Vermelha (IFRC, 2012):

\footnotetext{
"A função básica da logística de operações humanitárias compreende a aquisição e entrega de suprimentos e serviços solicitados, nos locais e horários que eles são necessários, garantindo o melhor custo-benefício. Nas operações de alívio de um desastre, estes materiais incluem itens que são vitais para a sobrevivência, como alimentos, água, abrigos temporários e medicamentos, dentre outros" (tradução nossa).
}

Thomas (2004) complementa a definição da IFRC afirmando que a função logística de operações humanitárias engloba uma gama de atividades, incluindo a preparação, planejamento, aquisição, transporte, armazenagem, rastreamento e localização, alfândega e desembaraço. 


\subsubsection{Níveis de planejamento da logística humanitária}

Ballou (2006) utiliza a classificação dos níveis de planejamento em logística em estratégico, tático e operacional. Através da aplicação destes conceitos em logística humanitária, assim como os apresentados por Apte (2009) e, também, pela IFRC (ASLANYAN, 2011) é possível exemplificar as atividades de acordo com os níveis de decisão.

Tabela 2.4 - Níveis de planejamento das decisões em logística humanitária.

\begin{tabular}{|c|c|c|c|}
\hline $\begin{array}{l}\text { Área de } \\
\text { decisão }\end{array}$ & Estratégico & Tático & Operacional \\
\hline Localização & $\begin{array}{l}\text { Onde pré-posicionar } \\
\text { suprimentos e ativos. }\end{array}$ & & \\
\hline $\begin{array}{l}\text { Estoques e } \\
\text { armazenagem }\end{array}$ & $\begin{array}{l}\text { Definir suprimentos e } \\
\text { ativos e as } \\
\text { capacidades. }\end{array}$ & $\begin{array}{l}\text { Pré-posicionar } \\
\text { estoques de acordo } \\
\text { com as estações do } \\
\text { ano e previsões. }\end{array}$ & $\begin{array}{l}\text { Detecção de } \\
\text { necessidades, } \\
\text { abastecimento e } \\
\text { reposição. }\end{array}$ \\
\hline $\begin{array}{l}\text { Transporte e } \\
\text { distribuição }\end{array}$ & $\begin{array}{l}\text { Políticas de } \\
\text { distribuição, modais e } \\
\text { estabelecimento de } \\
\text { parcerias. }\end{array}$ & $\begin{array}{l}\text { Definir veículos e } \\
\text { mobilizar de acordo } \\
\text { com as estações do } \\
\text { ano e previsões. }\end{array}$ & $\begin{array}{l}\text { Roteirização e } \\
\text { distribuição de última } \\
\text { milha. }\end{array}$ \\
\hline Compras & $\begin{array}{l}\text { Relacionamento com } \\
\text { fontes de suprimentos } \\
\text { e ativos. }\end{array}$ & $\begin{array}{l}\text { Selecionar e firmar } \\
\text { contratos com } \\
\text { fornecedores. }\end{array}$ & Liberação de pedidos. \\
\hline $\begin{array}{l}\text { Recursos } \\
\text { humanos }\end{array}$ & $\begin{array}{l}\text { Políticas para } \\
\text { desenvolver } \\
\text { capacidades. }\end{array}$ & $\begin{array}{l}\text { Treinamentos, } \\
\text { simulações e } \\
\text { reciclagens periódicas. }\end{array}$ & \\
\hline
\end{tabular}

Fonte: Adaptado de Ballou (2006), Apte (2009) e Aslanyan (2011).

\subsubsection{As estratégias logísticas e os tipos de desastres}

O tipo de desastre e sua extensão determinam a dificuldade da operação logística de resposta e a estratégia logística a ser adotada (APTE, 2009). Os tipos de materiais a serem utilizados, assim como suas necessidades temporais, diferem 
conforme a complexidade do desastre (MSF, 1997). Através de uma curva de sobrevivência, Fiedrich; Gehbauer e Rickers (2000) mostram que a probabilidade de sobrevivência diminui severamente após as primeiras 72 horas. Em algumas situações, nesse período, os suprimentos de alívio necessitam ser enviados sem uma avaliação adequada das necessidades, pois não existe tempo, tampouco recursos físicos e humanos disponíveis. A Figura 10 ilustra o grau de dificuldade encontrado conforme esses fatores.

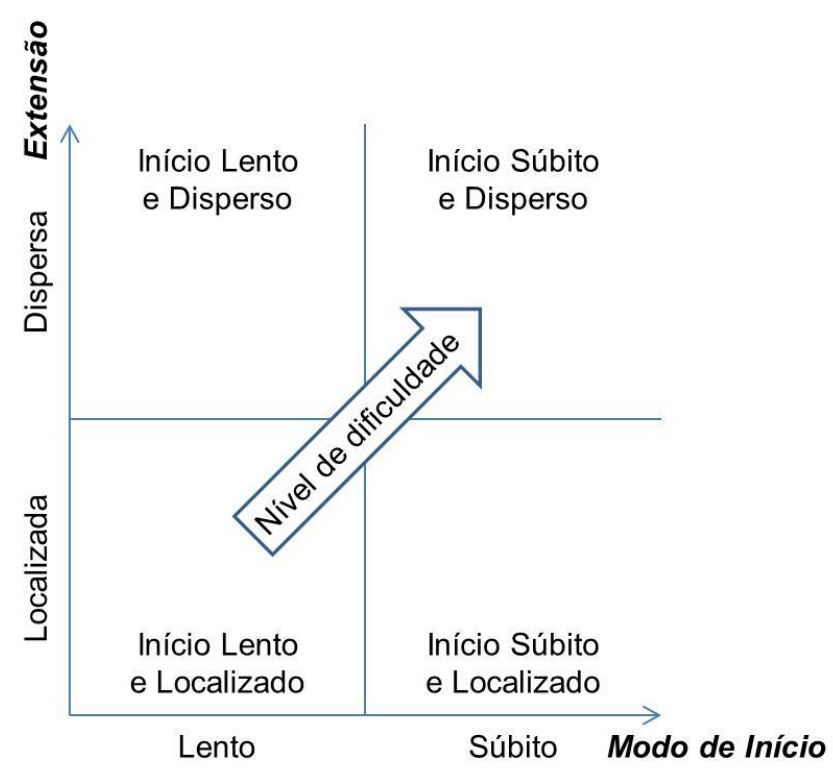

Figura 10 - Nível de dificuldade da operação de resposta. Fonte: Apte (2009).

Atividades de preparação e pré-posicionamento reduzem essas dificuldades. Apte e Yoho (2011) descrevem quatro estratégias fundamentais que podem ser empregadas na resposta a desastres naturais: pré-posicionamento; envio antecipado (proativo) de materiais; envio gradual de bens e suprimentos; e aumento rápido de capacidade dos locais próximos ao desastre. A Tabela 2.5 resume e exemplifica a essas estratégias, que podem ser utilizadas individualmente ou em conjunto, conforme a fase do desastre. 
Tabela 2.5 - Estratégias Logísticas X Desastres.

\begin{tabular}{|c|c|c|c|c|c|}
\hline \multirow[b]{2}{*}{ Estratégia Logística } & \multicolumn{4}{|c|}{ Extensão e modo de inicio } & \multirow[b]{2}{*}{ Fase } \\
\hline & $\begin{array}{c}\text { Disperso e } \\
\text { súbito }\end{array}$ & $\begin{array}{c}\text { Localizado } \\
\text { e súbito }\end{array}$ & \begin{tabular}{|l|}
$\begin{array}{l}\text { Disperso e } \\
\text { lento }\end{array}$ \\
\end{tabular} & $\begin{array}{c}\text { Localizado } \\
\text { e lento }\end{array}$ & \\
\hline Pré-posicionamento & $\odot$ & $\bullet$ & $\odot$ & $\odot$ & Preparação \\
\hline Envio antecipado & 0 & O & 0 & $\bullet$ & Preparação \\
\hline Envio gradual & ○ & $\odot$ & $\odot$ & $\odot$ & $\begin{array}{l}\text { Resposta e } \\
\text { recuperação }\end{array}$ \\
\hline Aumento rápido & $\bullet$ & $\bullet$ & 0 & O & Resposta \\
\hline Exemplo & $\begin{array}{c}\text { Tsunami do } \\
\text { Oceano } \\
\text { Índico } 2004\end{array}$ & \begin{tabular}{|c} 
Terremoto \\
no Haiti 2010
\end{tabular} & $\begin{array}{l}\text { Pandemia de } \\
\text { H1N1 } 2009\end{array}$ & $\begin{array}{c}\text { Furacão } \\
\text { Katrina } 2005\end{array}$ & \\
\hline
\end{tabular}

Fonte: Adaptado de Apte e Yoho (2011).

\subsubsection{Pré-posicionamento}

O pré-posicionamento de materiais é a armazenagem de suprimentos de alívio em quantidade e locais previamente definidos para atendimento a prováveis desastres. Adequado quando o lead time de abastecimento dos suprimentos ultrapassa o período de tempo em que podem ser necessários ou quando é importante preservar os recursos de transporte. Na determinação onde pré-posicionar materiais os tradeoffs entre a redução de tempo de distribuição e o risco associado se estiver próximo a uma potencial zona de perigo devem ser considerados. Capacidade para préposicionamento não é obtida através de terceirização ou colaboração (APTE; YOHO, 2011). Campbell e Jones (2011) descreveram um método para determinar onde pré-posicionar suprimentos em antecipação a um desastre, considerando-se vários cenários diferentes. Procuraram incorporar o risco associado com a colocação de material em uma área que pode ser afetada pelo desastre, bem como o inventário necessário para responder eficazmente a um desastre.

Pré-posicionamento é desejável nos casos em que o desastre pode ser localizado e súbito, pois proporciona agilidade no processo de resposta. Em casos de desastres dispersos o pré-posicionamento pode não pode ser viável, pois pode requerer 
grandes quantidades de estoques para abastecer uma vasta região, incorrendo em altos custos. Pré-posicionamento seria uma estratégia logística desejável para desastres como o tsunami do Oceano Índico em 2004, o terremoto no Haiti em 2010 e o furacão Katrina em 2005, pois encurtaria o tempo de abastecimento. HolguínVeras et al. (2014) também recomendam o pré-posicionamento, principalmente, para utilização na resposta imediata a uma catástrofe. A viabilidade econômica de manter suprimentos de emergência por um longo período de tempo também deve ser considerada (CAMPBELL; JONES 2011).

Para dimensionamento das áreas de armazenagem para pré-posicionamento de materiais e também como uma referência para estabelecimento de critérios de decisão sobre o assunto, o estado norte-americano da Flórida (FDEM, 2005) estabelece requisitos construtivos e operacionais "ideais" para um armazém com esta finalidade: $4.600 \mathrm{~m}^{2}$ de área adequada ao armazenamento; $14.000 \mathrm{~m}^{2}$ de pátio para estacionamento e manobras; pelo menos uma doca para carga/descarga (preferencialmente duas); uma área de $30 \times 30 \mathrm{~m}$ livres de cabos e que permita pouso de helicóptero; uma empilhadeira; e, pelo menos, duas paleteiras; disponibilidade de sistemas de comunicação e de água potável, além de estar localizado em região segura e próximo a rodovias.

\subsubsection{Envio antecipado (proativo) de materiais}

Uma alternativa ao pré-posicionamento é o envio de suprimentos de alívio para uma área próxima a um eventual desastre, segura e não susceptível, após a emissão de alerta ou perigo eminente, com o objetivo de reduzir os lead times de abastecimento e de atendimento às vítimas. Também denominado de envio proativo, pois é realizado com antecedência visando reduzir futuros problemas. Envio antecipado (proativo) de materiais deve ser utilizado para desastres de início lento, pois permitem o planejamento e resposta. Com os avanços obtidos nas ciências de previsão os organismos podem antecipar os recursos na expectativa de um desastre, ao invés de esperar a solicitação da área de impacto potencial (APTE; 
YOHO, 2011). Um exemplo de possível utilização desta estratégia seria o furacão Katrina, em 2005, pois sua chegada era conhecida com antecedência, entretanto não foi utilizada (CAMPBELL; JONES 2011).

\subsubsection{Envio gradual de bens e suprimentos}

Envio gradual de materiais refere-se à entrega de suprimentos para uma área afetada por desastres, de acordo e na quantidade necessária ao atendimento. Análogo ao just in time tem a vantagem de evitar o excesso de estoques e atender somente os tipos e quantidades de materiais necessários. Este tipo de estratégia também impede a zona de desastre de ser saturada com materiais não necessários, que poderiam reduzir a eficácia global do processo de resposta. As estratégias anteriormente apresentadas requerem áreas de armazenamento e equipes para realizar o transporte, entretanto quando esses recursos não estão plenamente disponíveis, o envio gradual é uma estratégia recomendada. Quando também as necessidades na área de desastre não são conhecidas ou alteram-se ao longo do tempo a estratégia de envio gradual é uma alternativa viável. Indicada quando existem restrições de transporte e armazenagem de materiais, como, por exemplo, o terremoto no Haiti, em 2010, onde havia portos danificados, falta de capacidade das pistas de pouso, bem como equipamentos de movimentação e diversos tipos de donativos aguardando para serem enviados (APTE; YOHO, 2011).

\subsubsection{Aumento rápido de capacidade}

Um aumento na capacidade de transporte, mão de obra e equipamentos em locais fora da área do desastre é uma alternativa para abastecimento aos locais afetados. Nessa estratégia, após o desastre, localidades não afetadas, próximas ao local, têm sua capacidade incrementada e passam a abastecer esses locais atingidos por desastre. Essa estratégia é o último recurso quando o pré-posicionamento ou envio 
proativo de materiais não são viáveis. É indicada para desastres de início rápido quando ocorrer um déficit de capacidade de resposta ou as necessidades tiverem um aumento durante a operação (APTE; YOHO, 2011).

\subsubsection{Gerenciamento da fase de resposta a um desastre}

Anteriormente ao desastre, o ciclo de preparação exerce um papel fundamental para a resposta. Apte (2009) resume a importância da preparação e o gerenciamento operacional de um desastre: "Dinheiro não consegue resolver problemas quando falta a preparação e o gerenciamento de operações".

As fases de um desastre (representadas na Figura 7) mostram como entidades gerenciam os acidentes e seu ciclo social, desde a fase anterior, de preparação, até a reconstrução do bem-estar. Quando um acidente ocorre (no início da fase "resposta" da figura), toda uma cadeia de socorro e alívio é acionada. A procura de uma grande variedade de suprimentos ocorre repentinamente e em enormes quantidades. De acordo com Pettit e Beresford (2005), existem diversas semelhanças entre a logística de operações humanitárias e a logística militar devido à incerteza das demandas; dificuldades no abastecimento provocadas pela infraestrutura degradada; ausência de algumas funções do Estado; socorro e atendimento a feridos; e constante observação da mídia. O fluxo geral de recursos para as áreas afetadas é mostrado na Figura 11. 


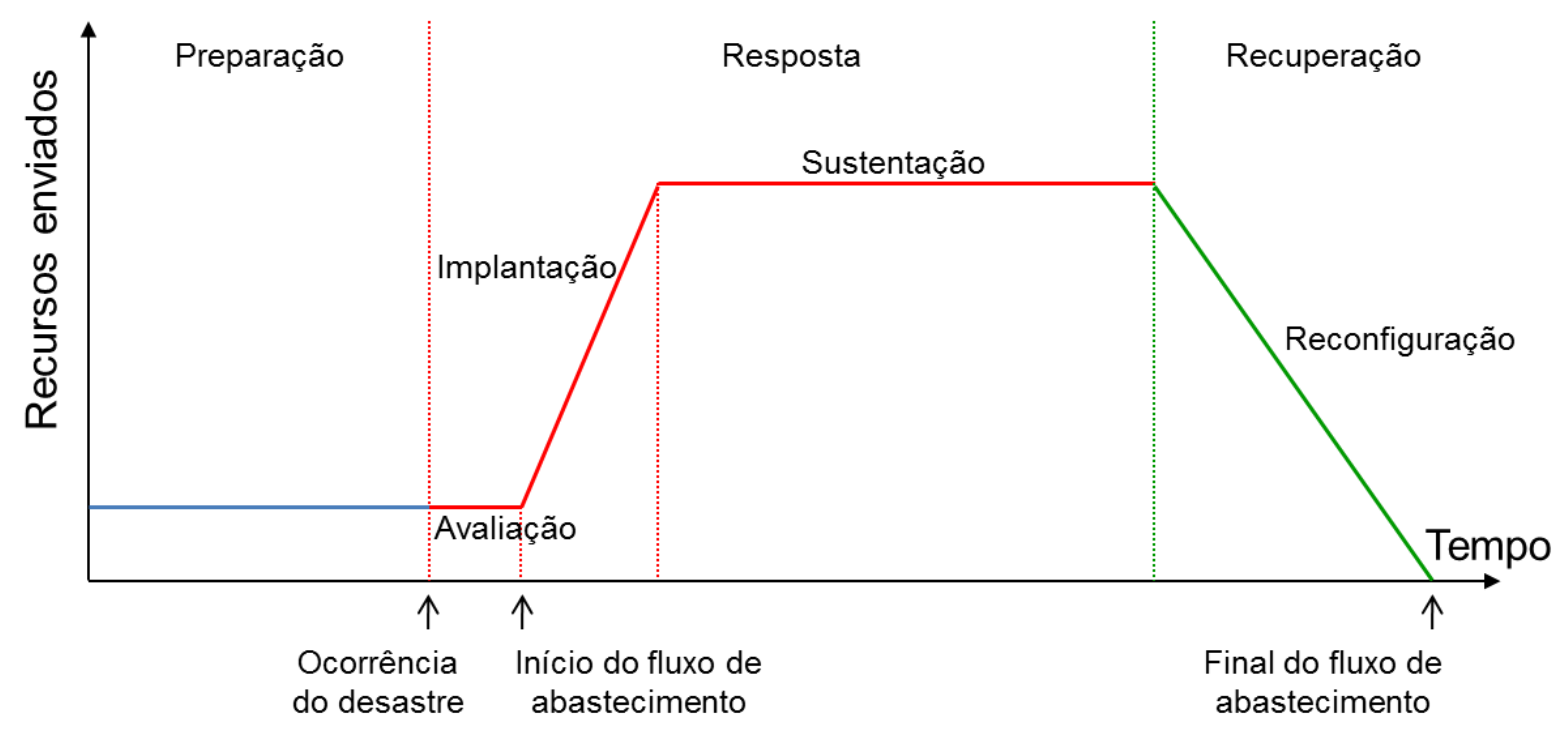

Figura 11 - Fluxo de materiais conforme a fase do desastre.

Fonte: Adaptado de Balcik e Beamon (2008) e Apte (2009).

Quanto às necessidades de materiais, o fluxo de informações ao longo da cadeia é fundamental para a agilidade e o correto abastecimento. Com base em Tomasini e Van Wassenhove (2009a), este fluxo de recursos pode ser assim descrito:

- Avaliação: o mínimo de recursos é necessário para identificar a necessidade em geral;

- Implantação (ramp-up): corresponde aos primeiros dias da ajuda. A demanda de recursos cresce para atender as necessidades. Nesta etapa o foco da cadeia de suprimentos deve ser a rapidez para que as operações sejam iniciadas;

- Operações de sustentação (sustain): as operações são sustentadas por um período de tempo e o foco é na implantação dos programas definidos e priorizados, após avaliação e implantação. Nesta etapa, custo e eficiência passam a ser considerados na cadeia de suprimentos;

- Reconfiguração (ramp-down): são reduzidas as quantidades de recursos mobilizadas para a área. As organizações e/ou Estados focam na estratégia de saída. 
A duração de cada etapa do ciclo de vida varia de acordo com as características dos desastres. No entanto, a velocidade das operações de socorro durante os primeiros momentos, após a ocorrência do desastre, afeta significativamente a vida da população atingida. Assim, a capacidade de um Estado ou de uma organização de ajuda de mobilizar os seus recursos na avaliação e implantação das fases é fundamental para o sucesso da resposta a desastres (TOMASINI; VAN WASSENHOVE, 2009a). Holguín-Veras et al. (2014) afirmam que as fases de avaliação e implantação são caóticas e que os principais objetivos nesta etapa são a avaliação das condições e a definição de meios para estabilizar a situação.

A estratégia para localização de suprimentos ao longo da cadeia humanitária é relevante para o tempo de atendimento a um desastre, assim como os tipos de materiais ali estocados para atendimento a cada uma das fases (BALCIK; BEAMON, 2008). Depois de um evento, a procura por suprimentos de ajuda muda com 0 tempo. Alguns itens são necessários imediatamente nas primeiras fases das operações de socorro, enquanto outros podem ser fornecidos durante as fases posteriores. Os tipos de suprimentos variam de acordo com as necessidades e podem ser itens alimentícios, não alimentícios, médicos e equipamentos. 


\section{Revisão da literatura sobre modelos estocásticos e multicritério aplicados a operações humanitárias}

Esta parte da revisão de literatura complementa o capítulo anterior e aborda os modelos de localização utilizados e otimização estocástica, assim como a metodologia multicritério para apoio ao processo de tomada de decisão. Neste capítulo, a pesquisa foi iniciada a partir dos artigos de revisões literárias elaborados por Altay e Green (2006) e Leiras et al. (2014) sobre aplicações de pesquisa operacional em operações humanitárias.

\subsection{Modelos de localização de instalações}

De uma maneira descritiva, um modelo de localização definido para logística empresarial que melhor se adapta a este trabalho, segundo citação de Ballou (2006), pode ser assim definido:

"Encontre o número, o tamanho e as localizações de armazéns em uma rede logística que minimizarão os custos fixos e variáveis que movimentarão todos os produtos através da rede selecionada sujeito às seguintes condições:

- O suprimento disponível não pode ser excedido para cada produto.

- A demanda de todos os produtos deve ser satisfeita.

- O processamento de cada armazém não pode exceder sua capacidade.

- Um processamento mínimo de um armazém deve ser alcançado antes que ele possa ser aberto.

- Todos os produtos para um mesmo usuário devem ser atendidos por um mesmo armazém." 
Ballou (2006) também afirma que os métodos de resolução do problema de localização podem ser classificados conforme cinco critérios:

- Força direcionadora: é o principal fator para o problema e o que terá a maior influência no modelo. Por exemplo, os critérios econômicos são fundamentais para uma análise de localização de plantas fabris e depósitos. No varejo o principal critério é a receita gerada, enquanto em serviços de emergência (bombeiros, resgate e ambulâncias,) o tempo de atendimento é prioritário.

- Número de instalações: os problemas de localização podem envolver a localização de uma instalação somente, enquanto outros envolvem a escolha de mais de uma instalação (múltiplas) que operam simultaneamente.

- Escolhas contínuas ou discretas: métodos contínuos são aqueles que buscam todas as possíveis localizações em um espaço geográfico contínuo. Nos modelos de modelagem discretos a(s) melhor(es) alternativa(s) dentre locais pré-selecionados é escolhida por suas características potenciais e são, na prática, os mais utilizados para a localização de múltiplas instalações.

- Agregação dos dados: problemas de localização de instalações, normalmente, abrangem uma grande quantidade de configurações para serem analisadas. Para controlar o porte do problema e alcançar uma solução, frequentemente, dados relacionados são agregados. Todavia, quanto menor esse nível de agregação dos dados, melhor a precisão do resultado obtido.

- Horizonte de tempo: os problemas que abordam múltiplos períodos de tempo são denominados dinâmicos. Os problemas que avaliam um período de tempo somente, por exemplo, um ano, são conhecidos por estáticos.

Brandeau e Chiu (1989) classificam também os métodos conforme a técnica utilizada na solução dos modelos. Segundo Martos (2000), os métodos podem ser agrupados em: 
- Otimizadores ou exatos: todas as alternativas são avaliadas e a melhor é selecionada. Matematicamente é demonstrado que a solução obtida é ótima nas condições e restrições definidas no processo de modelagem.

- Heurísticos: uma heurística é utilizada para reduzir o tempo do processo de busca de soluções para obter uma satisfatória para o problema, em vez de garantir uma solução ótima. Deste modo, o tempo de processamento é reduzido.

- Simulação: através de um modelo matemático, que represente os principais componentes de uma rede, o comportamento das alternativas em estudo é avaliado. Frequentemente, o modelo é estocástico e através de sucessivas simulações é possível obter diversas informações de natureza estatística para subsidiar o processo de tomada de decisão.

No processo de modelagem são adotados os conceitos de Pidd (1999) e Geoffrion (1976), que afirmam que o objetivo é o conhecimento (insight) obtido sobre a estrutura do problema, o comportamento do modelo e as relações entre variáveis e não somente os valores que resultam desta modelagem. Nesta tese, o processo de otimização irá resultar em proposição de localidades que minimizam o custo total operacional através da abertura ou não de depósitos de suprimentos de alívio, levando em consideração custos de abertura de depósito, de transporte e penalidades pelo não atendimento da demanda. A partir destes resultados de modelagem e da observação das variáveis são selecionados locais que otimizem o processo.

\subsection{Modelos de localização de instalações de operações humanitárias}

Embora exista uma abundância de artigos sobre gerenciamento de desastres nas ciências sociais e humanas, Altay e Green (2006) afirmaram, nesta época, que a 
comunidade que atua com pesquisa operacional ainda está iniciando uma produção acadêmica que proporcione uma massa crítica sobre o assunto. Neste artigo os autores concluem que, principalmente, devido ao aquecimento global (independentemente da natureza antropogênica ou não), existe uma tendência crescente de aumento de desastres, havendo um grande potencial de estudos de pesquisa operacional nessa área.

As primeiras publicações científicas sobre operações de ajuda humanitária eram focadas na rapidez do atendimento a emergências. No artigo de Toregas, et al. (1971), através de um modelo determinístico de cobertura (set covering), são localizadas instalações de serviços de emergência que minimizam o tempo ou distância de atendimento a um ponto de demanda. Embora Altay e Green (2006) não considerem este tipo de aplicação como uma atividade de logística de operações humanitárias, 0 atendimento a emergências originou artigos sobre 0 assunto. Os autores ressaltam que este tipo de modelo possui diversas aplicações como corpo de bombeiros; escolas; e depósitos de materiais, em que exista a necessidade de atendimento mediante a um nível de serviço.

Sherali e Carter (1991) propuseram um modelo de localização de abrigos para minimizar o tempo de remoção das pessoas desabrigadas até os abrigos, utilizando programação não linear. Eles validaram seu modelo através da utilização de dados reais de Virginia Beach, Virginia, EUA. Current e O'Kelly (1992) elaboraram um modelo de localização com a maximização de área coberta para localização de sirenes em caso de acidente nuclear ou desastres naturais.

Após o acidente do navio Exxon Valdez, que provocou vazamento de petróleo no mar do Alasca, em 1989, trabalhos foram publicados visando a localização de estoques de materiais utilizados em emergências. Wilhelm e Srinivasa (1996) desenvolveram um modelo de localização de instalações de materiais para limpeza, em casos de vazamentos de óleo, com aplicação na baía de Galveston, Texas. lakovou; Ip e Douligeri (1996) apresentaram um modelo de programação inteira mista para a localização de depósitos de equipamentos para resposta a derramamentos de petróleo, assim como o inventário necessário em cada depósito, 
visando otimizar os tempos dos procedimentos táticos que ocorrem quando há um vazamento.

O evento sísmico de 26 de dezembro de 2004, no Oceano Índico, também conhecido por Banda Aceh, gerou um tsunami de grandes consequências, que atingiu desde o Quênia até a Indonésia, provocando 225 mil mortes e deslocando milhões de pessoas (ALTAY; GREEN, 2006). Este fenômeno levou a detecção de que os organismos de socorro e ajuda não possuíam uma estrutura logística capaz de atender ocorrências de tal magnitude e ocasionou, no meio acadêmico, a necessidade de estudos científicos na área. Publicações acadêmicas sobre o assunto, a partir deste período, tiveram um crescimento substancial (PERES et al., 2012).

Algumas publicações, embora não totalmente voltadas ao problema de localização, contribuíram para o desenvolvimento de logística de operações humanitárias, pois abordaram o problema de distribuição a partir de locais já definidos. Haghani e Oh (1996) desenvolveram um modelo aplicando o problema de fluxo em redes, com multimodalidade, multiproduto e com janela de tempo como uma ferramenta de tomada de decisão, que pode, potencialmente, ser usada nas respostas às emergências e no planejamento das operações de socorro. $O$ artigo aborda $O$ problema de determinar a programação e roteirização dos modais de transporte disponíveis, horários de entrega dos materiais e os respectivos planos de carga.

Barbarosoglu; Özdamar e Çevik (2002) dividiram o problema das operações de socorro e alívio, utilizando helicópteros em problemas de nível tático e operacional, e detectaram a necessidade da utilização de ferramentas de análise multicritério em estudos desta natureza, permitindo uma participação interativa no processo de decisão.

Modelos de localização e pré-posicionamento de materiais podem ser observados no trabalho de Deckle et al. (2005), no qual um modelo de localização para centros de recuperação de desastres foi desenvolvido através da utilização Programação Inteira Mista, onde cada residência, em um condado da Flórida, deveria estar a menos de 20 milhas de cada centro. Drezner; Drezner e Salhi (2006) estudaram o 
pré-posicionamento de centros de atendimentos de vítimas, em casos de grandes desastres, através de um modelo multiobjetivo. Os locais são previamente avaliados e podem ser estabelecidos em universidades, escolas, parques públicos, estádios e ginásios de esportes amplos o suficiente para acomodar um elevado número de pessoas; e que encontram-se em locais relativamente seguros e possam acomodar um heliporto para remoção aérea.

Akkihal (2006) identificou locais para pré-posicionamento de materiais necessários para a fase de preparação através de um modelo de $p$-medianas, usando séries históricas sobre acidentes, minimizando a distância da instalação aos locais de atendimentos e estabelecendo pesos diferenciados a cada local da possível demanda, conforme o histórico de desabrigados.

O problema de localização de instalações de pré-posicionamento de materiais para atendimento humanitário, em caso de desastres súbitos, também foi abordado por Balcik e Beamon (2008), através de um modelo de localização de máxima cobertura (maximal covering location), que determina o número e localização de centros de distribuição em uma rede e a quantidade de suprimentos de alívio a ser abastecida para atender às necessidades das pessoas afetadas pelos desastres. O problema consistiu, dadas as incertezas e as limitações de recursos em um ambiente de socorro, em determinar a localização de $p$ facilidades, de forma a atender a maior parcela de uma determinada população, dado um tempo de resposta. Outro conceito apresentado por Balcik e Beamon (2008) foi o de estimar as incertezas e os materiais conforme o tipo de evento (por exemplo, a necessidade de um kit de higiene pessoal é maior em um caso de inundação do que em um caso de seca).

Lin et al. (2011) (2012), em publicação sequencial, complementaram o problema de Balcik e Beamon (2008), inserindo a priorização de materiais em caso de terremoto, com abordagem estocástica, utilizando o algoritmo genético e heurística da decomposição e atribuição (DAH) na solução do problema. Os resultados mostraram que o algoritmo genético proporcionou boas soluções, enquanto a DAH proporcionou soluções mais rápidas, porém com redução de 4,3\% na qualidade da solução quando comparada ao algoritmo genético. 
O problema de máxima cobertura também foi abordado por Viswanath e Peeta, (2003) que formulam um modelo multiproduto com dois objetivos (MCNDP) num projeto de rede para a identificação de vias críticas, para uma resposta a um eventual desastre. O trabalho busca minimizar o tempo total de viagem sobre as rotas selecionadas e maximizar a cobertura da demanda total. Restrições orçamentárias são introduzidas.

Problemas de localização e associados com roteirização podem ser observados no artigo de Yi e Özdamar (2007), no qual foi proposto, para a solução do problema, um procedimento em duas fases a fim de coordenar o transporte de produtos e a remoção de feridos. Na primeira fase é maximizado o atendimento da demanda e a retirada de feridos e na segunda uma roteirização para este atendimento é realizada. Um objetivo similar é apresentado em Campbell; Vandenbussche e Hermann (2008), que formulam duas funções objetivo diferentes para o roteamento de veículos que transportam itens críticos em uma operação de alívio e estudam os modelos correspondentes.

Ukkusuri e Yushimito (2008) modelam o pré-posicionamento de suprimentos para atendimento a desastres como um problema de localização de instalações, considerando também a roteirização de veículos. Os autores inseriram possíveis rupturas na rede de abastecimento humanitário. Matisziw e Murray (2009) formularam um modelo para verificar a resiliência da rede em operações e possíveis perdas de nível de serviço, através do rompimento de arcos dessa rede. O modelo busca encontrar soluções, utilizando os caminhos disponíveis, e foi aplicado no sistema de autoestrada de Ohio para apoiar a avaliação da vulnerabilidade a desastres.

Um problema de distribuição com coleta e entrega em situações de emergência é estudado por Özdamar; Ekinci e Küçükyazici (2004), no qual a oferta é limitada e a disponibilidade de produtos varia ao longo do horizonte de planejamento. O problema do transporte é resolvido periodicamente, de acordo com a dinâmica do abastecimento e das necessidades durante a fase de entregas de suprimentos de alívio, com o objetivo de minimizar o tempo de atendimento nos pontos de demanda. Um ponto que ficou em aberto neste artigo foi que, em caso de oferta menor que a 
demanda, os desabastecimentos poderiam ocorrer sempre nos mesmos locais, através do modelo de transporte.

Alguns artigos destacam-se por natureza aplicada a problemas reais relativos a Operações Humanitárias, como o trabalho de Görmez; Köksalan e Salman (2011), que propôs a localização de instalações de resposta a desastres em Istambul (Turquia), através da utilização de equipamentos e recursos públicos existentes, além de sugerir novas instalações para atuação como pontos de abastecimento regional. Chawaguta e Gonçalves (2011) desenvolveram um modelo de transbordo de fluxos em redes para subsidiar o plano anual de distribuição de ajuda alimentar, realizado pelo WFP, na Etiópia. Rath e Gutjahr (2014) consideraram um problema enfrentado por organizações internacionais de ajuda (aplicado a International Red Cross/Crescent), após a ocorrência de um desastre natural, que é o estabelecimento de instalações para abastecimento de suprimentos. Um modelo de otimização de três objetivos: um econômico de médio prazo; um econômico de curto prazo; e uma função objetivo humanitário, foram utilizados para a localização dos depósitos. A aplicação ocorreu em Manabi, Equador.

A abordagem determinística para localização e/ou pré-posicionamento de suprimentos para atendimento a emergências gerou diversos estudos de natureza aplicada, como o trabalho de Duran; Gutierrez e Keskinocak (2011), que utilizaram Programação Inteira Mista na determinação da melhor configuração de rede de préposicionamento de depósitos para atendimento à emergências oriundas de desastres naturais da organização de ajuda humanitária CARE Internacional, considerando o investimento inicial (inventário inicial de lotação e configuração do armazém); os custos operacionais (itens de socorro, transporte, armazenagem e funcionamento); e o tempo médio de resposta, com o objetivo de responder: dado um investimento inicial, qual é a configuração da rede que minimiza o tempo médio de resposta? Para encontrar a configuração da rede de abastecimento que minimiza o tempo médio de resposta a demanda de todos os locais, ignoraram os custos operacionais, pois não foi possível obter informações sobre atendimentos anteriores da CARE (custo de abastecimento e transporte), obtiveram dados históricos de casos típicos, e assim aplicaram um modelo de Programação Inteira Mista (MIP). As 
soluções apontaram o resultado "matemático" da modelagem, porém foram alterados por critérios de facilidades logísticas. Este problema mostra a necessidade de utilização de ferramentas estruturadas de apoio à decisão na avaliação dos resultados de um processo de modelagem.

\subsection{Localização de instalações utilizando otimização estocástica}

A Programação Linear (LP) é uma poderosa ferramenta utilizada para planejamento, entretanto, muitas vezes, existe dificuldade em estimar de maneira precisa ou elaborar previsões para algumas informações utilizadas no processo de modelagem. Em tais casos, é necessária uma abordagem que leve em consideração o impacto da incerteza durante esse processo. A hipótese de que todos os parâmetros do modelo são conhecidos de maneira determinística limita a sua utilidade em planejamento mediante incerteza, pois, nos modelos determinísticos toda informação para composição dos parâmetros e variáveis é considerada disponível. A solução ótima dos modelos determinísticos pode ser inviabilizada, em caso de perturbação dos dados (BEN-TAL; NEMIROVSKI, 2000). Em eventos como desastres existe a incerteza na determinação dos componentes do modelo. Quando um ou mais elementos de um modelo de Programação Linear é representado por uma variável aleatória, este modelo é denominado de Modelo Estocástico de Programação Linear (SLP) (SEN; HIGLE, 1999).

Nos modelos estocásticos a incorporação da incerteza tem sido adotada através de duas abordagens. Na primeira, os valores dos parâmetros não são conhecidos e o que se sabe são suas distribuições probabilísticas. Neste caso, na formulação, as variáveis aleatórias são substituídas por seus valores esperados, podendo não fornecer uma solução viável no que diz respeito às restrições do problema (WETS, 1989). 
A outra abordagem adotada é baseada em uma análise de esperar para ver (waitand-see), também conhecida como análise de cenários (what-if). Esta abordagem simula o processo como se possível fosse atrasar todas as decisões até o último momento, depois que todas as incertezas forem resolvidas. Como resultado, os Problemas de Programação Linear (PPL), associados com todos os possíveis resultantes dos valores aleatórios, são resolvidos. Isto produz um conjunto de vetores de decisão, uma para cada resultado possível da variável(is) aleatória(s) (HIGLE, 2005).

Nos modelos de dois estágios, as variáveis de decisão são classificadas de acordo com sua aplicação: antes ou depois de um resultado de variável aleatória. As decisões, que devem ser tomadas antes da realização da variável aleatória, são conhecidas como de primeiro estágio, enquanto as que são implementadas posteriormente a essa realização são do segundo estágio de decisões. As variáveis do primeiro estágio de decisão são, frequentemente, associadas com questões de planejamento e atribuídas a decisões estratégicas. Variáveis de segundo estágio estão, normalmente, associadas a decisões táticas e operacionais (SEN; HIGLE, 1999).

Num modelo de dois estágios a solução do segundo estágio do problema depende da solução de primeiro estágio, todavia o primeiro estágio não pode ser resolvido sem a compreensão do comportamento do problema de segundo estágio (SHAPIRO; DENTCHEVA; RUSZCYNSKI, 2009). Essa característica torna a solução dos modelos estocásticos mais complexa que modelos equivalentes determinísticos, demandando um maior esforço computacional e, consequentemente, um tempo maior para a solução do problema.

Uma característica da Programação Linear Estocástica são os cenários. Para a sua montagem cada evento possível para o problema é definido, assim como sua probabilidade de ocorrência. Os valores dos parâmetros são, então, estabelecidos para cada cenário identificando, além dos valores dos parâmetros, estimativas dos resultados possíveis para as variáveis estocásticas (SEN; HIGLE, 1999). 


\subsubsection{Desempenho da solução estocástica}

Noyan (2012) observa que o EVPI (Expected Value of Perfect Information) e o VSS (Valor da Solução Estocástica) são as duas medidas de desempenho da solução estocástica mais conhecidas. Estes indicadores são elaborados para avaliar os ganhos na modelagem utilizando programação estocástica quando comparada a uma abordagem determinística que não leva em consideração probabilidades nos eventos aleatórios associados à modelagem.

O valor esperado da informação perfeita - EVPI mede a perda devido à presença de incerteza, quanto o tomador de decisão poderia ter pagado para se obter de antemão a informação perfeita, ou seja, qual o estado da natureza irá ocorrer (MOREIRA, 2007).

O EVPI é representado pela diferença entre a solução do problema obtida sob incerteza (recourse problem - RP), conhecida a distribuição de probabilidade (LEIRAS, 2011), e a solução obtida caso o tomador tivesse a capacidade de fazer a previsão perfeita (wait-and-see - WS). Quanto menor o EVPI, melhor o modelo estocástico acomoda as incertezas (BIRGE; LOUVEUX, 1997).

Em uma abordagem realista o EVPI isoladamente pode não ser a medida mais adequada (BORTOLOSSI; PAGNONCELLI, 2008), já que a solução de previsão perfeita (wait and see - WS) é impossível de ser obtida na prática. Desta forma, outro conceito importante em otimização é o VSS. O VSS mede o ganho em considerar 0 modelo estocástico ao invés de basear-se em um modelo determinístico associado à média ponderada das variáveis aleatórias. O VSS é definido pela diferença entre a média de uma solução do problema de valor esperado (EEV) e a solução estocástica (RP) (BIRGE; LOUVEUX, 1997). O VSS pode ser interpretado como o benefício esperado pelo tomador de decisão, que levou em consideração a incerteza, ou como a perda esperada pelo tomador de decisão, que optou pela modelagem determinística, usando os parâmetros 
estocásticos médios. Outra maneira de representar o EVPI e VSS é sobre a forma percentual. Consiste na divisão desses valores pela solução da previsão perfeita (WS).

Nos artigos sobre localização de instalações anteriormente citados, em que foram utilizadas modelagens estocásticas para problemas de operações humanitárias, apenas dois deles utilizaram o VSS e o EVPI como ferramentas para avaliação e comparação de modelos. A Tabela 3.1 mostra como cada um dos autores abordou essa avaliação.

Tabela 3.1 - Avaliação do desempenho de modelos estocásticos.

\begin{tabular}{ll}
\hline \multicolumn{1}{c}{ Autor } & \multicolumn{1}{c}{ Avaliação do desempenho da solução } \\
\hline $\begin{array}{l}\text { Chang; Tseng e Chen, } \\
\text { (2007) }\end{array}$ & $\begin{array}{l}\text { Apenas comparou os custos da solução estocástica < } \\
\text { determinística < atual (média e desvio padrão). Diferença entre } \\
\text { estocástica e determinística = 0,647\%. }\end{array}$ \\
\hline $\begin{array}{l}\text { Rawls e Turnquist } \\
\text { (2012) }\end{array}$ & $\begin{array}{l}\text { Não aborda o desempenho da solução. Este tópico foi } \\
\text { complementado pelo estudo de Noyan (2012). }\end{array}$ \\
\hline $\begin{array}{l}\text { Mete e Zabinsky } \\
\text { (2010) }\end{array}$ & $\begin{array}{l}\text { Usou o equivalente determinístico para obter a solução } \\
\text { estocástica, entretanto não comparou os resultados. }\end{array}$ \\
\hline $\begin{array}{l}\text { Salmerón e Apte } \\
\text { (2010) }\end{array}$ & $\begin{array}{l}\text { EVPI entre 24\% e 25\% da solução WS, VSS médio entre } \\
\text { cenários = 47\% da solução WS. No cenário mais favorável = } \\
\text { 256\% da solução WS. }\end{array}$ \\
\hline $\begin{array}{l}\text { Bozorgi-Amiri; } \\
\text { Jabalameli e Mirzapour }\end{array}$ & $\begin{array}{l}\text { Comparou solução determinística com soluções estocásticas - } \\
\text { ganho médio = 3,8\%. }\end{array}$ \\
\hline $\begin{array}{l}\text { Murali; Ordóñez e } \\
\text { Dessouky (2012) }\end{array}$ & Foco na metodologia da solução. \\
\hline $\begin{array}{l}\text { Tricoire; Graf e Gutjahr } \\
\text { (2012) }\end{array}$ & Não aborda o desempenho da solução. \\
\hline $\begin{array}{l}\text { Zhang et al. (2012) } \\
\text { (2011) }\end{array}$ & Focado no algoritmo, ganho de 26,4\% no tempo. \\
\hline $\begin{array}{l}\text { Noyan (2012) } \\
\text { EVPI 54,05\% a 58,42\%, VSS 0,84\% a 5,41\% da solução WS. }\end{array}$ \\
\hline $\begin{array}{l}\text { Realiza análise de sensibilidade em função da variação do } \\
\text { risco. }\end{array}$ \\
\hline
\end{tabular}




\subsubsection{Localização de instalações humanitárias utilizando otimização estocástica}

A seguir, são descritos trabalhos em que foi utilizada otimização estocástica na solução de problemas aplicados à logística de operações humanitárias, com destaque para os modelos de Rawls e Turnquist (2012) e Mete e Zabinsky (2010), que foram os modelos que serviram de base para a construção do modelo desta tese.

Modelos de dois estágios de programação estocástica são aplicados à localização de instalações utilizadas em Operações Humanitárias como o trabalho de Chang; Tseng e Chen (2007), que utilizam otimização estocástica na determinação da localização de armazéns para estoques de materiais, alocação e distribuição de recursos de resgate em casos de inundações urbanas. Devido à incerteza, o problema de inundação é formulado como modelo de dois estágios de programação estocástica (o primeiro estágio minimiza as distâncias e o segundo realiza a alocação dos estoques).

Rawls e Turnquist (2010) apresentam um modelo estocástico de dois estágios para localização de instalações para planejamento de resposta a emergências, determinando a localização e as quantidades de vários suprimentos de emergência a serem pré-posicionados sob incerteza, que foi abordada, considerando vários cenários que podem ocorrer em um desastre, atribuindo a cada um deles variações na demanda e penalidades para a demanda não atendida. Devido à complexidade do problema, a heurística Lagrangeana L-shaped foi utilizada na solução. Complementando o estudo, Rawls e Turnquist (2011) apresentaram um acréscimo ao publicado, utilizando restrições de qualidade de serviço e de distância média dos depósitos até os nós de demanda, realizando uma aplicação no sul dos EUA. Posteriormente, Rawls e Turnquist (2012) adaptaram o modelo para alocação dinâmica de instalações pré-eventos (72 horas de antecedência) para atendimentos às demandas de curto prazo garantindo $100 \%$ de atendimento às necessidades. Mostraram que, para uma mesma situação-problema, a variação no valor das 
penalidades afeta a quantidade de depósitos abertos, assim como o custo total, indicando que a subjetividade deste valor afeta a solução do problema. O modelo foi calibrado conforme as penalidades, entretanto o método de calibração não foi descrito nos artigos.

Noyan (2012) incorporou ao modelo a medição de risco, utilizando também programação estocástica de dois estágios, introduzindo os conceitos do valor esperado da informação perfeita (EVPI) e valor da solução estocástica (VSS) na estrutura do modelo, utilizando o método da decomposição de Benders para a solução do modelo. Os resultados mostraram a relevância da atribuição dos valores de riscos na localização de instalações humanitárias.

Mete e Zabinsky (2010) avaliaram a localização de armazéns de suprimentos médicos e níveis de estoque necessários para cada fonte médica (primeiro estágio), bem como requisitos de entrega de suprimentos, por meio de um segundo estágio de roteirização de veículos, que desagrega a informação estratégica em um planejamento operacional. O modelo captura a informação específica de cada desastre e seus possíveis efeitos, através da utilização de cenários, avaliando preparação e risco, conforme as incertezas do evento. Uma observação sobre o modelo é a composição da função objetivo de primeiro e segundo estágio, no qual tempo e custo se confundem. O artigo não detalha a solução desta observação, porém em testes realizados pelo autor, somente transformando tempo em custo, seria possível a solução.

O trabalho de Salmerón e Apte (2010) aborda um modelo estocástico de dois estágios, no qual a decisão de primeiro estágio refere-se à estratégia de localizar instalações de suprimentos de alívio e o segundo refere-se ao atendimento da área afetada, realizando as atividades de transporte necessárias para atendimento à população. A função objetivo minimiza o número esperado de mortes e os cenários estabelecidos são as incertezas sobre o local e severidade do evento.

Otimização multiobjetiva foi utilizada no trabalho de Bozorgi-Amiri; Jabalameli e Mirzapour Al-e-Hashem (2013), que desenvolveram uma abordagem multiobjetivo de programação estocástica robusta para a logística de socorro a emergências em 
ambiente sob incerteza. $\mathrm{Na}$ abordagem, não apenas a demanda, mas também os custos dos suprimentos, do processo de aquisição e de transporte são considerados como os parâmetros incertos, existindo também a possibilidade de ruptura de um dos depósitos estabelecidos. A função objetivo minimiza o custo total e penaliza o não atendimento da demanda. Citam que 0 valor da penalidade pode ser estabelecido através de métodos multicritério.

Nolz; Semet e Doerber (2011) também formularam um problema de otimização multiobjetivo no projeto de um sistema logístico para garantir a distribuição adequada da ajuda de emergência pós-desastre natural, quando danos a infraestrutura podem interromper a entrega de ajuda humanitária. O problema é formulado englobando três funções objetivo e resolvido através de um algoritmo genético. A primeira função objetivo minimiza a medida de risco; a segunda minimiza a soma das distâncias entre todos os habitantes e seus postos de serviço mais próximos; e a terceira minimiza o tempo de viagem total.

Um modelo biobjetivo com demanda estocástica foi formulado por Tricoire; Graf e Gutjahr (2012). A função objetivo minimiza: (i) custo (abertura para centros de distribuição, mais distribuição até os pontos de demanda); e (ii) a demanda não atendida. Para a solução do problema de Programação Inteira foi utilizada a heurística branch and cut. Dados reais de aplicação no Senegal mostraram a viabilidade da abordagem.

Modelo de cobertura foi utilizado por Murali; Ordóñez e Dessouky (2012), que consideram um problema de localização de instalações capacitadas para determinar os pontos onde medicamentos contra um hipotético ataque com antraz, em Los Angeles, são entregues à população. Foi formulado um caso especial de localização com máxima cobertura e o modelo decide os locais a serem abertos, bem como a quantidade de suprimentos atribuídos a cada local mediante incerteza na demanda. Os resultados comparam as soluções usando a heurística de locação-alocação e a metaheurística simulated annealing. Para uma quantidade de 40 instalações a serem abertas, a heurística de locação-alocação apresentou um desempenho $(89,66)$ melhor em relação à cobertura comparada a simulated annealing $(82,45)$. 
Zhang et al. (2012) abordam a questão dos desastres secundários que ocorrem após um grande desastre natural. Exemplos destes desastres podem ser citados como os eventos de Tōhoku, no Japão, em 2011, no qual um acidente nuclear ocorreu após um desastre de origem sísmica. No problema foram abordadas demandas de natureza estocástica para o primeiro e o segundo desastres de maneira individualizada, com probabilidades diferentes para cada caso. Este problema pode ser denominado como problema de alocação em tempo real de múltiplos incidentes, múltiplas respostas e de recursos múltiplos. A função objetivo contém a minimização dos custos de resgate.

\subsubsection{Outras aplicações de otimização estocástica em logística de operações humanitárias}

Outros estudos sobre otimização estocástica, não abordando o assunto Localização, foram também avaliados, pois agregam conhecimento para utilização nesta tese. Erkut e Ingolfsson (2000) utilizaram otimização estocástica na avaliação do risco de desastres de origem tecnológica no transporte de materiais. Citam que não é adequada a definição de 1994 do Guia do Departamento de Transporte Americano (U.S. Department of Transportation Guidelines) de que risco é o resultado do produto de uma probabilidade por uma consequência quantificável de um acidente, pois eventos catastróficos possuem baixas probabilidades, e essa definição pode levar os tomadores de decisão a ignorarem tais eventos ou essas baixas probabilidades terem pouco impacto nos resultados dos modelos adotados. Os autores levam fortemente em consideração a população exposta ao risco. Postulam que um desastre no transporte de materiais que afete 1.000 pessoas pode ter um custo muito maior que 100 vezes do que um que afete 10 pessoas, levando-se em consideração o custo financeiro e o de imagem pública negativa, principalmente em função ao destaque que pode existir por parte da mídia. 
Barbarosoglu e Arda (2004) elaboraram um modelo estocástico de dois estágios para um problema de fluxo em redes, considerando dois níveis de informação para aplicação em planejamento do transporte de commodities vitais para os primeiros socorros aos afetados por um desastre (fase de resposta). Um modelo multiproduto, multimodal de fluxo em rede é desenvolvido para descrever o fluxo de material em uma rede. Uma amostra finita de cenários para oferta de capacidade e demanda foi elaborada para a modelagem. A magnitude do desastre e seu impacto sobre o sistema disponível para transporte e os recursos disponíveis são tratados de forma estocástica, levando a incerteza na capacidade dos arcos da rede. Encontraram um EVPI de $0,8 \%$ e um VSS de $6,7 \%$ para o cenário mais crítico.

Beamon e Kotleba, (2006b) desenvolvem um modelo de controle de estoque estocástico que determina o ponto de pedido ideal e pontos de reabastecimento para um socorro de emergência de longo prazo. A demanda irregular, padrões e restrições incomuns que ocorrem em grandes emergências, frequentemente, ultrapassam as capacidades de resposta das organizações não governamentais. Essa limitação foi abordada através do desenvolvimento de um modelo estocástico de controle de inventário, que determina quantidades ideais de pedido e prioriza os pontos de entrega. Estes autores comentam a limitação de pesquisas na área de controle de estoques em operações humanitárias.

\subsubsection{Penalidades pelo não atendimento}

A penalidade para o não atendimento influencia diretamente o resultado do modelo. Trata-se de um valor difícil de estipular e, muitas vezes, essa quantificação pode gerar questionamentos. Um custo bastante discutido na literatura é o que refere-se ao valor da vida humana. Na literatura sobre Transportes, esse valor pode variar entre 0,5 e 8,4 milhões de dólares americanos, de acordo com agências de transporte norte-americanas, canadenses ou europeias (WEISBROD; LYNCH; 
MEYER, 2009). Na literatura sobre Meio Ambiente, baseado em análise de 26 publicações, esse valor foi estipulado em 6,1 milhões de dólares americanos (VICTORIA TRANSPORT POLICY INSTITUTE, 2009). Na literatura sobre logística de operações humanitárias, Holguín-Veras et al. (2013), com base na literatura sobre Transportes, atribuiu o valor de 5 milhões de dólares americanos.

Devido à dificuldade para mensuração, o valor da penalidade atribuído ao modelo pode variar conforme os critérios utilizados o os objetivos na modelagem, além do comportamento desejado do modelo. Neste tópico são apresentados critérios utilizados em logística de operações humanitárias, que contribuíram para a elaboração deste trabalho.

Os valores de penalidades para os artigos de Rawls e Turnquist (2010), (2011) (2012) variam entre 10 a 50 vezes o valor do produto (na maioria dos casos 20). Mostraram que, para uma mesma situação-problema, a variação no valor das penalidades afeta a quantidade de depósitos abertos, assim como o custo total, indicando que a subjetividade deste valor afeta a solução do problema.

Noyan (2012) complementa os artigos publicados por Rawls e Turnquist (2010), (2011) (2012), acrescentando incerteza na demanda e no nível de danos causado por desastres. $O$ valor da penalidade foi estabelecido como 10 vezes (em alguns casos 5 vezes) o valor do produto.

Mete e Zabinsky (2010) não estabelecem valores para a penalização do não atendimento, porém afirmam que as penalidades devem ser usadas em casos de atraso e que os gestores de desastres têm a liberdade na calibração desse parâmetro para priorizar a utilização dos materiais disponíveis, sob diferentes cenários.

Bozorgi-Amiri; Jabalameli e Mirzapour Al-e-Hashem (2013) utilizaram também um modelo estocástico para localização de instalações, considerando incerteza na demanda, transporte e no valor dos produtos adquiridos. Afirmam que as penalidades podem ser estipuladas através de métodos multicritério, entretanto não detalham a utilização dessa metodologia. As penalidades foram estabelecidas entre 
5 e 10 vezes o valor do produto, independentemente, de cenário e um multiplicador foi acrescentado para alterar o valor da penalidade por produto, conforme o cenário.

Salmerón e Apte (2010) tratam a penalidade de maneira determinística e utilizaram um indicador em função do número de vítimas entre a população não removida (termo: que ficou para trás) por unidade de material não entregue (pessoas $/ \mathrm{ft}^{3} \mathrm{x}$ 1000). O modelo é influenciado pela taxa de sobrevivência da população, caso essa taxa for igual a 1, indicando que toda população não removida sobreviverá, materiais necessitam ser entregues. Caso a taxa de sobrevivência seja reduzida a prioridade passa a ser a remoção de pessoas.

Barbarosoglu e Arda (2004) inseriram a penalidade pela falta e, assim como, pela manutenção de materiais. Utilizaram uma grande variação desse valor para avaliar o comportamento do modelo (EVPI e VSS), observando a partir de qual valor o comportamento do modelo, em função das penalidades, produz um mesmo resultado, alterando somente o valor do custo total.

Holguín-Veras et al. (2013) aborda o conceito de custos sociais que é composto de custos logísticos mais o custo de privação, que leva em consideração o sofrimento humano devido à falta de algum material ou serviço necessário a sobrevivência. $A$ privação possui um crescimento não linear, pois quanto maior o tempo de falta do material, sua necessidade cresce de maneira não linear, pois pode acarretar o óbito das vítimas. O componente tempo ou entrega tardia passa também a ser avaliado nesse conceito. $O$ valor da penalidade utilizado na modelagem por entrega não efetuada é constante e obtido a partir da aproximação de uma função logarítmica particionada.

Salmerón; Kline e Densham (2011) elaboraram uma ferramenta de otimização para auxiliar no planejamento de missão e da programação de missões de assistência humanitária para a Marinha dos EUA. Auxilia as equipes de frota a examinar em um navio, que execute uma missão por um período prolongado (por exemplo, seis meses), como alternar as equipes para melhor fornecer assistência humanitária. A penalidade ocorre em função de cada utilização de portos, com o objetivo de evitar embarques excessivos. 
Balcik; Beamon e Smilowitz (2008) elaboram um modelo de Programação Inteira Mista para determinar a distribuição de última milha alocando recursos de forma equitativa, com base no suprimento, na capacidade do veículo e nas restrições de tempo de entrega, com o objetivo de minimizar os custos de transporte e maximizar o auxílio aos beneficiários da ajuda. Classifica os materiais em dois tipos: materiais tipo 1 são aqueles que, ao chegar às localidades de demanda, são imediatamente distribuídos aos beneficiários da ajuda. Assume-se que não exista estoque desses materiais. Tipo 2, são os itens que são consumidos regularmente e cuja demanda ocorre periodicamente ao longo do horizonte de planejamento (por exemplo, alimentos, kits de higiene). Para esses materiais existe estoque e backorders. A penalidade foi tratada como variável em função do fator, conforme o tipo de material e da fração da demanda insatisfeita.

Rottkemper; Fischer e Blecken (2011) elaboraram um modelo de transbordo para a distribuição e inventário sob incerteza em operações humanitárias. As penalidades são atribuídas às demandas não atendidas pelo depósito no período da necessidade e aumentam se não atendidas no próximo período. Indicam a avaliação da adequação através de análise de sensibilidade.

A penalização pelo não atendimento é utilizada, principalmente, nas fases de preparação e resposta a um desastre. Critérios financeiros são os mais utilizados para a penalização do não atendimento, embora não exista uma modo padrão para definição de qual atributo deva ser considerado como referência. A Tabela 3.2 resume a maneira com que cada um dos autores utilizou a penalidade, a unidade $e$ a fase do desastre: 
Tabela 3.2 - Critérios utilizados para penalidades.

\begin{tabular}{|c|c|c|c|}
\hline Autor & Tipo de penalidade & Unidade & $\begin{array}{l}\text { Fase do } \\
\text { desastre }\end{array}$ \\
\hline $\begin{array}{l}\text { Rawls e Turnquist (2010), } \\
\text { (2011) e (2012) }\end{array}$ & $\begin{array}{l}\text { Entre } 10 \text { a } 50 \text { vezes o valor } \\
\text { do produto por falta. }\end{array}$ & $\$$ & Preparação \\
\hline Noyan (2012) & $\begin{array}{l}10 \text { vezes (em alguns casos } \\
5 \text { vezes) o valor do produto } \\
\text { por falta. }\end{array}$ & $\$$ & Preparação \\
\hline Mete e Zabinsky (2010) & $\begin{array}{l}\text { Não estabelece parâmetro } \\
\text { exato, liberdade na } \\
\text { calibração. }\end{array}$ & Tempo & Preparação \\
\hline Bozorgi-Amiri et al. (2013) & $\begin{array}{l}10 \text { vezes o custo de } \\
\text { aquisição do produto por } \\
\text { falta. }\end{array}$ & $\$$ & Preparação \\
\hline Salmerón e Apte (2010) & $\begin{array}{l}\text { Número de vítimas entre a } \\
\text { população não removida. }\end{array}$ & $\begin{array}{l}\text { Pessoas / } \\
\left(\mathrm{ft}^{3} \times 1000\right)\end{array}$ & Preparação \\
\hline Barbarosoglu e Arda (2004) & $\begin{array}{l}\text { Constante: entre USD35 e } \\
50 \text { por unidade, variando } \\
\text { ate } 500.000 \text { na análise de } \\
\text { sensibilidade. }\end{array}$ & $\$$ & Preparação \\
\hline Holguín-Veras et al. (2013) & $\begin{array}{l}\text { Não linear, considera USD } \\
10.000 \text { para cada ponto } \\
\text { não atendido diariamente, } \\
\text { limitado a USD5 M. }\end{array}$ & $\$$ & Resposta \\
\hline $\begin{array}{l}\text { Salmerón; Kline e } \\
\text { Densham (2011) }\end{array}$ & $\begin{array}{l}\text { Para desencorajar } \\
\text { utilização excessiva de } \\
\text { portos }=0,01 \text {. }\end{array}$ & $\begin{array}{l}\text { Unidade de missão } \\
\text { (valor especifico } \\
\text { para o problema) }\end{array}$ & $\begin{array}{l}\text { Preparação / } \\
\text { Resposta }\end{array}$ \\
\hline $\begin{array}{l}\text { Balcik; Beamon; Smilowitz } \\
(2008)\end{array}$ & $\begin{array}{l}\text { Para cada ponto de } \\
\text { demanda não atendido: } \\
\text { Material Tipo 1: } 100 \\
\text { Material Tipo 2: } 4 \text { a } 32 .\end{array}$ & $\$$ & Resposta \\
\hline $\begin{array}{l}\text { Rottkemper; Fischer; } \\
\text { Blecken (2011) }\end{array}$ & $\begin{array}{l}\text { Constante: entre } 90 \text { e } 180 \\
\text { por unidade (aumento de } \\
10 \text { MU se não abastecido } \\
\text { no próximo período). }\end{array}$ & $\begin{array}{c}\text { Unidades } \\
\text { monetárias (MU) }\end{array}$ & Resposta \\
\hline
\end{tabular}

\subsubsection{Estabelecimento de probabilidades para cenários}

Budnitz et al. (1998) recomendam a utilização de painel de especialistas para a estimativa de probabilidades de desastres (terremotos). Salmeron e Apte (2010) também utilizaram painel de especialistas em planejamento de emergências no 
estabelecimento das probabilidades de cenários. Afirmam que a criação dos cenários é um dos aspectos mais delicados no processo de modelagem.

A metodologia Delphi foi aplicada para análise em logística de operações humanitárias para avaliação de frota (COTTAM; CHALLACOMB; ROE, 2004), assim como uma ferramenta integrada ao método multicritério (ZAPATA, 1995) e, também, utilizada na área de saúde pública para sistematizar a obtenção das informações junto aos experts. Budnitz et al. (1998) recomendam a utilização de painel de especialistas para a estimativa de probabilidades de desastres (terremotos). Devido a incertezas e múltiplas interpretações de eventos geológicos a abordagem com vários especialistas leva em consideração os diferentes pontos de vista. Trata-se de uma metodologia estruturada para avaliar sistematicamente, através de construção estatística, julgamentos de especialistas em determinado assunto e gera um resultado do grupo. O termo especialista pode ser definido como pessoa cuja formação e experiência the permitiu chegar a um domínio sobre um assunto que ultrapassa o nível médio. García Valdés e Suárez Marín (2013) descrevem as nove atividades da metodologia organizadas em três fases (preparatória, consulta aos especialistas e consenso); recomendam o anonimato dos participantes e consultar entre 7 a 30 especialistas. Rowe e Wright (2001), por sua vez, recomendam entre 5 a 20 experts.

\subsection{Métodos multicritérios de tomada de decisão}

\subsubsection{Definições e utilização}

A metodologia Multicritério de Apoio à Decisão (MCDA) objetiva auxiliar analistas, facilitadores e decisores em situações nas quais haja a necessidade de identificação 
de prioridades quando existem diversos critérios, o que ocorre normalmente quando coexistem interesses em conflito (GOMES; ARAYA; CARIGNANO, 2004). MCDA aborda diversas disciplinas, destacando-se a psicologia, administração de negócios, engenharia e pesquisa operacional (OLSON, 1996).

Belton e Stewart (2002) definiram MCDA contemplando suas três dimensões:

- Abordagem formal;

- Presença de vários critérios;

- Decisões tomadas por indivíduos ou grupos de indivíduos.

Essas dimensões, similares a estudos sobre gestão de recursos naturais (MENDOZA; MARTINS, 2006), são razões pelas quais o MCDA pode ser um método aplicado a decisões humanitárias, pois contempla vários aspectos como:

- Abordagem estruturada e racional capaz de integrar elementos-chave de gestão humanitária;

- Existência de diversos critérios em questões humanitárias;

- Contempla a presença de múltiplos stakeholders e grupos de interesse, cada um com seus próprios pontos de vista, objetivos e exigências.

Korhonen; Moskowitz e Wallenius (1992) elaboraram uma revisão de literatura para os problemas de decisão com múltiplos critérios. Mostraram um histórico das metodologias e classificaram os problemas de tomada decisão, além de abordarem como apoiar os tomadores de decisão na estruturação e resolução de tais problemas. Apresentaram e discutiram as alternativas discreta e contínua. Citaram que os métodos multicritérios de tomada de decisão (MCDM) iniciaram-se com Charnes e Cooper (1961), que desenvolveram a programação por metas; e com Keeney e Raiffa (1976), que desenvolveram métodos e a teoria de utilidade multiatributo. MCDM pode ser definido como a escolha dentre um conjunto finito (normalmente) ou infinito de alternativas, utilizando um ou mais critérios. Inicialmente, os problemas de MCDM eram focados em algoritmos e soluções para 
problemas com múltiplos objetivos. A partir da década de 1980, após a divulgação do trabalho de Keeney e Raifa (1976), estudos voltados para compreensão do processo decisório e do comportamento dos tomadores de decisão são apresentados.

No tocante a nomenclatura, Triantaphyllou e Baig (2005) afirmam que a nomenclatura MCDA e MCDM tem o mesmo significado e identificam que MCDM pode ser utilizado para descrever problemas contínuos. Belton e Pictet (2002) comentam que existem algumas diferenças no emprego da matemática e na medição das preferências e afirmam que o termo "Decision Conference" também pode ser utilizado como MCDA e que muita discussão em torno desta nomenclatura origina-se devido à diferenças idiomáticas entre as línguas inglesa e francesa.

Belton e Stewart (2002) também sugerem que as metodologias MCDA devem integrar fortemente teoria e prática. Propõem também uma combinação com outras metodologias que possam criar sinergias que promovam um avanço no conhecimento.

\subsubsection{Classificação e paradigmas}

Os problemas de MCDA podem ser classificados, primeiramente, como discretos ou contínuos em sua maneira de representar as alternativas de decisão. No problema discreto é apresentado um número limitado de alternativas. Esses problemas podem ser categorizados de acordo com a abrangência: poucas ou muitas alternativas e poucos ou muitos critérios (KORHONEN; MOSKOWITZ; WALLENIUS, 1992). São denominados problemas "discretos", porque os conjuntos de alternativas consistem tipicamente de uma quantidade moderada de escolhas. Exemplos de problemas discretos podem ser a escolha de um determinado conjunto de veículos para realizar entrega de mercadorias ou a localização de um aeroporto. Problema contínuo (também denominado de problema de otimização) é aquele em que o espaço da 
solução é ininterrupto e definido pelas restrições, ou seja, pode existir um número infinito de soluções viáveis. O exemplo de um problema contínuo é um modelo de minimização de custos, onde equações são usadas para representar o comportamento dos custos de uma operação (WALLENIUS et al., 2008). Gomes; Araya e Carignano (2004) afirmam que os métodos contínuos são conhecidos também como programação multiobjetivo e os discretos possuem conjunto finito de alternativas e uma pequena quantidade de variáveis. Tanto o problema discreto quanto o contínuo são comuns na prática (BELTON, 1986).

Adicionalmente, existem outras diferenças entre os problemas de alternativas discretas e contínuas, considerando os conjuntos de alternativas viáveis. Os problemas com alternativas discretas possuem uma maior possibilidade de serem modelados, considerando incertezas nos valores dos atributos ou critérios, do que nos problemas de múltiplos critérios contínuos (ou de otimização). Outra diferença é a maneira em que as funções de valor ou utilidade são levadas em consideração. Muitas abordagens de problemas de múltiplos critérios discretos buscam representar matematicamente os aspectos de utilidade ou uma função valor adotada por um tomador de decisão para, em seguida, aplicar estes resultados e estimar os valores das alternativas. Em métodos multicritérios contínuos, normalmente, não há nenhuma tentativa de capturar matematicamente a função de valor do tomador de decisão. Em vez disso, a filosofia é orientar e obter do tomador de decisão informações implícitas sobre suas preferências. As informações implícitas são obtidas através de respostas para perguntas tais como: (a) qual das duas soluções é a mais preferida; (b) qual dos vários trade-offs é o mais preferido; e (c) quais valores de critérios podem ser relaxados para permitir a melhoria de outros critérios (WALLENIUS et al., 2008). Por causa dos diferentes tipos de problemas, diferentes famílias de abordagens evoluíram para resolver problemas de alternativas discretas e problemas contínuos.

Larichev e Olson (2001) analisaram MCDA aplicado à problemas de localização de instalações e agruparam essas abordagens em paradigmas. Na classificação da metodologia MCDA, três tipos de aplicação ou grupos de teorias foram 
desenvolvidas para os problemas (BELTON e STEWART, 2002) e podem ser assim definidas:

- Modelos de mensuração de valor: é estabelecido um sistema de pontuação para representar o grau de preferência de cada alternativa em relação as demais. Essa pontuação é desenvolvida inicialmente para cada critério individualmente e, então, agregada em uma soma ponderada de performance da alternativa neste critério. Larichev e Olson (2001) comentam que, em países de língua inglesa, a ênfase tem sido na implementação do conceito de utilidade. Esse argumento é baseado no conceito de que a função de valor e a alternativa com maior utilidade será a escolha do tomador de decisão. Existem várias técnicas desenvolvidas para implementar este conceito, com destaque para o MAVT e o MAUT (KEENEY; RAIFFA, 1976) e o AHP (SAATY, 1990), embora Larichev e Olson (2001), de maneira diferente de Belton e Stewart (2002), classifiquem o AHP em um outro paradigma devido a presunção de que a estimativa de todos os critérios pode ser representada quantitativamente e que a transformação de características qualitativas em números, com base em uma escala universal, é sempre fidedigna.

- Modelos de meta ou nível de referência: para cada critério são estabelecidos níveis desejados ou satisfatórios. O processo é procurar opções que atinjam ou estejam mais próximas destas metas. Estes modelos podem ser utilizados no início de modelagem de um problema multicritério para eliminar alternativas menos viáveis (LØKEN, 2007).

- Modelos de sobreclassificação (outranking): as alternativas são comparadas par a par, em termos de cada critério para identificar a extensão da preferência que cada alternativa possui em relação a outra. Ao agregar essa informação, de preferência através dos critérios relevantes, o modelo busca estabelecer a dominância de uma alternativa em relação a outra. A preferência é determinada com base em concordância e discordância (LARICHEV; OLSON, 2001). Concordância significa que, em um par de 
alternativas, uma é superior à outra. Discordância significa o inverso, quando uma em um par de alternativas é inferior à outra. Os sistemas mais conhecidos desta metodologia são a família Electre e o Promethee.

Para os problemas múltiplos critérios contínuos as abordagens para a resolução podem ser enquadradas nas seguintes categorias: métodos interativos; programação por metas; algoritmos de vetor máximo; e algoritmo evolucionário. Essas categorias não são necessariamente mutuamente exclusivas (WALLENIUS et al., 2008; OLSON, 1996).

\subsubsection{Métodos multicritérios de tomada de decisão aplicados à localização de instalações}

Ross e Soland (1980) argumentam que os problemas que envolvem a localização de instalações públicas são realmente problemas multicritério e devem ser modelados como tal. Na época do estudo os problemas multicritério eram relativamente novos, mas os autores visualizaram sua aplicação no setor público e o potencial que a metodologia possui para lidar com os tradeoffs existentes entre os critérios. Nos problemas de localização de instalações públicas, observaram que de custo e nível de serviço são critérios frequentes.

Farahani; SteadieSeifi e Asgari (2010) elaboraram um artigo de revisão no qual analisaram a aplicação de métodos multicritério em problemas de localização, fornecendo uma análise de tais problemas em três categorias, incluindo problemas biobjetivo, multiobjetivo, multiatributo e seus métodos de solução. Além disso, forneceram uma visão geral sobre vários critérios utilizados, definiram e classificaram os tipos e metodologias para solução dos problemas, de acordo com a abordagem adotada no problema de decisão. Uma de suas conclusões recomenda a utilização de modelos estocásticos em problemas de localização. 
Os problemas foram classificados como multiatributo ou multiobjetivo, conforme Figura 12:

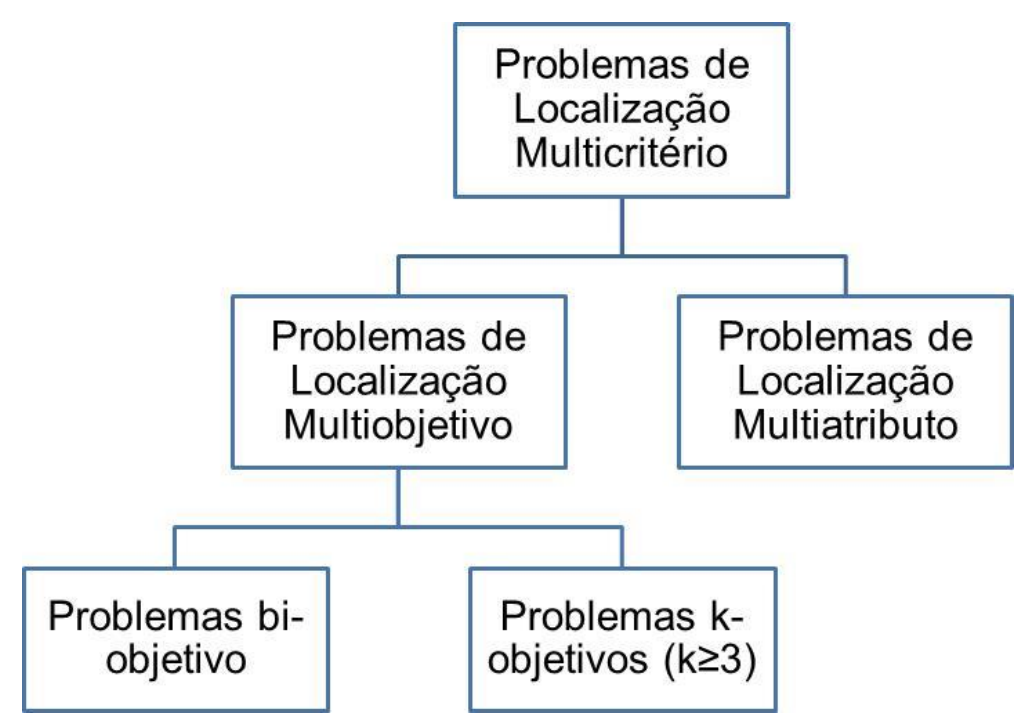

Figura 12 - Classificação dos problemas de localização multicritério.

Fonte: Farahani; SteadieSeifi e Asgari (2010).

Nos problemas denominados multiatributos, geralmente, há um número limitado e predeterminado de alternativas (discreto). Estas alternativas visam satisfazer o objetivo em um nível especificado e o decisor seleciona a melhor solução (ou soluções) entre todas as alternativas, de acordo com a prioridade de cada objetivo e a interação entre eles.

As técnicas denominadas multiobjetivo tentam buscar a melhor alternativa, considerando as diversas interações que melhor satisfazem o decisor, observando o atendimento às restrições e atendendo a alguns níveis aceitáveis de um conjunto de objetivos.

Cheng; Chan e Huang (2003) criticam os modelos multiobjetivo afirmando que são focados na matemática e ignoram critérios qualitativos, que também podem ser subjetivos. Em um estudo para localização de um aterro sanitário integraram Análise de Decisão Multicritérios (MCDA) e Programação Linear Inteira Mista Inexata, pois possuíam a necessidade de considerar critérios qualitativos e quantitativos, tangíveis, intangíveis e, muitas vezes, contraditórios. Primeiramente, executaram um modelo de programação linear com o objetivo de minimizar o custo total e otimizar o 
fluxo dos resíduos. Em uma etapa posterior, levaram em consideração o custo total e outros critérios para determinar a melhor alternativa de localização. Esse processo integrado de análise pode ser visualizado através da Figura 13:

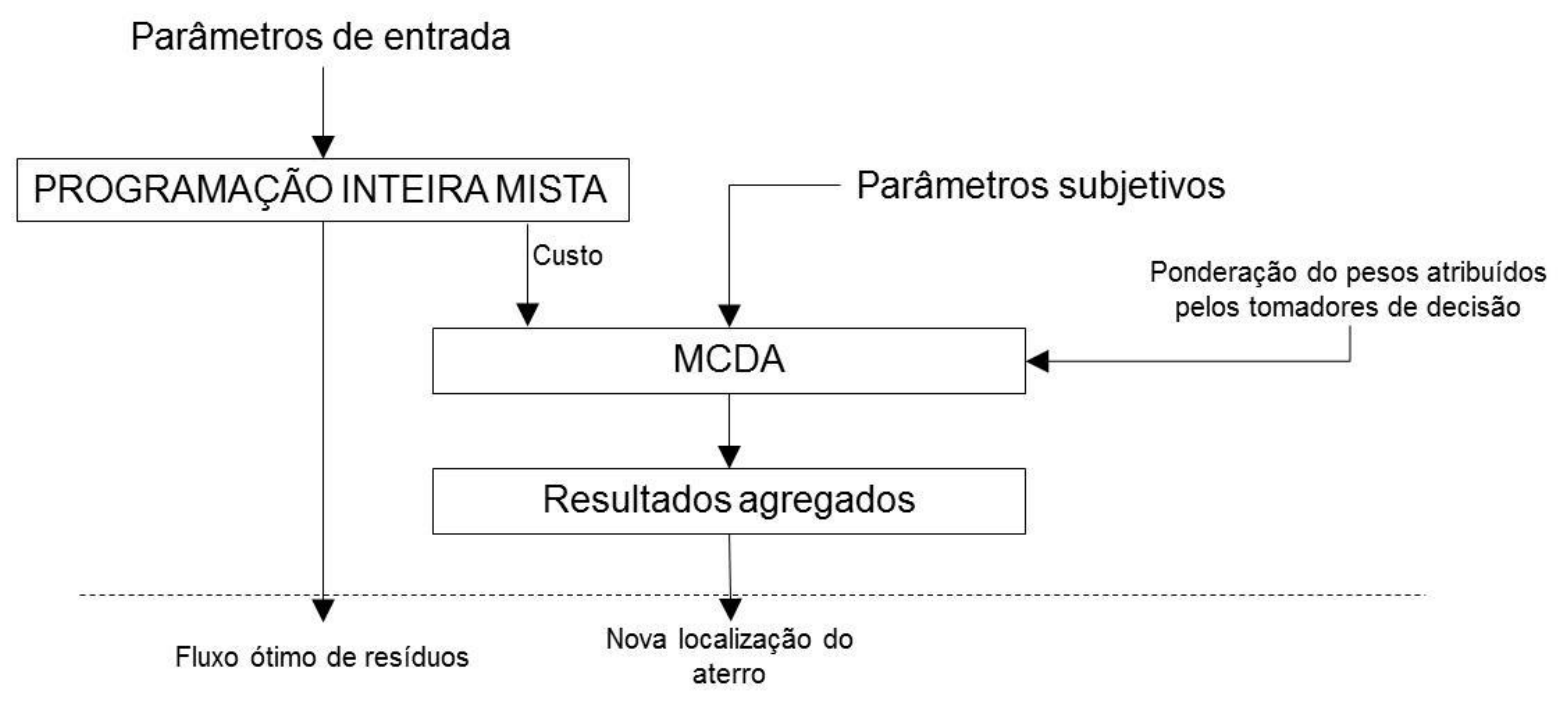

Figura 13 - Integração MCDA e programação linear. Fonte: Cheng; Chan e Huang (2003).

A Programação Linear Inteira Mista Inexata leva em consideração as incertezas e os parâmetros incertos são modelados em função dos intervalos com os limites inferior e superior conhecidos (distribuição probabilística desconhecida).

Ressaltam também a importância do papel da incerteza na localização de instalações. Afirmam que a incerteza pode ser encontrada de três tipos:

- Dados imprecisos: os dados são apresentados de forma aproximada. Caracterizado pelas palavras "cerca de" e "aproximadamente".

- Dados entre faixas de valores: não é conhecido o exato valor, mas o intervalo em que o dado pode se encontrar.

- Dados linguísticos: estes dados não possuem medições científicas precisas, mas são representados sob a forma verbal, como "alto", "baixo" ou "médio". Esse tipo de dado é comumente encontrado em julgamentos humanos subjetivos. 
Bruno; Ghiani e Improta (1998) avaliaram localização de linhas de trânsito rápido, tais como metrô, corredores de ônibus e monotrilhos, e afirmaram que essa análise representa um problema de decisão muito complexo, pois devem ser levados em consideração um grande número de interesses, muitas vezes, discordantes, critérios não quantificáveis e incerteza dos dados. Propõem um modelo com duas etapas: a primeira, a geração de um pequeno número de soluções eficientes considerando critérios quantitativos, tais como minimização de distâncias percorrida por pedestres, cobertura ou custo; e a segunda etapa, a escolha da melhor localização da linha, considerando critérios quantificáveis e não quantificáveis, por meio de metodologias de decisão multicritério. No caso o método Promethee foi utilizado.

Sarkis e Sundarraj (2002) relataram um estudo de localização de um armazém de peças de reposição para a Digital Equipment Corporation para atendimento a regiões na Ásia e Pacífico. Nesse estudo, também foram utilizadas duas etapas para a análise. Na primeira, através de um método multicritério denominado Processo Analítico em Rede (ANP), foram estabelecidos os critérios de acessibilidade, tempo, risco, aspectos regulatórios, estratégicos e mão de obra. Através da aplicação do método houve uma redução de 21 possíveis localidades para 3. Após essa etapa um modelo de transbordo foi aplicado, minimizando os custos de transporte para a definição de somente um local.

Yoshizaki e Montibeller (2009) afirmam que fatores intangíveis podem alterar uma configuração de rede resultante de um modelo matemático. Na tomada de decisão de localização de uma instalação, modelos de rede tradicionais levam em consideração fatores quantitativos e objetivam minimizar o custo total ou maximizar a rentabilidade ou a cobertura. Critérios não quantitativos, como, por exemplo, qualificação de mão de obra; características geográficas do local; malha viária também são importantes na tomada de decisão de localização. Os autores sugerem uma metodologia com a utilização de Multi-criteria Decision Analysis (MCDA), levando-se em consideração estes critérios.

A estrutura metodológica para a análise de decisão multicritério é definida através das etapas descritas na Figura 14, em que podem ser observadas as etapas do 
processo decisório no sentido do fluxo e no sentido contrário o processo de aprendizagem para próximas decisões:

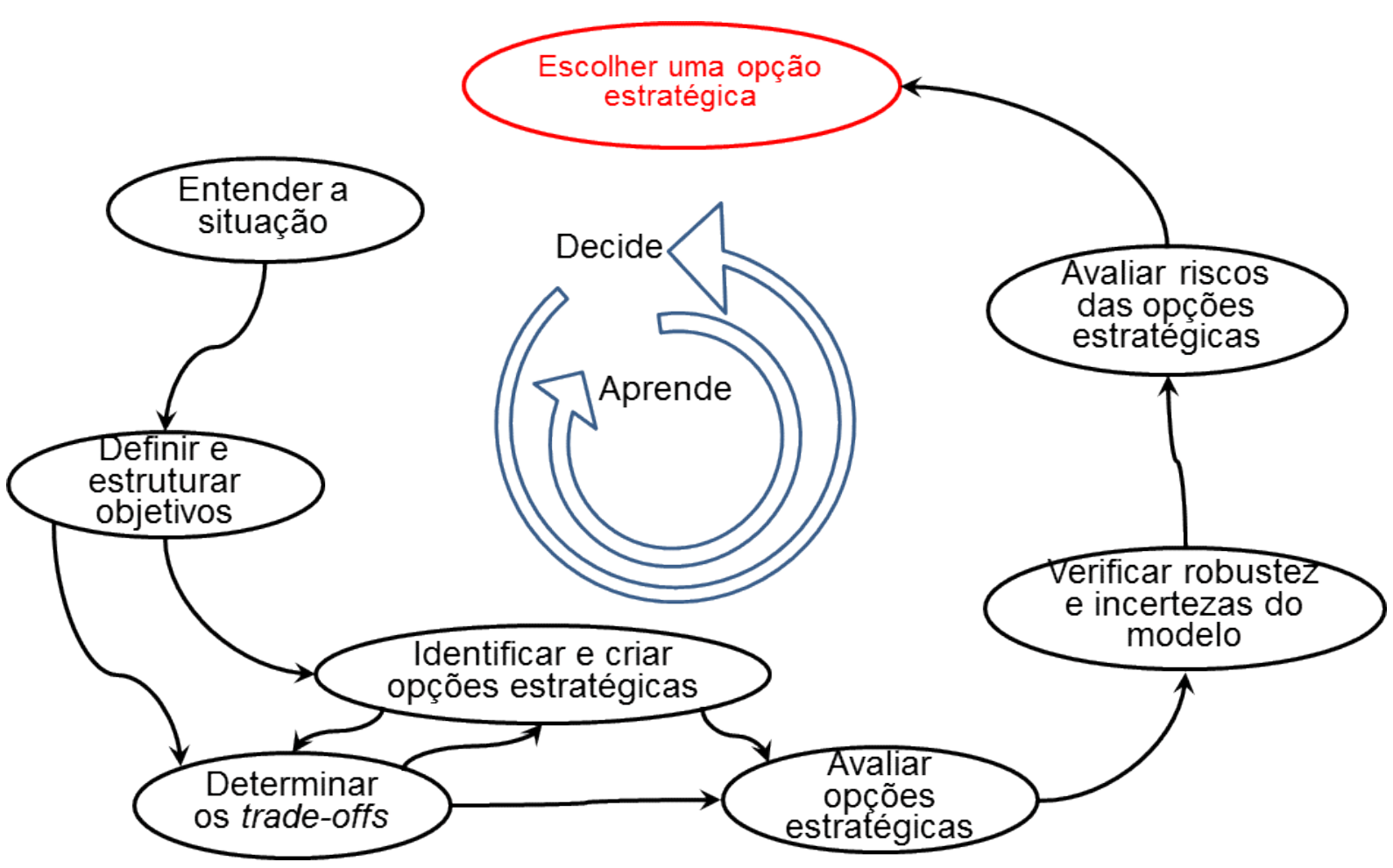

Figura 14 - Metodologia para a análise de decisão multicritério.

Fonte: Adaptado de Montibeller e Franco (2007).

As etapas não necessitam ser seguidas necessariamente em uma sequência linear, podendo ser reavaliadas e retomadas pelos participantes durante todo o processo.

Por envolver várias partes interessadas de uma organização no processo decisório a análise multicritério proporciona também o comprometimento destas partes com a decisão tomada, facilitando a implementação.

Farahani; SteadieSeifi e Asgari (2010) buscaram na literatura os principais critérios utilizados na localização de instalações sob um ponto de vista de aplicações práticas:

- Em problemas de localização de critério único, esse critério geralmente tem sido custo ou cobertura. Criticam esse tipo de abordagem, pois em 
localização de instalações, devido à natureza destes problemas, deve-se considerar, pelo menos, mais de um critério que, muitas vezes, pode estar em conflito com o primeiro.

- Nos problemas multiobjetivo, além do custo são observados também a utilização de critérios gerais, como cobertura; nível de serviço; riscos ambientais; e lucro, além de critérios específicos ao problema avaliado, como, por exemplo, riscos sociais e políticos.

- Nos problemas denominados multiatributo a quantidade de critérios apresentada na literatura é elevada e incluem custos (terreno, transporte, instalação; manutenção); incremento de receita; riscos ambientais; poluição; concorrência; acessibilidade; proximidades à rodovias, portos, aeroportos e terminais; questões políticas e regulatórias; mão de obra; ambiente de negócios; possiblidade de expansão e distâncias.

Hokkanen e Salminem (1997) também utilizaram MCDA na localização de instalações para tratamento de resíduos sólidos. Abordaram o problema inserindo também grupos de interesse na definição dos critérios, denominados de grupos locais (moradores fixos, de veraneio e associações), autoridades e as empresas de coleta de lixo. Os critérios foram divididos em quatro grandes categorias: econômico; técnico; meio ambiente; e relação homem $X$ ambiente construído.

Farahani e Asgari (2007) também localizaram alguns centros de distribuição (CDs) em um sistema de logística militar com dois objetivos: minimizar o número de CDs e localizá-los nas melhores regiões possíveis. A quantidade de CDs é um objetivo comum em localização, entretanto "melhor região possível" é um objetivo que dependia de 24 atributos, sendo que 8 desses atributos eram denominados de não compensatórios, que significa o atendimento a um nível mínimo especificado. Um exemplo deste tipo de critério, uma especificação militar, era a necessidade do CD ficar a mais de $90 \mathrm{~km}$ da fronteira. Um local potencial situado a uma distância menor, mesmo que atenda plenamente a todos outros critérios, não seria selecionado. Restrições de cobertura também foram adicionadas. 
Em seu trabalho, Ferreti (2011) também propôs a utilização de técnicas de multicritério na localização de aterro sanitário para a cidade de Torino (Itália). Sua contribuição foi o desenvolvimento de um sistema multicritério de apoio à decisão, baseado na integração dos Sistemas de Informação Geográfica (SIG) e uma técnica específica de análise de decisão multicritério denominada Processo Analítico em Rede (ANP). Com o uso de escala de cores, os critérios determinados são representados em mapas posteriormente, conforme a ponderação, os mapas são sobrepostos e as áreas adequadas podem ser visualizadas. Barbosa et al. (2010) também utilizaram AHP e GIS, através da sobreposição de mapas e escala de cores, para avaliar a localização de depósito de suprimentos de alívio.

Ensslin et al. (2010) utilizou uma abordagem quali-quantitativa e a metodologia MCDA-C (construtivista) na avaliação do desempenho de empresas terceirizadas do setor de telecomunicações. Entende-se por uma abordagem quali-quantitativa, que é qualitativa na estruturação ao identificar os critérios e construir as escalas ordinais; e quantitativa ao transformar escalas ordinais em cardinais e ao avaliar os resultados a partir desta integração.

Aplicando também a linha construtivista, Moraes et al. (2010) utilizou o processo construtivista para elaboração usado para definir benchmarks e identificar oportunidades de melhorias, em programas de saúde. Neste artigo a metodologia multicritério foi utilizada na definição de maneiras de mensuração na prestação de serviços à população. Estabelece critérios mínimos para atendimento. Ressaltam também a importância em se utilizar um facilitador para auxiliar os tomadores de decisão na validação da estrutura decisória.

Menou et al. (2010) utilizou ferramentas estocásticas e MCDA para localizar um hub para centralização de carga aérea no Marrocos. No processo de localização combinaram fatores qualitativos e quantitativos, ordinais e cardinais, além de considerar as incertezas dos cardinais, especialmente, informações imprecisas e/ou parciais. No modelo de localização inseriram uma variação de $\pm 10 \%$ em tais critérios. 
Montibeller e Franco (2007) afirmam que a localização de instalações permanentes ao longo de uma cadeia de suprimentos é uma decisão estratégica. A tomada deste tipo de decisão considera múltiplos objetivos, frequentemente, conflitantes a interconexão de políticas estratégicas; as consequências de longo prazo, que resultam da implementação das decisões; e a necessidade das partes interessadas estarem engajadas nessas discussões sobre a estratégia.

\subsubsection{Métodos multicritérios de tomada de decisão aplicados à localização de instalações humanitárias}

Nesta tese foram avaliados 45 artigos obtidos em periódicos revistos por pares (peer review) com aplicação de metodologia multicritério na localização de instalações (humanitárias ou não). Destes artigos, 16 referem-se à logística de operações humanitárias ou gestão de desastres e emergências. Em 14 deles foi possível identificar aplicação em uma ou mais fases de um desastre. Observando os critérios utilizados nesses artigos, conforme a fase do desastre (em função de aplicação em mais de uma fase ou sobreposição nas aplicações, algumas fases foram agrupadas) e a totalização. Pode-se observar que, de acordo com a fase do desastre, os critérios utilizados diferem, porém os critérios relativos aos atributos geográficos e físicos do local, assim como a distância e características da distribuição, são bastante empregados. O critério custo, embora em menor quantidade, aparece em três das quatro fases. Essa identificação de critérios pode ser observada na Tabela 3.3: 
Tabela 3.3 - Critérios de localização conforme a fase do desastre.

\begin{tabular}{|c|c|c|}
\hline Fase do desastre & $\begin{array}{l}\text { Critérios agrupados adotados na seleção } \\
\text { de local }\end{array}$ & $\begin{array}{l}\text { Qtde de } \\
\text { vezes }\end{array}$ \\
\hline \multirow{9}{*}{$\begin{array}{l}\text { Prevenção/Mitigação } \\
\text { (7 artigos) }\end{array}$} & Geográfico e Físico & 15 \\
\hline & Demográfico & 8 \\
\hline & Distância e distribuição & 6 \\
\hline & Socioeconômico & 3 \\
\hline & Meteorológico & 2 \\
\hline & Uso do solo & 2 \\
\hline & Ambiental & 1 \\
\hline & Custo & 1 \\
\hline & Recursos humanos & 1 \\
\hline \multirow{7}{*}{$\begin{array}{l}\text { Preparação } \\
\text { (3 artigos) }\end{array}$} & Distância e distribuição & 6 \\
\hline & Geográfico e Físico & 2 \\
\hline & Ambiental & 1 \\
\hline & Custo & 1 \\
\hline & Recursos Humanos & 1 \\
\hline & Segurança & 1 \\
\hline & Socioeconômico & 1 \\
\hline \multirow{3}{*}{$\begin{array}{l}\text { Preparação / Resposta } \\
\text { (3 artigos) }\end{array}$} & Distância e distribuição & 11 \\
\hline & Custo & 1 \\
\hline & Socioeconômico & 1 \\
\hline \multirow{3}{*}{$\begin{array}{l}\text { Resposta / } \\
\text { Recuperação } \\
\text { (1 artigo) }\end{array}$} & Socioeconômico & 2 \\
\hline & Ambiental & 1 \\
\hline & Demográfico & 1 \\
\hline \multirow{10}{*}{$\begin{array}{l}\text { Total } \\
\text { (14 artigos) }\end{array}$} & Distância e distribuição & 23 \\
\hline & Geográfico e Físico & 18 \\
\hline & Demográfico & 9 \\
\hline & Socioeconômico & 7 \\
\hline & Ambiental & 3 \\
\hline & Custo & 3 \\
\hline & Meteorológico & 2 \\
\hline & Recursos humanos & 2 \\
\hline & Uso do solo & 2 \\
\hline & Segurança & 1 \\
\hline
\end{tabular}

Observação: Em função do agrupamento, alguns critérios são considerados mais que 14 vezes, por exemplo, o critério distância e distribuição agrega também a acessibilidade ao local, tipos de veículos, tempo de viagem e confiabilidade das vias. 
Um dos métodos utilizados para apoio à decisão de instalações humanitárias é o AHP. Este método possui a vantagem da não necessidade de interação entre os tomadores de decisão, facilitando assim a aplicação, entretanto em uma decisão de localização, devido à multiplicidade de critérios na aplicação, o próprio método detecta uma matriz de avaliação inconsistente e exige ajustes nas comparações par a par. A utilização desta metodologia foi encontrada em 7 dos 16 artigos revistos (ARMAŞ, 2012; HASEKIOGULLARI; ERCANOGLU, 2012; GARFİ; TONDELLI; BONOLI, 2009; GARFÌ et al., 2011; MARTINS; SILVA; CABRAL, 2012; NOGUEIRA; GONÇALVES, 2010).

Malaver e Regnier (2009) também aplicaram o AHP para seleção de local de instalação de armazém da WFP, na Etiópia, e estabeleceram os seguintes critérios de primeiro nível e que, em alguns casos, também foram desdobrados em critérios de segundo nível:

- Infraestrutura desdobrada em (2ำ nível): segurança, capacidade do edifício, condições da edificação, qualidade das vias.

- Localização desdobrada em (2ำ nível): proximidade à população necessitada, proximidade aos portos e acesso aos serviços de apoio.

- Transporte desdobrado em (2ำ nível): acesso aos fornecedores locais, disponibilidade e qualidade dos transportadores.

- Custos (somente $1^{\circ}$ nível).

- Estabilidade (somente 1ํo nível).

Uma vantagem da AHP, citada pelos autores, foi a possibilidade da utilização desta técnica com um mínimo de informações disponíveis, pois necessita somente do estabelecimento de critérios e de avaliadores. A matriz de consistência foi de 0,2088, bem acima do valor recomendado de 0,1 , evidenciando a necessidade de ajustes pós-avaliação. Barbosa et al. (2010) também utilizaram AHP e obtiveram também uma matriz de decisão inconsistente para localização de depósito de suprimentos de alívio na região do Vale do Paraíba Paulista. 
No Brasil, Fernandes (2010), em sua tese de doutorado, elaborou um estudo pioneiro no assunto, também aplicando o método AHP em logística de operações humanitárias para localização de uma central para recebimento, controle e distribuição de recursos em situação emergencial no Vale do Itajaí (SC), acrescentando Recursos Humanos e Meio Ambiente aos critérios elaborados por Malaver e Regnier (2009). O trabalho aplicou um modelo composto de duas fases distintas: na primeira, foi localizada uma central de suporte para situações emergenciais com a utilização de AHP. Na segunda fase foi desenvolvida uma rede dinâmica geo-referenciada para a distribuição de recursos emergenciais, utilizando SIG e acessível via web. O modelo é capaz de determinar a menor distância entre a central de suporte localizada pelo AHP e os pontos de distribuição nas regiões afetadas através do algoritmo de Dijkstra.

A discussão entre a aplicação do AHP e sua comparação com outros métodos multicritério, como o MAVT, foi um assunto bastante discutido entre pesquisadores, como, por exemplo, o artigo de Harker e Vargas (1987), que criticou o AHP, principalmente em função das inconsistências e a forma que essa dificuldade é solucionada. A discussão foi acentuada na década de 1990, inclusive gerando uma edição especial do Journal of Multi-Criteria Decision Analysis (Volume 6, edição 6, 1997), formada a partir do artigo de Salo e Hämäläinen (1997). O AHP é criticado por desvincular a avaliação dos critérios das alternativas existentes. Isso é provocado pela forma que o AHP obtém a ponderação de critérios (através de questões do tipo: o quanto um critério é mais importante que outro), não considerando as alternativas no impacto desta comparação. Outra crítica é ao fato do AHP não capturar a cardinalidade das preferências devido ao intervalo (1-9) de sua escala fundamental (SALO; HÄMÄLÄINEN, 1997).

Em uma edição do Journal Management Science (Volume 36, edição 3, 1990) cinco artigos discutiram o assunto com base no artigo publicado por Dyer (1990), que afirmou que o AHP é falho, principalmente, devido à arbitrariedade na classificação das alternativas pela escala fundamental e à inversão dessa classificação (rank reversal) provocada pela inserção de alternativas muito próximas quando avaliadas através da escala fundamental. 
Belton (1986) afirma que os métodos que abordam funções de valor e utilidade são mais transparentes e de mais fácil compreensão, entretanto possuem a fraqueza em não incorporar verificações de consistência dos julgamentos. Porém, o método AHP assume fortemente uma escala de avaliação que não permite grande flexibilidade ao processo e avaliação das alternativas. Afirma também que qualquer metodologia de tomada de decisão encoraja o tomador de decisão a pensar nos critérios e alternativas, além de avaliar a performance de cada critério e alternativa em relação aos objetivos a serem atingidos. Em uma discussão sobre o artigo de Salo e Hämäläinen (1997), Belton e Gear (1997) avaliam que o debate sobre os méritos relativos às diversas abordagens multicritério mostram um saudável interesse da pesquisa científica no assunto, por outro lado, desaprovam fortemente toda essa discussão e publicação de artigos voltados a criticar uma ou outra abordagem e que as diferentes escolas deveriam buscar compreensão do processo de apoio à decisão.

Vitoriano et al. (2011) em um trabalho sobre distribuição de suprimentos de ajuda postulam que em logística de operações humanitárias minimização de custo não é o foco em uma fase de resposta e que parâmetros como tempo de resposta, equidade da distribuição, prioridade do item, confiabilidade e segurança das rotas são mais relevantes. Apesar da utilização de uma metodologia essencialmente quantitativa, a programação por metas envolveu uma interação junto aos tomadores de decisão na condução do problema. Uma matriz pay-off foi elaborada considerando, em cada linha, a otimização individual de cada parâmetro e os valores dos outros parâmetros. A avaliação desta matriz auxilia a análise do problema, pois permite visualizar o impacto desta otimização individual em cada um dos outros parâmetros, evidenciando os "conflitos" entre os atributos. A partir dessa matriz, os tomadores de decisão estabeleceram as metas para os atributos e o problema foi resolvido através de programação inteira mista. $O$ modelo foi aplicado a um estudo de caso baseado no terremoto do Haiti de 2010, a fim de ilustrar seu comportamento obtendo resultados promissores.

Ortuño; Tirado e Vitoriano (2011) utilizaram um modelo lexicográfico de programação por metas que contempla dois níveis de prioridade entre os objetivos. 
O principal objetivo do modelo é entregar a quantidade planejada de materiais e fazer isso da melhor maneira possível. A disponibilidade dos veículos e o orçamento podem fazer esse objetivo impossível de ser atingido. Para evitar essa situação, o modelo considerou como meta de primeiro nível a entrega da maior quantidade de materiais, levando em consideração a quantidade global disponível a ser distribuída. O atendimento a essa meta é assumido como sendo, imensamente, preferido a realização de qualquer outro conjunto de metas, estabelecendo, portanto, uma prioridade lexicográfica entre esse objetivo e aos demais que estão incluídos no segundo nível. No problema, o segundo nível inclui os outros seis critérios que são: orçamento disponível; tempo de carregamento; risco de saque; confiabilidade mínima das vias; distribuição equitativa; e prioridade para um nó especifico. Os desvios em relação às metas serão penalizados, com base nas preferências do tomador de decisão. Essas penalidades são inseridas no modelo como parâmetros. O trabalho foi aplicado no Níger (África) em um projeto de distribuição administrado pela Caritas Development.

Nolz; Doerner, e Hartl (2010) elaboraram um planejamento de rotas para distribuição de água em caso de catástrofe. Especialmente nas situações pós-desastre, caracterizado por instabilidade e pela necessidade imediata de ajuda, decisões eficazes necessitam ser tomadas rapidamente. Por esta razão, é muito útil se as decisões de planeamento forem tomadas através de um sistema de suporte à decisão que leve em consideração os aspectos monetários e não monetários. $O$ artigo foi desenvolvido a partir de um problema da Cruz Vermelha austríaca, que é especializada em água e saneamento em desastres e tem responsabilidade atribuída pela IFRC pelas unidades de distribuição de água à população nesses eventos. No modelo para a localização de tanques de água, os tipos de meios de distribuição considerados para atendimento a população foram caminhões, automóveis e burros e o modelo considerou três tipos de vias, de acordo com a possibilidade de ruptura nos caminhos (um caminho de vias sólidas, outro de vias que possam ser parcialmente danificadas por desastres e outro por regiões longínquas que possam ser severamente danificados em casos de desastres). Os critérios de localização minimizam a soma das distâncias entre toda população de um local e sua fonte de água mais próxima, juntamente com a máxima cobertura, 
que minimiza a quantidade de pessoas que não possuem disponibilidade de um tanque de água dentro de uma distância máxima pré-definida e a minimização do tempo de viagem baseado na distância e que serviu de referência para o custo. $O$ modelo foi testado em Aceh, Indonésia, que foi severamente afetada pelo tsunami de 2004, utilizando uma metaheurística derivada do algoritmo genético para solução do problema multicritério.

Najafi; Eshghi e Dullaert (2013) propuseram um modelo em rede para auxiliar gestores de desastres na programação das atividades logísticas na fase de resposta, para suprimentos de materiais de alívio, e na remoção de feridos, com base na demanda e na oferta. O modelo incorpora incertezas que ocorrem na prática e utiliza programação estocástica. $O$ modelo linear proposto inclui três funções objetivo incorporando as questões humanitárias, através da minimização do não atendimento a demanda de materiais e da remoção de pessoas feridas e as questões não humanitárias, como os custos de gestão, através da minimização do número de veículos utilizados. O modelo foi utilizado para roteirização, incluindo o transporte combinado (caminhão, trem, helicóptero e ambulância). Em um teste, no Irã para terremotos, avaliou-se o desempenho do modelo, obtendo reduções na utilização de helicópteros e na quantidade de feridos não removidos. No trabalho, em sua revisão de literatura, classificaram 19 artigos publicados entre 1996 e 2012, que abordam o gerenciamento da fase de resposta de desastres, por meio da aplicação de pesquisa operacional sob 3 classes e 12 critérios. A Tabela 3.4 resume esta classificação: 
Tabela 3.4 - Classificação dos modelos aplicados à fase de resposta.

\begin{tabular}{|c|c|c|c|}
\hline Classe & Critério & Quantidade & \\
\hline \multirow{15}{*}{ Modelagem } & Modelagem & $\begin{array}{l}\text { Linear } \\
\text { Não linear }\end{array}$ & $\begin{array}{r}18 \\
1\end{array}$ \\
\hline & \multirow{3}{*}{ Tipo de função objetivo } & Custo & 5 \\
\hline & & Humanitária & 11 \\
\hline & & Custo e Humanitária & 2 \\
\hline & \multirow{2}{*}{ Qtde de função objetivo } & Única & 13 \\
\hline & & Múltipla & 6 \\
\hline & \multirow{3}{*}{ Metodologia de solução } & Heurística & 11 \\
\hline & & Meta Heurística & 2 \\
\hline & & Exata & 6 \\
\hline & \multirow{2}{*}{ Roteirização } & Predefinida & 4 \\
\hline & & Definida pelo modelo & 15 \\
\hline & \multirow{4}{*}{ Método de otimização } & Determinística & 15 \\
\hline & & Estocástica & 1 \\
\hline & & Robusta & 2 \\
\hline & & Fuzzy & 1 \\
\hline \multirow{7}{*}{ Transporte } & \multirow{2}{*}{ Modal } & Único & 13 \\
\hline & & Mais de um & 6 \\
\hline & \multirow{2}{*}{ Combinação de modais } & Considera & 7 \\
\hline & & Não considera & 12 \\
\hline & \multirow{3}{*}{ Veículos disponíveis } & Predefinidos & 16 \\
\hline & & Com Incerteza & 1 \\
\hline & & Sem restrição & 2 \\
\hline \multirow{6}{*}{ Fluxo } & \multirow{2}{*}{ Tipo de fluxo } & Único & 12 \\
\hline & & Mais de um (retorno) & 7 \\
\hline & \multirow{2}{*}{ Tipo de suprimento } & Determinístico & 17 \\
\hline & & Incerto & 2 \\
\hline & \multirow{2}{*}{ Tipo de demanda } & Determinística & 15 \\
\hline & & Incerta & 4 \\
\hline
\end{tabular}

Fonte: Adaptado de Najafi; Eshghi e Dullaert (2013).

A tabela mostra uma concentração de publicações com foco determinístico e, em casos de desastres, a incerteza é componente pouco empregado nos modelos, assim como a utilização de cenários para compreensão das consequências de um desastre. Em atividades humanitárias requisitos operacionais específicos e custo devem ser considerados.

Caruzzo; Manso e Belderrain (2013) avaliaram o planejamento do sistema de meteorologia brasileiro sob a ótica do meteorologista-especialista, com o objetivo de 
adequar as atividades no apoio das operações relacionadas a desastres naturais e de logística de operações humanitárias. Utilizaram a teoria de valor multiatributo (MAVT) e, para construir a estrutura hierárquica dos critérios e subcritérios, as preferências dos meteorologistas foram identificadas por entrevistas. Elaboraram diversos cenários para identificar as alternativas potenciais e obtiveram resultados indicando que a melhor alternativa era o atendimento parcial aos critérios e subcritérios avaliados. Também apresentaram investimentos necessários para atendimento das demandas da Defesa Civil e apoio às respostas de desastres naturais, e que para um correto gerenciamento de um desastre é necessário entender quais são os fatores críticos e a limitação para obter informações para apoiar a decisão.

Ferreira et. al. (2010) propuseram um método para analisar a tomada de decisões durante a fase de resposta a desastres. Através de jogos e cenários objetiva compreender como os gestores tomam decisões durante os desastres. O jogo simula um terremoto que afeta os sistemas de transporte e avalia as ações do gestor, a fim de identificar padrões de tomada de decisão, pontos fortes e pontos fracos. Dois padrões típicos foram revelados: apoio ao resgate imediato e apoio à restauração das linhas vitais de suprimentos; com uma clara demonstração de que as necessidades e os recursos disponíveis são avaliados paralelamente durante o processo decisório. O jogo é recomendado especialmente para treinamento dos tomadores de decisões em um eventual desastre.

Opasanon e Miller-Hooks (2006) consideraram os atributos de arco (capacidade das vias e tempo de viagem) estocásticos e variáveis ao longo do tempo para buscar soluções no transporte durante operações de resposta a emergências. Utilizaram uma função de desutilidade linear para representar as preferências dos tomadores de decisão.

Os trabalhos apresentados demonstram a aplicabilidade do método multicritério à localização de instalações humanitárias. Os critérios diferem conforme a fase do desastre, porém aqueles que envolvem aspectos geográficos e físicos da localidade, bem como a distância e características da distribuição e das vias, são comuns a 
diversas fases. O critério custo é relevante e foi considerado pelos autores em três das quatro fases.

\subsection{Teoria de valor multiatributo (MAVT)}

MAUT e MAVT são uns dos métodos multicritério amplamente utilizados por profissionais e acadêmicos (BELTON; STEWART, 2002) e destacam-se dentre os modelos de mensuração de valor. MAUT foi descrito por Keeney e Raiffa (1976) como uma abordagem para resolver problemas com alternativas discretas. No MAVT, ainda segundo Belton e Stewart (2002), as preferências do decisor são estruturadas de maneira a representar os múltiplos objetivos relacionados ao problema. A MAVT pode ser considerado uma extensão da MAUT. A MAVT incorpora a importância do peso dos critérios na tomada de decisão ( $\mathrm{CHO}$; 2003), enquanto a MAUT inclui as preferências do decisor em relação ao risco na função de utilidade (GIACON, 2012).

Keeney (1992) propõe iniciar um processo de tomada de decisão multicritério pela estruturação do problema. Com o aprofundamento das pesquisas sobre o assunto essa abordagem foi atualizada por Franco e Montibeller (2010b).

A Figura 15 ilustra o processo de realização de intervenções MCDA e descreve a estruturação do problema conforme Franco e Montibeller (2010b). Na Fase 1, a situação é exposta e o facilitador auxilia na definição do problema, projeta o processo de decisão e define os participantes. Uma vez que essa fase estiver concluída, inicia-se a Fase 2, que consiste em estruturar uma árvore de valor, definir os atributos e identificar as alternativas de decisão. Concluída essa segunda fase, o facilitador pode finalmente realizar a Fase 3, que é a avaliação de alternativas de decisão. O fluxo natural de fases é indicado com a seta cheia mais escura na Figura 15, porém o processo é recursivo (indicado na figura por setas claras hachuradas), pois permite retornos às fases anteriores, devido às mudanças que a estruturação 
do modelo MCDA possa provocar na definição do problema, nas partes interessadas (stakeholders), nos atributos ou nas alternativas do problema.

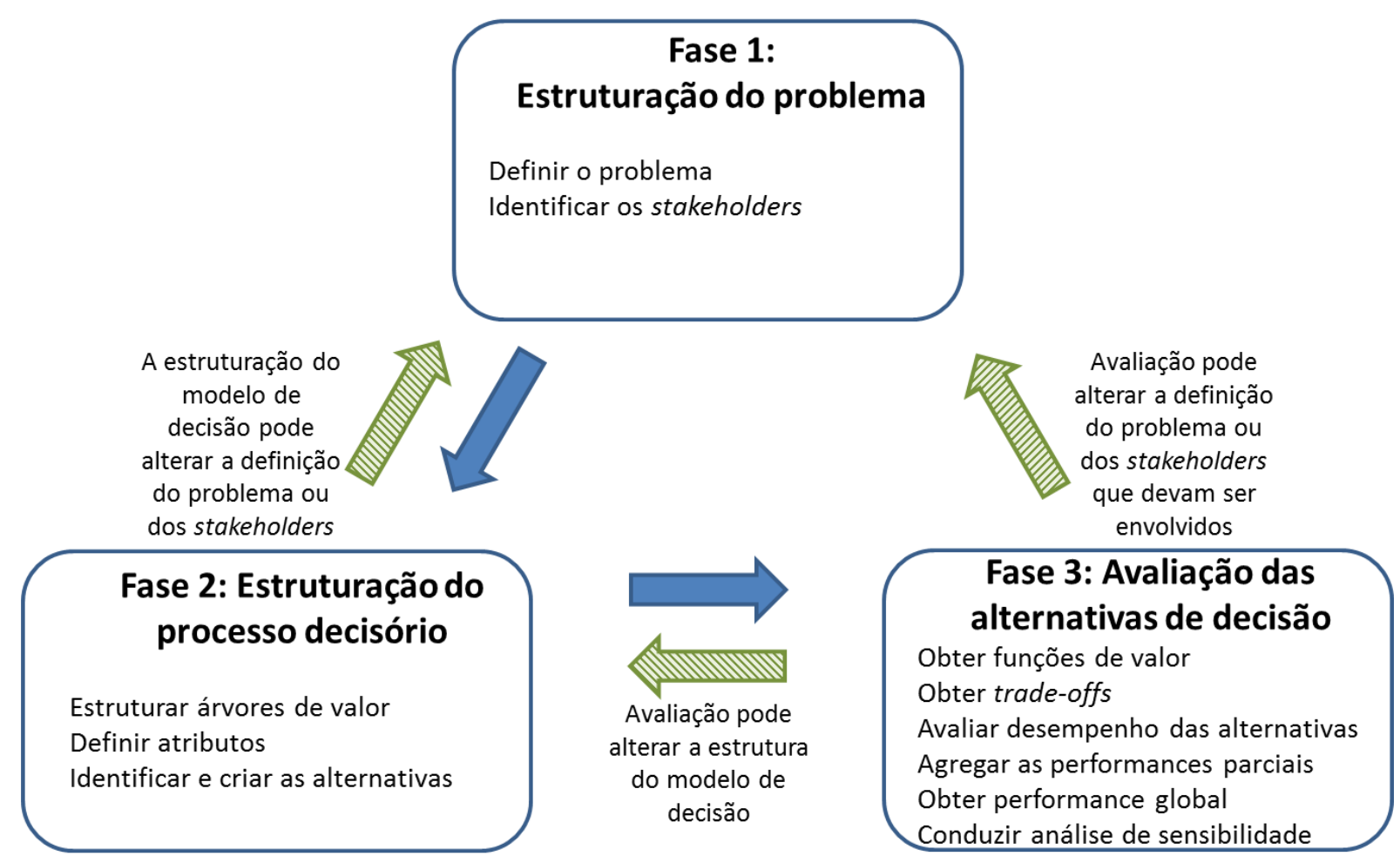

Figura 15 - Estrutura de um modelo MCDA. Fonte: Adaptado de Franco; Montibeller (2010b).

\subsubsection{Estruturação do problema}

A estruturação ou construção de modelos MCDA em intervenções reais não é atividade trivial, principalmente, devido à complexidade intrínseca dos modelos, em que os objetivos necessitam ser articulados, definidos e medidos por atributos. Além disso, a definição de um conjunto de alternativas a serem avaliadas nem sempre é simples, pois os tomadores de decisão podem ter dificuldades para analisar o problema ou considerar alternativas inovadoras. Existem duas tarefas principais na 
estruturação do problema que são a definição do problema e o escopo dos participantes na decisão (stakeholders) (FRANCO; MONTIBELLER, 2010b).

Franco e Montibeller (2010a) afirmam que, em Pesquisa Operacional, a forma de suporte mais utilizada em aplicações organizacionais é a utilização de um especialista que desenvolve um modelo, resolve esse modelo, encontrando uma solução ótima ou quase ótima, e recomenda essa solução, pouco existindo interação entre cliente e desenvolvedor do modelo durante o processo. Essa maneira de suporte é denominada Expert Mode.

Outra maneira é a realização do processo decisório de maneira conjunta (desenvolvedor do modelo e cliente) em todas as etapas: estruturação e definição do problema; apoio na avaliação das alternativas; e planejamento da implementação. Essa maneira é denominada de Facilitated Mode, no qual o desenvolvedor do modelo não é apenas um analista, mas facilita a compreensão do problema por parte do cliente e a equipe de decisão. Esse tipo de suporte pode também ser utilizado em outras situações organizacionais, não se restringindo ao processo decisório.

\subsubsection{Definição do problema}

O uso de estruturas analíticas de decisão é bem adaptado a situações que são claramente definidas, mas nem tão adaptado quando tais situações estão mal estruturadas ou desorganizadas. Antes do início das discussões para tomada de decisão, o problema e os objetivos devem estar claramente definidos, principalmente, para se evitar o "resolver certo o problema errado".

Franco e Montibeller (2010b) afirmam que quando um problema encontra-se mal definido e mal estruturado, durante o processo decisório, essa definição continua sendo discutida entre os tomadores de decisão. Essa situação leva a um desconforto e a insatisfação desses tomadores de decisão por não conseguirem compreender e, consequentemente, lidar com a situação. Watson e Buede (1987) 
afirmam que estruturar o problema consiste em definir quem são os tomadores de decisão; quais são os relacionamentos existentes; quais os objetivos da decisão a ser tomada; e quais as alternativas existentes ou possíveis de serem geradas.

\subsubsection{Participantes na decisão (stakeholders)}

No processo de tomada de decisão a identificação das partes interessadas (stakeholders) é necessária no processo de avaliação e implementação de decisão. Uma falha no tratamento das informações e preocupações das partes interessadas pode acarretar em um mau desempenho ou no fracasso do processo decisório. Atender as partes interessadas é também importante para satisfazer aqueles envolvidos ou afetados pela decisão (FRANCO; MONTIBELLER, 2010b).

Bryson (2004) revisou a literatura sobre o conceito de stakeholder e relata que existem algumas diferenças, sobretudo na inclusão de alguns grupos. Cita a existência de definições que contemplam apenas as pessoas ou grupos que possuem poder para influenciar as decisões, outras definições buscam conceitos que abordam democracia e justiça social, inserindo grupos de interesse de menor poder. Por fim, define stakeholder como sendo "qualquer grupo ou indivíduo que pode afetar ou é afetado pela realização dos objetivos estabelecidos por uma organização" (BRYSON, 2004).

Bryson também cita algumas variantes relacionadas ao setor público e não empresarial nesta definição, que auxiliam na aplicação deste conceito a logística de operações humanitárias:

- Todas as partes que são ou serão afetadas pela decisão.

- Qualquer pessoa, grupo ou organização que possa gerar uma reclamação sobre a decisão ou pelos recursos utilizados ou ainda que serão afetados pelos resultados gerados. 
- Pessoas ou pequenos grupos com o poder de negociação capaz de alterar a estratégia.

- Indivíduos ou grupos que dependem da decisão para cumprir seus objetivos e metas.

Bryson (2004) relaciona cinco técnicas relevantes para análise do papel dos stakeholders, dessas, Franco e Montibeller (2010b) destacam o diagrama de poder $X$ interesse. Nessa técnica um diagrama no formato de uma matriz $2 \times 2$, onde as dimensões são partes interessadas na decisão em questão e o poder desta parte interessada em afetar a sua implementação ou impacto (ACKERMANN; EDEN, 2011). Quatro grandes categorias de stakeholders são, então, estabelecidas, conforme ilustrado na Figura 16:

- Players: possuem tanto interesse quanto poder significativo.

- Sujeitos: que têm interesse, mas pouco poder de decisão.

- Definidores de contexto: possuem poder, mas pouco interesse direto, podendo participar, por exemplo, da elaboração das regras.

- População em geral: consiste de partes interessadas com pouco interesse ou poder.

No processo decisório categorizar cada stakeholder permite determinar as bases de poder como deve ser levado em consideração os interesses. 


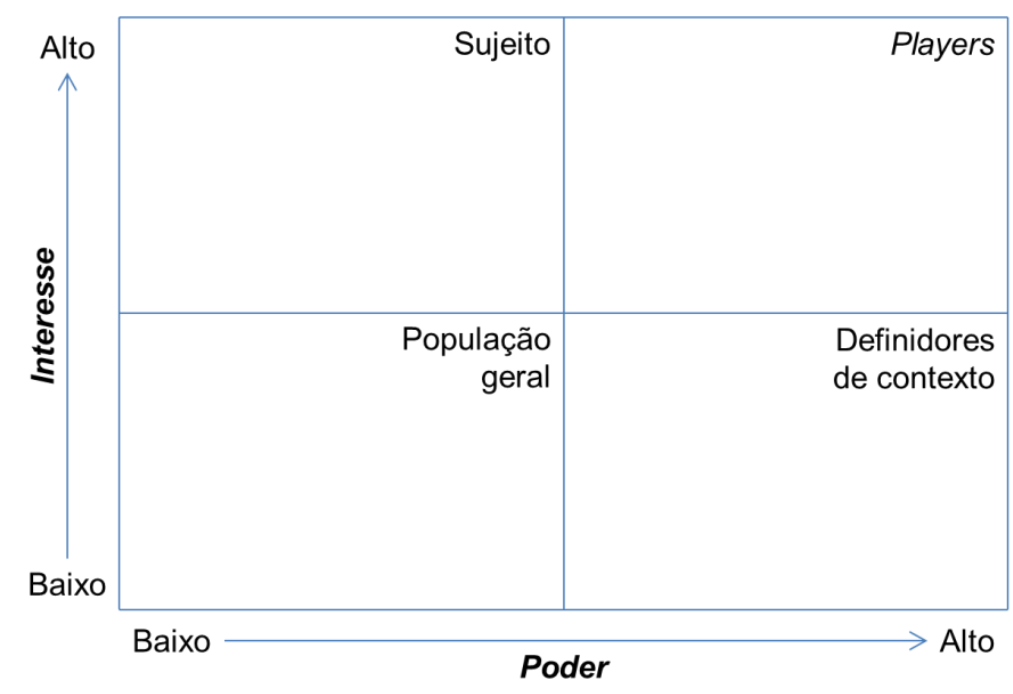

Figura 16 - Diagrama poder $\mathrm{x}$ interesse.

Fonte: Ackermann; Eden (2011).

Para a identificação dos stakeholders Franco e Montibeller (2010b) e Bryson (2004) apresentam a seguinte metodologia:

- Inicialmente uma pessoa ou um grupo inicia o processo fazendo uma análise preliminar para estabelecer as partes interessadas, utilizando, por exemplo, o diagrama poder $x$ interesse. Essa etapa é realizada em ambiente de preparação (ACKERMANN; EDEN, 2011) e é útil para auxiliar o tomador de decisão a pensar estrategicamente e em como criar as condições necessárias para decisão.

- Depois de avaliados os resultados desta análise, um grupo maior de interessados é estabelecido, se apropriado. O grupo deve ser convidado a apresentar e debater a relação de partes interessadas que possam ter necessidade de envolvimento na decisão. Novamente, o diagrama poder $\mathrm{x}$ interesse pode ser utilizado como um ponto de partida.

- Após a conclusão desta análise o grupo deve ser encorajado a pensar cuidadosamente sobre quem não está presente, mas que deve estar em discussões subsequentes durante o processo decisório. O grupo deve avaliar cuidadosamente as vantagens e desvantagens do envolvimento de outros 
stakeholders. A análise do diagrama poder $\mathrm{x}$ interesse deve ser apresentada a todos novos membros do processo decisório.

- Por último, o grupo deve ser definido para a tomada de decisão. Geralmente, são incluídas as lideranças envolvidas, os patrocinadores (se houver) e especialistas. As partes interessadas devem ser incluídas quando existirem razões boas e prudentes. Eles não devem ser incluídos quando o seu envolvimento não é necessário, ou impraticável, ou inadequado.

\subsubsection{Estruturação do processo decisório}

\subsubsection{Estruturação das árvores de valor}

Giacon (2012) afirma que o primeiro passo na construção de um modelo de avaliação MCDA é representar os objetivos que os tomadores de decisão querem alcançar e que a árvore de valor é uma ferramenta efetiva para conduzir a estruturação do pensamento nessa análise, especialmente, nos modelos MAVT e MAUT (KEENEY; RAIFFA, 1976).

Mapas cognitivos vêm sendo largamente utilizados na estruturação de problemas (PRADO, 2011) para a construção de árvores de valor. O termo mapeamento cognitivo é utilizado para descrever a atividade de mapear o pensamento de uma pessoa sobre um problema ou questão. Um mapa cognitivo é a representação desse pensamento sob a forma de um grafo (EDEN, 2004) e demonstra ao tomador de decisão as conexões entre as variáveis, os meios disponíveis e os objetivos que deseja alcançar (MONTIBELLER, 2000).

A decomposição do mapa possibilita o estabelecimento, através de uma estrutura arborescente, dos pontos de vista fundamentais, que explicitam os valores 
considerados importantes para os tomadores de decisão, assim como definem as características das ações que são de interesse dos decisores. Nessa estrutura um critério mais complexo de nível superior é decomposto em subcritérios de mensuração mais fácil (ENSSLIN; MONTIBELLER; NORONHA, 2001).

Montibeller e Belton (2006) elaboraram uma revisão para avaliação das abordagens utilizadas na concepção de mapas causais no processo de tomada de decisão. Tais mapas permitem uma rica representação de ideias através da modelagem de cadeias de argumentação complexas e são adequados para vários tipos de análise. Sob uma perspectiva topológica, mapa causal é uma rede, na qual os nós representam conceitos e as ligações entre esses representam a causalidade, que objetiva representar o discurso de uma pessoa. Quando utilizado no suporte à tomada de decisão, esse discurso frequentemente assume uma estrutura hierárquica do tipo causas e efeitos, em que as opções são os meios para atingir os objetivos dos tomadores de decisão. Um facilitador pode ser empregado no processo de estruturação do problema: Quando isso ocorre o direcionamento preferencial pode surgir naturalmente a partir de um processo de negociação, mesmo considerando que o facilitador não é neutro (ENSSLIN; MONTIBELLER NETO; NORONHA, 2001), porque, a partir do seu próprio sistema de valores e da sua visão subjetiva, interpreta e constrói os eventos que compõem o problema (BANA e COSTA et al.,1999)

Franco e Montibeller (2010b) descrevem que a árvore de valor decompõe o objetivo fundamental em objetivos operacionais, que podem ser mais facilmente empregados para avaliar o desempenho das alternativas de decisão. Duas abordagens clássicas (KEENEY, 1992) para estruturação de uma árvore de valores são utilizadas, top down (de cima para baixo) e bottom up (de baixo para cima). A abordagem top down, alinhada com o VFT (Value Focused Thinking - Pensamento Baseado em Valores), decompõe o objetivo fundamental em objetivos, que por sua vez são decompostos em subobjetivos e, assim, sucessivamente. A abordagem bottom up, alinhada com o AFT (Alternative Focused Thinking - Pensamento Baseado em Alternativas), identifica quais atributos diferenciam as alternativas e agrupa os atributos conforme sua natureza ou tipo, compondo a árvore de valor. 
A Figura 17 ilustra os principais aspectos a serem identificados durante a abordagem VFT.

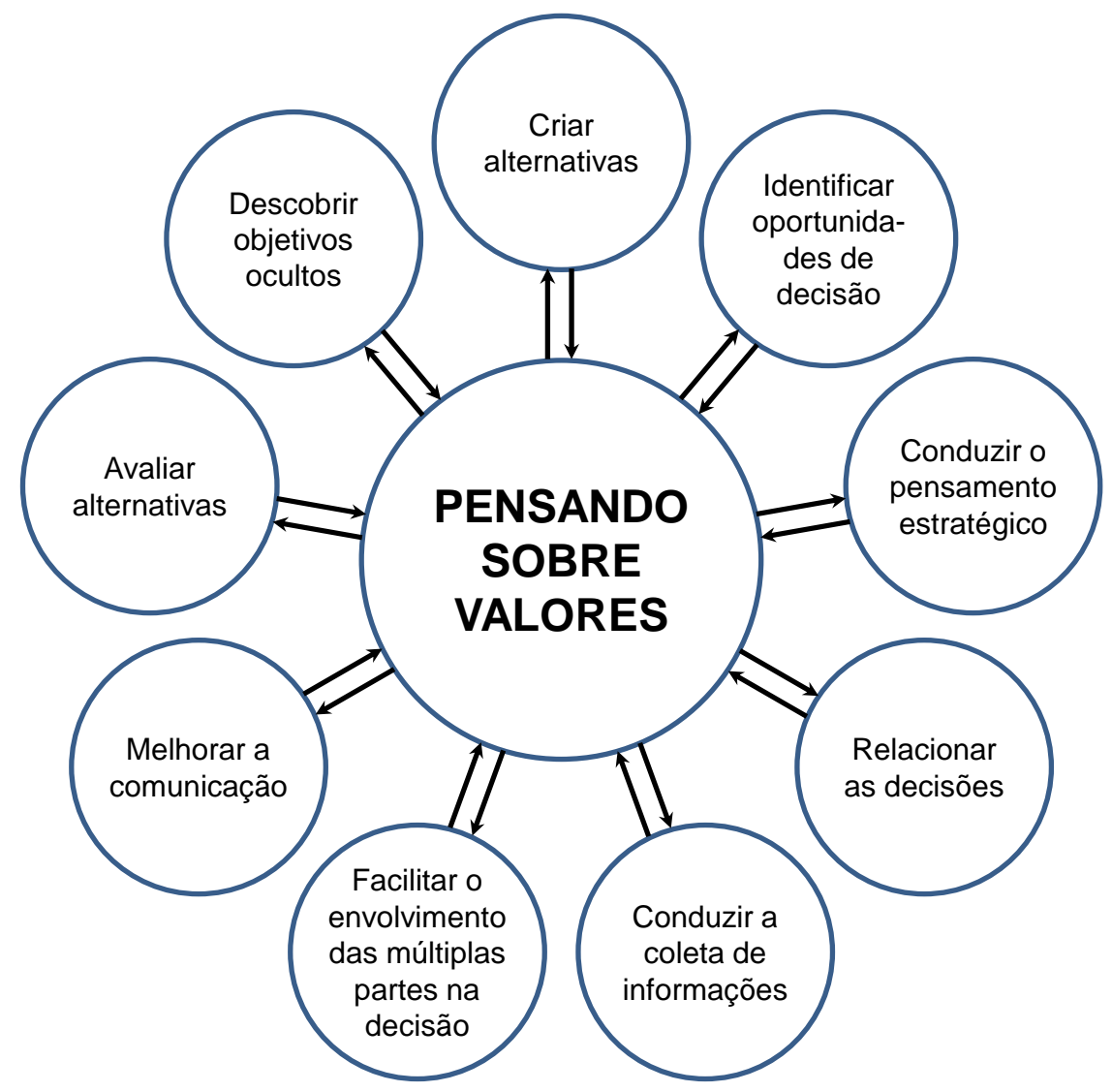

Figura 17 - Visão geral do VFT.

Fonte: Keeney (1992) (tradução nossa).

Os autores também destacam um conjunto de propriedades que os objetivos em uma árvore de valor devem possuir:

- Essencial: devem considerar todos os objetivos fundamentais envolvidos no processo de decisão.

- Compreensível: devem ter um significado claro para todos os membros do grupo envolvido na tomada de decisão.

- Operacional: deve ser possível medir o desempenho das alternativas de decisão em relação a cada um dos objetivos fundamentais. 
- Não redundante: não devem ser estabelecidos dois ou mais objetivos para o mesmo fim.

- Conciso: deve ser considerado o menor número de objetivos necessários para a análise.

- Independência preferencial: deve ser possível medir o desempenho das alternativas de decisão em um único objetivo, desconsiderando o seu desempenho em relação aos outros objetivos. A ordem (ordinalidade) e a intensidade (cardinalidade) das ações não dependem da performance destas ações nas demais (ENSSLIN; MONTIBELLER; NORONHA, 2001). Dessa maneira uma função de agregação simples pode ser utilizada para agregar os desempenhos parciais.

\subsubsection{Definição dos atributos}

Os termos critério e atributo são utilizados frequentemente como sinônimos e não serão diferenciados nesta tese (GIACON, 2012). Para cada objetivo colocado no nível inferior da árvore de valor um atributo associado deve ser estabelecido. Esse atributo é um índice de desempenho utilizado para medir o impacto da adoção de cada alternativa de decisão sobre o objetivo que está sendo perseguido. Há duas dimensões a serem observadas nos atributos: o alinhamento com o objetivo fundamental e a forma como é mensurado (KEENEY, 1992). Atributos podem ser classificados entre naturais (ligados diretamente ao objetivo e podem ser contados ou fisicamente medidos), proxy ou representativos (ligados indiretamente ao objetivo e podem ser contados ou fisicamente medidos) ou construídos (são desenvolvidos quando não existem atributos naturais) (KEENEY, GREGORY, 2005).

Independentemente do seu tipo, cada atributo deve seguir cinco propriedades a serem empregados em um modelo MCDA de avaliação (PRADO, 2011), (KEENEY, GREGORY, 2005): 
- Não ambíguo: O atributo deve apresentar uma clara relação entre a adoção de uma alternativa de decisão e o respectivo impacto dessa alternativa.

- Abrangente: $O$ atributo deve cobrir toda a gama de possíveis consequências, se as alternativas de decisão forem implementadas.

- Direto: Os níveis de atributo devem descrever o mais diretamente possível as consequências importantes da implementação de uma alternativa.

- Operacional: A informação exigida pelo atributo pode ser obtida na prática e é possível fazer os trade-offs entre os objetivos.

- Compreensível: Consequências e valores dos trade-offs usando o atributo podem ser claramente compreendidos pelo grupo de tomada de decisão e comunicado a outras partes interessadas.

Atributos quantitativos tendem a serem menos ambíguos do que os qualitativos. Um ponto chave sobre abrangência de um atributo é a especificação dos limites superior e inferior do atributo (máximo possível e mínimo aceitável, respectivamente).

\subsubsection{Identificação e criação das alternativas}

A outra grande tarefa em um modelo de estruturação MCDA é a definição de quais alternativas de decisão serão avaliadas pelo modelo. A identificação e criação de novas alternativas é certamente um dos aspectos importantes do MCDA. Não importa o quão cuidadoso e sofisticado o modelo de avaliação seja, pois, se as alternativas de decisão em consideração são fracas, esta decisão terá pouco valor. (GIACON, 2012).

Um aspecto importante na estruturação de um modelo MCDA é que as alternativas de decisão devem ter a mesma natureza. (por exemplo, municípios). Franco e Montibeller (2010b) destacam que existem diversas técnicas que podem ser utilizadas na criação e definição das alternativas de decisão, tais como brainstorming 
e mapas cognitivos, dentre outros, e que as ferramentas particularmente úteis são aquelas em que as alternativas de decisão são criadas a partir de consideração dos objetivos dos tomadores de decisão ou dos valores considerados pelos stakeholders. Através da combinação de alternativas existentes novas opções podem ser criadas, observando as melhores características de cada alternativa.

\subsubsection{Avaliação das alternativas de decisão}

Para avaliação das alternativas, Franco e Montibeller (2010b) descrevem as seguintes etapas: obter funções de valor; obter os trade-offs; avaliar desempenho das alternativas; agregar as performances parciais; obter performance global; e conduzir a análise de sensibilidade.

\subsubsection{Obtenção das funções de valor}

A função de valor mostra o comportamento de valor de atributo em relação ao seu desempenho. Cada atributo definido deve possuir uma função de valor (GIACON, 2012). A função de valor deve demonstrar as preferências do tomador de decisão sobre as consequências e os trade offs de cada possível escolha no processo de decisão. A função de valor deve representar o comportamento dos tomadores de decisão em relação às preferências, não existindo valores corretos ou errados (KEENEY, 1992).

Para sua obtenção os tomadores de decisão estabelecem os limites superior e inferior, definindo para cada atributo o que consideram como "o melhor possível". 
Esse valor é estabelecido como o valor máximo para o atributo (100). De maneira similar estabelecem "o pior possível" como valor mínimo para o atributo (0) definindo, assim, a amplitude. A próxima etapa é estabelecer pontuação para os atributos que se encontram entre o melhor e pior possível. Neste trabalho foi adotado o método da bissecção, no qual os tomadores de decisão estabelecem, na função de valor do atributo, um valor para o ponto médio situado entre o melhor e o pior possível. Após a identificação do ponto médio, o método pode ser utilizado para determinar o ponto da quarta parte e, assim, sucessivamente. Convém ressaltar que os pontos estabelecidos não necessitam corresponder às alternativas existentes. Essa dinâmica é realizada para todos os atributos. (GOODWIN; WRIGHT, 2004).

\subsubsection{Obtenção dos pesos dos atributos}

A definição dos pesos de cada atributo é utilizada na priorização dos objetivos da decisão, na qual é mensurada a importância de cada atributo no processo decisório. A simples atribuição de um peso intuitivo sem estabelecimentos de limites a cada um dos atributos pode acarretar problemas ao processo decisório (GOODWIN; WRIGHT, 2004). São utilizados para converter performances parciais de uma opção (medido por funções de valor) em seu no seu desempenho global. Os limites máximos e mínimos de cada atributo são estabelecidos com base na metodologia denominada de swing-weights, na qual os tomadores de decisão definem qual é o atributo mais relevante através de uma simulação, em que somente um dos atributos pudesse ser selecionado para a decisão. Este atributo recebe então o valor 100. A seguir é selecionado outro atributo e, então, confrontado com o primeiro e atribuído um valor comparativo (menor que 100). A dinâmica se repete para todos os outros atributos. Após a atribuição dos valores as pontuações são normalizadas (somatório igual a um) com o objetivo de formar as constantes de escala utilizadas para cada um dos atributos do modelo (GIACON, 2012). 


\subsubsection{Avaliar desempenho das alternativas}

Cada alternativa deve ter seu desempenho em cada um dos atributos avaliado, conforme a função de valor estabelecida (MONTIBELLER; FRANCO, 2007). Na função de valor a alternativa é avaliada e obtida sua pontuação no critério correspondente (PRADO, 2011).

\subsubsection{Agregar as performances parciais das alternativas}

Após a avaliação de cada alternativa em cada um dos atributos avaliado, um modelo aditivo é utilizado para agregar o desempenho, que pode ser assim definido (KEENEY, 2002):

$\mathrm{u}\left(x_{1}, x_{2}, \ldots, x_{n}\right)=k_{1} u_{1}\left(x_{1}\right)+k_{2} u_{2}\left(x_{2}\right)+\cdots+k_{n} u_{n}\left(x_{n}\right)$

Onde:

u: são os valores correspondentes das funções de valor obtidos pela alternativa nos atributos $1,2 \ldots \mathrm{n}$.

k: são os valores correspondentes aos pesos dos atributos $1,2, \ldots \mathrm{n}$.

No modelo aditivo cada valor obtido pela alternativa é multiplicado pelo peso do atributo. Trata-se de uma metodologia simples, entretanto requer que a independência entre os atributos seja assegurada (GOODWIN; WRIGHT, 2004). 


\subsubsection{Obter performance global}

Após o processo de avaliação de todas as alternativas os resultados globais devem ser analisados pelo tomador de decisão. Análises adicionais podem ser efetuadas a fim de avaliar se o desempenho geral das funções de valor, das avaliações das alternativas e dos pesos dos atributos é adequado (GOODWIN; WRIGHT, 2004).

\subsubsection{Conduzir a análise de sensibilidade.}

A análise de sensibilidade é realizada para verificar a robustez de opções mediante mudanças nos parâmetros utilizados no processo decisório. (GOODWIN; WRIGHT, 2004). Considerando-se as fontes de incertezas, seus impactos e variações sobre os parâmetros e suas consequências sobre as ações, pode ser difícil de medir precisamente performances e estabelecer ações alternativas. A análise de sensibilidade deve ser realizada considerando essas variações, com o objetivo de encontrar opções robustas, que são capazes de lidar com essas incertezas. Uma árvore de valor bem estruturada facilita 0 desenvolvimento da análise de sensibilidade (BELTON; ACKERMANN; SHEPHERD, 1997).

Fechamento do capítulo

Neste capítulo foi apresentada uma revisão de literatura para estabelecimento da fundamentação teórica para a elaboração da tese. Foram abordados tópicos referentes a desastres, cadeias de suprimentos, logística de operações humanitárias, programação linear estocástica, modelos de localização 
determinísticos e estocásticos aplicados à logística humanitária, métodos multicritério e teoria do valor multiatributo. Além dos tópicos abordados, foi objetivado também estabelecer a fronteira do conhecimento atual em localização de instalações em logística de operações humanitárias para o desenvolvimento de conceitos necessários para esta tese. 


\section{Modelo de programação estocástica}

Este capítulo descreve o modelo de programação estocástica de dois estágios para localização de instalações e foi elaborado com base nos trabalhos apresentados na revisão de literatura e nas etapas descritas no tópico 1.3 Atividades da pesquisa. São expostos a descrição e a formulação do problema, a região geográfica de aplicação, os cenários estabelecidos e a descrição e forma de obtenção de cada um dos parâmetros dependentes e não dependentes dos cenários.

\subsection{Descrição do problema}

O modelo de otimização é aplicado a um estudo de caso na região administrativa do Vale do Paraíba Paulista, com a finalidade de avaliação da quantidade e quais locais devem ser utilizados como depósito de suprimentos de alívio. O usuário do resultado e ponto de vista da abordagem é a Defesa Civil estadual, que armazena os materiais e coordena sua distribuição.

A região foi escolhida devido aos dados históricos e informações geográficas disponíveis e, principalmente, por ser uma região suscetível à ocorrência de desastres naturais (deslizamentos de terra e inundações), com grande número de desabrigados e desalojados, conforme observado em eventos recentes nas cidades de Queluz (2000) e São Luiz do Paraitinga (2010); e, também, por ser local de um possível desastre antropogênico, devido à proximidade com a usina nuclear de Angra dos Reis. A escolha do estudo de caso considera uma abordagem intencional, baseada no acesso direto aos dados necessários ao estudo. Para cálculo da demanda e das quantidades de materiais para atendimento às vítimas foi considerado a eventual ocorrência de desastre em um horizonte de cinco anos. 
Em caso de um desastre na região, o abastecimento às vítimas é iniciado a partir dos suprimentos de alívio armazenados no(s) depósito(s). Esse(s) depósito(s) recebem os materiais adquiridos através de contratos de compra previamente firmados, e a compra acontece somente em caso de ocorrência da demanda (prazo de entrega varia entre um a três dias, conforme o material). $O$ depósito também possui a função de processamento das doações a serem enviadas ao local do desastre e possui uma capacidade nominal de armazenagem, durante o período sem a ocorrência de desastre, e uma capacidade incidental, que é adicionada a capacidade nominal durante a ocorrência de um desastre.

A partir do depósito, os suprimentos de alívio, previamente armazenados, comprados ou recebidos através de doações, são enviados aos locais do desastre para atendimento às vítimas, através do modal rodoviário, existindo a possibilidade de ocorrer rupturas nas vias de acesso aos locais afetados. Na modelagem estocástica os cenários foram estabelecidos conforme a magnitude do desastre, a divulgação pela mídia e as eventuais rupturas nas vias de acesso.

As cidades abrangidas são: Aparecida, Arapeí, Areias, Bananal, Caçapava, Cachoeira Paulista, Campos do Jordão, Canas, Cruzeiro, Cunha, Guaratinguetá, Igaratá, Jacareí, Jambeiro, Lagoinha, Lavrinhas, Lorena, Monteiro Lobato, Natividade da Serra, Paraibuna, Pindamonhangaba, Piquete, Potim, Queluz, Redenção da Serra, Roseira, Santa Branca, Santo Antônio do Pinhal, São Bento do Sapucaí, São José do Barreiro, São José dos Campos, São Luís do Paraitinga, Silveiras, Taubaté e Tremembé, que totalizam 1.980.890 habitantes (IBGE, 2010).

Os locais candidatos a depósitos são: São Paulo (depósito central da Defesa Civil), Caçapava, São José dos Campos, Taubaté e Tremembé. Os locais candidatos foram escolhidos através da metodologia multicritério, mediante entrevistas e reuniões (duas durante os anos de 2011 e 2012, no início do processo de modelagem) preliminares com os tomadores de decisão da Defesa Civil, considerando atributos com características restritivas (atende ou não atende), especialmente, por já possuírem um depósito em operação (São Paulo) ou por serem sedes de unidades da Polícia Militar com coordenação de Defesa Civil (São José dos Campos e Taubaté) e, consequentemente, uma melhor disponibilidade 
operacional ou ainda por se situarem em localidades com menores riscos meteorológicos e geológicos; sem históricos de ocorrências relevantes e de desabrigados e desalojados, portanto, com menor probabilidade de ruptura nas vias. Os depósitos são instalados, em princípio, em unidades da Polícia Militar, Corpo de Bombeiros ou Defesa Civil, utilizando uma infraestrutura já existente e necessitando apenas da adequação dos locais, assim como, a aquisição de equipamentos de movimentação e armazenagem.

A Figura 18 ilustra o posicionamento geográfico das localidades e dos depósitos.

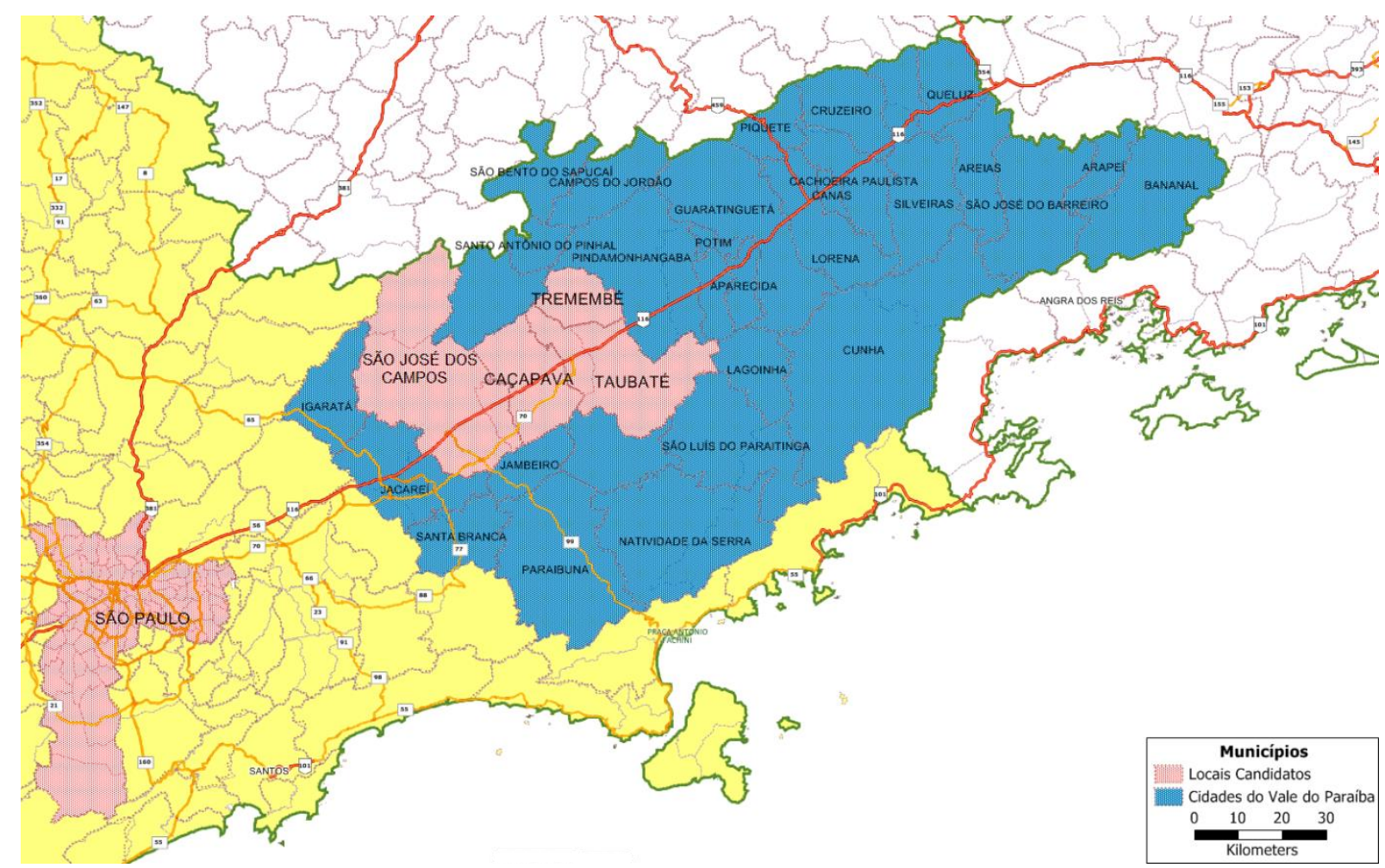

Figura 18 - Localização das cidades e dos locais candidatos (depósitos).

Informações detalhadas sobre o modelo e a forma de obtenção dos parâmetros estão descridas nos tópicos posteriores deste capítulo. 


\subsection{Modelo matemático}

O modelo propõe a determinação de locais de instalação de uma ou mais centrais de distribuição permanentes para armazenagem de suprimentos de alívio voltados ao atendimento à vítimas de desastres naturais, que porventura ocorram na região. A função objetivo minimiza o custo total de atendimento composto pelos custos de abertura do depósito e fixo anual, transporte e penalidade pelo não atendimento. As restrições podem ser agrupadas como de capacidade (armazenagem e transporte), de materiais disponíveis (estoque, doações e compras) e de nível mínimo de atendimento (demanda mínima e cobertura).

O problema estudado é modelado através de otimização estocástica de dois estágios e tem como base os trabalhos apresentados por Mete e Zabinsky (2010) e Rawls e Turnquist (2011). A Figura 19, ilustra a estrutura do modelo e as etapas em que os parâmetros e as variáveis são utilizados: 
c: cenários

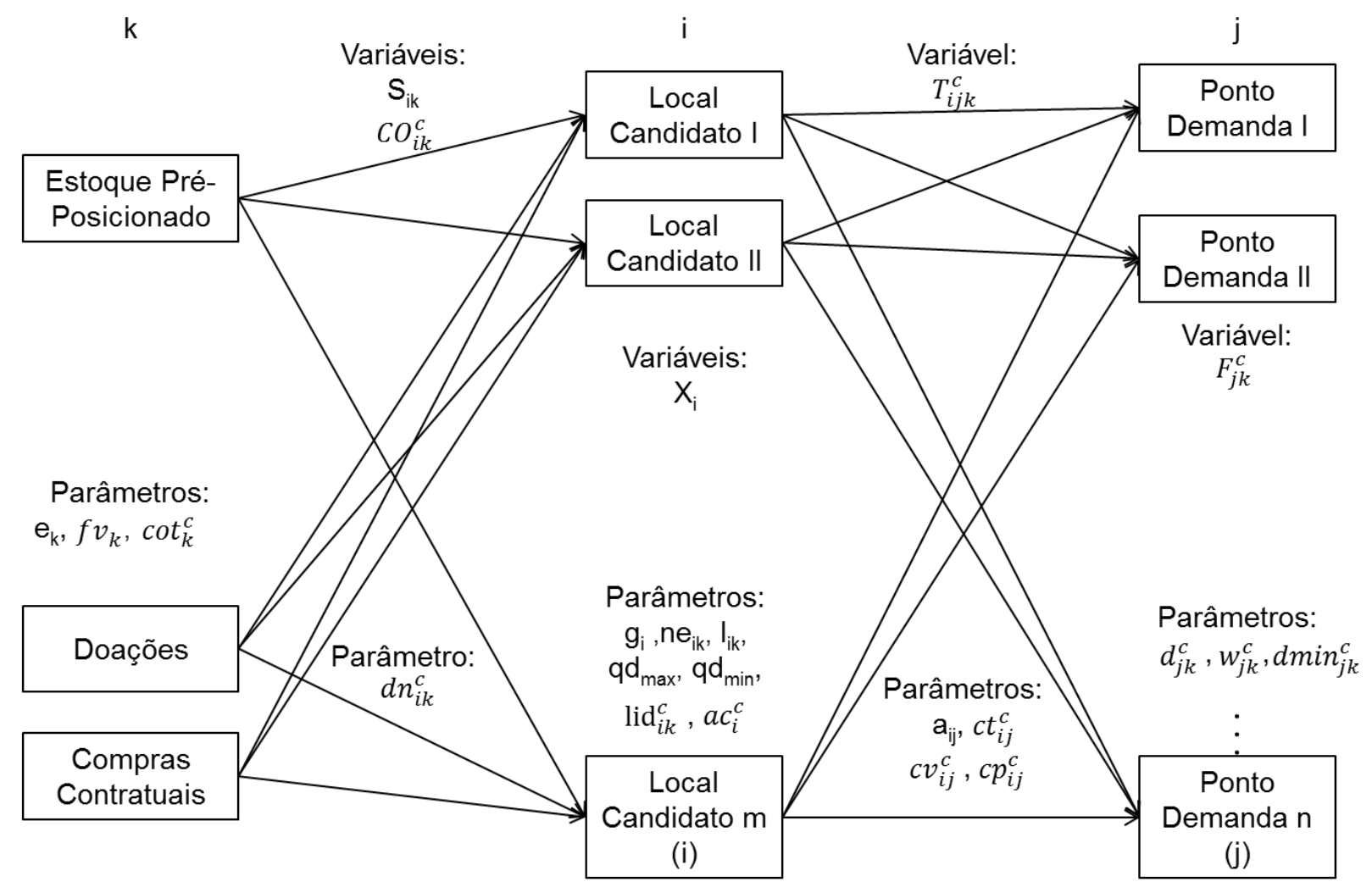

Figura 19 - Estrutura do modelo.

\section{Descrição do modelo (formato NPS):}

\section{1 ํe estágio}

\section{Conjuntos}

I: depósitos disponíveis ( $€$ I)

$\mathrm{K}$ : tipo de suprimentos $(\mathrm{k} \in \mathrm{K}$ )

$\mathrm{J}:$ pontos de demanda $(\mathrm{j} \in \mathrm{J})$

C: cenários $(c \in C)$

\section{Variáveis de decisão de 1ํestágio:}

$\mathrm{X}_{\mathrm{i}}$ : binária, operar ou não determinado depósito (abre/fecha - binária- adimensional). 
$S_{\text {ik: }}$ nível de estoque médio (do período) do suprimento k no depósito i (kg).

\section{Variáveis de decisão de $2^{\circ}$ estágio:}

$T_{i j k}^{c}$ : quantidade do item $\mathrm{k}$ a transportar do depósito i ao ponto de demanda j, no cenário c $(\mathrm{kg})$.

$F_{j k}^{c}$ : demanda não satisfeita de $\mathrm{k}$ no ponto de demanda j, no cenário $\mathrm{c}(\mathrm{kg})$.

$\mathrm{CO}_{i k}^{c}$ : compras do suprimento $\mathrm{k}$, alocadas no depósito i, no cenário $\mathrm{c}(\mathrm{kg})$.

$C O \_A U X_{k}^{c}$ : variável binária auxiliar para somente efetuar compras do suprimento $\mathrm{k}$, se necessário (binária adimensional).

\section{Parâmetros:}

Não dependentes de cenário:

gi: custo anual de instalação e operação do depósito i (\$).

$e_{\mathrm{k}}$ : quantidade total disponível do suprimento $\mathrm{k}(\mathrm{kg})$.

$\mathrm{l}_{\mathrm{ik}}$ : capacidade nominal de armazenagem do suprimento k no depósito i $(\mathrm{kg})$.

ne $e_{\mathrm{ik}}$ : nível mínimo anual de estoque do suprimento k no depósito i (kg).

qd max: número máximo de depósitos a serem abertos (quantidade - adimensional).

$\mathrm{qd}_{\min }$ : número mínimo de depósitos a serem abertos (quantidade - adimensional).

$f v_{k}$ : fator de conversão peso $X$ volume do suprimento $k\left(m^{3} / \mathrm{kg}\right)$.

$a_{\mathrm{ij}}$ : binária que assume 1 , se a distância é menor que a distância máxima, e 0 , em caso contrário (matriz de cobertura).

bigM: número grande auxiliar para efetuar compras do suprimento k, se necessário (adimensional) e verificação de distâncias.

Dependentes de cenário:

$c t_{i j}^{c}$ : custo de transporte do depósito i ao ponto de demanda j, no cenário $\mathrm{C}(\$ / \mathrm{kg})$. 
$w_{j k}^{c}$ : penalidade por unidade de $\mathrm{k}$ não fornecida ao ponto de demanda j, no cenário $\mathrm{C}$ $(\$ / \mathrm{kg})$.

$d n_{i k}^{c}$ : quantidade de doações de $\mathrm{k}$ recebidas no depósito i, no cenário $\mathrm{C}(\mathrm{kg})$.

$d_{j k}^{c}$ : demanda pelo suprimento $\mathrm{k}$ no ponto de demanda j, no cenário $\mathrm{C}(\mathrm{kg})$

lid $d_{i k}^{c}$ : capacidade incidental de armazenagem do suprimento $\mathrm{k}$, acrescida no depósito i, no cenário $C(\mathrm{~kg})$.

$a c_{i}^{c}$ : parâmetro binário referente à acessibilidade do depósito potencial i $(1$ acessível, 0 não acessível), no cenário $C$.

$c p_{i j}^{c}$ : capacidade de transporte (em peso) do estoque i para o ponto de demanda $\mathrm{j}$, no cenário $C(\mathrm{~kg})$.

$c v_{i j}^{c}$ : capacidade de transporte (em volume) do estoque i para o ponto de demanda $\mathrm{j}$, no cenário $\mathrm{C}\left(\mathrm{m}^{3}\right)$.

$d \min _{j k}^{c}$ : demanda mínima a ser abastecida do suprimento $\mathrm{k}$ no ponto de demanda $\mathrm{j}$, no cenário $C(\mathrm{~kg})$.

$\cot _{k}^{c}$ : limite contratual de compras emergenciais do suprimento $\mathrm{k}$, a ser adquirido no cenário $\mathrm{C}(\mathrm{kg})$.

\section{Função objetivo de $1^{\circ}$ estágio:}

Minimizar o [(custo de instalação e operação dos estoques) + função objetivo de $2^{\circ}$ estágio representada pelo (custo de transporte no cenário $c$ + penalidade pelo não atendimento à demanda no cenário c)]

$\min \sum_{\mathrm{i}} \mathrm{g}_{\mathrm{i}} \mathrm{X}_{\mathrm{i}}+\mathrm{E}_{\mathrm{C}}[\mathrm{Q}(\mathrm{X}, \mathrm{S}, \mathrm{c})]$ 
Para um item k, a quantidade estocada em todos os depósitos não pode superar a quantidade máxima disponível.

$\sum_{\mathrm{i}} \mathrm{S}_{\mathrm{ik}} \leq \mathbf{e}_{\mathbf{k}} \forall \mathbf{k} \in \mathbf{K}$

O nível de estoque é limitado pela capacidade do depósito i

$\mathrm{l}_{\mathrm{ik}} \mathrm{X}_{\mathrm{i}} \geq \mathrm{S}_{\mathrm{ik}} \forall \mathrm{i} \in \mathrm{I}, \mathrm{k} \in \mathrm{K}$

O nível de estoque mínimo de k no depósito i aberto.

$\mathrm{ne}_{\mathrm{ik}} \mathrm{X}_{\mathrm{i}} \leq \mathrm{S}_{\mathrm{ik}} \quad \forall \mathrm{i} \in \mathrm{I}, \mathrm{k} \in \mathrm{K}$

Garante a quantidade máxima de depósitos a serem abertos.

$\sum_{\mathrm{i}} \mathrm{X}_{\mathrm{i}} \leq \mathrm{qd}_{\max } \forall \mathrm{i} \in \mathrm{I}$

Garante a quantidade mínima de depósitos a serem abertos.

$\sum_{\mathrm{i}} \mathrm{X}_{\mathrm{i}} \geq \mathrm{qd}_{\min } \forall \mathrm{i} \in \mathrm{I}$

Garante a distância mínima do ponto de demanda j a, pelo menos, um depósito i.

$\sum_{i} X_{i} a_{i j} \geq 1 \forall j \in J$

\section{2o estágio}




\section{Função objetivo de $2^{\circ}$ estágio:}

Minimizar o (custo de transporte no cenário $\mathrm{C})+$ (penalidade pelo não atendimento à demanda no cenário $\mathrm{C}$ )

$\mathrm{Q}(\mathrm{X}, \mathrm{S}, \mathrm{c})=\min \sum_{\mathrm{i}} \sum_{\mathrm{j}}\left(\mathrm{ct}_{\mathrm{ij}}^{\mathrm{c}} \sum_{\mathrm{k}} \mathrm{T}_{\mathrm{ijk}}^{\mathrm{c}}\right)+\sum_{\mathrm{j}} \sum_{\mathrm{k}} \mathrm{w}_{\mathrm{jk}}^{\mathrm{c}} \mathrm{F}_{\mathrm{jk}}^{\mathrm{c}}$

\section{Restrições de 2º estágio:}

Assegura que quantidade do item $\mathrm{k}$ a transportar do estoque $\mathrm{i}$ ao ponto de demanda j, esteja disponível em i

$\sum_{j} T_{i j k}^{c} \leq S_{i k}+d n_{i k}^{c}+C_{i k}^{c} \forall i \in I, k \in K, c \in C$

Calcula a demanda não atendida $f_{j k}$

$\mathrm{F}_{\mathrm{jk}}^{\mathrm{c}}=\mathrm{d}_{\mathrm{jk}}^{\mathrm{c}}-\sum_{\mathrm{i}} \mathrm{T}_{\mathrm{ijk}}^{\mathrm{c}} \mathrm{ac}_{\mathrm{i}}^{\mathrm{c}} \forall \mathrm{j} \in \mathrm{J}, \mathrm{k} \in \mathrm{K}, \mathrm{c} \in \mathrm{C}$

Assegura que o suprimento $\mathrm{k}$, a transportar do estoque i ao ponto de demanda $\mathrm{j}$, esteja em depósito com suficiente capacidade (nominal + incremental) de armazenagem, aberto por $\mathrm{x}_{\mathrm{i}}$,

$\left(l_{i k}+\operatorname{lid}_{i k}^{c}\right) X_{i} \geq \sum_{j} T_{i j k}^{c} a_{i}^{c} \quad \forall i \in I, k \in K, c \in C$

Assegura a capacidade de transporte em peso do suprimento $\mathrm{k}$ no estoque $\mathrm{i}$

$\sum_{k} T_{i j k}^{c} \leq \mathrm{cp}_{\mathrm{ij}}^{\mathrm{c}} \forall \quad \mathrm{i} \in \mathrm{I}, \mathrm{j} \in \mathrm{J}, \mathrm{c} \in \mathrm{C}$ 
Assegura a capacidade de transporte em volume do suprimento k no estoque i.

$\sum_{\mathrm{k}} \mathrm{T}_{\mathrm{ijk}}^{\mathrm{c}} \mathrm{fv}_{\mathrm{k}} \leq \mathrm{cv}_{\mathrm{ik}}^{\mathrm{c}} \forall \quad \forall \quad \mathrm{i} \in \mathrm{I}, \mathrm{j} \in \mathrm{J}, \mathrm{c} \in \mathrm{C}$

Assegura que uma demanda mínima de k no ponto de demanda j é atendida.

$\sum_{\mathrm{i}} \mathrm{T}_{\mathrm{ijk}}^{\mathrm{c}} \mathrm{ac}_{\mathrm{i}}^{\mathrm{c}} \geq \mathrm{dmin}_{\mathrm{jk}}^{\mathrm{c}} \quad \forall \mathrm{j} \in \mathrm{J}, \mathrm{k} \in \mathrm{K}, \mathrm{c} \in \mathrm{C}$

Necessidade de compra:

Condição para compra do suprimento k: co_aux = 0 se Demanda - Estoque Doações $>0$

$\operatorname{bigM}\left(1-\mathrm{CO}_{-} \mathrm{AUX} \mathrm{X}_{\mathrm{k}}^{\mathrm{c}}\right)>\sum_{\mathrm{j}} \mathrm{d}_{\mathrm{jk}}^{\mathrm{c}}-\sum_{\mathrm{i}} \mathrm{S}_{\mathrm{ik}}-\sum_{\mathrm{i}} \mathrm{dn}_{\mathrm{ik}}^{\mathrm{c}} \forall \mathrm{k} \in \mathrm{K}, \mathrm{c} \in \mathrm{C}$

Não solicita compra: co_aux $=1$ se Estoque + Doações - Demanda $\geq 0$

$\operatorname{bigM}$ CO_AUX $\mathrm{k}_{\mathrm{k}}^{\mathrm{c}} \geq \sum_{\mathrm{i}} \mathrm{S}_{\mathrm{ik}}+\sum_{\mathrm{i}} \mathrm{dn}_{\mathrm{ik}}^{\mathrm{c}}-\sum_{\mathrm{j}} \mathrm{d}_{\mathrm{jk}}^{\mathrm{c}} \forall \mathrm{k} \in \mathrm{K}, \mathrm{c} \in \mathrm{C}$

Atribui compra do suprimento $\mathrm{k}$ somente se co_aux $=0$

$\mathrm{CO}_{\mathrm{ik}}^{\mathrm{c}} \leq \operatorname{bigM}\left(1-\mathrm{CO}_{-} \mathrm{AUX} \mathrm{K}_{\mathrm{k}}^{\mathrm{c}}\right) \quad \forall \mathrm{i} \in \mathrm{I}, \mathrm{k} \in \mathrm{K}, \mathrm{c} \in \mathrm{C}$

Assegura que a compra do suprimento $\mathrm{k}$, seja alocada para depósito aberto por $\mathrm{x}_{\mathrm{i}}$ $\cot _{\mathrm{k}}^{\mathrm{c}} \mathrm{x}_{\mathrm{i}} \geq \mathrm{CO}_{\mathrm{ik}}^{\mathrm{c}} \quad \forall \quad \mathrm{i} \in \mathrm{I}, \mathrm{k} \in \mathrm{K}, \mathrm{c} \in \mathrm{C}$

Assegura que o total de compras do suprimento k, alocados em cada depósito i não ultrapasse o total geral contratual, no cenário $\mathrm{C}$. 
$\cot _{\mathrm{k}}^{\mathrm{c}} \geq \sum_{\mathrm{i}} \mathrm{CO}_{\mathrm{ik}}^{\mathrm{c}} \forall \mathrm{k} \in \mathrm{K}, \mathrm{c} \in \mathrm{C}$

Assegura que a compra do suprimento $\mathrm{k}$ seja realizada somente após o consumo do material estocado e da doação recebidas em i.

$\sum_{\mathrm{i}} \mathrm{CO}_{\mathrm{ik}}^{\mathrm{c}} \leq \sum_{\mathrm{j}} \mathrm{d}_{\mathrm{jk}}^{\mathrm{c}}-\sum_{\mathrm{i}} \mathrm{S}_{\mathrm{ik}}-\sum_{\mathrm{i}} \mathrm{dn}_{\mathrm{ik}}^{\mathrm{c}}+\mathrm{CO}_{-} \mathrm{AUUX} X_{\mathrm{k}}^{\mathrm{c}}$ bigM $\forall \mathrm{k} \in \mathrm{K}, \mathrm{c} \in \mathrm{C}$

Variáveis:

Não negatividade

$\mathrm{S}_{\mathrm{ik}}, \mathrm{T}_{\mathrm{ijk}}^{\mathrm{c}}, \mathrm{F}_{\mathrm{jk}}^{\mathrm{c}}, \mathrm{CO}_{\mathrm{ik}}^{\mathrm{c}} \geq 0 \quad \forall \mathrm{i} \in \mathrm{I}, \mathrm{j} \in \mathrm{J}, \mathrm{k} \in \mathrm{K}, \mathrm{c} \in \mathrm{C}$

Binárias

$\mathrm{X}_{\mathrm{i}}, \mathrm{CO} \_\mathrm{AUX}_{\mathrm{k}}^{\mathrm{c}} \in\{0,1\} \quad \forall \mathrm{i} \in \mathrm{I}, \mathrm{k} \in \mathrm{K}, \mathrm{c} \in \mathrm{C}$

\subsection{Validação do modelo}

Anteriormente ao início da aplicação do modelo, foi realizada a validação técnica e gerencial do modelo, conforme estabelecido por Geoffrion (1976). Numa primeira etapa, foi realizada a verificação técnica, analisando a consistência entre os dados de entrada e os resultados obtidos e se o software adotado manipula os dados de uma maneira matematicamente correta. Neste trabalho, essa verificação foi realizada a partir de execução em escala reduzida do modelo, utilizando poucos materiais (3), executando manualmente o modelo, através de uma planilha do Microsoft ${ }^{\circledR}$ Excel 2010, e comparando com os resultados obtidos pelo software. Foi 
utilizado somente um cenário, as penalidades foram arbitradas e foi considerada a abertura de somente um depósito. As restrições foram inseridas mediante três situações:

- Sem restrições ativas e sem necessidade de compras (modelo aliviado).

- Restrições de capacidade (peso) de transporte ativa e sem necessidade de compra de materiais.

- Restrições de capacidade (peso) de transporte ativa e necessidade de compra de um material.

Após essa etapa foram analisados os resultados obtidos. Os valores obtidos mostraram resultados idênticos entre o modelo e a planilha Excel e, numa análise gerencial, os resultados refletiam valores factíveis. Convém ressaltar que as penalidades não estavam calibradas nessa execução em escala reduzida.

\subsection{Estabelecimento de cenários}

A gravidade dos desastres foi estabelecida de acordo com a magnitude, a extensão e a classificação da Defesa Civil, conforme os níveis II (médio porte), III (grande porte) e IV (catástrofe). O desastre nível I (pequeno porte) não foi considerado, pois a própria comunidade facilmente supera suas consequências, não requerendo, portanto, o abastecimento de suprimentos de alívio por parte da Defesa Civil estadual.

A divulgação em mídia foi considerada em dois níveis (baixa ou alta). Outra consideração são as possíveis rupturas que possam afetar a acessibilidade dos canais de suprimentos aos locais afetados (OLIVEIRA; GONÇALVES, 2013), alterando os custos de transporte e o abastecimento. Para desastres nível II (de médio porte), devido sua própria magnitude, não foram consideradas as rupturas. 
Nos cenários de desastres níveis III e IV, com rupturas, foi considerado também a alta divulgação por parte da mídia.

\subsubsection{Probabilidades dos cenários}

As probabilidades foram estabelecidas com base em painel de especialistas no assunto, principalmente para testes da robustez do modelo.

Foram considerados 8 cenários escolhidos com base:

- Na gravidade dos desastres;

- Na divulgação realizada em mídia sobre o evento;

- Em possíveis rupturas na cadeia de suprimentos.

Para determinação dos valores das probabilidades foi utilizado o método Delphi devido ao anonimato, pois, dentre os especialistas, existia relação de subordinação funcional, o que poderia influenciar as opiniões. O questionário contendo a descrição dos desastres e os cenários foi disponibilizado em website (serviço SurveyMonkey) para especialistas em Defesa Civil, Monitoramento de Desastres, Geologia, Meteorologia, Arquitetura e Jornalismo. De 19 questionários enviados aos especialistas, foram obtidas 9 respostas, compondo desta forma, uma quantidade superior a mínima recomendada à análise (na literatura esse valor mínimo varia entre 5 e 7$)$.

As probabilidades foram adotadas com base na média após a realização de duas rodadas de consultas a experts, de acordo com Rowe e Wright (2001), que recomendam entre 2 a 4 rodadas. Foi realizado teste de hipótese com $\alpha=5 \%$ e não ocorreram diferenças entre as médias da $1^{\text {a }}$ e $2^{\underline{a}}$ rodadas. Essas probabilidades estão relacionadas na Tabela 4.1 e foram assim definidas (entre parênteses está a numeração do cenário): 
Tabela 4.1 - Probabilidades dos cenários.

\begin{tabular}{l|ccc}
\hline & Nível II & Nível III & Nível IV \\
\hline Baixa divulgação & $24,00 \%(1)$ & $8,11 \%(2)$ & $1,00 \%(3)$ \\
\hline Alta divulgação & $26,44 \%(4)$ & $15,33 \%(5)$ & $7,33 \%(6)$ \\
\hline $\begin{array}{l}\text { Alta divulgação pela mídia e } \\
\text { rupturas nos acessos }\end{array}$ & N/A & $13,56 \%(7)$ & $4,22 \%(8)$ \\
\hline
\end{tabular}

Para analisar o efeito de outras medidas de tendência central, em 5.8 Análise de sensibilidade deste trabalho, serão avaliadas também a mediana e a média aparada (outliers z-score 2,12) (COUSINEAU; CHARTIER, 2010) dos valores.

\subsection{Parâmetros considerados na modelagem}

\subsubsection{Parâmetros de primeiro estágio (não dependentes de cenários)}

\subsubsection{Custo de instalação e operação do depósito}

O custo de instalação e operação de um depósito foi estimado com base na necessidade de mão de obra e na aquisição de equipamentos de armazenagem para as instalações. Conforme dimensionamento realizado em conjunto com a equipe de Defesa Civil do estado de São Paulo, para cada novo depósito instalado no interior do estado existe a necessidade de $25 \%$ da jornada de trabalho de um militar (posto: soldado) dedicado apenas à gestão do estoque de suprimentos de alívio em períodos normais (sem desastres). Os equipamentos de armazenagem e movimentação foram estimados conforme a área disponível no depósito central (São Paulo) com capacidade para 120 posições palete e equipamento de movimentação 
e pesagem, conforme FDEM (2005) (normas do estado norte-americano da Flórida). Os valores de custo de instalação tomados com base em Frazelle e Sojo (2006) equivale a 40 dólares por posição (cotação US\$1 = R \$2,3 - novembro 2013).

Para o depósito de São Paulo, devido à atual existência de mão de obra para sua operação, foi considerado um incremento de apenas 10\% nesta mão de obra para controle de entrada e saída de materiais. Os valores referentes a esse parâmetro estão relacionados no Apêndice 2.

\subsubsection{Quantidade total disponível e nível mínimo anual de estoque}

A quantidade de estoque disponível foi obtida com base no histórico anual de movimentações de materiais do estoque central da Defesa Civil do estado de São Paulo (SÃO PAULO, 2012a). Considerando o período de 2004 a 2012, foi obtida a média das máximas movimentações para cada item no período. Os valores referentes a esse parâmetro, assim como os valores de aquisição dos produtos e a média histórica dos estoques, estão relacionados no Apêndice 2.

A informação sobre o nível mínimo de estoque em cada depósito não se encontra disponível e foi arbitrada em $20 \%$ da quantidade de estoque disponível para os possíveis depósitos situados no Vale do Paraíba e 50\% para o depósito central de São Paulo.

\subsubsection{Capacidade nominal de armazenagem}


Para o armazém de São Paulo foi considerada uma capacidade nominal de 120 posições palete e um peso de $1.200 \mathrm{~kg}$ para cada palete (total 144 toneladas), similar à capacidade atual do depósito. Para cada depósito a ser instalado no interior foi considerada, com base em informações da Defesa Civil, 25\% da capacidade do depósito de São Paulo. Em situações de desastre essa capacidade é ampliada, através do parâmetro de $2^{\circ}$ estágio capacidade incidental, podendo ser utilizada outras áreas para recebimento, triagem, formação de kits e embalagem de doações e materiais comprados.

\subsubsection{Quantidade de depósitos a serem abertos}

O modelo elaborado, diferentemente dos outros modelos de localização de instalações humanitárias, pode localizar uma quantidade de depósitos previamente estabelecida, oscilando entre um e o total de locais candidatos a depósitos. Neste modelo foram estabelecidos esses limites para avaliação de resultados entre 1 e 5 depósitos, o que proporciona 31 soluções possíveis (5 locais candidatos entre 1 e 5 locais escolhidos).

\subsubsection{Matriz de cobertura}

A partir de uma distância máxima de 200 km entre o depósito e o ponto de demanda foi elaborada a matriz binária que assume 1 , se a distância é menor que a distância máxima, e 0 em caso contrário. $O$ Apêndice 3 relaciona os valores das distâncias. 


\subsubsection{Parâmetros de segundo estágio (dependentes de cenários)}

\subsubsection{Custo de Transporte}

Para obtenção dos custos de transporte dos suprimentos de alivio do depósito ao ponto de demanda foi considerada linearidade dos valores de custos em função da distância, com base nos trabalhos de Correa Jr (2001), que obteve uma relação linear para estimativa de cálculo de frete agrícola em função da distância, com um coeficiente de correlação $\left(R^{2}\right)$ de 0,94; e Martins e Caixeta Filho (1999), que estimaram custos de frete por funções lineares, também encontrando uma relação entre a distância percorrida e o preço do frete rodoviário no estado do Paraná para transporte de commodities agrícolas (milho, soja, farelo de soja e trigo). Nestes trabalhos a base utilizada foi o Sifreca (Sistema de Informações de Fretes) da Escola Superior de Agricultura "Luiz de Queiroz" (Esalq-Log), que avalia os valores de frete longo das cadeias agroindustriais.

Para a estimativa de valores para custos de transporte foi considerada esta linearidade e realizadas avaliações do Sifreca (2012) e, também, da Câmara Técnico Econômica da Associação Nacional de Transporte de Cargas e Logística (NTC, 2012) referentes aos valores de frete de transferência. Apesar de funções muito semelhantes, existindo uma correlação linear entre elas, os dados da NTC apresentaram um coeficiente de correlação $R^{2}=0,96$, enquanto o Sifreca apresentou $R^{2}=0,76$. A diferença pode ser explicada pelo fato do Sifreca considerar diversas commodities agrícolas durante diferentes períodos do ano com relações de oferta/demanda distintas para o frete, inclusive valores reduzidos em viagens de retorno, o que impacta a coeficiente de correlação na linearidade da função.

Foi aplicada, então, para cálculo do custo de transporte, a regressão linear referente aos dados de referências da NTC, pois representam valores relativos a dados comerciais de frete. Os resultados foram obtidos inserindo-se a distância como 
parâmetro de entrada da regressão. A fim de evitar valores muito baixos para entregas numa mesma localidade, foi considerado um valor mínimo de frete referente à distância de $50 \mathrm{~km}$, mesmo para uma distância inferior (pagamento por viagem).

A regressão linear obtida pode ser expressa através da seguinte equação (custo do transporte em $\mathrm{R} \$$ / ton, distância em $\mathrm{km}$ ):

Custo do transporte $=0,11214 \times$ distância +40.96494

As distâncias entre os possíveis depósitos e os pontos de demanda foram calculadas com base na distância geodésica, multiplicada por um fator de circuito de 1,23 (BALLOU, 2006). Para os cenários com rupturas, uma diferenciação considerada foi um acréscimo de 30\% nas distâncias, com base no acréscimo na utilização de vias alternativas para abastecimento à região da Serra da Mantiqueira (cidade: Campos do Jordão) e da Serra do Mar (cidade: Natividade da Serra). O Apêndice 3 relaciona esses valores das distâncias.

\subsubsection{Penalidade por unidade não fornecida}

A penalidade pelo não atendimento da demanda exerce papel fundamental nos resultados do modelo, principalmente no EVPI e VSS. Esse parâmetro necessita ser calibrado através de análise de sensibilidade para estabelecimento de seus limites. O Capítulo 5 Resultados do Modelo Estocástico e Análise detalha a avaliação realizada e os limites aferidos. O objetivo desse parâmetro é inviabilizar a falta de materiais, fazendo com que essa falta somente ocorra após o modelo utilizar todo o material disponível em estoque, doações e compras.

O limite inferior para um valor de penalidades é o maior custo de transporte entre as localidades, pois, abaixo desse valor existe a possibilidade de que o modelo possa 
viabilizar a falta. As penalidades foram estabelecidas como valores múltiplos do custo de transporte, partindo do maior valor. Outras formas de estabelecimento desse parâmetro são: através do valor do produto, conforme Rawls e Turnquist (2012); número de pessoas em risco por produto não atendido, conforme Salmerón e Apte (2010); ou ainda, mediante a maior necessidade do produto para a sobrevivência humana. $\mathrm{Na}$ análise de sensibilidade $\mathrm{o}$ valor do produto foi também considerado para valor de penalidade.

\subsubsection{Doações}

As quantidades doadas foram estimadas a partir do trabalho de Kawasaki et al. (2012), que avaliou as doações na inundação ocorrida no Vale do Paraíba, principalmente, nas cidades de São Luiz do Paraitinga e Guaratinguetá, no ano de 2010, que tiveram grande divulgação por parte da mídia (FARIAS, 2010; BOCCHINI, 2012; BRANCATELLI, 2010; ISKANDARIAN, 2010; NOVE MIL, 2010). As doações encaminhadas ao Centro de Triagem estabelecido corresponderam, em peso, a 6,87 vezes o estoque disponível pela Defesa Civil e a capacidade de armazenagem da Defesa Civil e Polícia Militar Estadual foram esgotadas (WESTPHALEN, 2010). Mediante essa grande repercussão de mídia, as doações, controladas pela Defesa Civil, totalizaram 450,5 toneladas distribuídas em roupas e calçados (51,5\%); água potável (32,6\%); alimentos (13,5\%); material de higiene pessoal e limpeza $(2,2 \%)$; e colchões $(<0,1 \%)$. O conceito mídia pode ser dividido em individual; comunitária; local; regional; nacional; e global (HJARVARD, 2012), conforme o nível de abrangência (HOUSTON; JPFEFFERBAUM; ROSENHOLTZ, 2012). Neste trabalho, foi considerada uma cobertura, ao menos regional, para a formação dos cenários.

Pode-se observar que as doações estão concentradas em roupas e calçados. Segundo Kawasaki et al. (2012), foram doados 340.000 itens somente para São Luiz do Paraitinga, município que possui uma população de 10.397 habitantes (IBGE, 
2010). Esse montante doado corresponde a 32,7 itens de vestuário para cada habitante, um excesso que, muitas vezes, é descartado após longo período sem utilização (PUPO, 2012). Outro aspecto relevante sobre doações é o estímulo provocado por uma extensa cobertura de mídia, como ocorrido no terremoto do Haiti, em 2010 (BESIOU; STAPLETON; VAN WASSENHOVE, 2011), proporcionando uma grande quantidade de materiais não solicitados, que congestionaram os canais logísticos, gerando gargalos e dificuldades no manuseio de materiais, com consequentes atrasos na operação de resposta.

No processo de modelagem somente foram consideradas doações para os itens destinados à população desabrigada/desalojada, assumindo que, para os itens destinados às equipes de socorro, sob responsabilidade do município (COMDECs), não existem doações. Para os cenários com grande divulgação de mídia foi considerado o mesmo nível de doações ocorridas no evento de São Luiz do Paraitinga para agasalho, camiseta, cesta básica, cobertor, colchão, colete, kit higiene, kit limpeza, lençol e tênis. São Paulo concentra 50\% das doações e o restante é distribuído igualmente entre os demais depósitos. Para os cenários com baixa divulgação de mídia foi arbitrado $10 \%$ desse valor. O Apêndice 7 descreve os valores por cenários, materiais e depósitos.

\subsubsection{Demanda de materiais}

Imediatamente após a ocorrência de um desastre (fase de resposta), os materiais enviados devem atender a dois objetivos fundamentais (COZZOLINO, 2012) que são: a restauração ou ativação de redes de abastecimento e de utilidades; e o atendimento ao maior número de vítimas possível, observando regras de necessidades humanas para sobrevivência. A capacidade e os gargalos na rede de abastecimento determinam as prioridades e, consequentemente, a demanda que pode diferir de necessidade (GOENTZEL, 2012), por exemplo, nas horas imediatamente após um desastre, alimento pode ser uma necessidade, entretanto pode não ocorrer esse abastecimento, pois material hospitalar e água são 
prioritários à sobrevivência humana. Lamont-Gregory; Henry e Ryan (1995) compilaram artigos sobre a resistência de um ser humano adulto no pós-desastre. A Tabela 4.2 apresenta o resultado deste estudo. Afirmam que essas regras de sobrevivência devem ser observadas na priorização do abastecimento.

Tabela 4.2 - Tempo de sobrevivência humana.

\begin{tabular}{|c|c|c|}
\hline Condição & Tempo de sobrevivência & Considerações \\
\hline $\begin{array}{l}\text { Sem abrigo } \\
\text { aquecimento }\end{array}$ & Entre 1 a 2 dias & $\begin{array}{l}\text { O metabolismo é alterado em } \\
\text { temperaturas abaixo de } 23^{\circ} \mathrm{C}\end{array}$ \\
\hline Sem água & Entre 2 a 3 dias & $\begin{array}{l}\text { Fatalidade com perda de } 30-40 \% \text { da } \\
\text { água corporal. }\end{array}$ \\
\hline Sem alimentação & $\begin{array}{l}14 \text { dias (em casos extemos } \\
\text { até } 68 \text { dias) }\end{array}$ & $\begin{array}{l}\text { Valores são menores em caso de } \\
\text { crianças }\end{array}$ \\
\hline
\end{tabular}

Fonte: Lamont-Gregory; Henry e Ryan (1995)

A estimativa de demanda em um desastre é uma informação pouco estruturada (VAN WASSENHOVE; ALLEN, 2012). É influenciada pelo risco do local e afetada diretamente pela vulnerabilidade e pelo perigo. $O$ fato de uma habitação estar em situação de vulnerabilidade representa uma potencial demanda por suprimentos de alívio, não constituindo uma demanda efetiva.

Os materiais e o cálculo da demanda são baseados no Projeto Esfera (THE SPHERE PROJECT, 2011) no Manual de Emergências do United Nations High Commissioner for Refugees (UNHCR, 2007) e no histórico de entidades, cuja missão é atuar em ajuda humanitária, como a Defesa Civil e WFP. A quantidade de suprimentos de alívio foi dimensionada com base na necessidade para atendimento aos 15 primeiros dias após o evento, especialmente inundações e deslizamentos, que possuem maior histórico de ocorrências. Esse tempo é baseado em um estoque mínimo para abastecimento aos desabrigados e desalojados (AKKIHAL, 2006), permitindo, assim, a existência de um tempo de reação para aquisição e chegada de suprimentos e um maior volume de doações. No Apêndice 1 desta tese, são relacionadas as quantidades por tipo de material. 
De acordo com a Defesa Civil do estado de São Paulo (PAIVA, 2012), os materiais ainda são classificados conforme o tipo de usuário: que podem ser os destinatários da ajuda (população vitimada) ou as equipes de resposta que se destinam ao local para prestação da ajuda humanitária.

Neste caso, os materiais são divididos em:

- Materiais destinados à população vitimada:

○ De uso individual: agasalhos, camiseta, cobertor, colchão, lençol, tênis.

- Por residência (estimado a partir de 4 pessoas/residência): cesta básica, kit higiene e kit de limpeza.

- Materiais destinados às equipes de resposta: bota, capa de chuva, capacete, colete, luva (1 para cada membro da Defesa Civil). Itens como fita para isolamento, lona plástica e pluviômetro são estimados de acordo com o porte da cidade e, neste trabalho, foi baseado em histórico de suprimento fornecido pela Defesa Civil (SÃO PAULO, 2012). Pelo menos 10 kits destes materiais foram considerados para cada município.

A demanda relativa aos desabrigados e desalojados foi obtida a partir do cálculo da população em risco. Os dados demográficos, que serviram de referência para cômputo desta população em risco, foram extraídos do Censo 2010 (IBGE, 2010).

Nas localidades que possuem um mapeamento de risco elaborado (SÃO PAULO, 2012) consta o número de domicílios em situação de risco muito alto, alto, médio e baixo. A população em risco para cada classificação foi obtida através da multiplicação deste valor pela quantidade média de habitantes por domicílio do município (IBGE, 2010). Dos 35 municípios do Vale do Paraíba, 23 possuem o mapeamento de risco elaborado (em janeiro de 2014), o que totaliza $65,7 \%$ dos municípios em estudo, contudo os municípios mais populosos estão mapeados, o que representa $90,6 \%$ da população total da região.

Nos mapeamentos, os riscos são classificados em baixo, médio, alto e muito alto, conforme Tominaga; Santoro e Amaral (2009) e de acordo com as peculiaridades 
geodinâmicas do município. Com base nessa classificação, para estimativa da demanda conforme os cenários, inicialmente foi calculada a população em situação de vulnerabilidade. Para os desastres Nível II foram consideradas as residências situadas em risco muito alto e alto; desastres Nível III as residências situadas em risco muito alto, alto e médio; e Nível IV as residências situadas em risco muito alto, alto, médio e baixo. Para as demais localidades do Vale do Paraíba, que não possuem mapa de risco, utilizou-se uma projeção de estimativa através de regra de três simples em função do total da região, considerando que cada município não mapeado segue a proporção total da região. Esta projeção foi menor que $10 \%$ da população total da região. A partir da deteç̧ão da população vulnerável partiu-se para a estimativa de demanda. O mapeamento de risco destaca a cidade de Guaratinguetá, como a que possui a maior população absoluta em situação de risco na região, e as cidades de Aparecida; Cunha; Paraibuna; e São Luís do Paraitinga, com valores superiores a $10 \%$ da população total residente em área de risco. $O$ mapeamento de risco do município de Campos do Jordão não detalha precisamente a quantidade de residências em áreas de risco, entretanto em discussões com a Defesa Civil e especialistas em Geologia, a cidade possui elevado potencial de risco, especialmente deslizamentos.

A estimativa da demanda foi baseada levando-se em consideração dois eixos. Num primeiro eixo a quantidade de pessoas em situação de vulnerabilidade, e num segundo eixo a magnitude do desastre e consequente dano que pode causar (perigo e dano potencial). Duas metodologias podem ser utilizadas para esta estimativa: uma tomando por base o histórico de consumo em desastres anteriores, outra através da multiplicação da população por um fator de ponderação. Neste trabalho a utilização de fator de ponderação mostrou-se mais confiável, apesar da existência de histórico, porém não era possível assegurar que esse histórico de fornecimento correspondesse a uma demanda efetiva.

Balcik e Beamon (2008), através da multiplicação das pessoas em situação de vulnerabilidade por um fator de ponderação, obtiveram uma estimativa de demanda, conforme o tipo de desastre e de material. Para Duran; Gutierrez e Keskinocak 
(2011), que também utilizaram fatores, estes valores foram de $0,75,0,5$ e 0,25, conforme as probabilidades de ocorrência alta, média e baixa respectivamente.

Neste trabalho, para desastres Nível IV (ou catástrofe) este fator foi alterado para 1, indicando que, para este tipo de desastre, toda a população vulnerável de todas as cidades da região seria afetada. Para os demais desastres, além das pessoas em situação de vulnerabilidade, é considerado que nem todas as cidades seriam atingidas, portanto a demanda não seria integral. Para estes casos foram adotados os mesmos valores de Duran; Gutierrez e Keskinocak (2011): 0,5 para desastres Nível III e 0,25 para desastres Nível II.

A Tabela 4.3 resume a estimativa da população que seria afetada por desastres num horizonte de 5 anos na região do Vale do Paraíba, utilizada como referência para cálculo da quantidade de materiais e o somatório da demanda total, conforme a magnitude do desastre e o fator de ponderação. A partir do número de vítimas encontrado é calculada a demanda para a região do Vale do Paraíba, respectivamente para desastres níveis II, III e IV, conforme a quantidade relacionada na Tabela 4.4 - Resumo das necessidades de materiais.

Tabela 4.3 - Estimativa da população afetada por desastres e demanda total.

\begin{tabular}{lrrr}
\hline $\begin{array}{c}\text { Magnitude do } \\
\text { desastre }\end{array}$ & \multicolumn{1}{c}{$\begin{array}{c}\text { II } \\
\text { (médio porte) }\end{array}$} & $\begin{array}{c}\text { III } \\
\text { (grande porte) }\end{array}$ & \multicolumn{1}{c}{$\begin{array}{c}\text { IV } \\
\text { (catástrofe) }\end{array}$} \\
\hline População afetada & 3.995 & 13.920 & 43.378 \\
\hline Demanda total $\mathbf{( k g )}$ & 55.195 & 188.966 & 585.853 \\
\hline
\end{tabular}

Outros métodos para estimar a demanda também foram avaliados. Akkihal (2006) utilizou dados históricos de desabrigados e desalojados devido a desastres naturais, prevendo uma demanda de materiais. Neste trabalho essa metodologia não foi adotada, devido à baixa disponibilidade de histórico de informações sobre desabrigados e desalojados.

Outra maneira de realizar essa estimativa da população em risco é a utilização dos dados do relatório de Vulnerabilidade Social e de Habitação - Existência de Áreas de 
Risco com Moradias (SEADE, 2012) do estado de São Paulo e a utilização das considerações de Confalonieri (2003) e Valencio et al. (2009), que vinculam a população brasileira socialmente mais vulnerável a uma susceptibilidade maior a desastres. A Fundação Seade divide a população conforme as seguintes vulnerabilidades sociais: nenhuma vulnerabilidade; vulnerabilidade muito baixa; vulnerabilidade baixa; média vulnerabilidade; vulnerabilidade alta; vulnerabilidade muito alta. Esta metodologia foi avaliada, porém não foi adotada devido à inexistência de informações para transformação das informações sobre vulnerabilidade social em situação de vulnerabilidade a desastres.

Quando não existem dados sobre vulnerabilidade, também é possível utilizar a metodologia abordada por Souza (2012), que avalia o risco em função da área do município e sua população, levando em consideração o perímetro e a população urbanos de uma localidade para avaliação do adensamento. Essa metodologia foi adotada para estimativa de demanda em municípios do estado de Santa Catarina. Outra metodologia, não quantitativa, a partir da população de uma região, é a de utilizar um painel de especialistas para estimar uma eventual demanda em casos de desastres (APTE, 2009).

A Tabela 4.4 resume os materiais; seus usuários, que podem ser a população desalojada/desabrigada ou os organismos de Defesa Civil Municipal (COMDECs); as opções de distribuição; e a quantidade de cada item distribuído. 
Tabela 4.4 - Resumo das necessidades de materiais.

\begin{tabular}{|c|c|c|c|c|c|}
\hline Item & Descrição & & Usuário & Distribuição & Qtde \\
\hline 1 & Agasalho & & População & Individual & 2 \\
\hline 2 & Bota & & COMDEC & Individual & 1 \\
\hline 3 & Camiseta & & População & Individual & 2 \\
\hline 4 & Capa de chuva & & COMDEC & Individual & 1 \\
\hline 5 & Capacete & & COMDEC & Individual & 1 \\
\hline 6 & Cesta Básica & & População & Familiar & 1 \\
\hline 7 & Cobertor & & População & Individual & 1 \\
\hline 8 & Colchão & & População & Individual & 1 \\
\hline 9 & Colete & & COMDEC & Individual & 1 \\
\hline 10 & Fita isolamento & & COMDEC & Município & 1 \\
\hline 11 & Kit Higiene & $\begin{array}{ll} & \text { (composição) } \\
2 & \text { cremes dentais } \\
4 & \text { sabonetes } \\
4 & \text { escovas dentais } \\
1 & \text { xampu }\end{array}$ & População & Familiar & 1 \\
\hline 12 & Kit Limpeza & $\begin{array}{l}\text { (composição) } \\
1 \text { alvejante } \\
2 \text { baldes } \\
1 \text { esponja } \\
1 \text { par de luvas } \\
1 \text { pá de lixo } \\
2 \text { panos de chão } \\
1 \text { rodo } \\
2 \text { sabões } \\
5 \text { sacos de lixo de 60 I } \\
1 \text { vassoura }\end{array}$ & População & Familiar & 1 \\
\hline 13 & Lençol & & População & Individual & 1 \\
\hline 14 & Lona plástica & & COMDEC & Município & 1 \\
\hline 15 & Luva & & COMDEC & Individual & 1 \\
\hline 16 & Pluviômetro & & COMDEC & Município & 1 \\
\hline 17 & Tênis & & População & Individual & 1 \\
\hline
\end{tabular}

Todos os materiais foram pesados e mensurados no depósito da Defesa Civil do Estado de São Paulo e sua demanda convertida em massa e volume para inserção no modelo. No Apêndice 2 estão relacionados os pesos unitários de cada material e no Apêndice 8 encontra-se detalhada a demanda de cada material por cidade, conforme o cenário. 


\subsubsection{Capacidade incidental de armazenagem}

Este parâmetro refere-se a uma capacidade adicional para armazenamento de materiais, criada somente em situações de desastres. São locais, geralmente, próximos aos locais de desastres, transformados em áreas de processamento, triagem e distribuição de materiais. Geralmente são áreas públicas, de organizações de ajuda ou entidades religiosas e podem ser citados como exemplos, escolas, ginásios de esportes, templos e quartéis (CARNEIRO et al., 2013). Para determinação destes valores, inicialmente, foi realizada uma tentativa com base em histórico, porém tais informações eram difusas e não permitiram atribuição de valores confiáveis. Em discussões com equipe de gestão de estoque da Defesa Civil, foi arbitrado um valor de 50\% (72 toneladas) da capacidade de armazenagem para desastres magnitude II (somente para o depósito de São Paulo), 100\% (144 toneladas) para os de magnitude III, e 500\% (720 toneladas) para os de magnitude IV (para todos os depósitos).

\subsubsection{Capacidades de transporte}

A capacidade de transporte foi calculada com base em, pelo menos, um caminhão, tipo truck, disponível para municípios com até 50.000 habitantes, atingido por desastres Nível II, com capacidade para 12 toneladas e 69,12 $\mathrm{m}^{3}$. Este valor foi obtido através de histórico de fornecimento do depósito de São Paulo. Para cidades maiores foi considerado uma capacidade de três veículos. Para os desastres Níveis III e IV, considerando-se uma mobilização maior, essas capacidades foram ampliadas, multiplicando-se por 4 e 12 respectivamente, também com base em histórico. 


\subsubsection{Parâmetro binário referente à acessibilidade do depósito potencial}

Parâmetro binário referente à acessibilidade do depósito potencial a um ponto de demanda (1 - acessível, 0 - não acessível). Foi considerado que um desastre, no qual ocorram rupturas (OLIVEIRA; GONÇALVES, 2013), obtenha alta divulgação por parte da mídia e que somente nos desastres Níveis III e IV essas rupturas venham a ocorrer. Nos cenários em que foi avaliada a ruptura, para os desastres nível III foi considerado que os arcos originados de um depósito foram rompidos, e para os de nível IV foi considerado que os arcos originados de dois depósitos foram rompidos.

\subsubsection{Demanda mínima de materiais}

O parâmetro demanda mínima de materiais é necessário para evitar que o modelo deixe de abastecer locais mais distantes em função da função objetivo, que minimiza os custos totais. Em conjunto com o pessoal da Defesa Civil, essa demanda mínima foi estimada entre $20 \%$ da demanda para os desastres níveis II e III e $5 \%$ da demanda para os desastres nível IV.

\subsubsection{Compras emergenciais}

Este parâmetro considera um limite superior (por questões orçamentárias) para compras, com valores previamente negociados pela Defesa Civil do Estado de São 
Paulo, conforme a legislação de compras públicas (também denominada Lei № 8.666) (BRASIL, 1993). Atualmente, existem contratos do tipo "Ata de Preços" para aquisição de materiais, conforme a ocorrência da demanda, regidos pela legislação de compras públicas. Caso não ocorra a demanda não são adquiridos tais materiais. Esse parâmetro foi estabelecido com base em um orçamento de $R \$ 1.000 .000,00$ (1 milhão de reais disponível para essas aquisições no ano de 2013) para desastres com baixa divulgação de mídia e um incremento para $R \$ 1.700 .000,00$ (1 milhão e setecentos mil reais) para desastres com alta divulgação de mídia. Os valores foram distribuídos proporcionalmente à média histórica dos estoques. Essa quantidade de materiais encontra-se detalhada no Apêndice 4 deste trabalho.

\subsubsection{Parâmetros de segundo estágio (não dependentes de cenários)}

\subsubsection{Fator de conversão peso $X$ volume}

Dentre os materiais, a relação peso $X$ volume é variada e uma avaliação somente por um destes fatores pode levar a considerações incorretas nas avaliações de capacidades. Esse parâmetro foi inserido para que o modelo seja capaz de avaliar a capacidade de peso e volume, através da multiplicação do peso pelo valor do parâmetro. Foi obtido por meio de trabalho de campo realizado no depósito central da Defesa Civil do Estado de São Paulo, onde todos os materiais foram pesados e mensurados.

\subsubsection{Número grande (bigM)}


Foi estabelecido o valor mínimo que proporcionou um desempenho satisfatório do modelo e o funcionamento das equações que utilizam o parâmetro. Para os cenários com maior demanda e quantidade de doações a totalização dos parâmetros e variáveis nas equações com a existência do bigM foi de 6,6 $\times 10^{6}$. Foi adotado, então, $7 \times 10^{6}$ para o processo de modelagem com as restrições ativas. Durante a fase de testes iniciais do modelo, quando foram aliviadas as restrições, os resultados das variáveis foram maiores e valor de bigM foi de $10^{9}$. Nesta tese, em 5.1 Resultados computacionais: operação do modelo, são também mostrados os tempos de execução do modelo em função do bigM.

Fechamento do capítulo

Neste capítulo foi descrito o modelo estocástico de programação linear para localização de instalações para armazenagem de suprimentos de alívio. Em seguida, a aplicação do modelo desenvolvido, a descrição dos cenários estocásticos e a forma de obtenção dos parâmetros foram detalhadas com o objetivo de demonstrar o desenvolvimento e a implementação do modelo. 


\section{Resultados do Modelo Estocástico e Análise}

Neste capítulo são apresentados os resultados obtidos pelo modelo. Ao final do texto, conclusões, principalmente, sobre as capacidades da Defesa Civil são exibidas.

\subsection{Resultados computacionais: operação do modelo}

O modelo foi implementado empregando o software AIMMS 3.13, utilizando o solver CPLEX 12.5, em processador Intel Core 2 Quad® Q9650 CPU 3GHz, 4 Gb RAM, sistema operacional de 32 bits, em ambiente Windows $7 \AA$.

Os tempos e detalhes da execução dos modelos estocástico e determinístico foram distribuídos conforme a Tabela 5.1:

Tabela 5.1 - Tempos e detalhes da execução.

\begin{tabular}{lrr} 
& Estocástico & Determinístico \\
\hline Tempo de Execução & $18,92 \mathrm{~s}$ & $0,28 \mathrm{~s}$ \\
Variáveis & 29.470 & 3.766 \\
Variáveis inteiras & 141 & 22 \\
Não zeros & 213.467 & 27.261 \\
Restrições & 15.812 & 2.176 \\
Iterações & 35.155 & 2.656 \\
\hline
\end{tabular}

Análise e ajuste do parâmetro bigM (número grande): 
O parâmetro bigM influenciou o tempo de solução do problema, justificando o ajuste inicial de $7 \times 10^{6}$ para o modelo estocástico e $10^{9}$ para o modelo totalmente aliviado. Foi testado em diversas ordens de grandeza até próximo ao limite do software $\left(10^{20}\right)$ e os tempos de resolução comparados.

Os resultados para a execução sequencial dos modelos Estocástico, Estocástico wait and see, Determinístico e Estocástico modificado foram os observados na Tabela 5.2:

Tabela 5.2 - Alteração do tempo de execução em função de M.

\begin{tabular}{cc} 
Valor de M & $\begin{array}{c}\text { Tempo de } \\
\text { Execução (s) }\end{array}$ \\
\hline $7 \times 10^{6}$ & 38,51 \\
$7 \times 10^{9}$ & 46,82 \\
$7 \times 10^{12}$ & 47,97 \\
$7 \times 10^{19}$ & 84,63 \\
\hline
\end{tabular}

\subsection{Calibração das penalidades}

As penalidades pelo não atendimento da demanda são estabelecidas mediante uma calibração do modelo (Mete e Zabinsky, 2010), verificando o impacto desse valor nos resultados, principalmente no EVPI e VSS. Apesar de possuir uma unidade monetária, diferentemente de custos como transporte, compras e mão de obra, não há um desembolso efetivo para a penalidade, podendo provocar uma característica de imaterialidade a esse custo em uma análise por parte do tomador de decisão. Neste modelo os objetivos dessa calibração é fazer com que a falta somente ocorra devido às restrições do modelo, inviabilizando o não abastecimento de materiais, não produzindo com isso resultados indesejados, assim como proporcionar valores de penalidades compatíveis com os demais custos resultantes. 
Rawls e Turnquist (2010, 2011, 2012), Noyan (2012), Mete e Zabinsky (2010) e Bozorgi-Amiri; Jabalameli e Mirzapour Al-e-Hashem (2013) vinculam as penalidades ao valor do produto. Este tipo de penalização é válido para cadeias de suprimentos empresariais, em que o lucro e o custo de estoque são calculados em relação ao valor do produto. Na cadeia humanitária, fatores como sofrimento humano, conforme Holguín-Veras et al. (2013), devem ser considerados e o valor do material não contém essa característica, portanto não seria adequado para esta modelagem. Neste trabalho, a penalidade é considerada a mesma para todos os produtos e o custo de transporte foi escolhido como um valor de referência inicial. O maior custo de transporte entre as localidades é limite inferior inicialmente estabelecido, pois, abaixo desse valor o modelo viabiliza a falta, uma vez que para a localidade, o custo do não abastecimento é menor que o custo de transporte. Com base em valores múltiplos do custo de transporte, foi testado o modelo e observado o comportamento dos resultados, principalmente nas quantidades de faltas e nos valores de EVPI e VSS. Esses valores múltiplos foram de 1 a 10.000 vezes o maior custo de transporte. O alto valor para o limite superior é atribuído para verificação do comportamento do modelo nessa faixa de valores, da mesma forma que realizado em Barbarosoglu e Arda (2004). A Figura 20 ilustra o comportamento do total de depósitos abertos e das faltas em função das penalidades. 


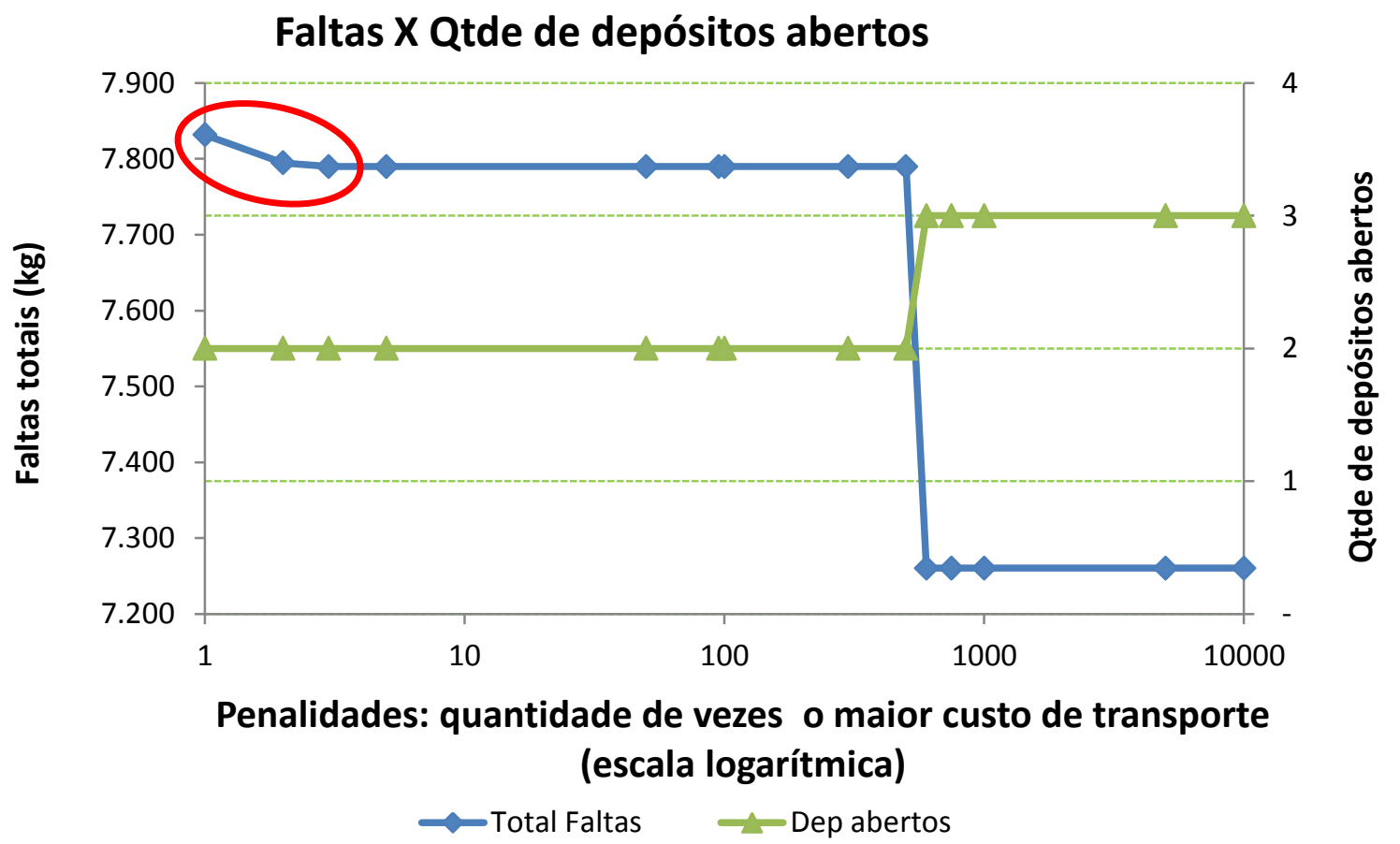

Figura 20 - Total de faltas e depósitos abertos em função da penalidade.

Observa-se que, até na faixa de 1 a 3 vezes o maior custo de transporte (em destaque), o nível de faltas é maior que os demais valores. Com dois locais abertos, devido à restrição de cobertura, materiais deixam de ser distribuídos. Em uma análise sobre o comportamento das faltas, nesses valores de penalidades baixos (1 a 3), em cenários com maior demanda, locais mais distantes (Bananal) deixaram de ser abastecidos. Em cenários com menor demanda, ocorreram diferenças na alocação, entretanto o total de faltas não foi alterado. Nessa faixa, o custo de não abastecer ainda é viável economicamente. Desta forma, 3 vezes o maior custo de transporte foi o limite inferior estabelecido para as penalidades. A partir desse valor, o nível de faltas permanece estável até a abertura de mais um depósito. Entre 500 e 600 vezes é aberto mais um depósito. Isso indica que até esse nível havia restrição, impedindo que materiais disponíveis fossem utilizados. A restrição, nesse caso, era a soma de capacidade de armazenagem e capacidade incidental. Uma análise específica sobre faltas em cada cenário é realizada em 5.7 Análise de faltas. 
A Figura 21 ilustra o comportamento do VSS e EVPI, em função das penalidades, e exibe a quantidade de depósitos abertos pela RP.

Observando o comportamento do EVPI e do VSS, é possível verificar que o EVPI, a partir de 95 vezes o maior custo de transporte, tem um comportamento ascendente e depois volta a cair. Isso ocorre porque a solução WS (wait-and-see) para cálculo do EVPI abre depósitos por cenários e, a partir de penalidade igual a 95 vezes o maior custo de transporte, inicia a abertura de mais um depósito em alguns cenários, aumentando a diferença dos custos fixos entre a solução do problema obtida sob incerteza (recourse problem - RP) e a solução obtida, caso tivesse a capacidade de fazer a previsão perfeita (WS), indicando uma redução na acomodação das incertezas. Essa abertura de depósitos aumenta conforme aumenta o valor da penalidade e, consequentemente, o EVPI, até que o terceiro depósito é aberto pela solução estocástica (RP). A partir deste ponto é observada a queda do valor do percentual do EVPI (valor absoluto permanece), pois é mantida a mesma quantidade de depósitos nas 2 soluções e, conforme o valor da penalidade aumenta, a parcela dos custos fixos de abertura é reduzida proporcionalmente no custo total, passando o custo de penalidade representar cada vez mais uma maior parcela do custo total. O Apêndice 5 mostra a quantidade aberta de depósitos por cenários pelas soluções RP e WS.

O VSS apresenta uma tendência logarítmica crescente com variações nessa tendência nos pontos de mudança da quantidade de depósitos abertos. Isso ocorre porque, em todas as situações, a solução determinística abre somente 2 depósitos. Comportamento similar do VSS também foi obtido por Salmerón e Apte (2010) e Noyan (2012). 


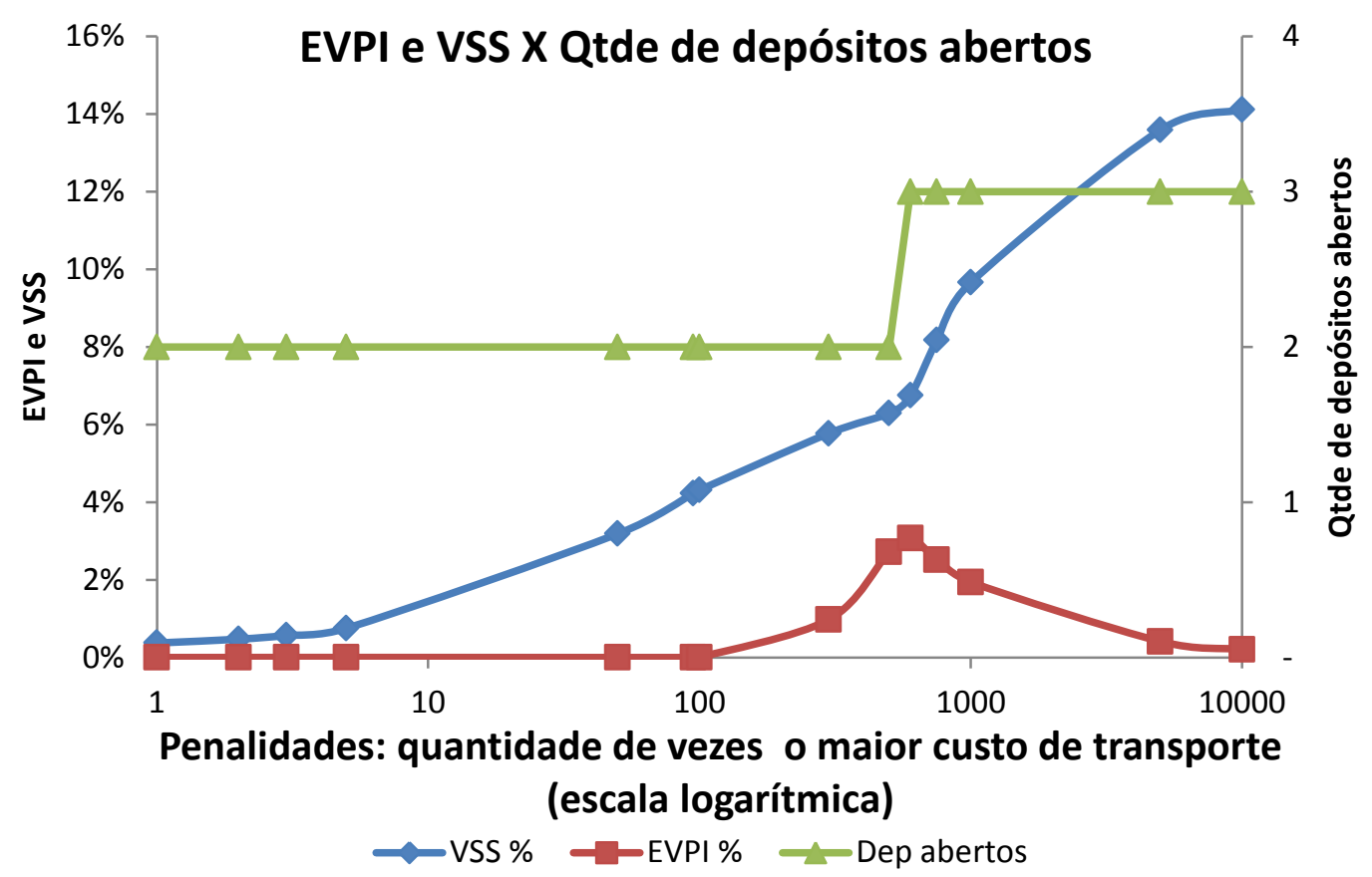

Figura 21 - VSS e EVPI em função das penalidades.

Com base no exposto, é possível assumir que a penalidade entre 3 e 95 vezes o valor máximo do custo de transporte produz resultados equivalentes. Acima desse valor o EVPI é alterado e valores muito elevados podem levar a resultados de penalidade elevados em comparação aos demais custos. Quanto mais alto o valor da penalidade maior é o valor do VSS. Com base na análise, neste trabalho para análises posteriores, foi adotado o valor de 95 vezes o maior custo de transporte. Alterações nesse valor, assim como no padrão de penalização, são avaliadas em 5.8 Análise de sensibilidade.

\subsection{Solução determinística}

Na solução determinística os valores obtidos, utilizando a média ponderada dos parâmetros, para um horizonte de cinco anos, e um valor de penalidade igual a 95 vezes o valor do frete, o custo fixo de abertura é o maior componente do custo total. 
Esse resultado (Tabela 5.3) decorre, principalmente, das restrições de atendimento. No modelo determinístico, no qual socorre à redução das faltas devido à ponderação dos parâmetros, o custo das penalidades não é elevado.

Tabela 5.3 - Resultados do modelo determinístico.

\begin{tabular}{|l|r|}
\hline & $\begin{array}{c}\text { Modelo Determinístico } \\
\text { (R\$) }\end{array}$ \\
\hline Custo Fixo & $80.864,64$ \\
\hline Custo de Transporte & $17.388,57$ \\
\hline Custo das Penalidades & $4.171,08$ \\
\hline Custo Total & $102.424,29$ \\
\hline \multirow{2}{*}{ Depósitos abertos } & São Paulo \\
\cline { 2 - 2 } & Tremembé \\
\hline
\end{tabular}

\subsection{Solução estocástica}

De maneira diferente da solução determinística, os valores obtidos mostram que as penalidades (95 vezes o valor do frete) influenciam fortemente os resultados em função da falta de materiais. Maneiras de melhoria nos resultados são possíveis, principalmente, através de ajustes e alívios nas restrições, especialmente de capacidade, entretanto, após a discussão desses resultados com tomadores de decisão da Defesa Civil, foi escolhida a manutenção destes resultados, pois são os que mais se aproximam da realidade, principalmente, na ocorrência de uma eventual catástrofe. Na Tabela 5.4 estão descritos os custos e indicadores também para um valor de penalidade igual a 95 vezes o valor do frete e um horizonte de cinco anos para a solução estocástica (RP).

Tabela 5.4 - Resultados do modelo estocástico.

\begin{tabular}{|l|r|}
\hline & \multicolumn{1}{|c|}{ Estocástico (R\$) } \\
\hline Custo Fixo & $80.864,64$ \\
\hline Custo de Transporte & $17.957,34$ \\
\hline Custo das Penalidades & $149.019,97$ \\
\hline Custo Total & $247.841,94$ \\
\hline \multirow{2}{*}{ Depósitos abertos } & \multicolumn{2}{|c|}{ São Paulo } \\
\cline { 2 - 2 } & Tremembé \\
\hline
\end{tabular}


Em todos os cenários ocorreram faltas. Embora doações, estoques e materiais comprados sejam suficientes para o abastecimento em alguns cenários, não foram utilizados integralmente devido a restrições de capacidade dos depósitos. Outro custo relevante é o fixo para abertura de depósitos. O menor custo relativo é o custo de transporte, o que justifica uma abertura mínima de depósitos.

\subsection{Desempenho das soluções determinística e estocástica}

Neste tópico são detalhados os valores do EVPI e VSS utilizados para calibração das penalidades, utilizando a faixa de valores adotada. Os indicadores foram calculados e comparados com os resultados conseguidos por Noyan (2012), que obteve EVPI $54,05 \%$ a $58,42 \%$ e VSS $0,84 \%$ a $5,41 \%$; e os resultados alcançados por Salmerón e Apte (2010), que obteve EVPI entre 24\% e 25\% e VSS médio entre cenários de $47 \%$, podendo chegar a $256 \%$ (valores percentuais em relação a solução WS).

Levando em consideração (BIRGE; LOUVEAX, 1997) que o EVPI quanto menor o valor melhor é a solução e o VSS quanto maior o valor melhor é a solução, e que, para este modelo, o valor do VSS depende e varia em função do valor das penalidades, pode-se concluir, com base nos valores do EVPI, que o modelo apresenta bons resultados na acomodação das incertezas e um resultado compatível como valores encontrados na literatura para o VSS. Dentro da faixa de valores adotada para as penalidades de 3 a 95 vezes o valor do frete, os resultados apresentados estão detalhados na Tabela 5.5, que mostra os valores obtidos para cada uma das soluções de um modelo estocástico. 
Tabela 5.5 - EVPI e VSS.

\begin{tabular}{lrrrr}
\hline & $\begin{array}{c}\text { Penalidade 3 } \\
\text { vezes o frete } \\
(\mathbf{R} \$)\end{array}$ & $\begin{array}{c}\text { Penalidade 5 } \\
\text { vezes o frete } \\
(\mathbf{R} \$)\end{array}$ & $\begin{array}{c}\text { Penalidade 50 } \\
\text { vezes o frete } \\
(\mathbf{R} \$)\end{array}$ & $\begin{array}{c}\text { Penalidade 95 } \\
\text { vezes o frete } \\
\mathbf{( R \$ )}\end{array}$ \\
RP & $103.527,87$ & $106.665,13$ & $177.253,54$ & $247.841,94$ \\
WS & $103.525,40$ & $106.662,66$ & $177.251,07$ & $247.839,47$ \\
EEV & $104.117,00$ & $107.469,59$ & $182.902,93$ & $258.336,28$ \\
EVPI & 2,47 & 2,47 & 2,47 & 2,47 \\
VSS & 589,13 & 804,46 & $5.649,39$ & $10.494,33$ \\
EVPI\% & $0,0024 \%$ & $0,0023 \%$ & $0,0014 \%$ & $0,0010 \%$ \\
VSS\% & $0,57 \%$ & $0,75 \%$ & $3,19 \%$ & $4,23 \%$ \\
\hline
\end{tabular}

Extrapolando o valor de 95 vezes o custo de transporte para as penalidades, adotando o valor de 600 , no qual está o pior caso para o valor de EVPI, foi de $3.07 \%$.

\subsection{Curva de ótimo e subótimos}

Com base nos resultados da otimização realizada pelo modelo estocástico, que indicaram a utilização de dois locais para localização do depósito de suprimentos de alívio, baseado no desempenho das soluções que melhor apresentaram resultados para minimização do custo total, foi elaborada a curva de ótimo e subótimos (Figura 22) Das 31 soluções possíveis foram selecionadas as 4 que apresentaram os melhores resultados na modelagem. Essas soluções são constituídas pelo depósito atualmente existente na cidade de São Paulo, que está presente em todas as soluções consideradas, devido ao custo fixo de instalação, e um depósito localizado na própria região. 


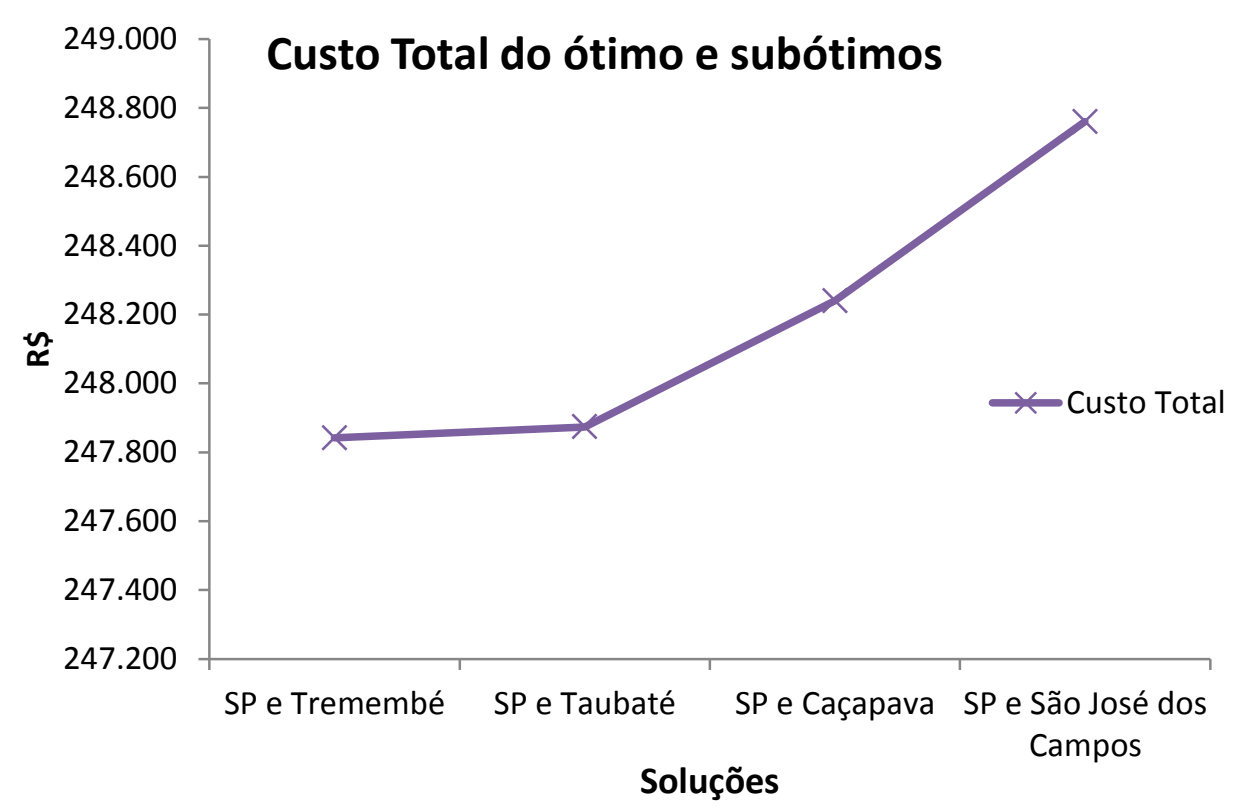

Figura 22 - Curva de ótimo e subótimos.

A solução São Paulo e São José dos Campos não faz parte da solução viável com dois depósitos, pois não satisfaz a restrição de cobertura, entretanto foi mantida apenas para fins comparativos. A curva de ótimo e subótimos é base para o modelo multicritério, para o atributo custos.

Os resultados foram obtidos através da alteração dos custos fixos dos locais, que faziam parte da solução ótima, tornando-os inviáveis. Soluções para a utilização de somente um depósito, assim como três depósitos, também foram testadas, atribuindo esses valores aos parâmetros que limitam a quantidade máxima e mínima, obrigando, desta forma, o modelo a produzir tais resultados. Soluções com apenas um depósito não foram viáveis, pois o atendimento à demanda mínima (depósitos no interior) ou a cobertura (depósito SP) não é satisfeito. Para a solução ótima com três depósitos o custo total foi de $\mathrm{R} \$ 298.559,48$ e os depósitos abertos foram São Paulo, Tremembé e Taubaté. Apesar da pouca exequibilidade da abertura de depósitos tão próximos um ao outro (distância Tremembé - Taubaté = $14 \mathrm{~km}$ ), esta solução foi considerada para fins comparativos durante a análise multicritério. 


\subsection{Análise de faltas}

Para cada cenário foram avaliadas as faltas de materiais e os motivos dessa falta. Nessa avaliação os materiais foram analisados conforme o usuário (população ou COMDEC), pois para os itens destinados às equipes de socorro COMDECs, não existem doações.

Foi observado que os cenários 1 e 4 (desastres nível II) e nos cenários 5 e 7 (nível III com alta divulgação) as faltas ocorreram devido à quantidade insuficiente de materiais para as COMDECs. Nesses casos, também compras foram efetuadas até o limite superior e, mesmo assim, não foi suficiente para atendimento à demanda.

Nos cenários 2 e 3 (desastres nível II e III com baixa divulgação) as faltas ocorreram devido à quantidade disponível de materiais e, em alguns casos, ainda com materiais em quantidade suficiente, às restrições de capacidade de armazenagem (nominal + incidental) que impediram que materiais, mesmo em estoque ou possíveis de serem comprados, fossem utilizados para atendimento. $O$ cenário 3 , devido ao baixo volume de doações e menor quantidade disponível de compras, foi o cenário que apresentou maior quantidade de faltas.

Os cenários 6 e 8 (desastres nível IV com alta divulgação) apresentaram faltas similares ao cenário 3 , entretanto em menor quantidade devido ao maior volume de doações e compras, principalmente, dos materiais destinados à população. Materiais disponíveis também não foram utilizados devido às restrições de capacidade de armazenagem (nominal + incidental).

A Tabela 5.6 resume as faltas de materiais em cada cenário, conforme o usuário e o motivo dessa falta (entre parênteses a quantidade de materiais que ocorreram faltas). O Apêndice 9 detalha essa quantidade $(\mathrm{kg})$ por material e por cenário (células sombreadas indicam faltas mesmo quando os materiais encontram-se disponíveis). 
Tabela 5.6 - Resumo de faltas de materiais.

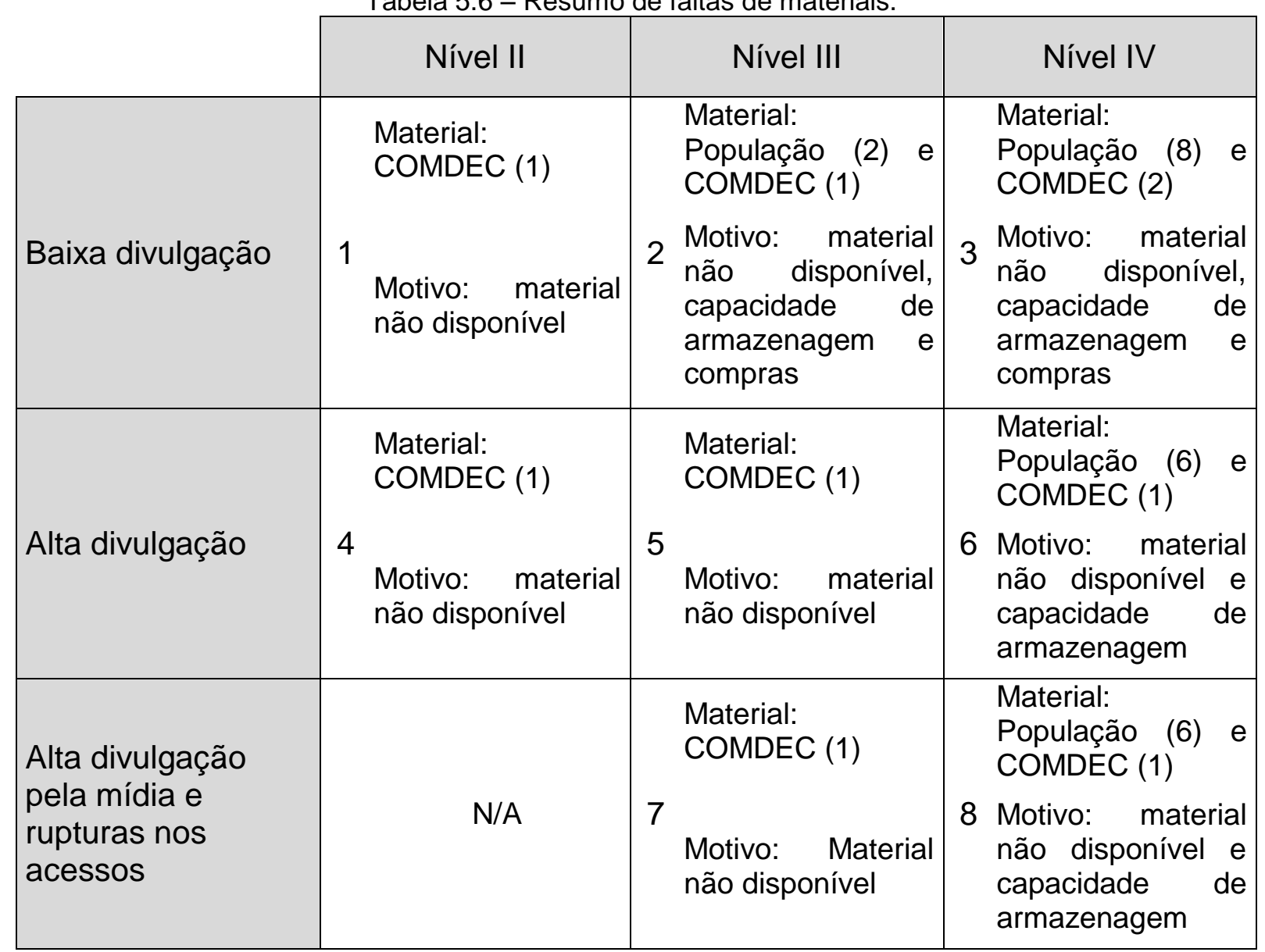

Os resultados do modelo mostram que em desastres de grande magnitude (nível IV e alguns cenários de nível III) a disponibilidade de materiais e orçamentos não são suficientes para a resposta a desastres. Conforme aumenta a magnitude do desastre, mais efetivas devem ser as ações de coordenação e na tomada de decisão. Planejamento de transportes e locais, onde são possíveis a triagem e a armazenagem de materiais para uma eventual necessidade de resposta a um desastre, é necessário.

\subsection{Análise de sensibilidade}


A análise de sensibilidade avalia importantes implicações em logística de operações humanitárias (BALCIK; BEAMON, 2008).

A análise de sensibilidade foi realizada para verificação das probabilidades dos cenários, mudanças nos critérios de atribuição de penalidades e rupturas dos arcos de transporte $A_{i}$ nos resultados do modelo.

Foram realizadas 6 execuções para análise do modelo sendo:

- 2 adotando diferentes probabilidades dos cenários.

- 2 com mudanças nos critérios de atribuição de penalidades.

- 2 variando o parâmetro $A_{i,}$ provocando rupturas nos arcos de transporte.

\subsubsection{Diferentes probabilidades dos cenários.}

Na estimativa de probabilidades dos cenários, através do método Delphi, foi utilizada a média das opiniões dos especialistas, entretanto a metodologia (ROWE; WRIGHT, 2001) estabelece que outras medidas de tendência central também podem ser utilizadas, como a mediana e a média aparada. $\mathrm{Na}$ Tabela 5.7, estão indicadas a média adotada, os valores de mediana e média aparada avaliadas conforme o cenário.

Tabela 5.7 - Média, mediana e média aparada das probabilidades.

\begin{tabular}{|c|l|c|c|c|}
\hline \multirow{2}{*}{$\begin{array}{c}\text { Baixa divulgação } \\
\text { pela mídia }\end{array}$} & Informação & Nível II & Nível III & Nível IV \\
\cline { 2 - 5 } & Mediana & $24,00 \%$ & $8,11 \%$ & $1,00 \%$ \\
\cline { 2 - 5 } & Média aparada & $32,53 \%$ & $0,00 \%$ & $0,00 \%$ \\
\hline \multirow{3}{*}{$\begin{array}{c}\text { Alta divulgação pela } \\
\text { mídia }\end{array}$} & Média & $24,43 \%$ & $6,57 \%$ & $0,00 \%$ \\
\cline { 2 - 5 } & Mediana & $30,12 \%$ & $15,33 \%$ & $7,33 \%$ \\
\cline { 2 - 5 } & Média aparada & $24,71 \%$ & $14,71 \%$ & $6,02 \%$ \\
\hline \multirow{2}{*}{$\begin{array}{c}\text { Alta divulgação pela } \\
\text { mídia e rupturas nos } \\
\text { acessos }\end{array}$} & Média & Nediana & $13,56 \%$ & $4,14 \%$ \\
\cline { 2 - 5 } & Média aparada & & $12,05 \%$ & $3,61 \%$ \\
\cline { 2 - 5 } & & $13,14 \%$ & $3,71 \%$ \\
\hline
\end{tabular}


Os resultados do modelo mostraram que o valor da média proporciona um cenário pior que os demais em termos de faltas e custo total. Isso ocorre em função de maiores probabilidades nos cenários de desastres de grande porte, catástrofes, e baixa divulgação de mídia. Os valores de EVPI e VSS não sofreram alterações expressivas. A Tabela 5.8 mostra os resultados obtidos:

Tabela 5.8 - Alterações dos resultados em função das probabilidades.

\begin{tabular}{|c|c|c|c|c|c|}
\hline & VSS \% & EVPI \% & $\begin{array}{l}\text { Depósitos } \\
\text { abertos }\end{array}$ & $\begin{array}{l}\text { Total Faltas } \\
(\mathrm{kg})\end{array}$ & $\begin{array}{l}\text { Custo Tota } \\
(R \$)\end{array}$ \\
\hline \multirow{2}{*}{ Média } & \multirow{2}{*}{$4,23 \%$} & \multirow{2}{*}{$0,0010 \%$} & São Paulo & \multirow{2}{*}{$7.789,90$} & \multirow{2}{*}{$247.841,94$} \\
\hline & & & Tremembé & & \\
\hline \multirow{2}{*}{ Mediana } & \multirow{2}{*}{$4,35 \%$} & \multirow{2}{*}{$0,0010 \%$} & São Paulo & \multirow{2}{*}{$5.382,32$} & \multirow{2}{*}{$199.654,35$} \\
\hline & & & Tremembé & & \\
\hline \multirow{2}{*}{$\begin{array}{c}\text { Media } \\
\text { Aparada }\end{array}$} & \multirow{2}{*}{$4,53 \%$} & \multirow{2}{*}{$0,0010 \%$} & São Paulo & \multirow{2}{*}{$6.251,15$} & \multirow{2}{*}{$218.005,64$} \\
\hline & & & Tremembé & & \\
\hline
\end{tabular}

\subsubsection{Mudanças nos critérios de atribuição de penalidades.}

Para a atribuição a penalidade foi considerada a mesma para todos os produtos e o custo de transporte foi escolhido como uma referência inicial. Holguín-Veras et al. (2013) aborda o conceito de custos sociais, que é composto de custos logísticos mais o custo de privação, que leva em consideração o sofrimento humano devido à falta de algum material. Com base nesse estudo foi alterada a penalização através da classificação de materiais, conforme a prioridade de necessidade de sobrevivência humana (GOENTZEL, 2012), priorizando os suprimentos de alívio necessários a alimentação e ao aquecimento humano. Foram considerados prioritários: agasalhos, camiseta, cesta básica, cobertor, colchão, lençol, tênis. Para os materiais não prioritários a penalidade foi reduzida em $50 \%$ e $80 \%$, observando para que não fique inferior a 3 vezes o valor máximo do custo de transporte, para 
não viabilizar faltas. Não foram observadas diferenças entre as faltas através da alteração do valor de penalidade, evidenciando que as faltas ocorrem por indisponibilidade de materiais ou devido à característica de armazenagem por produto.

Uma nova abordagem, através de alteração dessa capacidade, por meio do estabelecimento da capacidade de armazenagem por tipo de produtos e que possuem a mesma característica de armazenagem (roupas, alimentos, produtos de limpeza e de organização do local), mostrou-se ineficiente, pois esse agrupamento apresentou características idênticas à priorização, ou seja, sem incremento de capacidade entre os agrupamentos, não alterando os resultados.

\subsubsection{Variação do parâmetro $A_{i}$ causando rupturas nos arcos de transporte}

Nos cenários 7 e 8, os depósitos da solução foram rompidos e verificados os custos totais e o volume de faltas (VSS não foi verificado, pois não é aplicável o cálculo de média ponderada de parâmetro binário, inviabilizando a solução determinística).

As rupturas no depósito do interior do estado (Tremembé), fez com que o depósito de Taubaté fosse aberto no lugar do rompido (conforme esperado), com realocação dos suprimentos de alívio para um depósito sem rupturas nos arcos, sem redução no nível atendimento à demanda, alterando apenas o custo de transporte e, consequentemente, o custo total.

A ruptura no depósito de São Paulo provoca a abertura de mais um depósito (Caçapava), alterando os custos fixos e totais. O volume de faltas cresce substancialmente, conforme descrito na Tabela 5.9. Isso ocorre devido à capacidade e volume de doações, que é maior também nesse local, e a ruptura impede o abastecimento em cenários mais críticos. O Apêndice 10 detalha as faltas por material, com e sem ruptura, no depósito e São Paulo nos cenários 7 e 8. 
Tabela 5.9 - Alterações dos resultados devido a ruptura em SP.

\begin{tabular}{|l|r|r|}
\hline & $\begin{array}{c}\text { Estocástico sem } \\
\text { ruptura em SP }\end{array}$ & $\begin{array}{c}\text { Estocástico com } \\
\text { ruptura em SP }\end{array}$ \\
\hline Custo Fixo & $\mathrm{R} \$ 80.864,64$ & $\mathrm{R} \$ 142.215,95$ \\
\hline Custo de Transporte & $\mathrm{R} \$ 17.957,34$ & $\mathrm{R} \$ 16.131,06$ \\
\hline Custo das Penalidades & $\mathrm{R} \$ 149.019,97$ & $\mathrm{R} \$ 307.481,67$ \\
\hline Custo Total & $\mathrm{R} \$ 247.841,94$ & $\mathrm{R} \$ 465.828,67$ \\
\hline Faltas Totais & $254.834,6 \mathrm{~kg}$ & $417.161,7 \mathrm{~kg}$ \\
\hline \multirow{3}{*}{ Depósitos abertos } & São Paulo & São Paulo \\
\cline { 2 - 3 } & Tremembé & Tremembé \\
\cline { 2 - 3 } & & Caçapava \\
\hline
\end{tabular}

\subsection{Conclusões sobre os resultados do modelo}

Neste capítulo da tese foi proposto um modelo estocástico de dois estágios para localizar instalações destinadas à armazenagem de suprimentos de alívio. O conceito do modelo é a aplicação em qualquer situação. Para sua avaliação foi aplicado em um possível abastecimento no Vale do Paraíba Paulista, uma região com histórico de ocorrência de desastres naturais, fundamentada na revisão de literatura elaborada sobre o tema, que estabeleceu a fronteira do conhecimento sobre $o$ assunto.

Com base em dados históricos, medições em campo e parâmetros estimados, locais para instalação de depósito foram sugeridos. A quantidade de informações e dados necessários para implementação do modelo de otimização desse tipo é elevada e com diversas dificuldades em sua obtenção, especialmente, devido ao assunto possuir poucas publicações e ainda poucos dados acadêmicos.

A modelagem estocástica mostra que o principal componente é o custo de penalidades e, consequentemente, o resultado do modelo é extremamente sensível a esse valor. Os resultados sugerem que apenas dois depósitos sejam utilizados 
para abastecimento dos suprimentos de alívio. O depósito atualmente existente na cidade de São Paulo seria utilizado para esse fim e mais um depósito localizado na própria região. Essa proposição resulta dos valores dos custos de transporte relativamente menores em relação aos custos de instalação de depósitos e penalidades, entretanto, em caso de rupturas no acesso desse depósito, outro local é necessário para fazer o abastecimento. A metodologia multicritério de decisão (MCDA) é relevante para fazer essa escolha e a próxima etapa deste trabalho é a utilização dessa metodologia, considerando as possíveis soluções ótima e subótimas "São Paulo e Tremembé", "São Paulo e Taubaté" e "São Paulo e Caçapava". A alternativa "São Paulo e São José dos Campos", apesar de não fazer parte da solução devido ao não atendimento da cobertura, será mantida apenas para fins comparativos, especialmente quanto ao porte dos municípios.

Os resultados do modelo, a etapa atual deste trabalho e as próximas, podem ser visualizados através da adaptação e detalhamento da Figura 1 - Estrutura da metodologia de pesquisa. A Figura 23 descreve essa adaptação.

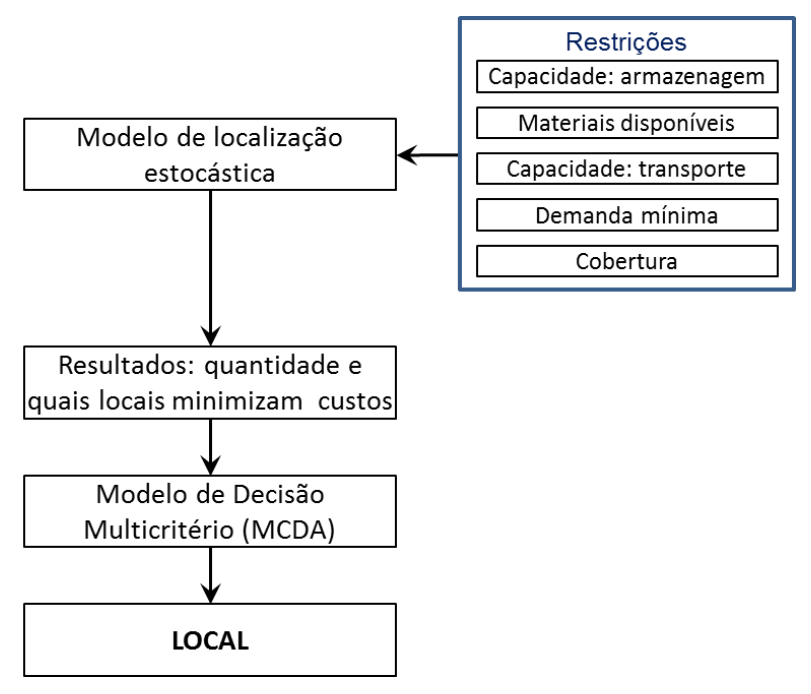

Figura 23 - Resultados da modelagem e próximas etapas.

Apesar de poucas informações disponíveis sobre alguns parâmetros e a necessidade de obter tais valores, os valores arbitrados foram estabelecidos, observando uma grandeza compatível com uma possível realidade. A variável compra, por exemplo, não era considerada no projeto original do modelo, porém foi 
inserida após uma sugestão de estudos por parte da Defesa Civil, assim como a detecção das incapacidades de atendimento e de capacidade de estocagem durante um desastre de nível IV (catástrofe).

A análise de sensibilidade mostrou que a capacidade de armazenagem foi a restrição com maior influência no resultado do modelo. Considerando que materiais comprados e doações somente ocorrem quando existe um desastre, nessa situação, capacidade adicional pode ser justificada. 


\section{Aplicação do Modelo de Decisão Multicritério}

Neste capítulo é descrito o processo de aplicação do modelo multicritério. A localização de instalações humanitárias envolve diversos tomadores de decisão: organizações de ajuda; Defesa Civil; militares; prestadores de serviços; fornecedores; e órgãos públicos (BESIOU; STAPLETON; VAN WASSENHOVE, 2011). Essas partes podem possuir prioridades e metas estratégicas diferentes. Devido a essa diversidade de participantes e objetivos, neste trabalho a utilização de um método multicritério é aplicável. A abordagem adotada é a MAVT, proposta por Keeney (1992) e revista por Franco e Montibeller (2010b) de VFT (Value Focused Thinking - Pensamento Baseado em Valores), que decompõe o objetivo fundamental, com a utilização de um facilitador durante o processo.

\subsection{Estruturação do problema}

O processo de realização de intervenções MCDA, neste trabalho, segue a estrutura ilustrada na Figura 15 (item 3.5.1 pag. 95). Na fase 1, a situação é exposta aos participantes e o facilitador auxilia na definição do problema, projetando o processo decisório e, em conjunto com lideranças da equipe de decisão, define os participantes. Uma vez que essa fase estiver concluída, inicia-se a fase 2, que consiste em estruturar uma árvore de valor, definir os atributos e identificar as alternativas de decisão. Concluída esta segunda fase, o facilitador pode finalmente conduzir a fase 3 , que aborda a avaliação das alternativas de decisão.

Foram realizadas uma reunião preliminar com liderança da equipe de decisão, duas reuniões com os stakeholders, duas reuniões de avaliação final e uma reunião para reavaliação, também com a liderança da equipe de decisão (6 encontros, totalizando aproximadamente 10 horas). 


\subsubsection{Definição do problema}

O problema foi definido anteriormente ao início do processo de modelagem, logo ao início das discussões sobre o tema e a tomada de decisão. A cada reunião com a equipe de decisão essa definição foi verificada e revalidada, podendo ser descrita como:

"Onde localizar instalação para armazenagem de suprimentos de alívio no Vale do Paraíba Paulista?"

Na reunião preliminar e nas duas reuniões com a equipe de decisão foram definidos e validados os seguintes objetivos estratégicos:

- Otimizar o gerenciamento e distribuição de suprimentos de alívio, em caso de desastres na região.

- Minimizar o sofrimento das vítimas.

\subsubsection{Participantes na decisão (stakeholders)}

A identificação das partes interessadas (stakeholders) deste trabalho foi realizada por meio da utilização das metodologias estabelecidas por Bryson (2004) e Franco e Montibeller (2010b) e relacionadas ao setor público e não empresarial. Foram seguidas as seguintes etapas:

- Em ambiente de preparação foi realizada uma análise preliminar, envolvendo o facilitador, o Diretor de Divisão da Defesa Civil e o Coordenador Regional 
de Defesa Civil do Vale do Paraíba (REDEC), para estabelecer as partes interessadas e elaborar um diagrama poder $\mathrm{x}$ interesse inicial.

- Durante a primeira reunião, o grupo de stakeholders foi incentivado a avaliar o diagrama poder $x$ interesse inicial para detecção de eventual ausência de parte interessada. De acordo com as discussões do grupo, não foram necessárias alterações e a matriz $2 \times 2$ (ACKERMANN; EDEN, 2011) ficou assim definida e ilustrada na Figura 24:

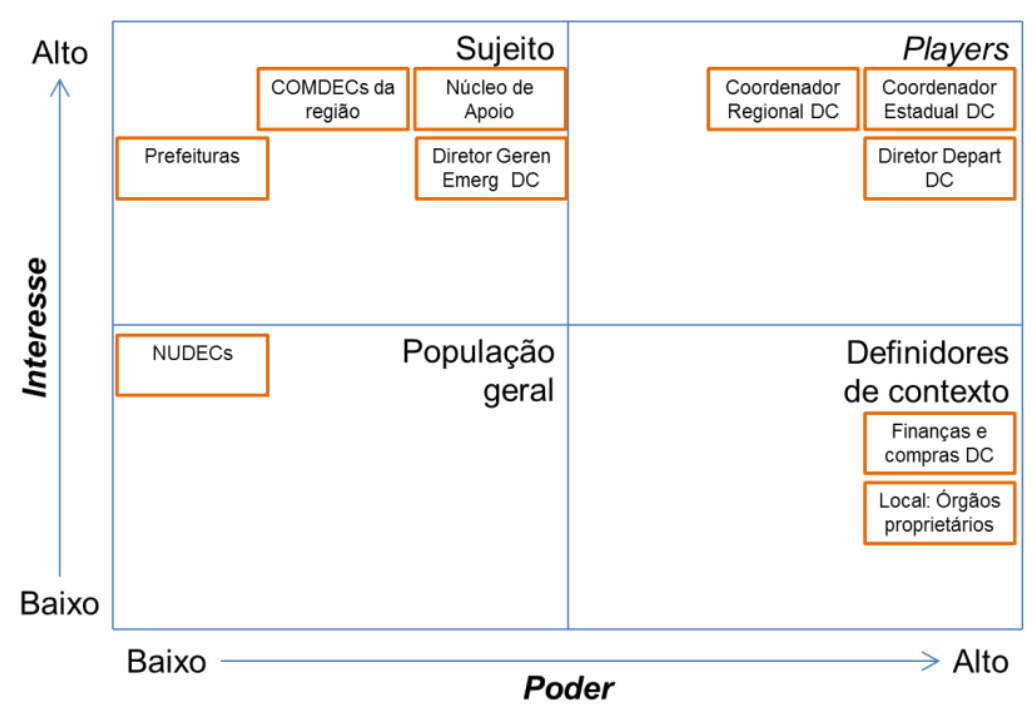

Figura 24 - Diagrama poder x interesse elaborado.

- Players: correspondem à alta administração da Defesa Civil estadual, que serão responsáveis pela decisão de instalação; além do Coordenador Regional de Defesa Civil, que detém o conhecimento dos locais candidatos e que será responsável pela operação do depósito.

- Sujeitos: correspondem aos Núcleos de Apoio da Defesa Civil, que supervisionam os depósitos e providenciam o abastecimento de materiais, conforme a demanda; ao Gerenciamento de Emergências, que aciona a distribuição; além das Coordenações Municipais (COMDECs) e da administração dos municípios da região, que serão os usuários dos suprimentos de alívio. 
- Definidores de contexto: correspondem aos organismos da Defesa Civil, que controlam orçamentos e legislação, que viabilizam economicamente a operação do depósito; além de outros órgãos setoriais da administração estadual que, porventura, possuem o espaço físico e podem disponibilizá-lo para utilização como armazém.

- População em geral: corresponde ao pessoal que pode ser afetado pela decisão, especialmente os habitantes das localidades que atuam junto aos Núcleos de Defesa Civil dos municípios da região.

Todos os "players" e "definidores de contexto" participaram do processo decisório. O Coordenador Estadual da Defesa Civil foi representado por seu Chefe de Gabinete. Dentre os "sujeitos" participaram integrantes dos Núcleos de Apoio e o Diretor de Gerenciamento de Emergências. Não houve representação dos Núcleos da Defesa Civil (população em geral).

\subsection{Estruturação do processo decisório}

Franco e Montibeller (2010b) descrevem três tarefas principais na estruturação de modelos de avaliação de MCDA:

- A representação dos objetivos sob a forma de uma árvore de valor.

- A definição de atributos para medir a realização dos objetivos.

- A identificação das alternativas de decisão.

O processo decisório foi estruturado a partir de reuniões com os stakeholders. Essas reuniões foram conduzidas na sede da Defesa Civil do Estado de São Paulo e na coordenadoria Regional de Defesa Civil da Região do Vale do Paraíba, atualmente sediada no município de Taubaté. Convém ressaltar que a localização da 
coordenação não é fixa, pois é baseada na unidade onde está situado o coordenador. Caso exista alteração do coordenador ou de seu local operacional, também é alterada a localização da coordenadoria regional. Em função disso, critérios que levem em consideração a distância em relação à coordenadoria regional serão avaliados na Análise de Sensibilidade do modelo multicritério.

\subsubsection{Estruturação das árvores de valor}

A árvore de valor foi elaborada através de uma abordagem top down, de acordo com Franco e Montibeller (2010b), e alinhada com o VFT, visando a decomposição do objetivo fundamental em objetivos e subobjetivos.

Neste trabalho, na primeira reunião, foram apresentados aos tomadores de decisão os critérios verificados na literatura acadêmica sobre o assunto e estabelecidos na Tabela 3.3 (etapa de preparação) e discutida sua relação com os objetivos do projeto, tomando o cuidado de esclarecer que os objetivos do projeto não estavam vinculados à literatura acadêmica. A apresentação desses critérios proporcionou redução da fase divergente e uma melhor objetividade à reunião.

Nas reuniões com os stakeholders, através de brainstorming, inicialmente, foram discutidos e mapeados os objetivos a serem atingidos ao se instalar um novo depósito de suprimentos de alívio e os valores considerados pelos tomadores de decisão. Após o mapeamento, foram detectadas características comuns entre os objetivos. Tais características permitiram a definição dos subcritérios e o agrupamento dos objetivos para a confecção da árvore de valor, conforme os subcritérios.

A partir desses objetivos, suas conexões e agrupamento, a árvore de valor foi estabelecida para o problema conforme ilustrado na Figura 25. 


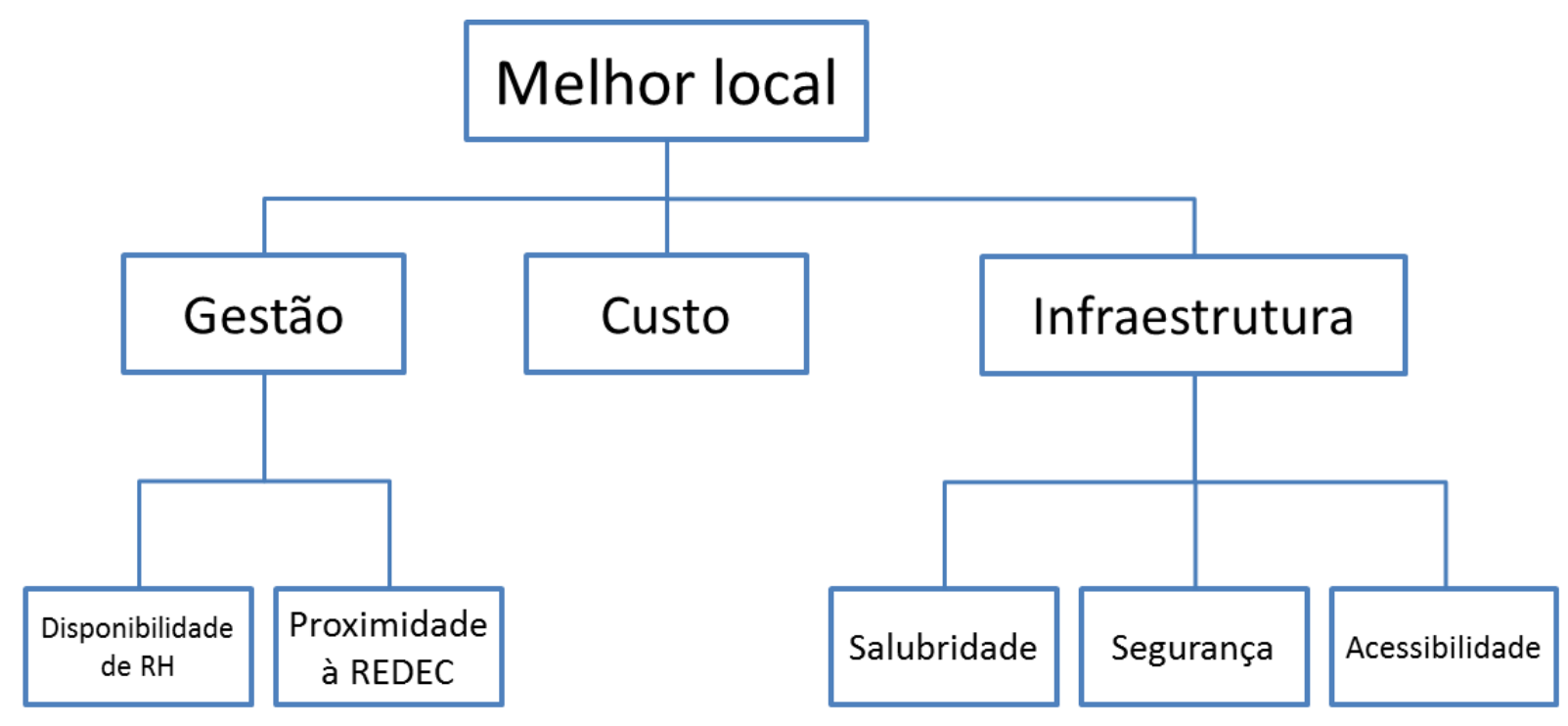

Figura 25 - Árvore de valor para a seleção do depósito.

Realizando uma comparação com os critérios de segundo nível da árvore de valor apresentada por Fernandes (2010), são observadas diferenças no atributo Meio Ambiente, que foi considerado, pelos decisores, que participaram do trabalho de Fernandes (2010), e no atributo Salubridade, que foi considerado pelos stakeholders deste trabalho. Embora suas características possam estar distribuídas entre os critérios de terceiro nível, não foi caracterizado como um atributo por Fernandes (2010).

\subsubsection{Definição dos atributos}

Para cada objetivo colocado no nível inferior da árvore de valor, um atributo foi associado para permitir a mensuração. As funções de valor descritas em tópicos a seguir detalham a implementação do atributo. 
1) Subcritério Custo: considerando que o depósito é estabelecido durante a fase de preparação a um desastre para ser utilizado durante a fase de resposta, este objetivo é estabelecido para a etapa de preparação a um desastre, pois necessita atender a um orçamento geral que engloba a instalação do depósito. Durante a fase de resposta a um desastre a minimização do sofrimento humano (HOLGUÍN-VERAS et al., 2013) é atividade prioritária em relação aos custos. Para medição desse objetivo o atributo considerado foi 0 custo operacional resultante do modelo estocástico, mensurado em reais.

2) Subcritério Gestão: dividido em dois objetivos, a seguir.

- Disponibilidade de Recursos Humanos: este objetivo leva em consideração o poder de mobilização de mão de obra durante a operação de resposta a um desastre. Uma característica da Defesa Civil do Estado de São Paulo é que as operações de resposta são iniciadas com auxílio de militares, especialmente, das forças estaduais. Essa característica proporciona às unidades da Polícia Militar e do Corpo de Bombeiros o fornecimento de recursos humanos (qualificados e não qualificados) durante as primeiras horas da operação e quanto maior a unidade, maior a quantidade de recursos humanos disponíveis. $\mathrm{O}$ atributo relacionado a esse objetivo estabelecido foi o porte da unidade militar do local (batalhão/regimento, companhia ou pelotão).

- Proximidade à REDEC: durante uma operação de resposta ao desastre, o Diretor Regional gerencia as ações de distribuição e quanto mais próximo o depósito estiver da coordenação, melhor a agilidade operacional. Este objetivo refere-se a quão próximo o depósito encontra-se à REDEC e seu atributo associado é mensurado em função da distância (em $\mathrm{km})$ em relação à REDEC. Outro aspecto a ser observado é que a REDEC é uma designação adicional a uma função (militar ou civil) estabelecida, portanto, não possui um local fixo, podendo ser modificada mediante a alteração do Diretor Regional.

3) Subcritério Infraestrutura: dividido em três objetivos a seguir. 
- Salubridade e ambiente de armazenamento: este objetivo visa atender às condições de armazenagem, principalmente de alimentos, e facilidade operacional do depósito, tais como temperatura de armazenagem, prevenção da deterioração e movimentação. O objetivo considera os aspectos: ventilação; porta de acesso; proteção contra roedores; piso; estantes; área disponível; e pátio, que são mensurados através de uma escala linear que considera a condição dos fatores.

- O objetivo Segurança foi considerado sob dois aspectos denominados de "Social" e "Riscos Naturais". O aspecto social do local refere-se à vulnerabilidade do local a desvios ou furtos de materiais; e Riscos Naturais referem-se à susceptibilidade do local à ocorrência de desastres naturais e, consequentemente, inviabilidade operacional. $O$ atributo Segurança foi estabelecido como qualitativo.

- Acessibilidade: esse objetivo visa avaliar a qualidade das vias de aceso ao depósito; condições de calçamento; iluminação no entorno; sinalização de orientação, além da consideração de vias alternativas, que possibilitem o acesso, em caso de rupturas. Esse atributo foi avaliado de maneira qualitativa, onde são considerados os aspectos relacionados.

Comparando-se os objetivos e atributos relacionados com a literatura pesquisada (Tabela 3.3), observa-se que os tomadores de decisão também consideraram o custo, porém houve uma divisão dos objetivos referentes aos benefícios em objetivos relativos à gestão e relativos à infraestrutura disponível no local. Alguns objetivos, como a disponibilidade operacional e a proximidade do comando, não foram detectados na literatura acadêmica. Os demais critérios, embora com nomenclatura diferente, possuem objetivo similar ao encontrado na literatura acadêmica.

Com a elaboração da árvore de valor e definição dos atributos foi adaptada e detalhada a Figura 1 - Estrutura da metodologia de pesquisa. Essa adaptação está definida conforme a Figura 26. 


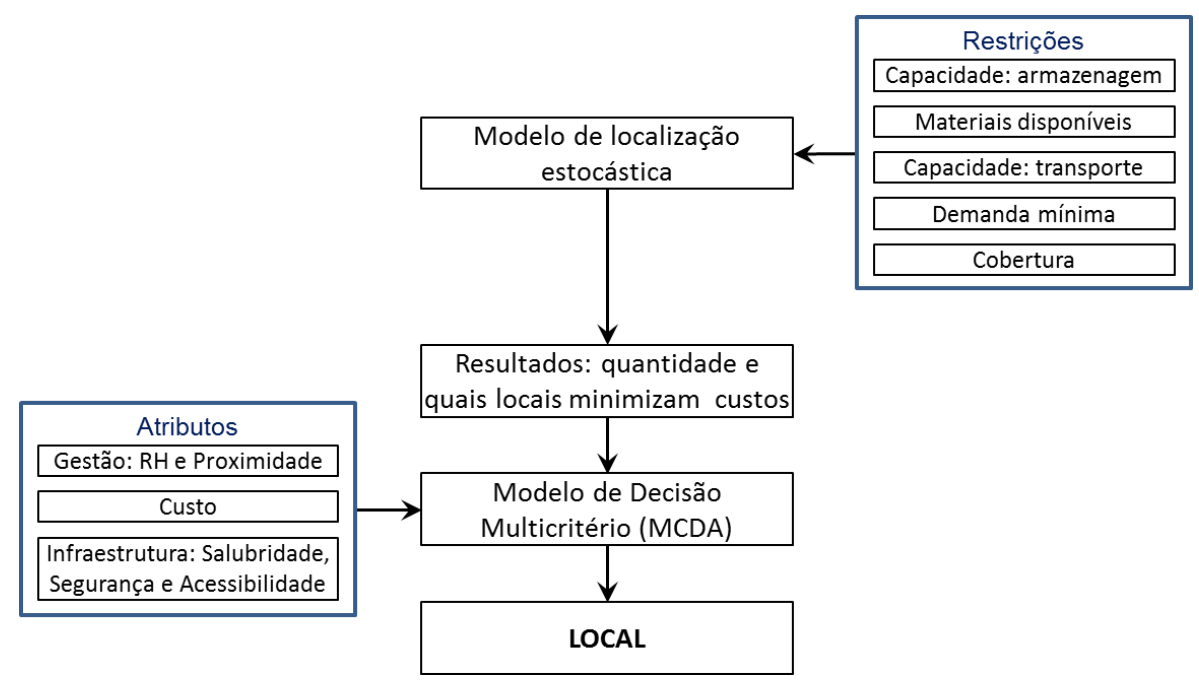

Figura 26 - Fluxo atual do processo de modelagem.

\subsubsection{Identificação e criação das alternativas}

Os locais candidatos foram discutidos em reuniões no início do processo de modelagem com base em disponibilidade operacional; riscos meteorológicos e geológicos; histórico de ocorrências e de desabrigados, que compõem os objetivos relativos à operação e à segurança. A disponibilidade operacional refere-se à característica de atendimento durante 24 horas, durante todos os dias da semana. Este atributo possui característica restritiva, pois caso algum dos locais não possua tal característica não deve ser selecionado.

Esses atributos definiram inicialmente as alternativas e referem-se aos municípios de: Caçapava, São Jose dos Campos, Taubaté, Tremembé e São Paulo. O modelo de programação linear estocástica mostrou o desempenho dos municípios em relação aos custos e à cobertura, e mostrou que a melhor solução são dois locais, e que o município de São Paulo está presente em todas as soluções, pois, devido à operação atual e instalações já disponíveis, os custos fixos para alocação dos suprimentos de alívio destinados ao Vale do Paraíba são apenas marginais. A solução estocástica também mostrou que os municípios de São Paulo e São José 
dos Campos, isoladamente, não proporcionam uma solução, tampouco uma solução somente com estes locais devido à restrição de cobertura. Em resumo, a solução estocástica mostrou que as alternativas a serem avaliadas são:

- São Paulo e Caçapava.

- São Paulo e Taubaté.

- São Paulo e Tremembé.

- Embora algumas soluções não façam parte da solução do modelo estocástico foram mantidas no modelo multicritério apenas como referência comparativa e análise de sensibilidade. Essas soluções são: São Paulo e São José dos Campos (2 locais); e São Paulo, Taubaté e Tremembé (3 locais) (essas soluções foram inseridas durante a primeira reunião de avaliação.)

\subsection{Avaliação das alternativas de decisão}

\subsubsection{Obtenção das funções de valor}

A função de valor foi obtida estabelecendo os limites superior e inferior para cada atributo. Os stakeholders definiram o que consideram como "o melhor possível", tanto para os atributos quantitativos quanto para os qualitativos. Esse valor é estabelecido como o valor máximo para o atributo (100). Da mesma maneira estabeleceram "o pior possível" como valor mínimo para o atributo (0) (ENSSLIN; MONTIBELLER; NORONHA, 2001), definindo, assim, a amplitude. Através do método da bissecção foram estabelecidos os pontos em $50 \%$, $25 \%$ e $75 \%$ para os 
atributos quantitativos e qualitativos. Essa dinâmica foi realizada para todos os atributos e o estabelecimento das funções encontra-se descrito a seguir:

Subcritério Custo:

Devido à não existência de um valor de referência estabelecido para mensuração deste atributo, o dado mais aproximado e utilizado para avaliação da ordem de grandeza no modelo multicritério é o valor da operação de resposta ao desastre de Itaóca, ocorrido em 2014 (SÃO PAULO, 2014), entretanto, diferente desse processo de modelagem, esses dados consideram o valor total da operação, desde a resposta imediata até o início da fase de reconstrução, e não são avaliadas penalidades pelo não atendimento.

Para estabelecimento da função de valor, neste processo de modelagem, foi utilizado o menor custo resultante da modelagem estocástica para a operação de um eventual desastre no Vale do Paraíba Paulista, sendo atribuído a este valor 100\%. O valor mínimo $(0 \%)$ tem como referência o máximo valor teórico admissível e foi obtido com base no orçamento da Defesa Civil, destinado ao atendimento às localidades situadas nas áreas abrangidas pela Operação Verão (SÃO PAULO, 2012), estabelecendo uma proporcionalidade com base na população dessas áreas e a do Vale do Paraíba (IBGE, 2010). Análise de sensibilidade para verificação do valor mínimo é conduzida neste trabalho. A Figura 27 representa os valores mínimo e máximo e a função de valor definida. 


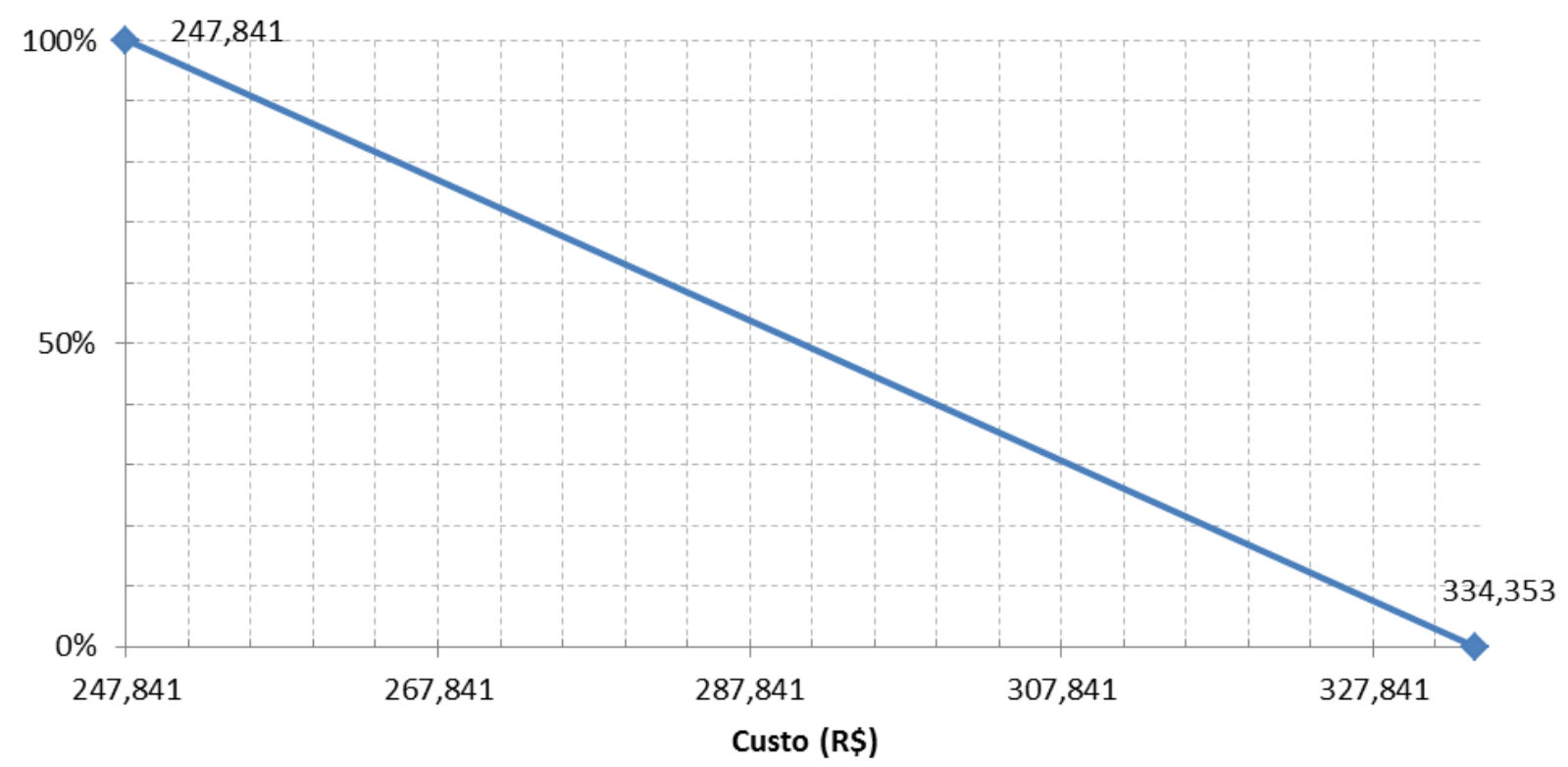

Figura 27 - Função de valor para o atributo custo.

Fonte: Adaptado pelo autor a partir do software V.I.S.A.

Subcritério Gestão, dividido em dois atributos a seguir:

Distância em relação à Coordenadoria Regional (proximidade à REDEC): O valor máximo é atribuído à localização do depósito no mesmo município, que atualmente encontra-se a REDEC, e à distância máxima admissível (pior possível), considerada pelos tomadores de decisão, foi de $80 \mathrm{~km}$. Durante a elaboração de função de valor os tomadores de decisão alteraram os pontos inicialmente estabelecidos pela bissecção de 50\%, 25\% e 75\% para 60\%, 20\% e 80\%. A Figura 28 ilustra a função de valor. 


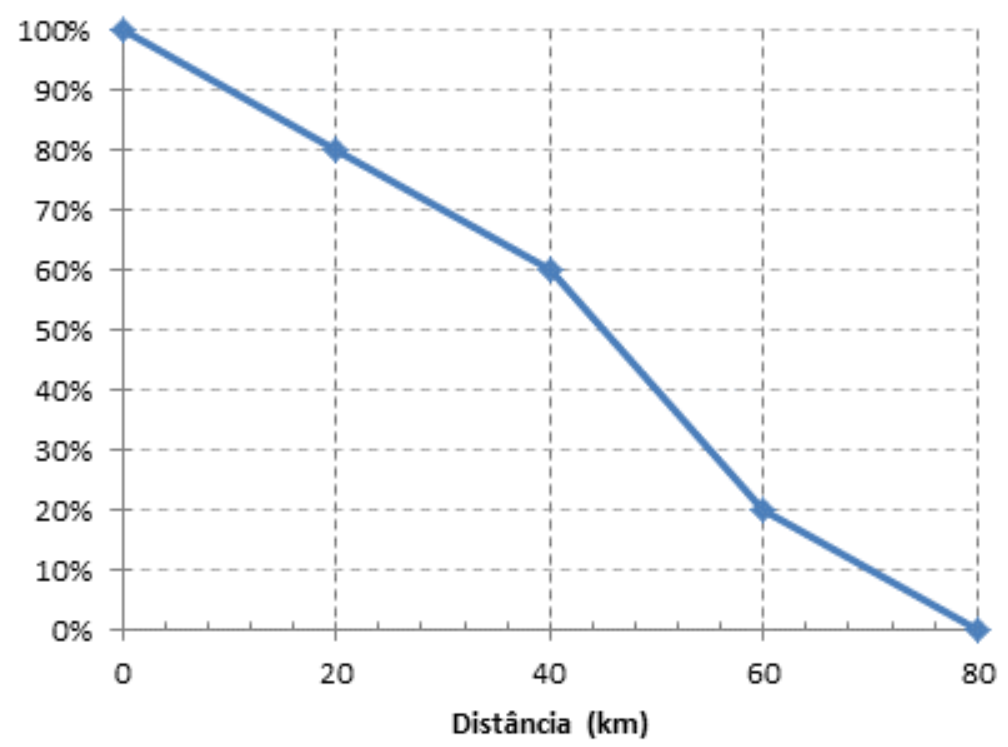

Figura 28 - Função de valor para o atributo distância em relação à REDEC.

Fonte: Adaptado pelo autor a partir do software V.I.S.A.

Porte da unidade militar do local (recursos humanos): para este atributo a função qualitativa de valor ficou assim definida:

- 100\%: local com uma unidade (batalhão ou regimento) da Polícia Militar.

- 75\%: local com uma companhia da Polícia Militar.

- 50\%: local com um pelotão da Polícia Militar.

- 0\%: local sem unidade da Polícia Militar.

Subcritério Infraestrutura, dividido em três atributos a seguir:

Segurança: analisando os aspectos "Sociais" e "Naturais" foram estabelecidos os valores com base em uma escala qualitativa. Admitindo-se que ausência de risco inexiste, são considerados riscos denominados raros e baixos. Locais que porventura apresentem riscos maiores não seriam escolhidos como locais candidatos. O valor mínimo da função de valor foi estabelecido com base na 
definição do pior aceitável (ENSSLIN; MONTIBELLER; NORONHA, 2001) para que um local possa ser considerado candidato. A função de valor ficou assim definida:

- $100 \%$ : local com raros riscos naturais e sociais.

- 50\%: local que apresenta risco raro para um aspecto e outro baixo.

- $0 \%$ : local com baixos riscos naturais e sociais

- Para riscos maiores o local não seria candidato (exclusão).

Salubridade do depósito: para elaborar esta função de valor foi necessária a decomposição do atributo (KEENEY, 1992) e a construção de um índice numérico (descritor) (ENSSLIN; MONTIBELLER; NORONHA, 2001). Os stakeholders decompuseram o atributo em 7 aspectos: ventilação, porta de acesso, proteção contra roedores, piso, estantes, área disponível e pátio. Esses aspectos foram avaliados, conforme sua situação para cada alternativa, e atribuído um valor (bom = 2 , médio $=1$ ou ruim $=0)$. A avaliação "boa" para todos os aspectos (14 pontos) é considerada $100 \%$ e ruim para todos os aspectos $0 \%$. Uma escala linear mensura conforme a avaliação obtida.

A Figura 29 ilustra a função de valor para o atributo. 


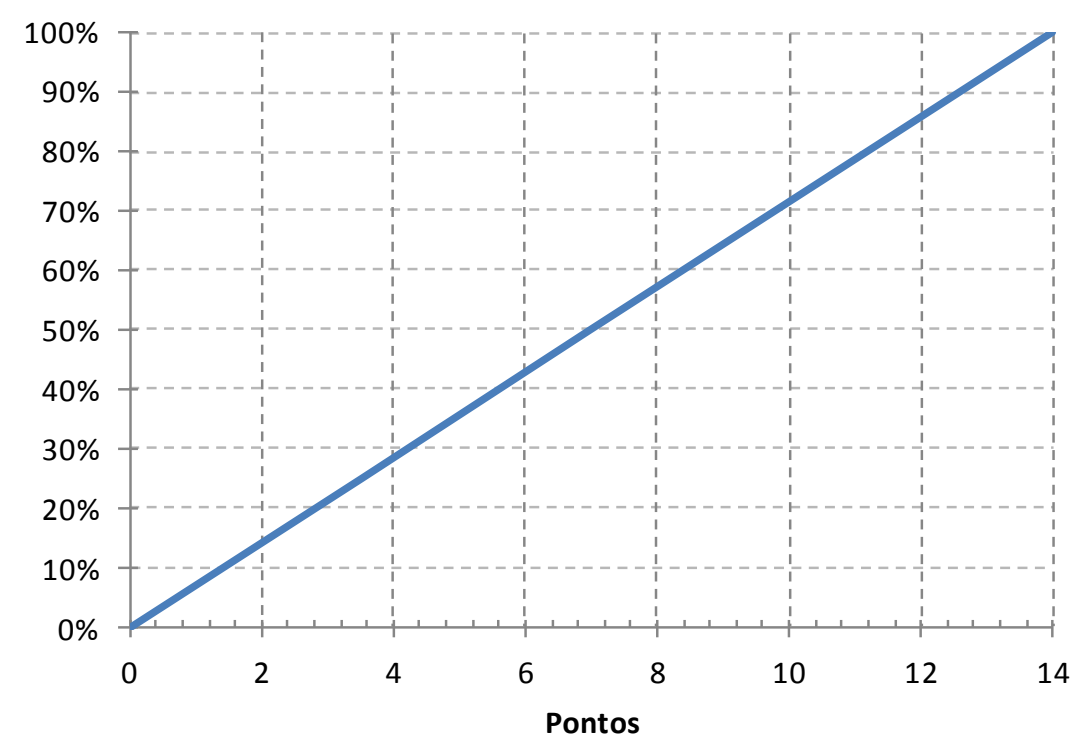

Figura 29 - Função de valor para o atributo salubridade do depósito. Fonte: Adaptado pelo autor a partir do software V.I.S.A.

Acessibilidade: para este atributo a função qualitativa de valor foi definida de maneira similar ao atributo Segurança, no qual o valor mínimo da função de valor foi estabelecido com base no pior aceitável (ENSSLIN; MONTIBELLER; NORONHA, 2001) e ficou assim definida:

- 100\%: Vias de acesso amplas, asfaltadas, boa iluminação no entorno, vias alternativas e sinalização de orientação.

- 50\%: Vias de acesso amplas, asfaltadas, boa iluminação no entorno, caminhos alternativos e sinalização de orientação.

- $0 \%$ : Vias estreitas, asfaltadas, pouca iluminação, sinalização deficiente e caminhos alternativos.

- Para condições de acesso piores o local não seria candidato (exclusão). 


\subsubsection{Obtenção dos pesos dos atributos}

A definição dos pesos de cada atributo foi estabelecida com base na metodologia denominada de swing-weights. Inicialmente os subcritérios Custos, Gestão e Infraestrutura foram avaliados pelos stakeholders e, posteriormente, a avaliação foi conduzida para cada um dos subcritérios.

A árvore de valor representada pela Figura 30 indica os pesos normalizados $(\Sigma=1)$ dos atributos após o swing-weights.

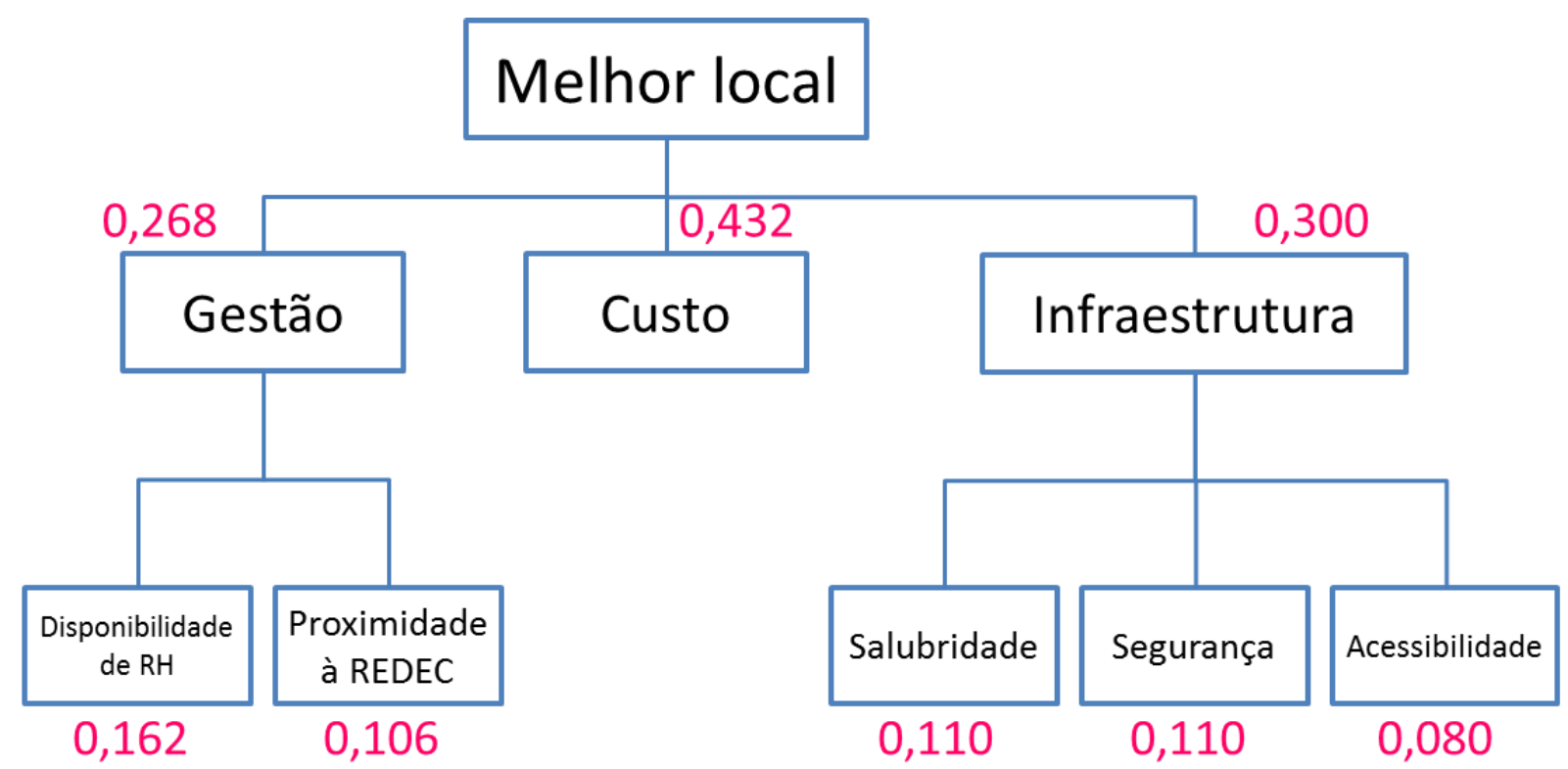

Figura 30 - Pesos normalizados dos atributos.

Fonte: Adaptado pelo autor a partir do software V.I.S.A.

\subsubsection{Avaliação do desempenho das alternativas}

Os stakeholders avaliaram o desempenho das alternativas em cada um dos atributos e, através da função de valor, sua pontuação no critério correspondente foi obtida. A Tabela 6.1 apresenta os resultados da avaliação. O software V.I.S.A. 
permitiu aos stakeholders uma visualização imediata do comportamento de seus julgamentos.

Tabela 6.1 - Resultados da avaliação das alternativas pelos stakeholders.

\begin{tabular}{l|c|c|c|c|c|c}
\hline $\begin{array}{l}\text { Local } \\
\text { Depósito SP + }\end{array}$ & $\begin{array}{c}\text { Distância em } \\
\text { relação à } \\
\text { REDEC (km) }\end{array}$ & $\begin{array}{c}\text { Recursos } \\
\text { Humanos }\end{array}$ & Custo (R\$) & $\begin{array}{c}\text { Acessibi- } \\
\text { lidade }\end{array}$ & $\begin{array}{c}\text { Salubridade } \\
\text { do depósito }\end{array}$ & Segurança \\
\hline Caçapava & 20 & 75 & $248.239,00$ & 50 & 6 & 50 \\
\hline Taubaté & 0 & 100 & $247.843,00$ & 100 & 11 & 50 \\
\hline Tremembé & 15 & 50 & $247.841,00$ & 0 & 8 & 0 \\
\hline $\begin{array}{l}\text { São José dos } \\
\text { Campos }\end{array}$ & 44 & 100 & $248.760,00$ & 100 & 11 & 100 \\
\hline $\begin{array}{l}\text { Taubaté + } \\
\text { Tremembé (3 } \\
\text { locais) }\end{array}$ & 0 & 100 & $298.600,00$ & 50 & 9,5 & 50 \\
\hline
\end{tabular}

O modelo estocástico de otimização indicou duas localidades para instalação do depósito de suprimento de alívio e os valores resultantes para os locais ótimo e subótimos são muito próximos. Ao final da primeira reunião de avaliação, quando os resultados preliminares puderam ser observados e devido à proximidade de valores de custos das soluções ótima e subótimas, foi decidida a inserção de uma alternativa com três localidades, o que proporcionou análise com valores não tão próximos para o atributo. $\mathrm{Na}$ análise de sensibilidade é avaliada uma possível exclusão deste atributo através da alteração das constantes de escala.

\subsubsection{Agregação das performances parciais das alternativas}

O modelo aditivo (KEENEY, 2002) foi utilizado para a agregação do desempenho (U) que cada alternativa obteve com base nos pesos dos atributos e nas funções de valor. 
$\mathrm{U}=k_{c} u_{c}+k_{d} u_{d}+k_{p} u_{p}+k_{s} u_{s}+k_{l} u_{l}+k_{a} u_{a}$

Onde:

$\mathrm{k}$ : corresponde aos valores do peso do atributo (ou constantes de escala).

u: correspondente na função de valor obtido pela alternativa.

Os índices dos atributos foram assim definidos:

- c: custo.

- d: distância em relação à REDEC.

- $\mathrm{p}$ : porte da unidade militar do local.

- s: segurança.

- I: salubridade do depósito.

- a: acessibilidade.

Os valores obtidos estão detalhados nos tópicos a seguir.

\subsubsection{Obtenção do desempenho global}

Os resultados de cada alternativa para os subcritérios Gestão e Infraestrutura (3ำ nível na árvore de valor) estão representados na Figura 31 e Figura 32, respectivamente.

Os resultados da Figura 31 mostram que, para o subcritério Gestão, o porte da unidade da Polícia Militar influencia a escolha do local, pois as unidades maiores 
obtiveram melhores resultados. Outra observação é a característica de proximidade pode alterar a decisão em função da alteração da localização do Coordenador Regional. Essa alteração é objeto de análise de sensibilidade do modelo.

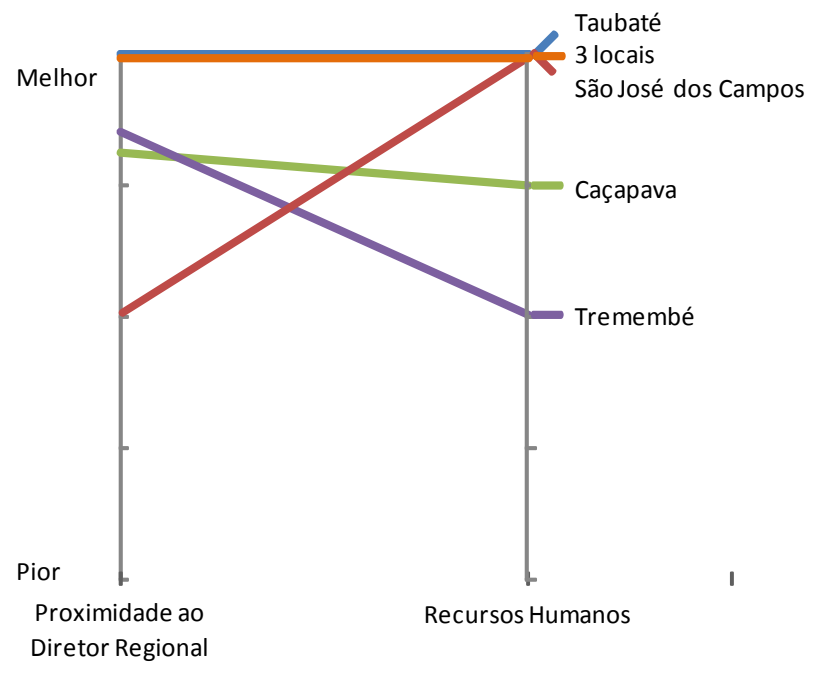

Figura 31 - Resultados para o subcritério Gestão.

Fonte: Adaptado pelo autor a partir do software V.I.S.A.

Os valores da Figura 32 mostram que cidades maiores, com maior quantidade de rodovias, apresentam melhores resultados em relação às cidades com menor disponibilidade rodoviária. Outra observação é que as cidades com unidades maiores da Polícia Militar dispõem de melhores locais de armazenagem e, consequentemente, melhores avaliações nos atributos Salubridade e Segurança.

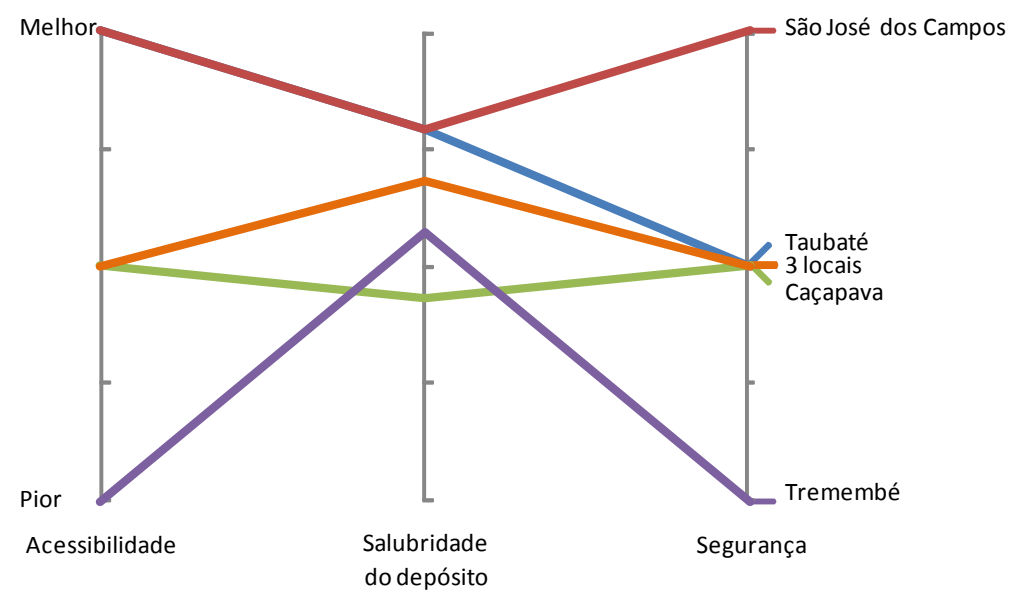

Figura 32 - Resultados para o subcritério Infraestrutura. Fonte: Adaptado pelo autor a partir do software V.I.S.A. 
Analisando os subcritérios (2ำ nível na árvore de valor) o resultado geral de cada um está representado na Figura 33:

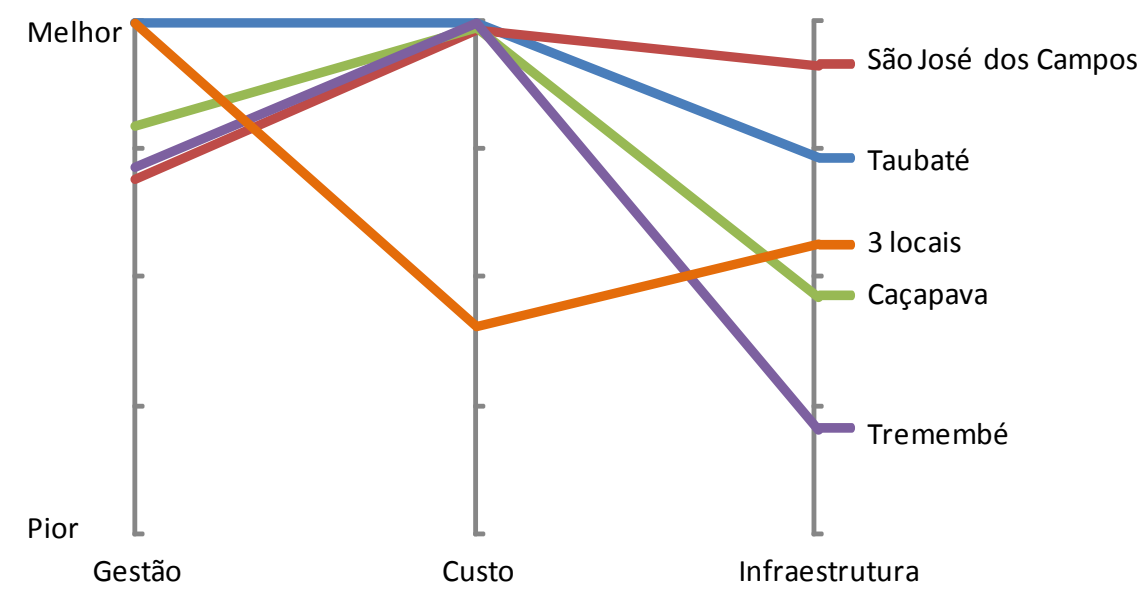

Figura 33 - Resultados para os subcritérios Custos, Gestão e Infraestrutura. Fonte: Adaptado pelo autor a partir do software V.I.S.A.

Como anteriormente observado, o atributo Custo apresenta valores de avaliação muito próximos nas soluções com dois locais. Para essa condição, esse resultado proporciona aos demais atributos grande influência na decisão, entretanto, essa afirmação não pode ser generalizada, pois a inserção da solução com três locais mostrou um comportamento diferente para o atributo Custos. Outro aspecto relevante é que a alternativa Tremembé, solução ótima do modelo estocástico, possui os piores resultados no atributo Infraestrutura.

O resultado final, após a aplicação do modelo multicritério, é representado pela Figura 34 e indica o município de Taubaté como o mais indicado para localização do depósito de suprimentos de alívio. 


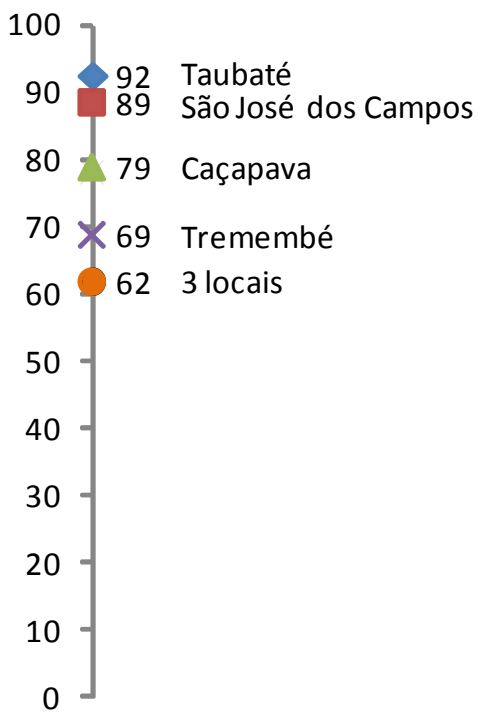

Figura 34 - Resultado global.

Fonte: Adaptado pelo autor a partir do software V.I.S.A.

Os resultados globais foram expostos aos stakeholders para análise, após a avaliação de todas as alternativas. A metodologia de avaliação apresentada por De Boer e Wegern (2003), indicada para avaliação de processos de seleção de fornecedores (PRADO, 2011), foi adaptada para o processo de localização de instalações. Esta metodologia estabelece um questionário preenchido em análise conjunta entre o facilitador e o Diretor do Núcleo de Apoio da Defesa Civil do Estado de São Paulo. O Apêndice 6 detalha o questionário preenchido. Os resultados foram considerados satisfatórios, assim como a aplicabilidade em outras localidades do Estado.

\subsubsection{Análise de sensibilidade e robustez dos resultados}

A análise de sensibilidade foi conduzida para o atributo Custo na alteração dos pesos dos atributos e de sua função de valor, objetivando avaliar se discrimina ou não soluções, para os atributos Infraestrutura e Gestão em seus pesos e, também, 
conduzida para Distância em relação à coordenadoria regional (subcritério de Gestão). O intuito é verificar se alterações nas análises realizadas durante os processos de estruturação e avaliação do modelo e modificações na gestão regional na Defesa Civil podem modificar os resultados do modelo. Após os resultados da análise de sensibilidade, uma reunião de reavaliação foi conduzida em função dos resultados da função de valor dos custos.

\subsubsection{Alterações dos pesos dos atributos}

Foram avaliados todos os subcritérios (custo, infraestrutura e gestão) em função da alteração dos pesos dos atributos, a fim de verificar se a alteração afeta o resultado final do modelo. Para cada um dos subcritérios, seus atributos foram também avaliados e agrupados nos resultados dos subcritérios.

Para o subcritério Custo à alteração do peso do atributo é representada através da Figura 35 (a linha pontilhada indica o peso do atributo atual):

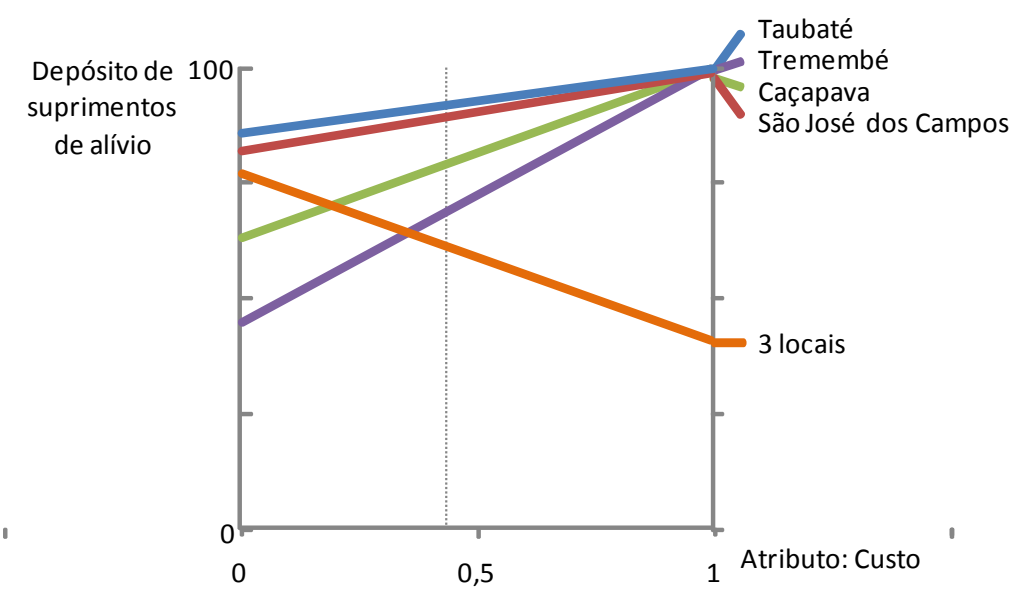

Figura 35 - Resultado global $X$ variação do peso do atributo Custo.

Fonte: Adaptado pelo autor a partir do software V.I.S.A.

Pode ser observado que a variação do peso do atributo para o subcritério Custo não afeta o resultado global do modelo, ou seja, a alternativa Taubaté possui a 
dominância na solução. Resultado similar para o Custo foi obtido por Prado (2011). Outro aspecto relevante, que pode também ser observado, é que com a remoção do atributo Custo (peso $=0$ ) a solução com três locais obtém melhor resultado, enquanto que para as demais alternativas a diferença é apenas ampliada entre a avaliação final dos locais.

Para o subcritério Infraestrutura a alteração do peso do atributo é representada através da Figura 36:

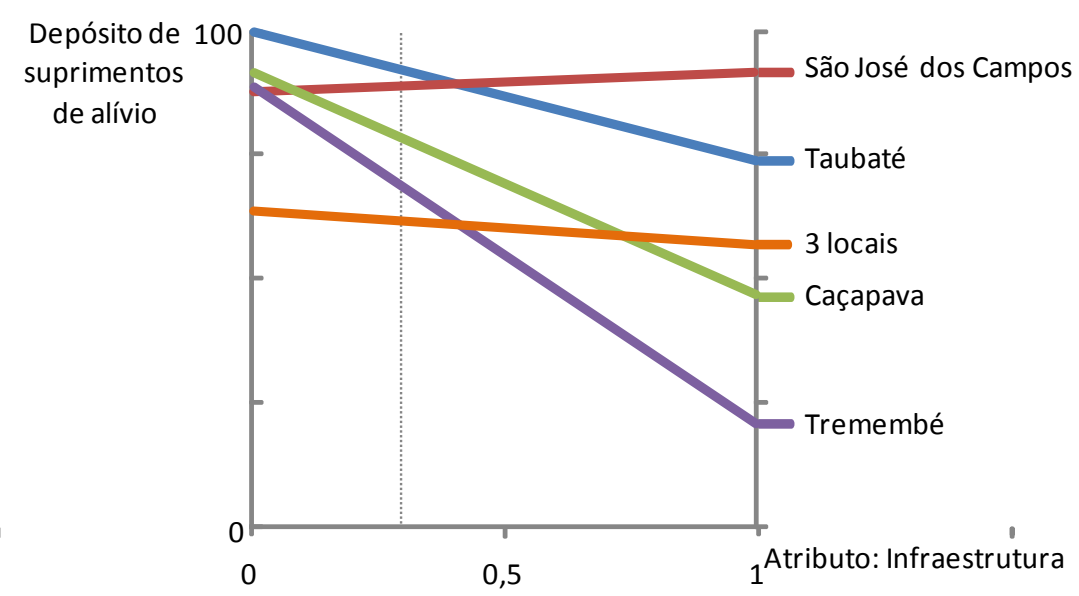

Figura 36 - Resultado global X variação do peso do atributo Infraestrutura.

Fonte: Adaptado pelo autor a partir do software V.I.S.A.

A variação do peso do atributo para o subcritério Infraestrutura pode afetar o resultado global do modelo. Esse fato pode ser explicado, principalmente, pelo atributo Segurança, no qual a alternativa Taubaté não possui as melhores avaliações e, em caso do aumento do peso do atributo (acima de 0,4), outra alternativa passa a ser viável.

Para o subcritério Gestão a alteração do peso do atributo é representada através da Figura 37: 


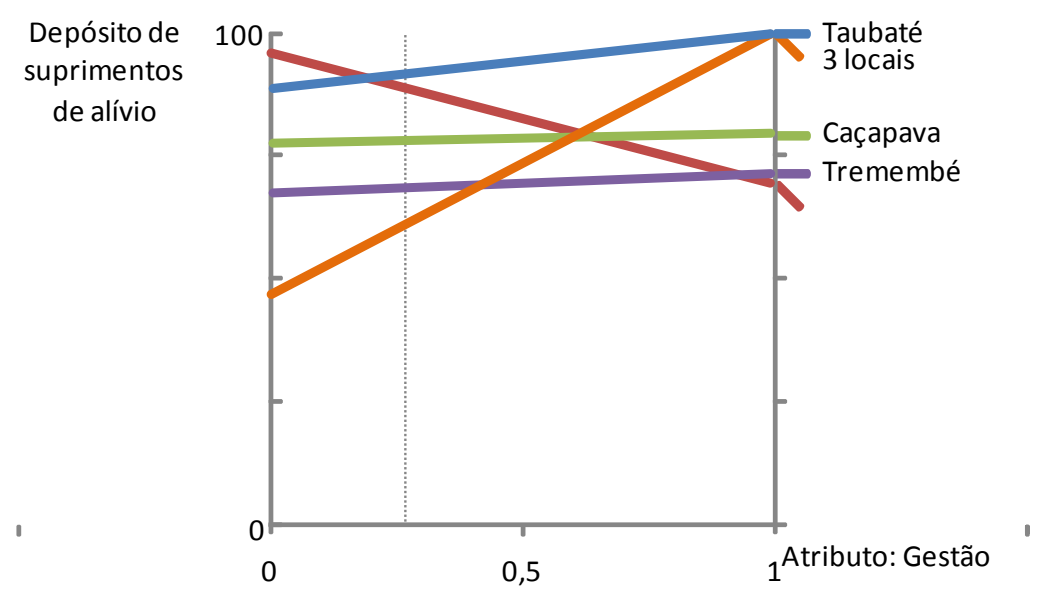

Figura 37 - Resultado global X variação do peso do atributo Gestão.

Fonte: Adaptado pelo autor a partir do software V.I.S.A.

Pode ser observado que o modelo é sensível à variação do peso do atributo para o subcritério Gestão. Esse fato ocorre devido ao atributo Distância em relação à coordenadoria regional, que atualmente encontra-se situada no município de Taubaté. Em caso de redução do peso do atributo (abaixo de 0,19 ) o resultado pode ser alterado.

\subsubsection{Distância em relação à coordenadoria regional}

Outro aspecto avaliado nessa análise de sensibilidade foi o atributo "Distância em relação à coordenadoria regional", pois a REDEC é uma designação adicional a uma função (militar ou civil) exercida, não possuindo um local fixo dentro da região, podendo ser alterada mediante a alteração do Diretor Regional. Foi observado que este atributo pode alterar o resultado do modelo.

A alteração do local foi avaliada para os municípios de Tremembé, Caçapava e São José dos Campos. Na Figura 38, é possível observar que o desempenho de São José dos Campos é superior ao modelo original no atributo Distância em relação à coordenadoria regional. (comparativo com Figura 31). Esta diferença proporciona a alteração do desempenho global. 
Os resultados apresentados na Figura 38, mostram onde ocorre a alteração da decisão para o critério Gestão e para o resultado final, respectivamente. Essa alteração ocorre caso o local sede do REDEC sejam os municípios de Caçapava ou São José dos Campos (desempenhos similares entre os municípios, figuras mostram Caçapava, pois São Jose dos Campos é solução apenas comparativa).

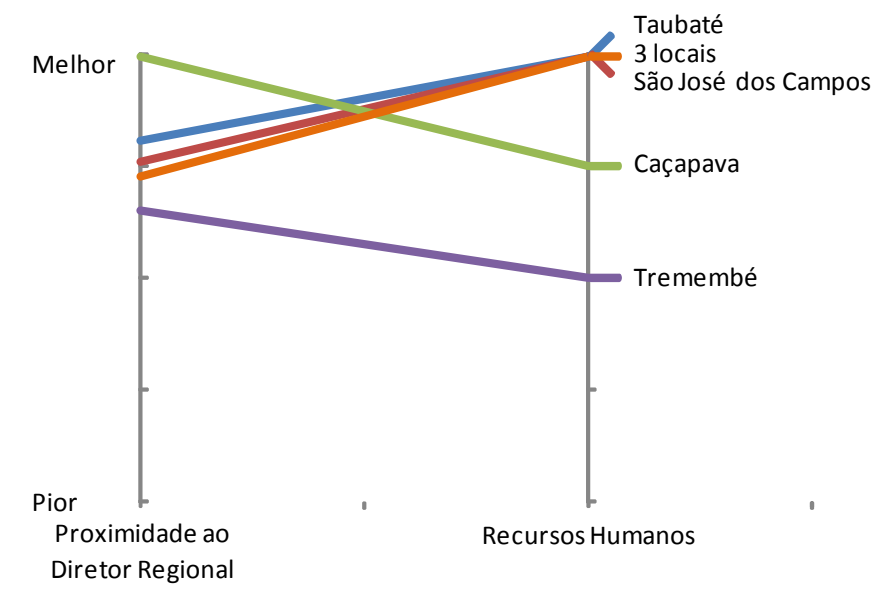

Figura 38 - Resultados para o subcritério Gestão com alteração do local da coordenadoria. Fonte: Adaptado pelo autor a partir do software V.I.S.A.

A Figura 39 mostra o desempenho global e seus respectivos valores para os locais. Essa alteração ocorre caso o local sede do REDEC sejam o municípios de Caçapava ou São José dos Campos.

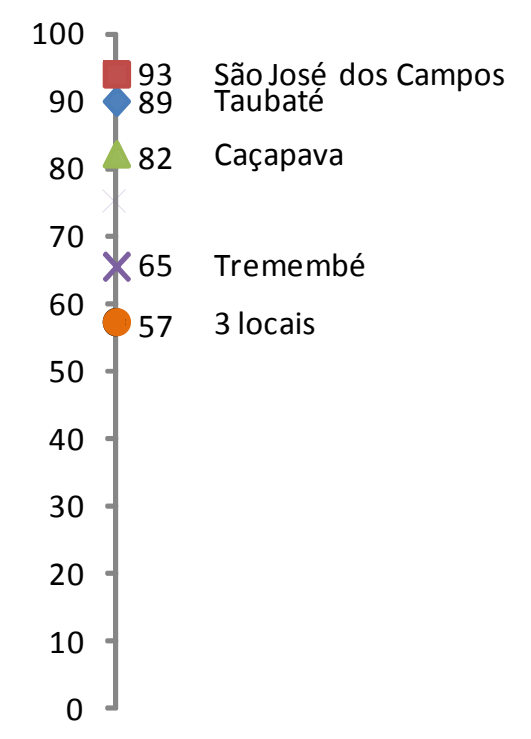

Figura 39 - Resultado global com alteração do local da coordenadoria. Fonte: Adaptado pelo autor a partir do software V.I.S.A. 
Apesar da alternativa "SP + São José dos Campos" ser apresentada apenas para fins comparativos, pode-se observar que o resultado final foi alterado e o modelo é sensível a esse atributo.

\subsubsection{Alteração da avaliação do atributo Custos}

Outra análise realizada aborda o comportamento do modelo multicritério caso mediante a alteração da função de valor. O valor mínimo $(0 \%)$ da função de valor foi acrescido em $50 \%$ e $100 \%$ e verificado o comportamento dos resultados. Apenas ocorreu o deslocamento da solução com três locais que obteve melhores resultados no atributo custo (78\% para acréscimo de $50 \%$ e $88 \%$ para acréscimo de $100 \%$ ), entretanto o resultado global não foi alterado. A Figura 40 mostra a alteração do comportamento dos custos e os outros atributos para o acréscimo de $100 \%$ (acréscimo de $50 \%$ apresentou comportamento bastante similar). Comparada com a Figura 33 pode ser observado (conforme esperado) o melhor desempenho do atributo Custo.

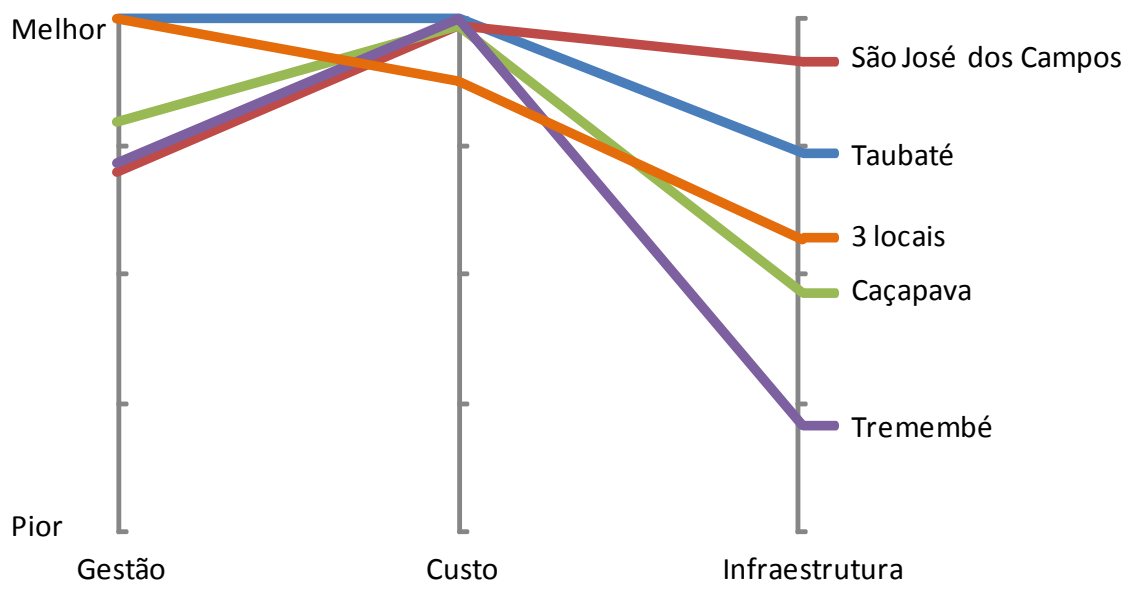

Figura 40 - Resultados para os subcritérios Custos, Gestão e Infraestrutura. Fonte: Adaptado pelo autor a partir do software V.I.S.A. 
A Figura 41 mostra o desempenho global e respectivos valores para as localidades, considerando o acréscimo de $100 \%$ do valor mínimo. Comparando esse resultado com o desempenho global apresentado na Figura 34, é observado que apenas a alternativa com três localidades tem o resultado alterado.

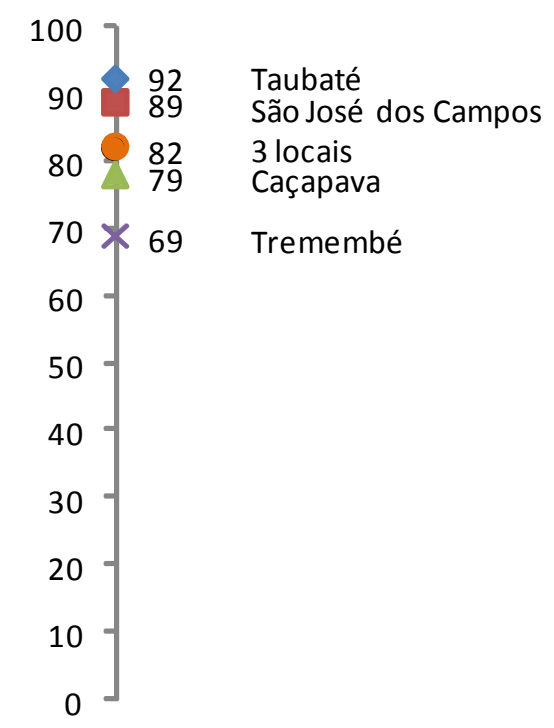

Figura 41 - Resultado global com alteração da função de valor de Custos. Fonte: Adaptado pelo autor a partir do software V.I.S.A.

Fechamento do capítulo:

Os resultados da modelagem multicritério e da análise de sensibilidade mostraram que características referentes às cidades de maior porte, situadas em entroncamentos rodoviários, possuem dominância nas soluções. Isso ocorre devido às ferramentas de gestão e infraestrutura nessas localidades, especialmente, unidades maiores da Polícia Militar, que proporcionam disponibilidade de recursos humanos, além da melhor acessibilidade viária. Esses locais proporcionam melhor robustez à solução, pois, além das características de otimalidade, possuem os atributos de Gestão e Infraestrutura, que garantem a operação sob diferentes cenários. As análises de sensibilidade mostraram que o resultado pode ser alterado mediante alterações no atributo Gestão (Distância em relação à coordenadoria regional). 


\section{Conclusões e estudos futuros}

Este capítulo final objetiva expor as conclusões e as contribuições desta tese. Como apresentado na Introdução, o objetivo deste trabalho foi propor uma metodologia para localização de instalações para armazenagem de suprimentos de alívio na fase de preparação para desastres, levando em consideração critérios quantitativos e qualitativos para uma tomada de decisão robusta. Suprimentos de alívio são materiais básicos para que as vítimas de um desastre tenham acesso a alimentação e higiene, principalmente, nas primeiras 72 horas após o evento.

Foi realizada uma revisão literária abordando a produção acadêmica referente à desastres, cadeias de suprimentos, logística de operações humanitárias, programação linear estocástica, modelos de localização determinísticos e estocásticos aplicados à logística humanitária e métodos multicritério. Verificou-se que a tomada de decisão, com base em modelos de localização, que utilizam ferramentas de pesquisa operacional, é ampla; entretanto artigos acadêmicos, que consideram também a utilização de ferramentas multicritério, anteriormente e posteriormente a modelagem, é escassa. Outra lacuna observada na literatura foi a de metodologias para atribuição de penalidades e calibração de modelos.

Posteriormente, foi proposta a modelagem com base nos artigos de Mete e Zabinsky (2010) e Rawls e Turnquist (2011). Parâmetros qualitativos foram definidos para a escolha de locais candidatos e a seleção desse local foi realizada com base naqueles que atendam às características de tais parâmetros. A seguir, um modelo linear estocástico foi utilizado para minimizar o custo total de atendimento, composto pelos custos de abertura do depósito e fixo anual; transporte; e penalidade pelo não atendimento, mediante restrições que podem ser agrupadas como de nível mínimo de atendimento (demanda mínima e cobertura); de capacidade (armazenagem e transporte); e de disponibilidade de materiais (estoque, doações e compras). Características específicas da operação humanitária, como compras emergenciais e rupturas nas vias de acesso, foram inseridas nessas restrições. 
Para avaliação, o modelo foi aplicado em abastecimento do Vale do Paraíba Paulista, uma região com histórico de ocorrências de desastres naturais. A demanda foi estimada com base nos mapas de risco dos municípios da região, onde a população em situação de vulnerabilidade, nas áreas de risco, é quantificada conforme susceptibilidade a magnitude do desastre; nos dados demográficos; e na utilização de guias internacionais para estimativa da quantidade de materiais.

No estabelecimento dos cenários utilizados na modelagem foram consideradas a magnitude do desastre, a quantidade de doações e possíveis rupturas nos acessos aos locais. Um painel de especialistas no assunto definiu as probabilidades de cada cenário.

Para a solução foi usado o AIMMS 3.13 com Solver CPLEX 12.5. O pacote apresentou tempos de solução baixos e extrema facilidade na inserção e extração de dados, mostrando facilidade operacional e desempenho muito satisfatório para solução do problema desse porte.

Os resultados da modelagem estocástica mostraram que o principal componente de custo refere-se à penalidades e o modelo é sensível a esse valor. $O$ modelo estocástico, além de minimizar os custos da operação, também mostrou a quantidade de depósitos a serem abertos e 0 atendimento em caso de rupturas em vias de acesso. Os resultados indicaram a abertura de dois depósitos para armazenamento dos suprimentos de alívio. O depósito atualmente existente na cidade de São Paulo seria utilizado para esse fim e mais um depósito seria localizado na própria região. Os resultados do modelo também mostraram que a diferença de custos entre os resultados não era acentuada e que diferenças qualitativas, entre os locais, afetam a decisão de escolha, justificando, desta forma, a aplicação de um modelo de decisão multicritério para o processo de tomada de decisão.

O desempenho estocástico do modelo foi avaliado por meio das medidas de EVPI e VSS, conforme Noyan (2012) e Salmeron e Apte (2010), e apresentou bons resultados para a acomodação de incertezas $A$ atribuição de penalidades e a 
calibração do modelo foram realizadas com base no comportamento do modelo, através dos indicadores EVPI e VSS.

A mídia apresenta papel fundamental durante um desastre, especialmente, porque influencia o nível de doações recebidas. Neste trabalho esse papel foi utilizado para o estabelecimento de cenários, considerando o aumento do volume de doações de materiais utilizados pela população afetada pelo desastre.

Os resultados mostram que a disponibilidade atual de materiais para grandes desastres e catástrofes, assim como, os orçamentos de compra não são suficientes para as operações de resposta a esses eventos. Nos cenários, com baixa divulgação de mídia, as faltas ocorreram devido à quantidade disponível de materiais e, em alguns casos, mesmo com materiais em quantidade suficiente em estoque ou possíveis de serem comprados, restrições de capacidade de armazenagem impediram que fossem utilizados para atendimento. Os cenários que mostram situações com alta divulgação de mídia apresentaram faltas em menor quantidade, devido ao maior volume de doações e compras, principalmente, em relação aos materiais destinados à população, todavia materiais disponíveis também não foram utilizados, devido às restrições de capacidade de armazenagem.

Conforme a magnitude do desastre aumenta, não somente o suprimento de materiais, mas também a tomada de decisões e ações de coordenação devem ser mais eficazes. Planejamento de transporte e locais, que permitam a triagem e armazenamento de materiais para responder a um desastre, também se fazem necessários.

Considerações sobre sofrimento humano (HOLGUÍN-VERAS et al. 2013) e variação de parâmetros (BALCIK; BEAMON, 2008) foram realizadas na análise de sensibilidade do modelo estocástico, demonstrando que a maior influência no resultado do modelo foi a capacidade de armazenagem. Pesquisas de campo mostraram ainda que este parâmetro é fundamental para atendimento aos desabrigados e desalojados (CARNEIRO et al., 2013). A definição prévia de locais, que possuam capacidade e possam ser utilizados como armazéns ou como pontos 
de triagem de doações, é uma boa estratégia de preparação a ser inserida nos planos de Defesa Civil.

Pelas características do problema, com critérios intangíveis e subjetivos, mediante riscos, a utilização somente do critério Custos não é robusta o suficiente para suportar a tomada de decisão. A utilização de ferramenta de decisão com múltiplos critérios possui facilidade de aplicação prática e propõe um formato racional e sistemático de escolha.

Após a modelagem estocástica, o modelo multicritério foi aplicado para a escolha do local, a abordagem MCDA adotada foi a MAVT, proposta por Keeney (1992), e revista por Franco e Montibeller (2010b). O processo foi estruturado através da elaboração de árvores de valor para a definição dos atributos e criação de alternativas. Posteriormente, em interação com os stakeholders, foram obtidas as funções de valor e os pesos de cada um dos atributos para, então, avaliar os locais candidatos; agregar os desempenhos; e obter o resultado global. Análise de sensibilidade para alterações nos pesos dos atributos foi efetuada. Os resultados mostraram sensibilidade ao atributo "Distância em relação à coordenação regional". Alguns resultados não eram esperados inicialmente, como a pouca discriminação do atributo Custos na solução com duas localidades, que requereu uma análise mais detalhada desse comportamento.

Municípios de maior porte, situados em entroncamentos rodoviários, mostraram desempenho superior aos demais, devido à disponibilidade de ferramentas de gestão e melhor infraestrutura nessas localidades. Os resultados da modelagem multicritério indicam que municípios sede de mesorregiões obtiveram resultados melhores em comparação aos demais. Uma comparação entre o resultado do modelo estocástico com o do modelo multicritério mostra alteração de localidade das soluções São Paulo e Tremembé para São Paulo e Taubaté. Essa alteração provocou um deslocamento de $14 \mathrm{~km}$ na solução, correspondendo à distância entre as localidades. 
Desta forma, os objetivos estabelecidos no Capítulo 1 deste trabalho de pesquisa que é "propor uma metodologia para localização de instalações para armazenagem de suprimentos de alívio em uma fase de preparação para um eventual desastre, levando em consideração critérios quantitativos e qualitativos para a tomada de decisão" podem ser considerados como atingidos.

\subsection{Contribuições do trabalho}

De maneira similar ao trabalho de Fernandes (2010), este trabalho acadêmico possui contribuições de método utilizado para a localização de instalações para armazenagem de suprimentos de alívio e contribuição de aplicação realizada, em que não somente os resultados da modelagem, mas também formas da obtenção dos parâmetros e outros produtos são oriundos do trabalho.

Este trabalho contribuiu no desenvolvimento de uma metodologia para o problema de localização de suprimentos de alivio através dos Modelos Estocásticos de Localização e, posteriormente, Métodos Multicritério para Tomada de Decisão. Essa abordagem proporcionou uma avaliação que considera parâmetros qualitativos e quantitativos na tomada de decisão sobre localização em logística de operações humanitárias e, consequentemente, mais robusta, pois é capaz de avaliar sua aplicabilidade mediante diferentes cenários.

Outra lacuna observada na literatura, e abordada neste trabalho, foi a de metodologia para atribuição de penalidades e calibração de modelos. A estimativa da demanda, utilizando informações disponíveis, como mapas de risco e dados demográficos, é um método que utiliza conhecimentos de instituições governamentais brasileiras e de fácil acesso. Também foram utilizadas restrições para alocação de produtos que possam ser adquiridos mediante contratos previamente negociados.

Neste trabalho, buscou-se também o entendimento de contextos referentes à preparação e resposta a desastres no Brasil, e não somente a visualização dos 
valores resultantes do processo de modelagem adotado. Para desastres maiores, uma estratégia de preparação que contemple ações de coordenação, como criação de capacidade incidental, priorização de materiais e planejamento de rotas são mais eficazes do que a abertura de mais depósitos.

O comportamento das faltas, e os motivos que as causaram, permite uma análise sobre a organização da Defesa Civil no Brasil (BRASIL, 2012), que é estruturada com base nos Planos Diretores de Defesa Civil, em nível municipal; e a abordagem regionalizada é limitada à cinco macrorregiões geográficas do país, não contemplando mesorregiões e microrregiões estaduais. Os planos de preparação e resposta são elaborados pelas cidades, entretanto, em desastres de grande magnitude, as estruturas físicas dos municípios atingidos podem ser rompidas, como pode ser observado nos desastres de São Luiz do Paraitinga, em 2010, e na região serrana do Rio de Janeiro, em 2011. Os municípios sede das meso e microrregiões, embora não atingidos pelo desastre, são comprometidos, especialmente, pela necessidade do fornecimento de mão de obra e de locais para recebimento e triagem de doações, e passam a operar como uma central de distribuição secundária (KAWASAKI et al., 2012) para o abastecimento da localidade afetada pelo desastre. Apesar da existência de coordenação regional, existem deficiências na integração regional. Uma abordagem regionalizada e que estabeleça características operacionais similares para os planos de preparação e resposta, e que considere o auxílio mútuo entre as localidades, especialmente, predefinição de locais para apoio logístico e compartilhamento de materiais, é recomendada, pois aumentaria a capacidade de armazenagem (no modelo denominada incidental). A integração, além desse aumento de capacidade, facilita também ações de treinamento e qualificação, o compartilhamento reduziria a necessidade de investimentos dos municípios em equipamentos, assim como a dependência de organismos estaduais seria reduzida.

Essa estrutura focada nos municípios, na qual é assumido que as cidades serão capazes de realizar as operações logísticas, mostrou-se ineficaz na resposta ao desastre de Tōhoku, no Japão, em 2011, pois muitas estruturas municipais existentes foram destruídas e cada prefeitura tomou decisões de modo independente, priorizando os materiais de maneiras diferentes umas das outras, 
com pouca troca de informações, evidenciando problemas de coordenação, o que acarretou na dificuldade na gestão de capacidade dos depósitos (HOLGUÍN-VERAS et al., 2014).

Outra questão observada é a necessidade de planos de alerta e resposta integrados dentro de uma mesma bacia hidrográfica. A legislação brasileira prevê essa integração (BRASIL; 2012), entretanto os planos de resposta e as capacidades de armazenagem e transporte não consideram esse aspecto. Estados e municípios, comumente, possuem seus limites geográficos através de cursos d'água, e, em algumas situações, municípios formam um conglomerado urbano separado apenas por um rio e não possuem planos de emergência integrados. Essa situação agravase quando estão situados em estados diferentes. Outro aspecto é a integração dos sistemas de monitoramento e alertas, principalmente para sobreaviso de municípios que situam-se a jusante de uma mesma bacia hidrográficas.

A logística de resposta a desastres é uma atividade crucial. Algumas recomendações em uma etapa de preparação à desastres são sugeridas, como a criação de um comitê para a logística de resposta, integrando a sociedade civil nesse processo, treinando e qualificando pessoal, o que proporciona ganhos de capacidades e consequente melhoria na operação logística (HOLGUÍN-VERAS et al., 2014).

A elicitação dos critérios de decisão, que devem ser contemplados num processo de localização de suprimentos de alívio, evidenciado através do desenvolvimento de uma árvore de valor, pode servir de referência para outros processos decisórios em logística de operações humanitárias e também para outros tipos de desastre.

No desenvolvimento deste trabalho foram encontradas algumas limitações e dificuldades, como a obtenção de opiniões de especialistas. Recomenda-se na aplicação, neste tipo de análise, uma seleção inicial de experts em quantidade, pelo menos, $100 \%$ maior que o valor desejado ou mínimo necessário, a fim de obter uma amostra possível de ser analisada.

Além do modelo, outro produto, oriundo da elaboração deste trabalho, é uma planilha para estimativa de demanda de materiais em caso de desastres (inclusive 
água), com base em The Sphere Project (2011) e nas informações e dados obtidos. Essa planilha foi distribuída aos representantes (COMDECs) dos municípios do Vale do Paraíba. O usuário insere a quantidade de desabrigados/desalojados ou a quantidade de habitações destruídas e a demanda quinzenal de suprimentos de alívio é estimada, assim como a necessidade de transporte.

Acidentes de grande porte podem ser uma realidade na região do Vale do Paraíba Paulista. Nas discussões com a Defesa Civil foi ressaltado que a divisa do Estado de São Paulo, encontra-se a uma distância geodésica inferior a $15 \mathrm{~km}$ da Central Nuclear de Angra dos Reis. Uma eventual evacuação, devido a acidente de origem tecnológica na região, poderia gerar uma demanda humanitária de grande porte.

\subsection{Propostas para estudos futuros}

Algumas percepções obtidas durante 0 desenvolvimento deste trabalho e análise de trabalhos científicos, que possam propiciar um aprimoramento, foram realizadas, dentre elas destacam-se:

- Integrar os processos de modelagem e utilizar um único software, pois, foram utilizados dois, processo de modelagem para elaborar a otimização estocástica e a análise com múltiplos critérios.

- Alterar o modelo estocástico, abrangendo restrições de capacidade por grupos de materiais (roupas, alimentos, produtos de limpeza e de organização do local) não avaliando as restrições de cada material de maneira isolada.

- Aprimorar a estimativa da demanda mínima, com base em análise de privação de materiais e seus efeitos no organismo humano, considerando o abastecimento baseado na priorização de materiais ao longo do tempo e 
utilizando períodos mais longos que às 72 horas iniciais. Atualmente, esses estudos estão limitados somente ao item água (HOLGUÍN-VERAS et al., 2013).

- Considerar estudos sobre o CNN Effect para avaliação do impacto da mídia em doações, considerando o veículo e o meio utilizado, bem como o efeito produzido por cada um deles.

- Aplicar este trabalho a outras regiões do Estado de São Paulo e outros locais do país ou no exterior, especialmente para efeito comparativo do modelo.

- Analisar o arranjo institucional da Defesa Civil, para que possa contemplar auxílio mútuo e coordenação integrada em municípios situados em uma mesma região.

Este modelo é uma análise isolada e acadêmica que pode proporcionar melhorias no atendimento à população desabrigada/desalojada. Também pode ser aplicado em outras regiões do Estado de São Paulo, bem como, em outros estados e nações.

A aplicação prática da metodologia junto a Defesa Civil gerou discussões relevantes sobre o assunto, na qual pessoal envolvido efetivamente nas operações apresentaram pontos de vista e que alguns atributos, que, muitas vezes, poderiam despertar menor importância em um ambiente acadêmico, possuem grande valor para aqueles que efetuam as atividades em campo, demonstrando, desta forma, a importância da interação entre pesquisadores e profissionais de operação. 


\section{REFERÊNCIAS}

ACKERMANN,F.; EDEN, C. Strategic Management of Stakeholders: Theory and Practice, Long Range Planning, v. 44, n. 3, p. 179-196, 2011.

AKKIHAL, A. R. Inventory Pre-positioning for Humanitarian Operations. 2006. 109 p. Dissertação (Mestrado) - Massachusetts Institute of Technology. Engineering Systems Division, Boston, 2006.

ALBALA-BERTRAND, J. M. Responses to complex humanitarian emergencies and natural disasters: An analytical comparison. Third World Quarterly, v. 21, n. 2, p. 215-227, 2000.

ALTAY, N.; GREEN, W. G. OR/MS research in disaster operations management, European Journal of Operational Research, v. 175, p. 475-493, 2006.

AMARAL, R.; GUTJAHR, M. R. Desastres naturais. Cadernos de Educação Ambiental. São Paulo: Instituto Geológico / SMA, 2011.

APTE, A. Humanitarian Logistics: A New Field of Research and Action. Foundations and Trends in Technology, Information and Operations Management. v. 3, n. 1, p. 1-100, 2009.

APTE, A.; YOHO, K. D. Strategies for Logistics in Case of a Natural Disaster. Defense Acquisition Research. Naval Postgraduate School, Monterey, California, 28 Sep. 2011.

ARMAŞ, I, Multi-criteria vulnerability analysis to earthquake hazard of Bucharest, Romania. Natural Hazards, v. 63, p. 1129-1156, 2012.

ARNOLD, A-K. What Influences Individual Donations to Disaster Victims. Disponível em: <http://blogs.worldbank.org/publicsphere/node/5742>. 2011. Acesso em 16 nov. 2012.

ASLANYAN, L. IFRC Global Logistics Service. Disponível em: <http://www.aidexpo.com/Assets/UserData/aidex/Presentations/A2_Wednesday\%2011.15.pdf>. 2011. Acesso em 23 set. 2013. 
BALCIK, B.; BEAMON, B. M.; SMILOWITZ, K. Last Mile Distribution in Humanitarian Relief. Journal of Intelligent Transportation Systems: Technology, Planning, and Operations, v.12, n. 2, p. 51-63, 2008.

BALCIK, B.; BEAMON B. M. Facility location in humanitarian relief. International Journal of Logistics: Research and Applications, v. 11, n. 2, p. 101-121, 2008.

BALDINI, G.; OLIVERI, F.; BRAUN, M.;SEUSCHEK, H.; HESS,E. Securing disaster supply chains with cryptography enhanced RFID", Disaster Prevention and Management, v. 21, n. 1, p. 51-70, 2012.

BALLOU, R. H. Gerenciamento da Cadeia de Suprimentos / Logística Empresarial. 5ed. Porto Alegre: Bookman Companhia Ed, 2006. 616 p.

BANA e COSTA, C. A.; ENSSLIN, L.; CORRÊA, E. C.; VANSNICK, J-C. Decision Support Systems in action: Integrated application in a multicriteria decision aid process. European Journal of Operational Research, v. 113, p. 315-335, 1999.

BANOMYONG, R.; SOPADANG, A. Using Monte Carlo Simulation to Refine Emergency Logistics Response Models: a case study. International Journal of Physical Distribution and Logistics Management, v. 40, n. 8/9, p.709- 721. 2010.

BARBAROSOGLU, G., ARDA, Y. A two-stage stochastic programming framework for transportation planning in disaster response. Journal of the Operational Research Society, v. 55, n. 1, p. 43-53, 2004.

BARBAROSOGLU, G.; ÖZDAMAR, L.; ÇEVIK , A. An interactive approach for hierarchical analysis of helicopter logistics in disaster relief operations. European Journal of Operational Research, v. 140, n. 1, p. 118-133, 2002.

BARBOSA, E. O.; MONTEIRO, V. L.; GIANNOTTI, M.A.; BRITO, JR I. Localização de depósito de suprimentos de alívio para atendimento a desastres naturais no Vale do Paraíba Paulista. In XXIV ANPET - Congresso Nacional de Pesquisa e Ensino em Transporte, 2010, Salvador. Anais Salvador BA: Anpet, 2010.

BEAMON, B. M., KOTLEBA, S. A. Inventory modeling for complex emergencies in humanitarian relief. International Journal of Logistics: Research and Applications, v. 9, n. 1, p. 1-18, 2006. 
BEAMON, B. M.; KOTLEBA, S.A. Inventory management support systems for emergency humanitarian relief operations in South Sudan. The International Journal of Logistics Management, v. 17, n. 2, p. 187-212, 2006b.

BELTON, V. Comparison of the analytic hierarchy process and a simple multiattribute value function. European Journal of Operational Research, v. 26, p. 721, 1986.

BELTON V.; GEAR T. On the meaning of relative importance. Journal of MultiCriteria Decision Analysis, v. 6, n. 6, p. 335-338, 1997.

BELTON, V.; STEWART, T.J. Multiple criteria decision analysis: an integrated approach. Boston : Kluwer Academic Publishers, 2002. 372 p.

BELTON, V; ACKERMANN, F; SHEPHERD, I. Integrated Support from Problem Structuring through to Alternative Evaluation Using COPE and V.I.S.A. Journal of Multi-Criteria Decision Analysis, v. 6, n. 3, p. 115-130, 1997.

BELTON, V; PICTET, J. Talking about the practice of MCDA. In: Aiding Decisions with Multiple Criteria. Essays in Honor of Bernard Roy. Bouyssou, D., Jacquet-Lagrèze, E., Perny, P., Slowiński, R., Vanderpooten, D., Vincke, P. (Ed.). Dordrecht: Kluwer Academic Publishers, p. 71-88, 2002. 558 p.

BEN-TAL, A.; NEMIROVSKI, A. Robust solutions of linear programming problems contaminated with uncertain data. Mathematical Programming, v. 88, p. 411424, 2000.

BERTAZZO, T. R., BRITO JR, I., LEIRAS, A., YOSHIZAKI, H. Revisão da literatura acadêmica brasileira sobre a gestão de operações em desastres naturais com ênfase em logística humanitária. Transportes, v. 21, n. 3, p. 31-39, 2013.

BESIOU, M.; STAPLETON, O.; VAN WASSENHOVE, L. System dynamics for humanitarian operations, Journal of Humanitarian Logistics and Supply Chain Management, v. 1, n. 1, p. 78-103, 2011.

BIRGE, J. R.; LOUVEAUX, F. Introduction to stochastic programming. New York: Springer, 1997. 
BLANCO, E.; GOENTZEL J. Humanitarian Supply Chains: A Review. In: 17nd Annual POMS Conference, Boston, 2006. Disponível em <http://ctltest1.mit.edu/sites/default/files/library/public/presentation_humanitarian_0406.pdf. >Acesso em: 15 mar. 2012.

\section{BLECKEN, A. Humanitarian Logistics: Modelling Supply Chain Processes of} Humanitarian Organisations. Haupt Verlag: Berne, 2010. 306 p.

BOCCHINI, B. Dois anos após inundação, Paraitinga está $80 \%$ reconstruída. Agência Brasil, 1 jan. 2012. Disponível em: <http://agenciabrasil.ebc.com.br/noticia/2012-01-01/dois-anos-apos-inundacaosao-luiz-do-paraitinga-esta-80-reconstruida>. Acesso em: 15 abr. 2012.

BORTOLOSSI, H. J.; PAGNONCELLI B. K. Uma Introdução a Otimização sob Incerteza. In: XI Simpósio de Pesquisa Operacional e Logística da Marinha, 2008. Rio de Janeiro. Anais Rio de Janeiro RJ: SPOLM, 2008.

BOZORGI-AMIRI, A.; JABALAMELI, M. S.; MIRZAPOUR AL-E-HASHEM, S. M. J. A multi-objective robust stochastic programming model for disaster relief logistics under uncertainty. OR Spectrum, v. 35, n. 4, p. 905-933, 2013.

BRANCATELLI, R. Ação da Defensoria aponta omissão e desvio de verba em tragédia de Paraitinga. O Estado de S. Paulo, 12 ago. 2010. Disponível em: <http://www.estadao.com.br/noticias/impresso,acao-da-defensoria-apontaomissao-e-desvio-de-verba-em-tragedia-de-paraitinga,593822,0.htm>. Acesso em: 15 abr. 2010.

BRANDEAU, M. L.; CHIU, S. S. An overview of representative problems in location research. Management Science, v.35, n. 6, p.645-74, 1989.

BRASIL, LEI № 8.666, DE 21 DE JUNHO DE 1993. Regulamenta o art. 37, inciso $\mathrm{XXI}$, da Constituição Federal, institui normas para licitações e contratos da Administração Pública e dá outras providências. Brasília, 1993.

, LEI № 12.608, DE 10 DE ABRIL DE 2012. Institui a Política Nacional de Proteção e Defesa Civil - PNPDEC; dispõe sobre o Sistema Nacional de Proteção e Defesa Civil - SINPDEC e o Conselho Nacional de Proteção e Defesa Civil - CONPDEC; autoriza a criação de sistema de informações e monitoramento de desastres. Brasília, 2012. 
Ministério da Integração Nacional, Secretaria Nacional de Defesa Civil. Política Nacional de Defesa Civil. Brasília, 2007.

BRYSON, J.M. What to do when stakeholders matter: stakeholder identification and analysis techniques. Public Management Review, v.6, n.1, p. 21-53, 2004.

BRUNO, G.; GHIANI, G.; IMPROTA G. A multi-modal approach to the location of a rapid transit line. European Journal of Operational Research, v. 104, p. 321332, 1998.

BUDNITZ, R.J.; APOSTOLAKIS, G.; BOORE, D.M.; CLUFF, L.S.; COPPERSMITH, K.J.; CORNELL, C.A.; MORRIS, P.A. Use of Technical Expert Panels: Applications to Probabilistic Seismic Hazard Analysis. Journal of Risk Analysis, v.18, N. 4, p. 463-469. 1998.

CAMPBELL, A.M.; JONES, P.C. Prepositioning supplies in preparation for disasters. European Journal of Operational Research, v. 209, p. 156-165, 2011.

CAMPBELL, A.M.; VANDENBUSSCHE, D.; HERMANN W, Routing for relief efforts. Transportation Science, v.42, n. 2, p. 127-145, 2008.

CARNEIRO, P. V.; COSTA, O. A. F.; KAWASAKI, B. C.; BRITO JR, I.; YOSHIZAKI, H. T. Y. Logística de resposta a desastres: $O$ caso das chuvas de Cubatão-SP em 2013. In: XXVII ANPET - Congresso Nacional de Pesquisa e Ensino em Transporte, 2013, Belém. Anais Belém PA: Anpet, 2013.

CARTER, W. N. Disaster management: a disaster manager's handbook. Mandaluyong City, Philippines: Asian Development Bank, 2008. 391 p.

CARUZZO, A.; MANSO, D.; BELDERRAIN, M. C. N. Planejamento do sistema de meteorologia no apoio da logística humanitária: a visão dos previsores utilizando a teoria de valor multiatributo. Pesquisa operacional para o desenvolvimento, v. 5, n.2, p. 266-290, 2013.

CASTRO, A. L. C. Manual de planejamento em Defesa Civil. V.1. Brasília: Ministério da Integração Nacional/Departamento de Defesa Civil, 1999. 
CEPED - SC, Centro Universitário de Estudos e Pesquisas sobre Desastres. Comunicação de riscos e de desastres. Curso a distância / Centro Universitário de Estudos e Pesquisas sobre Desastres. Florianópolis: CEPED, 2010.

CHANG, M.-S.; TSENG, Y.-L.; CHEN, J-W. A scenario planning approach for the flood emergency logistics preparation problem under uncertainty. Transportation Research Part E, v. 43, n. 6, p. 737-754, 2007.

CHAKRAVARTY; A.K. Humanitarian relief chain: Rapid response under uncertainty. International Journal of Production Economics, v. 151, p. 146157, 2014.

CHARNES, A.; COOPER, W.W. Management Models and Industrial Applications of Linear Programming. New York: John Wiley and Sons, 1961. 859 p.

CHAWAGUTA, B.; GONÇALVES, P. Optimizing Distribution of World Food Program's Food Aid in Ethiopia, USI: Working paper. 2011.

CHENG, S.; CHAN, C.W.; HUANG, G.H. An integrated multi-criteria decision analysis and inexact mixed integer linear programming approach for solid waste management. Engineering Applications of Artificial Intelligence, v. 16, p. 543-554, 2003.

CHO, K.T. Multicriteria Decision Methods: An Attempt to Evaluate and Unify. Mathematical and Computer Modelling, v. 37, p. 1099-1119, 2003.

CONFALONIERI, U. E. C. Variabilidade climática, vulnerabilidade social e saúde no Brasil. Terra Livre, Ano 19, v.1, n. 20, p. 193-204, 2003.

CORONEL, S. S. Corruption and the Watchdog Role of the News Media. Norris, $P$. (Ed.) Public sentinel : news media \& governance reform. The International Bank for Reconstruction and Development / The World Bank. Washington, DC: The World Bank, 2010. p. 111-136.

CORREA JR., G. Principais determinantes do preço do frete rodoviário para o transporte de soja em grãos em diferentes regiões brasileiras: uma análise econométrica. 2011.147 p. Dissertação (Mestrado) - Escola Superior de Agricultura "Luiz de Queiroz", Universidade de São Paulo, Piracicaba, 2011. 
COTTAM, H-R.; CHALLACOMBE, J.; ROE, M. Outsourcing of Trucking Activities by Relief Organisations. The Journal of Humanitarian Assistance, January 1, 2004, p. 1-26, 2004.

COUSINEAU, D.; CHARTIER, S. Outliers detection and treatment: a review. International Journal of Psychological Research, v. 3, n. 1, p. 58-67, 2010.

COZZOLINO, A. Humanitarian Logistics, Cross-Sector Cooperation in Disaster Relief Management. London: SpringerBriefs in Business, 2012. 48p.

CURRENT, J.; O'KELLY, M. Locating Emergency Warning Sirens. Decision Sciences, v. 23, n. 1, p. 221-234, 1992.

DE BOER, L.; WEGEN, L.L.M.V.D. Practice and promise of formal supplier selection: a study of four empirical cases. Journal of Purchasing \& Supply Management, v. 9, p. 109-118, 2003.

DECKLE, J.; LAVIERI, M. S.; MARTIN, E.; EMIR-FARINA,S H.; FRANCIS, R. L. A Florida County Locates Disaster Recovery Centers. Interfaces, v. 35, n. 2, p. 133-139, 2005.

DREZNER, T.; DREZNER, Z.; SALHI, S. A multi-objective heuristic approach for the casualty collection points location problem. The Journal of the Operational Research Society, v. 57, n. 6, p. 727-734, 2006.

DURAN, S.; GUTIERREZ, M. A.; KESKINOCAK, P. Pre-Positioning of Emergency Items Worldwide for CARE International. Interfaces, v. 41, n. 3, p. 223-237, 2011.

DYER, J. S. Remarks on the Analytic Hierarchy Process". Management Science, v. 36, n. 3, p. 249-258, 1990.

EDEN, C. Analyzing cognitive maps to help structure issues or problems.

European Journal of Operational Research, v. 159, p. 673-686, 2004.

EM-DAT: The OFDA/CRED International Disaster Database Université Catholique de Louvain, Classification. Disponível em <http://www.emdat.be/classification>. Acesso em: 2 abr. 2012. 
ENSSLIN, L.; GIFFHORN, E.; ENSSLIN, S.R; PETRI , S. M.; VIANNA, W.B. Avaliação do desempenho de empresas terceirizadas com o uso da metodologia multicritério de apoio à decisão - construtivista. Pesquisa Operacional, v. 30, n. 1, p.125-152, 2010.

ENSSLIN, L.; MONTIBELLER NETO, G.; NORONHA S. M. Apoio à decisão metodologias para estruturação de problemas e avaliação multicritério de alternativas. Florianópolis : Insular, 2001. 296 p.

ERKUT, E., A. INGOLFSSON. Catastrophe Avoidance Models for Hazardous Materials Route Planning. Transportation Science, v. 34, n. 2, p. 165-179, 2000.

FARAHANI, R. Z.; ASGARI, N. Combination of MCDM and covering techniques in a hierarchical model for facility location: A case study. European Journal of Operational Research, v. 176, p. 1839-1858, 2007.

FARAHANI, R. Z.; STEADIESEIFI, M.; ASGARI, N. Multiple criteria facility location problems: A survey. Applied Mathematical Modelling, v. 34, p. 16891709, 2010.

FARIAS, C. Bombeiros ainda procuraram homem desaparecido em São Luis do Paraitinga. R7, 5 jan. 2010. Disponível em: <http://noticias.r7.com/saopaulo/noticias/bombeiros-ainda-procuram-homem-desaparecido-em-sao-luis-doparaitinga-20100105.html>. Acesso em: 15 abr. 2012.

FDEM - Florida Division of Emergency Management Logistics. Technical Bulletin, LTB April, 2005. Disponível em <http://www.floridadisaster.org/Response/Logistics/ 2007/Documents/LTB\%2011.pdf>. Acesso em: 26 nov. 2013.

FEMA US Department of Homeland Security, Emergency Management Institute, Emergency Management. Disponível em <http://training.fema.gov/emiweb/ downloads/is1_Unit1.pdf>. Acesso em: 2 abr. 2012.

FERNANDES, C.W.N. O enfoque da logística humanitária na localização de uma central de inteligência e suporte para situações emergenciais e no desenvolvimento de uma rede dinâmica. 2010.225 p. Tese (Doutorado) Universidade Federal de Santa Catarina, Departamento de Engenharia de Produção, Florianópolis, 2010. 
FERREIRA, F.; SEVILLE, E.; DANTAS, A.; GIOVINAZZI, S. Extreme Events Decision Making in Transport Networks: A Holistic Approach Using Emergency Scenarios and Decision Making Theory. Journal of the Eastern Asia Society for Transportation Studies, v. 8, p.70-85, 2010.

FERRETI, V. A. Multicriteria Spatial Decision Support System Development for Siting a Landfill in the Province of Torino (Italy). Journal of Multi-Criteria Decision Analysis, v. 18, p. 231-252, 2011.

FIEDRICH, F.; GEHBAUER, F.; RICKERS, U. Optimized resource allocation for emergency response after earthquake disasters. Safety Science, v. 35, p. 41-57, 2000.

FRANCO L. A.; MONTIBELLER G, Facilitated modelling in operational research. European Journal of Operational Research, v. 205, n. 3, p. 489-500, 2010a.

FRANCO L. A.; MONTIBELLER G. Problem structuring for multi-criteria decision analysis interventions. Wiley Encyclopedia of Operations, Research and Management Science. Wiley: New York, 2010b.

FRAZELLE, E. H.; SOJO R. Logística de Almacienamento y Manejo de Materiales de Clase Mundial. Bogotá: Grupo Editorial Norma, 2006. 334 p.

GARCÍA VALDÉS, M.; SUÁREZ MARÍN, M. El método Delphi para la consulta a expertos en la investigación científica. Revista Cubana de Salud Pública, v. 39, n. 2, p. 253-267, 2013.

GARFÌ, M.; FERRER-MARTÍ, L.; BONOLI, A.; TONDELLI, S. Multi-criteria analysis for improving strategic environmental assessment of water programmes. A case study in semi-arid region of Brazil. Journal of Environmental Management, v. 92, p. 665-675, 2011.

GARFÌ, M.; TONDELLI, S.; BONOLI, A. Multi-criteria decision analysis for waste management in Saharawi refugee camps. Waste Management, v. 29, p. 27292739, 2009.

GEOFFRION, A. M. The purpose of mathematical programming is insight, not numbers. Interfaces, v.7, n.1, p.81-92, 1976. 
GIACON, J. C. R. Seleção de fornecedores por análise de decisão multicritério e otimização combinatória considerando aspectos de logística e sustentabilidade. 2012. 128 p. Engenharia de Sistemas Logísticos, Escola Politécnica, Universidade de São Paulo, São Paulo, 2012.

GIANNOTTI, M. A.; Desenvolvimento de ontologias para sistemas de apoio a logística humanitária baseados em serviços de informações geográficas: uma aplicação para bancos de alimentos. 2010. 181 p. Tese (Doutorado) Escola Politécnica da Universidade de São Paulo, Departamento de Engenharia de Transportes, São Paulo, 2010.

GOENTZEL, J. Three Experiences with Practical Research in Humanitarian Response. In: I Workshop de Logística Humanitária, Universidade de São Paulo, São Paulo, 2012.

GOMES, L. F. A. M.; ARAYA, M. C. G.; CARIGNANO, C. Tomada de decisão em cenários complexos. São Paulo: Pioneira Thomson Learning, 2004. 168 p.

GOODWIN, P.; WRIGHT, G. Decision Analysis for Management Judgment. 3ed. Chichester: John Wiley \& Sons, 2004. 477 p.

GÖRMEZ, N.; KÖKSALAN, M.; SALMAN, F. S. Locating disaster response facilities in Istanbul. Journal of the Operational Research Society, v. 62, p. 1239-1252, 2011.

GUHA-SAPIR, D.; VOS, F.; BELOW, R.; PONSERRE, S. Annual Disaster Statistical Review 2010: The Numbers and Trends. Brussels: CRED; 2011. 42 p.

HAGHANI, A.; OH, S. Formulation and solution of a multi-commodity, multi-modal network flow model for disaster relief operations. Transportation Research A, v. 30, n. 3, p. 231-250, 1996.

HARKER, P. T.; VARGAS, L. G. The theory of ratio scale estimation: Saaty's Analytic Hierarchy Process. Management Science, v. 33, n. 11, 1987.

HASEKIOGULLARI, G. D.; ERCANOGLU, M. A new approach to use AHP in landslide susceptibility mapping: a case study at Yenice (Karabuk, NW Turkey). Natural Hazards, v. 63, p. 1157-1179, 2012. 
HIGLE, J. L. Stochastic Programming: Optimization When Uncertainty Matters. INFORMS Tutorials in Operations Research, INFORMS, New Orleans, 2005.

HJARVARD, S. Midiatização: teorizando a mídia como agente de mudança social e cultural. Matrizes, v. 5, n. 2, p. 29-52, 2012.

HOKKANEN, J.; SALMINEM, P. Locating a Waste Treatment Facility by Multicriteria Analysis. Journal of Multi-Criteria Decision Analysis, v. 6, p. 175184, 1997.

HOLGUÍN-VERAS, J. On the Unique Features of Humanitarian Logistics: Research Implications. In: I Workshop de Logística Humanitária, Universidade de São Paulo, São Paulo, 2012.

HOLGUÍN-VERAS, J.; PÉREZ, N.; JALLER, M.; VAN WASSENHOVE, L. N.; AROS-VERA, F. On the appropriate objective function for post-disaster humanitarian logistics models. Journal of Operations Management, v. 31, n. 5, p. 262-280, 2013.

HOLGUÍN-VERAS, J.; PÉREZ, N.; UKKUSURI, S.; WACHTENDORF, T.; BROWN, B. Emergency logistics issues impacting the Response to Katrina: a synthesis and preliminary Suggestions for improvement. Transportation Research Record, n. 2022, p. 76-82. 2007.

HOLGUÍN-VERAS; J.; TANIGUCHI, E.; JALLER, M.; AROS-VERA, F.; FERREIRA, F; THOMPSON, R.G. The Tohoku disasters: Chief lessons concerning the post disaster humanitarian logistics response and policy implications. Transportation Research Part A: Policy and Practice, v. 69, p. 86-104, 2014.

HOUSTON, J.B.; PFEFFERBAUM, B.; ROSENHOLTZ, C.E. Disaster News: Framing and Frame Changing in Coverage of Major U.S. Natural Disasters, 2000-2010. Journalism \& Mass Communication Quarterly, v. 89, n. 4, p. 606623, 2012.

HOWDEN, M. How Humanitarian Logistics Information Systems Can Improve Humanitarian Supply Chains: A View from the Field. In: Proceedings of the 6th International ISCRAM Conference 2009, Proceedings Gothenburg, Sweden, May 2009. 
IAKOVOU, E.; IP, C. M.; DOULIGERI, S C. A. Optimal location and capacity of emergency cleanup equipment for oil spill response, European Journal of Operational Research, v. 96, n. 1, p. 72-80, 1996.

IBGE, Instituto Brasileiro de Geografia e Estatística. Censo 2010. Disponível em: <http://www.ibge.gov.br/home/estatistica/populacao/censo2010/default_resultado s_universo.shtm >. Acesso em: 01 dez. 2011.

IFRC International Federation of Red Cross and Red Crescent Societies, Introduction to Disaster Preparedness. 2000. Disponível em $<$ http://www.ifrc.org/Global/Publications/disasters/all.pdf>. Acesso em: 11 out. 2013.

International Federation of Red Cross and Red Crescent Societies, Introduction to the Guidelines for the Domestic Facilitation and Regulation of International Disaster Relief and Initial Recovery Assistance. Geneva: IFRC, 2008. 28 p.

International Federation of Red Cross and Red Crescent Societies, Types of disasters: Definition of hazard. Disponível em: <http://www.ifrc.org/en/whatwe-do/disaster-management/about-disasters/definition-of-hazard/>. Acesso em: 02 ago. 2011.

International Federation of Red Cross and Red Crescent Societies, Humanitarian logistics. Disponível em <http://www.ifrc.org/what-wedo/logistics//>. Acesso em:18 out. 2012.

International Federation of Red Cross and Red Crescent Societies, Annual Report, 2009. Disponível em: <http://www.ifrc.org/Global/Publications/annualreports/ar2009-en.pdf>. Acesso em: 02 ago. 2011.

ISKANDARIAN, C. Família recebe cerca de 700 desabrigados em São Luiz do Paraitinga. G1, 30 jan. 2010. Disponível em: <http://g1.globo.com/Noticias/SaoPaulo/0,,MUL1469024-5605,00familia+recebe+cerca+de+desabrigados+em+sao+luiz+do+paraitinga.html> . Acesso em: 15 abr. 2012. 
KAWASAKI, B. C.; BRITO JR, I.; LEIRAS, A.; YOSHIZAKI, H. T. Y. Logística de resposta a desastres: o caso das chuvas no Vale do Paraíba Paulista em janeiro de 2010. In: XXXII ENEGEP - Desenvolvimento Sustentável e Responsabilidade Social: As Contribuições da Engenharia de Produção, 2012, Anais Bento Gonçalves, 2012.

KEENEY, R.L. Common Mistakes in Making Value Trade-Offs. Operations Research, v.50, n.6, p. 935-945, 2002

KEENEY, R.L. Value-Focused Thinking: A Path to Creative Decision-making. Cambridge: Harvard University Press. 1992. 432 p.

KEENEY, R.L.; GREGORY, R.S. Selecting Attributes to Measure the Achievement of Objectives. Operations Research, v. 53, n. 1, p. 1-11, 2005.

KEENEY, R.L.; RAIFFA, H. Decisions with multiple objectives: preferences and value tradeoffs. New York: Wiley, 1976. $569 \mathrm{p}$.

KESSLER, M. Logistics Network Design in Africa. Haupt Verlag: Berne, 2013. $160 \mathrm{p}$.

KORHONEN, P.; MOSKOWITZ, H.; WALLENIUS, J. Multiple criteria decision support - A review. European Journal of Operational Research, v. 63, p. 361375, 1992.

KOVÁCS, G.; SPENS, K.M. Humanitarian logistics in disaster relief operations, International Journal of Physical Distribution \& Logistics Management, v. 37, n. 2, p. $99-114,2007$.

KOVÁCS, G; SPENS, K.M. (Ed.) Relief supply chain management for disasters: humanitarian aid and emergency logistics. Hershey PA: IGI Global, 2012. 253 p.

LAMONT-GREGORY, E.; HENRY, C.J.K.; RYAN, T.J. Evidence-based humanitarian relief interventions. The Lancet, v. 346, n. 8970, p. $312-313$. 1995.

LARICHEV, O.I., OLSON, D. L. Multiple Criteria Analysis in Strategic Siting Problems. Boston: Kluver Academic Publishers, 2001. 221 p. 
LEIRAS, A. Optimization under Uncertainty for Integrated Tactical and Operational Planning of the Oil Supply Chain. 2011.117 p.. Tese (Doutorado)

- Pontifícia Universidade Católica do Rio de Janeiro, Departamento de Engenharia Industrial, 2011.

LEIRAS, A.; BRITO JR, I.; PERES, E. Q.; BERTAZZO, T.R.; YOSHIZAKI, H. Literature review of humanitarian logistics research: trends and challenges. Journal of Humanitarian Logistics and Supply Chain Management, v. 4, n. 1, p. $95-130,2014$.

LIN, Y-H.; BATTA, R.; ROGERSON, P. A.; BLATT, A.; FLANIGAN, M. Location of temporary depots to facilitate relief operations after an earthquake. SocioEconomic Planning Sciences, v. 46, p. 112 - 123, 2012.

LIN, Y-H; BATTA, R.; ROGERSON, P.A.; BLATT, A.; FLANIGAN, M. A Logistics Model for Emergency Supply of Critical Items in the Aftermath of a Disaster, Socio-Economic Planning Sciences, v. 45, n. 4, p. 132-145, 2011.

LONG, D.C.; WOOD, D.F. The logistics of famine relief, Journal of Business Logistics, v. 16, n. 1, p. 213-29, 1995. Disponível em:

<http://findarticles.com/p/articles/mi_qa3705/is_199501/ai_n8724669/pg_2/?tag= mantle_skin;content>. Acesso em: 03 ago. 2011.

LØKEN, E. Use of multicriteria decision analysis methods for energy planning problems, Renewable and Sustainable Energy Reviews, v. 11, p. 1584-1595, 2007.

MALAVER, G.; REGNIER, C. Structuring Strategic Decisions Through Analytic Hierarchy Process: A Case Study in the Selection of Warehouse Location for WFP in Ethiopia. 2009. 105 p. Dissertação (Mestrado) Massachusetts Institute of Technology. Engineering Systems Division. Boston, 2009.

MARCELINO, E. V. Desastres Naturais e Geotecnologias: Conceitos Básicos. Instituto Nacional de Pesquisas Espaciais, Santa Maria, RS, 2007. Disponível em: <http://mtc-m18.sid.inpe.br/col/sid.inpe.br/mtc-

m18@80/2008/07.02.16.22/doc/publicacao.pdf>. Acesso em: 03 ago. 2011.

MARENGO, J. A.; VALVERDE, M. C.; OBREGON. G. O. Observed and projected changes in rainfall extremes in the Metropolitan Area of São Paulo. Climate Research, v. 57, p. 61-72, 2013. 
MARTINS, R. S.; CAIXETA FILHO, J. V. Subsídios à Tomada de Decisão da Escolha da Modalidade para o Planejamento dos Transportes no Estado do Paraná. Revista de Administração Contemporânea, v.3, n. 2, p. 75-96, 1999.

MARTINS, V. N.; E SILVA, D. S.; CABRAL, P. Social vulnerability assessment to seismic risk using multicriteria analysis: the case study of Vila Franca do Campo (São Miguel Island, Azores, Portugal). Natural Hazards, v. 62, p. 385-404, 2012.

MARTOS, A. C. Projeto de redes logísticas com consideração de estoques e modais: aplicação de programação linear inteira mista à indústria petroquímica. 2000. 98p. Dissertação (Mestrado) - Escola Politécnica, Universidade de São Paulo, São Paulo, 2000.

MARVEL, K.; BONFILS,C. Identifying external influences on global precipitation Proceedings of the National Academy of Sciences of the United States of America, v. 110, n. 48, p. 19301-19306, 2013.

MATISZIW, T.C.; MURRAY, A.T. Modeling s-t path availability to support disaster vulnerability assessment of network infrastructure. Computers \& Operations Research, v. 36, n. 1, p.16-26, 2009.

MENDOZA, G.A.; MARTINS, H. Multi-criteria decision analysis in natural resource management: A critical review of methods and new modelling paradigms. Forest Ecology and Management , v. 230, p. 1-22, 2006.

MENOU, A.; BENALLOU, A.; LAHDELMA R.; SALMINEN P. Decision support for centralizing cargo at a Moroccan airport hub using stochastic multicriteria acceptability analysis. European Journal of Operational Research, v. 204, p. 621-630, 2010.

MINGERS, J.; ROSENHEAD, J. Problem structuring methods in action. European Journal of Operational Research, v. 152, p. 530-554, 2004.

METE, H. O.; ZABINSKY, Z. B. Stochastic optimization of medical supply location and distribution in disaster management. International Journal of Production Economics, v. 126, n. 1, p. 79-84, 2010.

MONTIBELLER, G. Mapas Cognitivos Difusos para Apoio à Decisão. 2000. 322 p. Tese (Doutorado) - Universidade Federal de Santa Catarina, Departamento de Engenharia de Produção, Florianópolis, 2000. 
MONTIBELLER, G, FRANCO, L.A. Decision and Risk Analysis for the evaluation of strategic options. In: O'Brien FA, Dyson RG (Ed.), Supporting Strategy:

Frameworks, Methods and Models. Wiley: Chichester. 2007. p. 251-284

MONTIBELLER, G.; BELTON V. Causal maps and the evaluation of decision options-a review. Journal of the Operational Research Society, v. 57, p. 77979, 2006.

MORAES, L.; GARCIA, R.; ENSSLIN, L.; CONCEIÇÃO, M.J.; CARVALHO, S.M. The multicriteria analysis for construction of benchmarkers to support the Clinical Engineering in the Healthcare Technology Management. European Journal of Operational Research, v. 200, p. 607-615, 2010.

MOREIRA, D. A. Pesquisa operacional: curso introdutório. São Paulo: Pioneira Thomson Learning, 2007. 356 p.

MSF Médecins Sans Frontières. Refugee Health An approach to emergency situations. Oxford: Macmillan, 1997. 380 p.

MULVEY, J. M.; VANDERBEI, R. J.; ZENIOS, S. A. Robust optimization of largescale systems. Operations Research, v. 43, p. 264-281, 1995

MURALI, P.; ORDÓÑEZ, F.; DESSOUKY, M. M. Facility location under demand uncertainty: Response to a large-scale bio-terror attack. Socio-Economic Planning Sciences, v. 46, n. 1, p. 78-87, 2012.

MURRAY, S. How to deliver on the promises: supply chain logistics: humanitarian agencies are learning lessons from business in bringing essential supplies to regions hit by the tsunami", Financial Times, January 7, p. 9, 2005.

NAJAFI, M.; ESHGHI, K.; DULLAERT, W. A multi-objective robust optimization model for logistics planning in the earthquake response phase. Transportation Research Part E, v. 49, p. 217-249, 2013.

NAKANO, D. Métodos de Pesquisa Adotados na Engenharia de Produção e Gestão de Operações. In Cauchik, P.M. (Org.). Metodologia de Pesquisa em Engenharia de Produção e Gestão de Operações, Rio de Janeiro, Campus, p. 131-148, 2009. 
NATARAJARATHINAM, M.; CAPAR, I.; NARAYANAN, A, Managing supply chains in times of crisis: a review of literature and insights. International Journal of Physical Distribution \& Logistics Management, v. 39, n. 7, p. 535-573, 2009.

NATCATSERVICE. Breakdown into catastrophe categories. .2011. Disponível em $<$ https://www.munichre.com/app_pages/www/@res/pdf/NatCatService/database/c atastrophe_classes_touch_en.pdf?2>. Acesso em: 01 nov. 2012.

NOGUEIRA, C. W.; GONÇALVES, M. B. O desenvolvimento e aplicação de um modelo para localização de uma central de inteligência e suporte para recebimento, controle e distribuição de recursos em situações emergenciais. In: XXIV ANPET - Congresso Nacional de Pesquisa e Ensino em Transporte, 2010, Salvador. Anais Salvador BA: Anpet, 2010.

NOGUEIRA, C. W.; GONÇALVES, M. B.; NOVAES, A. G. A logística humanitária e medidas de desempenho: A perspectiva da cadeia de assistência humanitária. In XXII ANPET- Congresso Nacional de Pesquisa e Ensino em Transporte, 2008, Fortaleza. Anais Fortaleza CE: Anpet, 2008.

NOLZ, P.C.; DOERNER, K.F.; HARTL, R.F. Water distribution in disaster relief. International Journal of Physical Distribution \& Logistics Management, v. 40, n. 8/9, p. 693-708, 2010.

NOLZ, P.C.; SEMET, F.; DOERNER, K.F. Risk approaches for delivering disaster relief supplies, OR Spectrum, v. 33, p. 543-569, 2011.

NOVE MIL dos 11 mil habitantes de São Luiz do Paraitinga tiveram de deixar suas casas. O Globo, 2 jan. 2010. Disponível em

$<$ http://oglobo.globo.com/pais/nove-mil-dos-11-mil-habitantes-de-sao-luiz-doparaitinga-tiveram-de-deixar-suas-casas-3074774>. Acesso em: 05 abr. 2012.

NOYAN, N. Risk-averse two-stage stochastic programming with an application to disaster management Computers \&Operations Research, v. 39, p. 541-559, 2012.

NTC - Associação Nacional de Transporte de Cargas e Logística. Índice Nacional do Custo do Transporte de Lotações e Índice Nacional do Custo de Operações Urbanas, mês de referência: Maio de 2012. Disponível em:

<http://www.portalntc.org.br/index.php?option=com_remository\&ltemid=388\&func =select\&id=115. Acesso em 16 mai. 2012. 
OLIVEIRA, D.; GONÇALVES, M. B. Desenvolvimento de uma rede de transporte dinâmica geo-referenciada para situações emergenciais. In: Tópicos Emergentes e Desafios Metodológicos em Engenharia de Produção: Casos, Experiências e Proposições (Volume VII) (no prelo) Rio de Janeiro: ABEPRO, 2013

OLSON, D. L. Decision Aids for Selection Problems. New York: SpringerVerlag, 1996. $199 \mathrm{p}$.

OPASANON, S.; MILLER-HOOKS, E. Multicriteria adaptive paths in stochastic, time-varying networks. European Journal of Operational Research, v. 173, p. 72-91, 2006.

ORTUÑO, M.T.; TIRADO, G.; VITORIANO,·B. A lexicographical goal programming based decision support system for logistics of Humanitarian Aid. Top, v. 19, p. 464-479, 2011.

ÖZDAMAR, L.; EKINCI, E.; KÜÇÜKYAZICI, B. Emergency logistics planning in natural disasters. Annals of Operations Research, v. 129, n. 1, p. 217-245, 2004.

PAHO, Pan American Health Organization, Humanitarian supply management in logistics in the health sector, Washington, D.C.: PAHO, 2001. 189 p.

PAIVA, R. P. Estrutura da Defesa Civil - Divisão de Gerenciamento de Emergência, Coordenadoria Estadual de Defesa Civil do Estado de São Paulo, In Mesa Redonda de Logística Humanitária, Universidade de São Paulo, São Paulo, 2012.

PERES, E. Q.; BRITO JR, I.; LEIRAS, A.; YOSHIZAKI, H. Humanitarian logistics and disaster relief research: trends, applications and future research directions. In: 4th International Conference on Information Systems, Logistics and Supply Chain - ILS 2012. Proceedings Quebec, Canada, August 26-29, 2012.

PERRY R. W.; QUARANTELLI E.L. (Ed.).What is a disaster? New Answers to Old Questions. Delaware: International Research Committee on Disasters, 2005. $442 \mathrm{p}$.

PETTIT, S.; BERESFORD, A.K.C. Emergency relief logistics: an evaluation of military, non-military, and composite response models. International Journal of Logistics: Research and Applications, v. 8, n. 4, p. 313-331, 2005. 
PIDD, M. Just modeling through: a rough guide to modeling. Interfaces, v.29, n.2, p.118-132, 1999.

PINTO JR., O.; PINTO, I. R. C. A.; FERRO, M. A. S. A study of the long-term variability of thunderstorm days in southeast Brazil. Journal of Geophysical Research: Atmospheres, v. 118 (11), p. 5231-5246, 2013.

POLLACK, J. Multimethodology in series and parallel: strategic planning using hard and soft OR. Journal of the Operational Research Society, v. 60, p.156167, 2009.

PRADO, A. A. A. Análise de decisão multicritério aplicada na seleção de fornecedores de logística. 2011. 177 p. Dissertação (Mestrado) - Engenharia de Sistemas Logísticos, Escola Politécnica, Universidade de São Paulo, São Paulo, 2011.

PUPO, R. Milhares de roupas doadas para S. Luís de Paraitinga vão parar no lixo. O Estado de S. Paulo, 18 jun. 2012. Disponível em:

http://www.estadao.com.br/noticias/impresso,milhares-de-roupas-doadas-para--sluis-de-paraitinga-vao-parar-no-lixo-,887671,0.htm>. Acesso em: 28 ago. 2012.

RATH, S.; GUTJAHR, W. J. A math-heuristic for the warehouse location-routing problem in disaster relief. Computers \& Operations Research. v. 42, p. 25-39, 2014.

RATICK, S.; MEACHAM, B.; AOYAMA, Y. Locating Backup Facilities to Enhance Supply Chain Disaster Resilience. Growth and Change, v. 39, n. 4, p. 642-666, 2008.

RAWLS, C. G.; TURNQUIST, M. A. Pre-positioning and dynamic delivery planning for short-term response following a natural disaster. Socio-Economic Planning Sciences, v. 46, p. 46-54, 2012.

RAWLS, C. G.; TURNQUIST, M. A. Pre-positioning of emergency supplies for disaster response Transportation Research Part B, v. 44, n. 4, p. 521-534, 2010.

RAWLS, C. G.; TURNQUIST, M. A. Pre-positioning planning for emergency response with service quality constraints. OR Spectrum, v. 33, n. 3, p. 481-498, 2011. 
RICE JR., J.B.; CANIATO F. Building a secure and resilient supply chain network. Supply Chain Management Review, v. September/October, p. 22-30, 2003.

ROSENHEAD, J; ELTON, M; GUPTA, S.K. Robustness and optimality as criteria for strategic decisions. Operational Research Quarterly, v. 23, n. 4, p. 413-431, 1972.

ROSS, G.T.; SOLAND, R.M. A multicriteria approach to the location of public facilities. European Journal of Operational Research, v. 4, p. 307-321, 1980.

ROSSI, A. Ajuda em xeque, Página 22, v. 58, p. 32-37, Escola de Administração de Empresas de São Paulo da Fundação Getúlio Vargas, São Paulo, 2011.

ROTTKEMPER, B.; FISCHER, K.; BLECKEN, A. A transshipment model for distribution and inventory relocation under uncertainty in humanitarian operations. Socio-Economic Planning Sciences, v. 45, p. 132-145, 2011.

ROWE, G.; WRIGHT, G. Expert Opinions in Forecasting: The Role of the Delphi Technique. In: Principles of Forecasting: A Handbook for Researchers and Practitioners J.S. Armstrong (Ed.). Springer: New York, 2001, p. 125- 144.

SAATY, T. L. An exposition on the AHP in reply to the paper "remarks on the Analytic Hierarchy Process". Management Science, v. 36, n. 3, p. 259-268, 1990.

SALMERÓN, J.; APTE, A. Stochastic Optimization for Natural Disaster Asset Prepositioning. Production and Operations Management, v. 19, n. 5, p. 561574, 2010.

SALMERÓN, J.; KLINE, J.; DENSHAM, G. S. Optimizing Schedules for Maritime Humanitarian Cooperative Engagements from a United States Navy Sea Base. Interfaces, v. 41, n. 3, p. 238-253, 2011.

SALO, A. A.; HÄMÄLÄINEN, R. P. On the Measurement of Preferences in the Analytic Hierarchy Process. Journal of Multi-Criteria Decision Analysis, v. 6, p. 309-319, 1997. 
SAMPAIO, G. Extremos Climáticos sob a luz da ciência do clima. In: Seminário Extremos climáticos e seus desdobramentos no setor elétrico brasileiro, Coppe Universidade Federal do Rio de Janeiro, 2014.

SÃO PAULO, Coordenadoria Estadual de Defesa Civil. Mapeamento de Risco. 2012. Disponível em:

<http://www.sidec.sp.gov.br/producao/map_risco/pesqpdf3.php>. Acesso em: 21 nov. 2012.

SÃO PAULO, Polícia Militar do Estado de São Paulo. Apresenta dados sobre Operação Verão. São Paulo, SP [s.n.] 2012a.

SÃO PAULO, Coordenadoria Estadual de Defesa Civil. Relatório Final sobre o desastre de Itaoca. São Paulo, SP [s.n.] 2014.

SARKIS, J.; SUNDARRAJ, R.P. Hub Location at Digital Equipment Corporation: A Comprehensive Analysis of Qualitative and Quantitative Factors. European Journal of Operational Research, v. 137, p. 336-347, 2002.

SEADE Fundação Sistema Estadual de Análise de Dados. Informações dos Municípios Paulistas - IMP - Condições de Vida Índice Paulista de Vulnerabilidade Social IPVS. 2012. Disponível em <http://www.seade.gov.br/produtos/imp/>. Acesso em: 01 nov. 2012.

SEN, S.; HIGLE, J. L. An Introductory Tutorial on Stochastic Linear Programming Models. Interfaces, v. 29, n. 2, March-April, p. 33 - 61, 1999.

SHANE, S.; BONNER, R. Annan Nudges Donors to Make Good on Full Pledges, The New York Times Jan 7, 2005. Disponível em:

<http://www.nytimes.com/2005/01/07/international/worldspecial4/07quake. html?_r=1\&pagewanted=print\&position=.>Acesso em: 20 ago. 2012.

SHAPIRO, A.; DENTCHEVA, D.; RUSZCZYNSKI, A. Lectures on stochastic programming: modeling and theory. Philadelphia: MPS-SIAM, 2009. 436 p.

SHERALI, H. D.; CARTER, T. B. A location-allocation model and algorithm for evacuation planning under hurricane/flood conditions. Transportation Research B, v. 25, n. 6, p. 439-452, 1991. 
SIFRECA - Sistema de Informações de Fretes, Departamento de Economia, Administração e Sociologia. Escola Superior de Agricultura "Luiz de Queiroz" (ESALQ/USP). Disponível em

<http://sifreca.esalq.usp.br/sifreca/pt/fretes/rodoviarios/index.php>. Acesso em 16 mai. 2012.

SOUZA, J. C. Distribuição de centrais de apoio para logística humanitária preparação para resposta a desastres naturais. In: Simpósio de Pesquisa Operacional e Logística da Marinha, 2012. Rio de Janeiro 2012, Anais Rio de Janeiro RJ:, SPOLM 2012.

SWANN, J.; GANESAN, L. KESKINOCAK, P. Measurements in Humanitarian Logistics. Societal/Humanitarian Applications of OR/MS Fall 2009. Class notes and presentations. Disponível em: <http://www2.isye.gatech.edu/people/faculty/ Pinar_Keskinocak/teaching/isye4803-fall2009/measurement.pdf>. Acesso em: 07 out. 2013.

THE SPHERE PROJECT, The Humanitarian Charter and Minimum Standards in Humanitarian Response, 3 ed. Rugby, UK: Practical Action Publishing, 2011. $393 \mathrm{p}$.

THOMAS, A. Leveraging private expertise for humanitarian supply chains. Forced Migration Review, v. 21, p. 64-65, 2004.

THOMAS, A.S.; KOPCZAK, L.R. From logistics to supply chain management: The path forward in the humanitarian sector. Fritz Institute, San Francisco CA, 2005. Disponível em:

<http://www.fritzinstitute.org/PDFs/WhitePaper/Fromlogisticsto.pdf>. Acesso em: 03 ago. 2011.

TOBIN, G. A.; MONTZ, B. E. Natural hazards: explanation and integration.

The Guilford Press, New York, 1997. Disponível em:

$<$ http://books.google.com.br/books?hl=pt-

$B R \& \mid r=\& i d=R U G S o N v b M S E C \& o i=$ fnd \&pg =PA1\&dq=tobin+montz+Natural+Hazar ds:+Explanation+and+Integration\&ots=KHscQGrQb4\&sig=leVXdJ4suwGfz3fAcT BG5MAY9c\#v=onepage\&q\&f=false $>$. Acesso em: 10 ago. 2011.

TOMASINI, R. M.; VAN WASSENHOVE, L. N. From preparedness to partnerships: case study research on humanitarian logistics. International Transactions in Operational Research, v. 16, p. 549-559, 2009a. 
TOMASINI, R. M.; VAN WASSENHOVE, L. N. Humanitarian Logistics. London: Palgrave Macmillan, 2009b. $178 \mathrm{p}$.

TOMINAGA, L. K.; SANTORO, J.; AMARAL, R. (Org) Desastres naturais: conhecer para prevenir. São Paulo: Instituto Geológico, 2009. 196 p.

TOREGAS, C.; SWAIN, R.; REVELLE, C.; BERGMA, L. The location of emergency service facilities, Operations Research, v. 19, n. 6, p. 1363-1373, 1971.

TRIANTAPHYLLOU; E.; BAIG. K. The Impact of Aggregating Benefit and Cost Criteria in Four MCDA Methods. IEEE Transactions on Engineering Management, v. 52, n. 2, p. 213-226, 2005.

TRICOIRE, F.; GRAF, A.; GUTJAHR, W. J. The bi-objective stochastic covering tour problem. Computers \& Operations Research, v. 39, p. 1582-1592, 2012.

UKKUSURI, S. V.; YUSHIMITO, W. F. Location Routing Approach for the Humanitarian Prepositioning Problem. Transportation Research Record, v. 9, n. 1, p. 18-25, 2008.

UN/ISDR - International Strategy for Disaster Reduction. Living with risk: a global review of disaster reduction initiatives. Preliminary version. Technical report, New York and Geneva: ISDR Secretariat, 2002. 429 p.

UN/ISDR - International Strategy for Disaster Reduction. Terminology on Disaster Risk Reduction 2009. Disponível em <http://www.unisdr.org/files/7817_UNISDRTerminologySpanish.pdf>. Acesso em: 12 set. 2012.

UNHCR - United Nations High Commissioner for Refugees. Handbook for Emergencies. Third Edition. UNHCR Headquarters. Geneve, 2007. 582 p.

VALENCIO, N.; SIENA, M.; MARCHEZINI V.; GONÇALVES J. C, (Org.).

Sociologia dos desastres - construção, interfaces e perspectivas no Brasil, São Carlos: RiMa Editora, 2009. 268 p. 
VAN WASSENHOVE, L. N.; ALLEN A. M. The World of a Humanitarian Logistician. Management Report. 2012. INSEAD Social Innovation Centre. Humanitarian Research Group. Disponível em <http://www.insead.edu/ facultyresearch/centres/isic/humanitarian/documents/Full-final-Version-HRGManagement-Report-03072012.pdf>. Acesso em: 31 jan. 2014.

VAN WASSENHOVE, L.N. Humanitarian aid logistics: supply chain management in high gear. Journal of the Operational Research Society, v. 57, n. 5, p. 475489, 2006.

VICTORIA TRANSPORT POLICY INSTITUTE. Transportation Cost and Benefit Analysis. Cap 4. Quantification Techniques, 2009. Disponível em <http://vtpi.org/tca/>. Acesso em: 10 jan. 2014.

VISWANATH, K.; PEETA, S. The multicommodity maximal covering network design problem for planning critical routes for earthquake response. In: 82nd Annual meeting of the transportation research board, 2003, Proceedings Washington D.C., 2003.

VITORIANO, B.;-ORTUÑO, M. T.;-TIRADO, G.;'MONTERO, J. A multi-criteria optimization model for humanitarian aid distribution. Journal of Global Optimization, v. 51, n. 2, p. 189-208, 2011.

WALLENIUS, J.; DYER, J. S.; FISHBURN, P. C.; STEUER, R. E. ; ZIONTS, S.; DEB, K. Multiple Criteria Decision Making, Multiattribute Utility Theory: Recent Accomplishments and What Lies Ahead. Management Science, v. 54, n. 7, p. 1336-1349, 2008.

WATSON, S R.; BUEDE, D.M. Decision Synthesis: The Principles and Practice of Decision Analysis. Cambridge: Cambridge University Press.1987. 299 p.

WEISBROD, G.; LYNCH, T.; MEYER, M. Extending monetary values to broader performance and impact measures: Transportation applications and lessons for other fields. Evaluation and Program Planning, v. 32, p. 332-341, 2009.

WESTPHALEN, A.N. Com estoque lotado, PM encerra campanha de doações. 0 Estado de São Paulo, 12 jan. 2010. 2010. Disponível em:

<http://www.estadao.com.br/noticias/geral,com-estoque-lotado-pm-encerracampanha-de-doacoes,494537,0.htm>. Acesso em: 15 abr. 2012. 
Wets, R. J.-B. Stochastic programming. In: Nemhauser, G. L.; Kan, A. H. G. R.; Todd, M. J. (Ed.), Handbook for Operations Research and Management Science. Elsevier. 1989. p. 573-629.

WFP. World Food Programem, Facts Blast - Foods Purchase in 2010, May 2011, disponívelem<http://documents.wfp.org/stellent/groups/public/documents/commu nications/wfp187701.pdf>. Acesso em 10 out. 2012.

WILHELM, W. E.; SRINIVASA, A. V. Prescribing Tactical Response for Oil Spill Clean Up Operations. Management Science, v. 43, n. 3, p. 386-402, 1996.

YI, W.; ÖZDAMAR, L. A dynamic logistics coordination model for evacuation and support in disaster response activities. European Journal of Operational Research, v. 179, p.1177-1193, 2007.

YOSHIZAKI H.; MONTIBELLER G. A Framework for Locating Logistic Facilities with Optimization and Multi-Criteria Value Analysis. Working Paper LSEOR 09$111,2009$.

ZAGEFKA, H.; NOOR, M.; BROWN, R.; DE MOURA, G. R.; HOPTHROW, T. Donating to disaster victims: Responses to natural and humanly caused events. European Journal of Social Psychology, v. 41, p. 353-363, 2011.

ZAPATA, J. C. R. Modelo híbrido para estimativa de parâmetros de referência como suporte à avaliação social de projetos. 1995. $205 \mathrm{p}$. Dissertação (Mestrado) - Engenharia de Produção, Universidade Federal de Santa Catarina, Florianópolis, 1995.

ZHANG, J-H; LI, J.; LIU, Z-P. Multiple-resource and multiple-depot emergency response problem considering secondary disasters. Expert Systems with Applications, v. 39, p. 11066-11071, 2012. 


\section{APÊNDICES}

Apêndice 1: Demanda conforme os materiais:

Embora não abordado no modelo, devido a contrato específico de abastecimento em casos de emergência com a Companhia de Saneamento Básico do Estado de São Paulo, o tópico "água" foi considerado relevante e inserido neste apêndice tese devido ao seu caráter balizador para outros materiais e para possíveis estudos futuros.

Água potável: A quantidade necessária de água para uso doméstico pode variar e é baseada de acordo com o clima, as instalações sanitárias disponíveis, os hábitos das pessoas, suas práticas religiosas e culturais, tipo de roupas e de alimentos que utilizam. O consumo de água aumenta quanto mais próximo estiver da fonte de água. O recomendável é 15 litros por pessoa por dia (1/p/d) (mínimo 7,5 litros), assim distribuídos:

- Sobrevivência (ingestão e alimentos): 2,5 a 3 l/p/d.

- Higiene: 2 a 6 l/p/d.

- Cozimento: 3 a $6 \mathrm{l} / \mathrm{p} / \mathrm{d}$.

Estas quantidades podem variar de acordo com: o clima do local; características psicológicas dos indivíduos; tipos de alimentos; e normas culturais e sociais.

Alimentos: Requisitos nutricionais:

Necessidades: $2.100 \mathrm{kcal} /$ pessoa / dia, sendo:

- 10 por cento do total da energia fornecida por proteína.

- 17 por cento do total da energia fornecida por gordura.

Higiene e Limpeza: Segundo The Sphere Project (2011), os itens de higiene e limpeza podem ser quantificados segundo a necessidade pessoal em determinado 
período de tempo ou ainda pela necessidade familiar. As quantidades e os tipos de produtos são divididos em: de necessidades básicas ou adicionais.

Básicos:

- Baldes: 2 de 10 a 20 I por residência (1 para transporte e 1 para armazenagem).

- Sabonete: $250 \mathrm{~g}$ por pessoa/mês.

- Sabão de lavanderia: $200 \mathrm{~g}$ por pessoa/mês.

- Materiais de higiene íntima feminina: 1 kit por jovem/adulta do sexo feminino.

Adicionais:

- Creme dental: $100 \mathrm{~g} / \mathrm{mês}$.

- Escova de dentes: $1 /$ mês.

- Xampu: $250 \mathrm{ml} / \mathrm{mês}$

- Loção infantil: $250 \mathrm{ml} / \mathrm{mês}$.

- Aparelho de barbear descartável: 1/mês por jovem/adulto do sexo masculino.

- Roupa íntima feminina: 1 kit/mês por jovem/adulta do sexo feminino.

- Escova de cabelo e/ou pente: 1/mês.

- Cortador de unhas: $1 /$ mês.

- Fraldas: de acordo com a necessidade familiar.

Convém ressaltar que tais itens podem ser alterados conforme as práticas sociais, culturais e religiosas já existentes. 
Roupas: Todas as mulheres, meninas, homens e meninos devem ter, pelo menos, dois conjuntos completos de vestuário de tamanho correto e que sejam apropriados à cultura, estação do ano e clima do local.

Com o intuito de garantir o conforto térmico e condições de sono adequadas, todas as pessoas afetadas devem possuir um conjunto de cobertores, roupas de cama, colchões ou revestimentos para dormir e ainda, conforme a necessidade, rede de proteção ou repelentes contra insetos.

Outros itens também podem ser necessários, tais como utensílios para cozimento de alimentos, pratos e talheres, entretanto estes itens não ficam em estoque (PAIVA, 2012) e são adquiridos ou recebidos através de doações conforme necessidade detectada na fase de avaliação do desastre. 
Apêndice 2: Custo de instalação e operação, valores dos produtos, média histórica, peso unitário e parâmetros $E_{k}$

Custo de instalação e operação do estoque i (\$)

\begin{tabular}{|l|l|}
\hline Valor (R\$) & \multicolumn{1}{|c|}{ Local } \\
\hline $61.351,30$ & Caçapava \\
\hline $61.351,30$ & São Jose dos Campos \\
\hline $61.351,30$ & Taubaté \\
\hline $61.351,30$ & Tremembé \\
\hline $19.513,30$ & São Paulo \\
\hline
\end{tabular}

Valores de aquisição dos produtos, média histórica, peso unitário e parâmetro $E_{k}$.

\begin{tabular}{|l|r|r|r|r|}
\hline \multicolumn{1}{|c|}{ Material } & $\begin{array}{c}\text { Valor } \\
\mathbf{( R \mathbf { } )}\end{array}$ & $\begin{array}{c}\text { Peso } \\
\text { unitário }\end{array}$ & $\begin{array}{c}\text { Estoque } \\
\text { médio } \\
\mathbf{( 2 0 0 4 - 2 0 1 2 )}\end{array}$ & $\begin{array}{c}\text { Parâmetro } \\
\mathbf{e}_{\mathbf{k}}\end{array}$ \\
\hline Agasalhos & 23,00 & 0,965 & 1175 & $1.133,74$ \\
\hline Bota & 22,00 & 1,400 & 48 & 67,67 \\
\hline Camiseta & 4,64 & 0,160 & 765 & 122,45 \\
\hline Capa de chuva & 53,65 & 0,740 & 656 & 485,69 \\
\hline Capacete & 22,40 & 0,390 & 100 & 39,00 \\
\hline Cesta Básica & 54,50 & 19,800 & 3529 & $69.867,60$ \\
\hline Cobertor & 10,45 & 1,570 & 3602 & $5.654,62$ \\
\hline Colchão & 37,50 & 3,373 & 5794 & $19.542,10$ \\
\hline Colete & 9,90 & 0,200 & 100 & 20,00 \\
\hline Fita para isolamento & 37,00 & 1,500 & 263 & 394,50 \\
\hline Kit Higiene & 5,46 & 0,425 & 2097 & 891,07 \\
\hline Kit Limpeza & 25,61 & 3,218 & 1169 & $3.762,03$ \\
\hline Lençol & 5,20 & 0,260 & 3458 & 898,99 \\
\hline Lona plástica & 234,00 & 23,000 & 268 & $6.160,71$ \\
\hline Luva & 12,90 & 0,200 & 980 & 196,00 \\
\hline Pluviômetro & 160,00 & 0,700 & 14 & 9,98 \\
\hline Tênis & 10,60 & 0,455 & 616 & 280,09 \\
\hline
\end{tabular}


Apêndice 3: Distância (em km) entre cidades do Vale do Paraíba e os depósitos.

\begin{tabular}{|c|c|c|c|c|c|}
\hline (em km) & \multicolumn{5}{|c|}{ Depósito } \\
\hline Municipio & Cacapava & $\begin{array}{l}\text { S J dos } \\
\text { Campos }\end{array}$ & Taubate & Tremembe & Sao Paulo \\
\hline Aparecida & 69,37 & 94,34 & 48,08 & 42,94 & 212,95 \\
\hline Arapeí & 169,06 & 194,00 & 148,05 & 144,14 & 311,52 \\
\hline Areias & 145,88 & 170,86 & 124,58 & 119,22 & 289,45 \\
\hline Bananal & 183,49 & 208,33 & 162,62 & 159,04 & 325,34 \\
\hline Cacapava & 0 & 25,03 & 21,30 & 27,90 & 143,57 \\
\hline Cachoeira Paulista & 106,25 & 131,05 & 85,07 & 78,98 & 249,65 \\
\hline Campos do Jordao & 51,62 & 70,80 & 39,45 & 30,40 & 184,30 \\
\hline Canas & 98,46 & 123,29 & 77,24 & 71,29 & 241,91 \\
\hline Cruzeiro & 118,13 & 142,70 & 97,12 & 90,51 & 261,13 \\
\hline Cunha & 94,05 & 117,47 & 75,62 & 75,81 & 231,08 \\
\hline Guaratinguetá & 75,58 & 100,52 & 54,30 & 48,89 & 219,14 \\
\hline Igaratá & 58,18 & 33,98 & 78,97 & 83,46 & 88,90 \\
\hline Jacareí & 42,88 & 19,89 & 63,87 & 70,75 & 101,81 \\
\hline Jambeiro & 21,07 & 27,05 & 35,17 & 44,11 & 136,69 \\
\hline Lagoinha & 65,05 & 88,48 & 47,23 & 48,70 & 203,10 \\
\hline Lavrinhas & 124,70 & 149,41 & 103,57 & 97,25 & 267,94 \\
\hline Lorena & 89,08 & 113,86 & 67,92 & 61,79 & 232,46 \\
\hline Monteiro Lobato & 25,84 & 30,92 & 36,66 & 36,66 & 141,05 \\
\hline Natividade da Serra & 50,24 & 62,06 & 50,07 & 58,74 & 161,52 \\
\hline Paraibuna & 39,39 & 40,00 & 50,92 & 60,25 & 134,29 \\
\hline Pindamonhangaba & 39,20 & 63,85 & 18,51 & 11,89 & 182,45 \\
\hline Piquete & 94,42 & 118,32 & 74,18 & 66,52 & 236,02 \\
\hline Potim & 67,41 & 92,33 & 46,15 & 40,71 & 210,96 \\
\hline Queluz & 140,65 & 165,49 & 119,43 & 113,44 & 284,10 \\
\hline Redencao da Serra & 31,19 & 45,61 & 33,09 & 42,31 & 153,90 \\
\hline Roseira & 57,72 & 82,72 & 36,42 & 31,80 & 201,29 \\
\hline Santa Branca & 46,20 & 29,83 & 65,18 & 73,36 & 107,00 \\
\hline Santo Antonio do Pinhal & 37,87 & 55,80 & 30,20 & 22,94 & 169,59 \\
\hline Sao Bento do Sapucaí & 56,42 & 69,84 & 50,94 & 43,34 & 176,21 \\
\hline Sao José do Barreiro & 155,35 & 180,37 & 134,16 & 129,70 & 298,48 \\
\hline Sao José dos Campos & 25,03 & 0 & 46,31 & 52,19 & 118,63 \\
\hline Sao Luís do Paraitinga & 52,59 & 72,77 & 41,20 & 47,00 & 182,93 \\
\hline Silveiras & 123,11 & 148,10 & 101,81 & 96,53 & 266,67 \\
\hline Taubaté & 21,30 & 46,31 & 0 & 9,39 & 164,87 \\
\hline Tremembé & 27,90 & 52,19 & 9,39 & 0 & 170,70 \\
\hline
\end{tabular}


Apêndice 4: Quantidades de compras emergenciais conforme cenário (kg).

\begin{tabular}{|l|r|r|}
\cline { 2 - 3 } \multicolumn{1}{c|}{ Unidade (kg) } & \multicolumn{2}{c|}{ Cenários } \\
\hline Materiais & $\begin{array}{c}\text { Baixa divulgação de } \\
\text { mídia (1, 2 e 3) }\end{array}$ & $\begin{array}{c}\text { Alta divulgação de } \\
\text { mídia } \mathbf{4 , ~ 5 , ~ 6 , ~ 7 ~ e ~ 8 ) ~}\end{array}$ \\
\hline Agasalhos & $1.752,14$ & $2.978,64$ \\
\hline Bota & 72,08 & 122,54 \\
\hline Camiseta & $1.141,39$ & $1.940,36$ \\
\hline Capa de chuva & 978,83 & $1.664,01$ \\
\hline Capacete & 149,14 & 253,53 \\
\hline Cesta Básica & $5.262,52$ & $8.946,29$ \\
\hline Cobertor & $5.371,39$ & $9.131,37$ \\
\hline Colchão & $8.641,21$ & $14.690,05$ \\
\hline Colete & 149,14 & 253,53 \\
\hline Fita para isolamento & 392,23 & 666,79 \\
\hline Kit Higiene & $3.127,76$ & $5.317,20$ \\
\hline Kit Limpeza & $1.743,40$ & $2.963,79$ \\
\hline Lençol & $5.156,64$ & $8.766,28$ \\
\hline Lona plástica & 399,47 & 679,10 \\
\hline Luva & $1.461,54$ & $2.484,61$ \\
\hline Pluviômetro & 21,25 & 36,13 \\
\hline Tênis & 918,04 & $1.560,67$ \\
\hline
\end{tabular}


Apêndice 5: Quantidades de depósitos abertos por cenários pelas soluções RP (recourse problem) e WS (wait-and-see).

\begin{tabular}{|c|c|c|c|c|c|c|c|c|c|}
\hline \multirow[b]{2}{*}{$\begin{array}{c}\text { Penalidade ( } x \text { valor } \\
\text { do transporte) }\end{array}$} & & \multicolumn{8}{|c|}{ Cenário } \\
\hline & & 1 & 2 & 3 & 4 & 5 & 6 & 7 & 8 \\
\hline \multirow{2}{*}{3} & RP & \multicolumn{8}{|c|}{2} \\
\hline & WS & 2 & 2 & 2 & 2 & 2 & 2 & 2 & 2 \\
\hline \multirow{2}{*}{50} & RP & \multicolumn{8}{|c|}{2} \\
\hline & WS & 2 & 2 & 2 & 2 & 2 & 2 & 2 & 2 \\
\hline \multirow{2}{*}{95} & RP & \multicolumn{8}{|c|}{2} \\
\hline & WS & 2 & 2 & 2 & 2 & 2 & 2 & 2 & 2 \\
\hline \multirow{2}{*}{100} & $\mathbf{R P}$ & \multicolumn{8}{|c|}{2} \\
\hline & WS & 2 & 2 & 3 & 2 & 2 & 2 & 2 & 2 \\
\hline \multirow{2}{*}{300} & $\mathbf{R P}$ & \multicolumn{8}{|c|}{2} \\
\hline & WS & 2 & 3 & 3 & 2 & 2 & 3 & 2 & 3 \\
\hline \multirow{2}{*}{500} & RP & \multicolumn{8}{|c|}{2} \\
\hline & WS & 2 & 3 & 3 & 2 & 3 & 3 & 3 & 3 \\
\hline \multirow{2}{*}{600} & $\mathbf{R P}$ & \multicolumn{8}{|c|}{3} \\
\hline & WS & 2 & 3 & 3 & 2 & 3 & 3 & 3 & 3 \\
\hline \multirow{2}{*}{750} & RP & \multicolumn{8}{|c|}{3} \\
\hline & WS & 2 & 3 & 3 & 2 & 3 & 3 & 3 & 3 \\
\hline \multirow{2}{*}{1.000} & RP & \multicolumn{8}{|c|}{3} \\
\hline & WS & 2 & 3 & 3 & 2 & 3 & 3 & 3 & 3 \\
\hline \multirow{2}{*}{5.000} & $\mathbf{R P}$ & \multicolumn{8}{|c|}{3} \\
\hline & WS & 2 & 3 & 3 & 2 & 3 & 3 & 3 & 3 \\
\hline \multirow{2}{*}{10.000} & RP & \multicolumn{8}{|c|}{3} \\
\hline & WS & 2 & 3 & 3 & 2 & 3 & 3 & 3 & 3 \\
\hline
\end{tabular}


Apêndice 6: Questionário de avaliação preenchido.

\section{Complexidade do modelo}

O modelo agrega as informações de maneira adequada?

O modelo possui capacidade suficiente para utilizar as informações disponíveis?

É possível incorporar opiniões e crenças de maneira satisfatória?

É possível alcançar uma participação equitativa dos stakeholders envolvidos na decisão em grupo de maneira satisfatória?

O modelo é suficientemente flexível para incorporar mudanças no processo decisório?

\section{Custo / Benefício}

O resultado do modelo de decisão é útil?

O resultado do modelo de decisão é aceitável?

Os investimentos necessários são justificáveis?

O modelo é de fácil utilização pelo usuário?

A maneira como o modelo de decisão funciona é suficientemente clara?

O modelo de decisão aumentou a percepção sobre o processo decisório?

O modelo de decisão contribui para aprimorar a comunicação sobre a justificativa da decisão?

O modelo de decisão contribuiu para aprimorar as habilidades para a tomada de decisão?

Simbologia

\section{Atende}

Atende com ressalvas

Atende parcialmente

Não atende

Fonte: Adaptado de De Boer; Wegen (2003) e Prado (2011). 
Apêndice 7: Doações recebidas nos depósitos em kg.

\begin{tabular}{|c|c|c|c|c|c|c|c|c|c|c|}
\hline \multirow[b]{3}{*}{ Material } & \multicolumn{5}{|c|}{ Cenários com baixa divulgação de mídia (1, 2 e 3$)$} & \multicolumn{5}{|c|}{ Cenários com alta divulgação de mídia $(4,5,6,7$ e 8$)$} \\
\hline & \multicolumn{5}{|c|}{ Depósito } & \multicolumn{5}{|c|}{ Depósito } \\
\hline & Cacapava & $\begin{array}{l}\text { S J dos } \\
\text { Campos }\end{array}$ & Taubaté & Tremembé & Sao Paulo & Cacapava & $\begin{array}{l}\text { S J dos } \\
\text { Campos }\end{array}$ & Taubaté & Tremembé & Sao Paulo \\
\hline Agasalhos & 820,25 & 820,25 & 820,25 & 820,25 & $3.281,00$ & $8.202,50$ & $8.202,50$ & $8.202,50$ & $8.202,50$ & $32.810,00$ \\
\hline Bota & - & - & & & 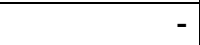 & & - & & - & \\
\hline Camiseta & 136,00 & 136,00 & 136,00 & 136,00 & 544,00 & $1.360,00$ & $1.360,00$ & $1.360,00$ & $1.360,00$ & $5.440,00$ \\
\hline Capa de chuva & - & - & - & - & - & - & - & - & - & - \\
\hline Capacete & - & - & - & - & - & - & - & - & - & 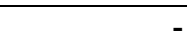 \\
\hline Cesta Básica & 762,50 & 762,50 & 762,50 & 762,50 & $3.050,00$ & $7.625,00$ & $7.625,00$ & $7.625,00$ & $7.625,00$ & $30.500,00$ \\
\hline Cobertor & $1.334,50$ & $1.334,50$ & $1.334,50$ & $1.334,50$ & $5.338,00$ & $13.345,00$ & $13.345,00$ & $13.345,00$ & $13.345,00$ & $53.380,00$ \\
\hline Colchão & 12,44 & 12,44 & 12,44 & 12,44 & 49,75 & 124,37 & 124,37 & 124,37 & 124,37 & 497,48 \\
\hline Colete & - & - & - & - & - & - & - & - & - & 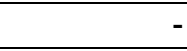 \\
\hline Fita para isolamento & - & - & - & - & - & - & - & - & - & - \\
\hline Kit Higiene & 68,39 & 68,39 & 68,39 & 68,39 & 273,55 & 683,87 & 683,87 & 683,87 & 683,87 & $2.735,49$ \\
\hline Kit Limpeza & 54,38 & 54,38 & 54,38 & 54,38 & 217,50 & 543,76 & 543,76 & 543,76 & 543,76 & $2.175,04$ \\
\hline Lençol & 221,00 & 221,00 & 221,00 & 221,00 & 884,00 & $2.210,00$ & $2.210,00$ & $2.210,00$ & $2.210,00$ & $8.840,00$ \\
\hline Lona plástica & - & - & - & - & - & - & - & - & - & - \\
\hline Luva & - & - & - & - & - & - & - & - & - & - \\
\hline Pluviômetro & - & - & - & - & - & - & - & - & - & 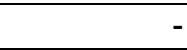 \\
\hline Tênis & 386,75 & 386,75 & 386,75 & 386,75 & $1.547,00$ & $3.867,50$ & $3.867,50$ & $3.867,50$ & $3.867,50$ & $15.470,00$ \\
\hline
\end{tabular}


Apêndice 8: Demanda de cada material por cidade, conforme o cenário $(\mathrm{kg})$.

\begin{tabular}{|c|c|c|c|c|c|c|c|c|c|c|c|c|c|c|c|c|c|}
\hline \multirow{3}{*}{\begin{tabular}{|l|} 
Cenários \\
Pessoas por kit \\
Critério de distribuição \\
\end{tabular}} & \multicolumn{17}{|c|}{ Nível II (1 e 4) } \\
\hline & & & & & & 4 & & & & & 4 & 4 & & & & & \\
\hline & Individual & Individual & Individual & Individual & Individual & Familiar & Individual & Individual & Individual & Município & Familiar & Familiar & Individual & Município & Individual & Município & Individual \\
\hline Usuário & Populacao & COMDEC & Populacao & COMDEC & COMDEC & Populacao & Populacao & Populacao & COMDEC & COMDEC & Populacao & Populacao & Populacao & COMDEC & COMDEC & COMDEC & Populacao \\
\hline Peso por unidade $(\mathrm{kg})$ & 0.97 & 1.40 & 0.16 & 0.74 & 0.39 & 19.80 & 1.57 & 3.37 & 0.20 & 1.50 & 1.08 & 3.43 & 0.26 & 23.00 & 0.20 & 0.70 & 0.46 \\
\hline Material & Agasalhos & Bota & Camiseta & $\begin{array}{l}\text { Capa de } \\
\text { chuva }\end{array}$ & Capacete & $\begin{array}{l}\text { Cesta } \\
\text { Básica } \\
\end{array}$ & Cobertor & Colchão & Colete & $\begin{array}{c}\text { Fita para } \\
\text { isolamento }\end{array}$ & Higiene & $\begin{array}{c}\text { Kit } \\
\text { Limpeza } \\
\end{array}$ & Lençol & $\begin{array}{l}\text { Lona } \\
\text { plástica }\end{array}$ & Luva & Pluviômetro & Tênis \\
\hline \begin{tabular}{|l|} 
Aparecida \\
\end{tabular} & 271,10 & 14,00 & 44,95 & 7,40 & 3,90 & $1.390,61$ & 441,06 & 947,50 & 2,00 & 10,50 & 75,70 & 240,77 & 73,04 & 161,00 & 2,00 & 0,49 & 127,82 \\
\hline Arape & 4,85 & 14,00 & 0,80 & 7,40 & 3,90 & 24,90 & 7,90 & 16,97 & 2,00 & & 1,36 & 4,31 & 1,31 & - & 2,00 & 西 & 2,29 \\
\hline Areias & 7,19 & 14,00 & 1,19 & 7,40 & 3,90 & 36,89 & 11,70 & 25,14 & 2,00 & & 2,01 & 6,39 & 1,94 & & 2,00 & & 3,39 \\
\hline Bananal & 19,89 & 14,00 & 3,30 & 7,40 & 3,90 & 102,02 & 32,36 & 69,51 & 2,00 & 1,50 & 5,55 & 17,66 & 5,36 & 23,00 & 2,00 & 0,07 & 9,38 \\
\hline $\mathrm{Cas}$ & 140,57 & 15,40 & 23,31 & 8,14 & 4,29 & 721,06 & 228,70 & 491,30 & 2,20 & 6,00 & 39,25 & 124,84 & 37,87 & 92,00 & 2,20 & 0,28 & 66,28 \\
\hline Paulista & 52 & 14,00 & 9,70 & 7,40 & 3,90 & 300,17 & 95,21 & 204,52 & 2,00 & 3,00 & 16,34 & 51,97 & 15,77 & 46,00 & 2,00 & 0,14 & 27,59 \\
\hline Campos & 92,95 & 14,00 & 15,41 & 7,40 & 3,90 & 476,80 & 151,23 & 324,87 & 2,00 & 3,00 & 25,96 & 82,55 & 25,04 & 46,00 & 2,00 & 0,14 & 43,83 \\
\hline Canas & 8,52 & 14,00 & 1,41 & 7,40 & 3,90 & 43,71 & 13,86 & 29,78 & 2,00 & & 2,38 & 7,57 & 2,30 & & 2,00 & & 4,02 \\
\hline $\mathrm{Cr}$ & 149,88 & 14,00 & 24,85 & 7,40 & 3,90 & 768,84 & 243,85 & 523,85 & 2,00 & 6,00 & 41,85 & 133,12 & 40,38 & 92,00 & 2,00 & 0,28 & 70,67 \\
\hline Cunh & 527 & 14,00 & 87,50 & 7,40 & 3,90 & $2.707,00$ & 858,58 & $1.844,43$ & 2,00 & 21,00 & 147,36 & 468,69 & 142,19 & 322,00 & 2,00 & 0,98 & 248,82 \\
\hline Guaratinguetá & 781,30 & 19,60 & 129,54 & 10,36 & 5,46 & $4.007,73$ & $1.271,14$ & $2.730,70$ & 2,80 & 30,00 & 218,17 & 693,90 & 210,51 & 460,00 & 2,80 & 1,40 & 368,39 \\
\hline & & 14 & 2,85 & 7,40 & 3,90 & 88,12 & $\quad 27,95$ & 60,04 & 2,00 & & 4,80 & 15,26 & 4,63 & & 2,00 & & 8,10 \\
\hline & 325,77 & 36,40 & 54,01 & $\begin{array}{r}19,24 \\
740\end{array}$ & $\begin{array}{r}10,14 \\
390\end{array}$ & $1.671,04$ & 530,01 & $1.138,58$ & 5,20 & 12,00 & 90,97 & 289,32 & 87,77 & 184,00 & $\begin{array}{l}5,20 \\
2,00\end{array}$ & 0,56 & 153,60 \\
\hline & & $\begin{array}{l}14,00 \\
1400\end{array}$ & & $\begin{array}{l}7,40 \\
740\end{array}$ & $\begin{array}{l}3,90 \\
3,90\end{array}$ & & & & & & & & & & & & \\
\hline \begin{tabular}{|l} 
Lagoinha \\
Lavrinhas
\end{tabular} & $\begin{array}{r}9,42 \\
12,82\end{array}$ & $\begin{array}{l}14,00 \\
14,00\end{array}$ & & $\begin{array}{l}7,40 \\
7,40\end{array}$ & $\begin{array}{l}3,90 \\
3,90\end{array}$ & $\begin{array}{l}48,34 \\
65,74\end{array}$ & 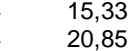 & & $\begin{array}{l}2,00 \\
2,00\end{array}$ & - & $\begin{array}{l}2,63 \\
3,58\end{array}$ & $\begin{array}{r}8,37 \\
11,38\end{array}$ & $\begin{array}{l}2,54 \\
3,45\end{array}$ & - & $\begin{array}{l}2,00 \\
2,00\end{array}$ & - & $\begin{array}{l}4,44 \\
6,04\end{array}$ \\
\hline & 160,57 & 14 & 26 , & 7 & 3,90 & 823,64 & 261 & 561 & 2,00 & 6,00 & 44,84 & 142,60 & $\begin{array}{r}r, 45 \\
43,26\end{array}$ & 92,00 & 2,00 & 0,28 & $\begin{array}{r}75,71 \\
75,71\end{array}$ \\
\hline Monte & 8,01 & 14,00 & 1,3 & 7,40 & 3,90 & 41,09 & 13,03 & 28,00 & 2,00 & & 2,24 & 7,11 & 2,16 & & 2,00 & & 3,78 \\
\hline Nativid & & 14,00 & 1,65 & 7,40 & 3,90 & 51,17 & 16,23 & 34,86 & 2,00 & & 2,79 & 8,86 & 2,69 & 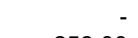 & 2,00 & & 4,70 \\
\hline & 414 & 14,00 & 68,74 & & 3,90 & $2.126,66$ & 674,52 & $1.449,02$ & 2,00 & 16,50 & 115,77 & 368,21 & 111,70 & 253,00 & 2,00 & 0,77 & 195,48 \\
\hline $\mathrm{Pi}$ & & & & & 7,02 & & & & 3, & & & 0,73 & & & 3,60 & 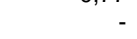 & 0,39 \\
\hline Piquet & 27 & 14,00 & 4,56 & 7,40 & 3,90 & 140,93 & 44,70 & 96,02 & 2, & 1,50 & 7,67 & 24,40 & 7,40 & 23,00 & 2,00 & 0,07 & 12,95 \\
\hline Pot & & & 6 & & & 193 & 61,24 & 131 & & & 10,51 & 33,43 & 10 & & 2,00 & 0,07 & 17,75 \\
\hline & 21,97 & 14,00 & 3,64 & 7 & 3,90 & 112,71 & 35,75 & 76,79 & 2 , & 1,50 & 6,14 & 19,51 & 5,92 & 23,00 & 2,00 & 0,07 & 10,36 \\
\hline Serra & & 14,00 & & & 3,90 & & - & . & 2 & & 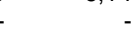 & - & - & - & 2,00 & - & \\
\hline & & 14, & & 7 & 3,90 & & & - & 2, & & - & & - & & 2,00 & & \\
\hline S & 26 & & 4 & & 3,90 & 137,35 & 43 & 93 & 2, & 1,50 & 7,48 & 23,78 & 7,21 & 23,00 & 2,00 & 0,07 & 12,62 \\
\hline nhal & 12,62 & 14,00 & 2 , & 7,40 & 3,90 & 64,74 & 20,54 & 44,11 & 2, & & 3,52 & 11,21 & 3,40 & & 2,00 & & 5,95 \\
\hline & 20,37 & & 3 & 7, & 3,90 & 104,50 & 33, & & 2 , & 1,50 & 5,69 & 18,09 & 5,49 & 23,00 & 2,00 & 0,07 & 9,61 \\
\hline $\mathrm{s}$ & 7 & & 1, & 7 & 3,90 & 40,71 & & 27 & 2 , & & 2,22 & 7,05 & 2,14 & & 2,00 & & 3,74 \\
\hline pos & 234,30 & 110,60 & 38,85 & 58,46 & 30,81 & $1.201,86$ & 381,19 & 818,89 & 15,80 & 9,00 & 65,43 & 208,09 & 63,13 & 138,00 & 15,80 & 0,42 & 110,47 \\
\hline São Luís do Paraitinga & 336,21 & 14,00 & 55,75 & 7,40 & 3,90 & $1.724,62$ & 547,00 & $1.175,08$ & 2,00 & 13,50 & 93,89 & 298,60 & 90,59 & 207,00 & 2,00 & 0,63 & 158,53 \\
\hline & 11 & & 1, & 7,40 & 3,90 & 57 & 18 & & 2 , & & 3,15 & 10 & 3,04 & & 2,00 & & 5,31 \\
\hline & 81 & 49 & 13 & 25,90 & 13,65 & 416,49 & 132,10 & 283 & 7, & 3,00 & 22,67 & 72,11 & 21,88 & 46,00 & 7,00 & 0,14 & 38,28 \\
\hline Tremembé & 16,02 & 14,00 & 2,66 & 7,40 & 3,90 & 82,16 & 26,06 & 55,98 & 2,00 & & 4,47 & 14,23 & 4,32 & & 2,00 & 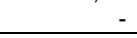 & 7,55 \\
\hline
\end{tabular}


Apêndice 8: Demanda de cada material por cidade, conforme o cenário, continuação (unidade: kg).

\begin{tabular}{|c|c|c|c|c|c|c|c|c|c|c|c|c|c|c|c|c|c|}
\hline \multirow{2}{*}{\begin{tabular}{|l} 
Cenários \\
Pessoas por kit
\end{tabular}} & \multicolumn{17}{|c|}{ Nível III (2. 5 e 7$)$} \\
\hline & & & & & & 4 & & & & & 4 & 4 & & & & & \\
\hline Critério de distribuição & Individual & Individual & Individual & Individual & Individual & Familiar & Individual & Individual & Individual & Município & Familiar & Familiar & Individual & Município & Individual & Município & Individual \\
\hline Usuário & Populacao & COMDEC & Populacao & COMDEC & COMDEC & Populacao & Populacao & Populacao & COMDEC & COMDEC & Populacao & Populacao & Populacao & COMDEC & COMDEC & COMDEC & Populacao \\
\hline Peso por unidade $(\mathrm{kg})$ & 0.97 & 1.40 & 0.16 & 0.74 & 0.39 & 19.80 & 1.57 & 3.37 & 0.20 & 1.50 & 1.08 & 3.43 & 0.26 & 23.00 & 0.20 & 0.70 & 0.46 \\
\hline Material & Agasalhos & Bota & Camiseta & $\begin{array}{l}\text { Capa de } \\
\text { chuva }\end{array}$ & oacete & $\begin{array}{l}\text { Cesta } \\
\text { Básica }\end{array}$ & Cobertor & Colchão & Colete & $\begin{array}{c}\text { Fita para } \\
\text { isolamento }\end{array}$ & Higiene & $\begin{array}{c}\text { Kit } \\
\text { Limpeza }\end{array}$ & Lençol & $\begin{array}{l}\text { Lona } \\
\text { plástica }\end{array}$ & Luva & Pluviômetro & Tênis \\
\hline \begin{tabular}{|l} 
Arapeí \\
Areias
\end{tabular} & 16,91 & $\begin{array}{l}14,00 \\
14,00\end{array}$ & $\begin{array}{l}2,80 \\
4,15\end{array}$ & $\begin{array}{l}7,40 \\
7,40\end{array}$ & $\begin{array}{l}3,90 \\
3,90\end{array}$ & $\begin{array}{r}86,75 \\
128,53\end{array}$ & $\begin{array}{l}27,52 \\
4077\end{array}$ & $\begin{array}{l}59,11 \\
87,58\end{array}$ & 2,00 & & $\begin{array}{l}4,72 \\
700\end{array}$ & $\begin{array}{l}15,02 \\
22,25\end{array}$ & $\begin{array}{l}4,56 \\
6,75\end{array}$ & & $\begin{array}{l}2,00 \\
200\end{array}$ & & $\begin{array}{r}7,97 \\
11,81\end{array}$ \\
\hline \begin{tabular}{|l} 
Areias \\
Bananal
\end{tabular} & $\begin{array}{l}25,06 \\
69,30\end{array}$ & $\begin{array}{l}14,00 \\
14,00\end{array}$ & $\begin{array}{r}4,15 \\
11,49\end{array}$ & $\begin{array}{l}7,40 \\
7,40\end{array}$ & $\begin{array}{l}3,90 \\
3,90\end{array}$ & $\begin{array}{l}128,53 \\
355,47\end{array}$ & $\begin{array}{r}40, / 7 \\
112,75\end{array}$ & $\begin{array}{r}87,58 \\
242,20\end{array}$ & Do & $\begin{array}{l}1,50 \\
3,00\end{array}$ & $\begin{array}{r}7,00 \\
19,35\end{array}$ & $\begin{array}{l}22,25 \\
61,55\end{array}$ & $\begin{array}{r}6,75 \\
18,67\end{array}$ & $\begin{array}{l}23,00 \\
46,00\end{array}$ & $\begin{array}{l}2,00 \\
2,00\end{array}$ & $\begin{array}{l}0,07 \\
0,14\end{array}$ & $\begin{array}{l}11,81 \\
32,67\end{array}$ \\
\hline Caçapava & 409,38 & 15,40 & 67,88 & 8,14 & 4,29 & $2.099,92$ & 666,03 & $1.430,80$ & 2,20 & 16,50 & 114,32 & 363,58 & 110,30 & 253,00 & 2,20 & 0,77 & 193,02 \\
\hline Cachoeira Paulista & 203,89 & 14,00 & 33,81 & 7,40 & 3,90 & $1.045,85$ & 331,71 & 712,60 & 2,00 & 7,50 & 56,93 & 181,08 & 54,93 & 115,00 & 2,00 & 0,35 & 96,13 \\
\hline Campos do Jordão & 323,86 & 14,00 & 53,70 & 7,40 & 3,90 & $1.661,27$ & 526,91 & $1.131,92$ & 2,00 & 12,00 & 90,44 & 287,63 & 87,26 & 184,00 & 2,00 & 0,56 & 152,70 \\
\hline Canas & 29,69 & 14,00 & 4,92 & 7,40 & 3,90 & 152,29 & 48,30 & 103,76 & 2,00 & 1,50 & 8,29 & 26,37 & 8,00 & 23,00 & 2,00 & 0,07 & 14,00 \\
\hline Cruzeiro & 522,23 & 14,00 & 86,59 & 7,40 & 3,90 & $2.678,78$ & 849,63 & $1.825,20$ & 2,00 & 21,00 & 145,83 & 463,80 & 140,70 & 322,00 & 2,00 & 0,98 & 246,23 \\
\hline Cunha & $1.055,45$ & 14,00 & 175,00 & 7,40 & 3,90 & $5.413,99$ & $1.717,16$ & $3.688,86$ & 2,00 & 40,50 & 294,73 & 937,38 & 284,37 & 621,00 & 2,00 & 1,89 & 497,65 \\
\hline Guaratins & $2.898,39$ & 19,60 & 480,56 & 10,36 & 5,46 & $14.867,38$ & $4.715,51$ & $10.130,00$ & 2,80 & 112,50 & 809,35 & $2.574,13$ & 780,91 & $1.725,00$ & 2,80 & 5,25 & $1.366,60$ \\
\hline S & 59,85 & 14,00 & 9,92 & 7,40 & 3,90 & 307,01 & 97,38 & 209,19 & 2, & 3,00 & 16,71 & 53,16 & 16,13 & 46,00 & 2,00 & 0,14 & 28,22 \\
\hline $\mathrm{J}$ & $1.255,63$ & 36,40 & 208,19 & 19,24 & 10,14 & $6.440,81$ & $.042,84$ & $4.388,49$ & 5,20 & 49,50 & 350,63 & $1.115,16$ & 338,31 & 759,00 & 5,20 & 2,31 & 592,03 \\
\hline eiro & 24,78 & 14,00 & 4,11 & 7,40 & 3,90 & 127,10 & 40,31 & 86,60 & 2,00 & 1,50 & 6,92 & 22,01 & 6,68 & 00 & 2,00 & 0,07 & 11,68 \\
\hline ha & 32,84 & 14,00 & 5,44 & 7,40 & 90 & 168,43 & 53,42 & 114,76 &, 00 & 1,50 & 9,17 & 29,16 & 8,85 & 23,00 & 2,00 & 0,07 & 15,48 \\
\hline Lavrinhas & 44,66 & 14,00 & 7,40 & 7,40 &, 90 & 229,06 & 72,65 & 156,07 & 2,00 & 1,50 & 12,47 & 39,66 & 12,03 & 23,00 & 2,00 & 0,07 & 21,06 \\
\hline I rena & 5 & 4,00 & 92,76 & 7,40 & 3,90 & $2.869,71$ & 910,19 & $1.955,30$ & 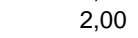 & 21,00 & 156,22 & 496,86 & 150,73 & 322,00 & 2,00 & 0,98 & 263,78 \\
\hline Monteir & 27,91 & 14,00 & 4,6 & 7,40 & 3,90 & 143,18 & 45,41 & 97,55 & 2,00 & 1,50 & 7,79 & 24,79 & 7,52 & 23,00 & 2,00 & 0,07 & 13,16 \\
\hline Nativ & 9 & 14,00 & & & 0 & & 49,77 & & 2, & & 8,54 & 27,17 & & & 2,00 & 0,07 & 14,42 \\
\hline Paraibu & $1.146,41$ & 14,00 & 190,08 & 7,40 & 3,90 & $5.880,54$ & $1.865,14$ & $4.006,75$ & 2,00 & 45,00 & 320,13 & $1.018,15$ & 308,88 & 690,00 & 2,00 & 2,10 & 540,53 \\
\hline Pindamonhangaba & 57,58 & 25,20 & 9,55 & 13,32 & 7,02 & 295,34 & 93,67 & & 3,60 & 1,50 & 16,08 & 51,14 & 15,51 & & 3,60 & 0,07 & 27,15 \\
\hline $\mathrm{Pic}$ & 95,73 & 14,00 & 15 & 7,40 & 3,90 & 491,03 & 155,74 & 33 & 2,00 & 3,00 & 26,73 & 85,02 & 25,79 & 46,00 & 2,00 & 0,14 & 45,13 \\
\hline Potim & 131,15 & 4,00 & 2 & 7,40 & 3,90 & 672,75 & 213,38 & 458 & 2, & 4,50 & 36,62 & 116,48 & 35,34 & 69,00 & 2,00 & 0,21 & 61,84 \\
\hline & 76,55 & & 12,6 & 7 & & 39 & 124,55 & 267,56 & 2 & 3,00 & 21,38 & 67,99 & 20,63 & 46,00 & 2,00 & 0,14 & 36,10 \\
\hline ão da Serra & 20,80 & 14,00 & 3,45 & 7,40 & 3,90 & 106,68 & 33,83 & 72,68 & 2, & 1,50 & 5,81 & 18,47 & 5,60 & 23,00 & 2,00 & 0,07 & 9,81 \\
\hline Rose & & 14,00 & & 7,40 & 3,90 & & & & 2, & & & & & & 2,00 & & \\
\hline Santa & 93,29 & 14,00 & 15,47 & 7,40 & 3,90 & 478,54 & 151,78 & 326,06 & 2,00 & 3,00 & 26,05 & 82,85 & 25,14 & 46,00 & 2,00 & 0,14 & 43,99 \\
\hline Santo & 43,98 & 14,00 & 7,29 & 7,40 & 3 & 225,58 & 71,55 & 153 & 2 , & 1,50 & 12,28 & 39,06 & 11,85 & 23,00 & 2,00 & 0,07 & 20,74 \\
\hline Sã & 70,98 & 14,00 & 11,77 & 7,40 & 3 & 364,10 & 115,48 & 248,08 & 2,00 & 3,00 & 19,82 & 63,04 & 19,12 & 46,00 & 2,00 & 0,14 & 33,47 \\
\hline$S$ & 27,65 & & 4, & & & & 44,99 & & 2 & 1,50 & 7,72 & 24,56 & 7,45 & 23,00 & 2,00 & 0,07 & 13,04 \\
\hline & $1.469,35$ & 110,60 & 243,62 & 58,46 & 30,81 & $7.537,06$ & $2.390,54$ & $5.135,43$ & 15,80 & 57,00 & 410,30 & $1.304,96$ & 395,89 & 874,00 & 15,80 & 2,66 & 692,80 \\
\hline São Luís do Paraitinga & 816,52 & 14,00 & 135,38 & 7,40 & 3,90 & $4.188,36$ & $1.328,43$ & $2.853,77$ & 2, & 31,50 & 228,01 & 725,17 & 219,99 & 483,00 & 2,00 & 1,47 & 384,99 \\
\hline Silveiras & 39,25 & 14,00 & 6,51 & 7,40 & 3,90 & 201,34 & 63,86 & 137,18 & 2,00 & 1,50 & 10,96 & 34,86 & 10,58 & 23,00 & 2,00 & 0,07 & 18,51 \\
\hline & 7,21 & 49,00 & 39, & 25,90 & 13,65 & $1.216,80$ & 385,93 & 829,08 & 7, & 9,00 & 66,24 & 210,68 & 63,91 & 138,00 & 7,00 & 0,42 & 111,85 \\
\hline Tremembé & 451,86 & 14,00 & 74,92 & 7,40 & 3,90 & $2.317,81$ & 735,14 & $1.579,26$ & 2,00 & 18,00 & 126,18 & 401,30 & 121,74 & 276,00 & 2,00 & 0,84 & 213,05 \\
\hline
\end{tabular}


Apêndice 8: Demanda de cada material por cidade, conforme o cenário, continuação (unidade: $\mathrm{kg}$ ).

\begin{tabular}{|c|c|c|c|c|c|c|c|c|c|c|c|c|c|c|c|c|c|}
\hline \multirow{2}{*}{\begin{tabular}{|l} 
Cenários \\
Pessoas por kit
\end{tabular}} & \multicolumn{17}{|c|}{ Nível IV (3, 6 e 8$)$} \\
\hline & & & & & & 4 & & & & & 4 & 4 & & & & & \\
\hline Critério de distribuição & Individual & Individual & Individual & Individual & Individual & Familiar & Individual & Individual & Individual & Município & Familiar & Familiar & Individual & Município & Individual & Município & Individual \\
\hline Usuário & Populacao & COMDEC & Populacao & COMDEC & COMDEC & Populacao & Populacao & Populacao & COMDEC & COMDEC & Populacao & Populacao & Populacao & COMDEC & COMDEC & COMDEC & Populacao \\
\hline Peso por unidade $(\mathrm{kg})$ & 0.97 & 1.40 & 0.16 & 0.74 & 0.39 & 19.80 & 1.57 & 3.37 & 0.20 & 1.50 & 1.08 & 3.43 & 0.26 & 23.00 & 0.20 & 0.70 & 0.46 \\
\hline Material & Agasalhos & Bota & Camiseta & $\begin{array}{c}\text { Capa de } \\
\text { chuva }\end{array}$ & acete & $\begin{array}{c}\text { Cesta } \\
\text { Básica }\end{array}$ & Cobertor & Colchão & Colete & $\begin{array}{c}\text { Fita para } \\
\text { isolamento }\end{array}$ & Higiene & $\begin{array}{c}\text { Kit } \\
\text { Limpeza }\end{array}$ & Lençol & $\begin{array}{c}\text { Lona } \\
\text { plástica }\end{array}$ & Luva & luviômetro & Tênis \\
\hline \begin{tabular}{|l} 
Aparecida \\
\end{tabular} & $5.719,76$ & 14,00 & 948,35 & 7,40 & 3,90 & $29.339,71$ & $9.305,73$ & $19.990,84$ & 2,00 & 222,00 & $1.597,20$ & $5.079,86$ & $1.541,08$ & $3.404,00$ & 2,00 & 10,36 & $2.696,88$ \\
\hline Arapeí & 52,70 & 4,00 & 8,74 & 7,40 & 3,90 & 270,34 & 85,74 & 184,20 & 2,00 & 1,50 & 14,72 & 46,81 & 14,20 & 23,00 & 2,00 & 0,07 & 24,85 \\
\hline Areias & 78,08 & 14,00 & 12,95 & 7,40 & 3,90 & 400,52 & 127,04 & 272,90 & 2,00 & 3,00 & 21,80 & 69,35 & 21,04 & 46,00 & 2,00 & 0,14 & 36,82 \\
\hline Bananal & 215,95 & 14,00 & 35,80 & 7,40 & 3,90 & $1.107,70$ & 351,33 & 754,74 & 2,00 & 9,00 & 60,30 & 191,79 & 58,18 & 138,00 & 2,00 & 0,42 & 101,82 \\
\hline Caçapava & $1.670,39$ & 15,40 & 276,96 & 8,14 & 4,29 & $8.568,34$ & $2.717,64$ & $5.838,11$ & 2,20 & 64,50 & 466,45 & $1.483,52$ & 450,05 & 989,00 & 2,20 & 3,01 & 787,60 \\
\hline Cachoeira Paulista & 635,35 & 14,00 & 105,34 & 7,40 & 3,90 & $3.259,05$ & $1.033,68$ & $2.220,58$ & 2,00 & 24,00 & 177,42 & 564,27 & 171,18 & 368,00 & 2,00 & 1,12 & 299,57 \\
\hline Campos do Jordão & $1.009,21$ & 14,00 & 167,33 & 7,40 & 3,90 & $5.176,80$ & $1.641,93$ & $3.527,25$ & 2,00 & 39,00 & 281,82 & 896,31 & 271,91 & 598,00 & 2,00 & 1,82 & 475,85 \\
\hline Canas & 92,52 & 14,00 & 15,34 & 7,40 & 3,90 & 474,56 & 150,52 & 323,34 & 2,00 & 3,00 & 25,83 & 82,17 & 24,93 & 46,00 & 2,00 & 0,14 & 43,62 \\
\hline Cruzeiro & $1.627,34$ & 14,00 & 269,82 & 7,40 & 3,90 & $8.347,50$ & $2.647,59$ & $5.687,63$ & 2,00 & 63,00 & 454,42 & $1.445,28$ & 438,45 & 966,00 & 2,00 & 2,94 & 767,30 \\
\hline Cunha & $2.110,91$ & 14,00 & 350,00 & 40 & 3,90 & $10.827,98$ & $3.434,33$ & $7.377,73$ & 0 & 82,50 & 589,46 & $1.874,75$ & 568,74 & $1.265,00$ & 2,00 & 3,85 & 995,30 \\
\hline Guaratin & $8.761,33$ & 19,60 & $1.452,66$ & 10,36 & 5,46 & $44.941,52$ & $14.254,18$ & $30.621,24$ & 2,8 & 340,50 & $2.446,54$ & $7.781,15$ & $2.360,56$ & $5.221,00$ & 2,80 & 15,89 & $4.130,99$ \\
\hline & 186,51 & 14,00 & 30,92 & 7,40 & 3,90 & 956,71 & 303,44 & 651,86 & 2, & 7,50 & 52,08 & 165,64 & 50,25 & 11 & 2,00 & 0,35 & 87,94 \\
\hline careí & $2.511,27$ & 36,40 & 416,38 & 19,24 & 10,14 & $12.881,62$ & $4.085,69$ & $8.776,99$ & 5,20 & 97,50 & 701,25 & $2.230,32$ & 676,61 & $1.495,00$ & 5,20 & 4,55 & . 184,07 \\
\hline & 61,95 & 14,00 & 10,27 & 7,40 & 90 & 317,75 & 100,78 & & 2,00 & 3,00 & 17,30 & 55,02 & 16,69 & 46 & 2,00 & 0,14 & 29,21 \\
\hline ha & 2,32 & 14,00 & 16,97 & 40 & 90 & 524,86 & 47 & & 0 & 4,50 & 8,57 & 0,87 & 27,57 & 6 & 2,00 & 0,21 & 48,24 \\
\hline Lavrinhas & 9,15 & 4,00 & 23,07 & 7,40 & 90 & 713,79 & 226,39 & 486,35 & 2,00 & 6,00 & 38,86 & 123,59 & 37,49 & 92,00 & 2,00 & 0,28 & 65,61 \\
\hline Iorena & 1.743 & 100 & 289,05 & 7,40 & 90 & $8.942,49$ & $2.836,30$ & $6.093,03$ & 0 & 67,50 & 486,81 & $1.548,30$ & 469,71 & $.035,00$ & 2,00 & 3,15 & 821,99 \\
\hline Monte & 86,98 & 14,00 & 1 & 7,40 & 3,90 & 446,16 & 51 & 30 & 2, & 3,00 & 24,29 & 77,25 & 23,43 & 46,00 & 2,00 & 0,14 & 41,01 \\
\hline Nati & & 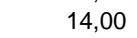 & & & 0 & 600,35 & & & $2, C$ & & 32,68 & & & & 2,00 & 0,21 & 55,18 \\
\hline Paraib & $2.562,93$ & 14,00 & 424,94 & 7,40 & 3,90 & $13.146,63$ & $4.169,74$ & $8.957,55$ & 2,00 & 99,00 & 715,68 & $2.276,20$ & 690,53 & $1.518,00$ & 2,00 & 4,62 & $1.208,43$ \\
\hline Pindamonh & $1.437,78$ & 520 & & 13,32 & 7.02 & & & & 3, & & 49 & & & & 3,60 & 2,59 & 677,92 \\
\hline & 3,30 & 14,00 & 49,46 & 7,40 & 3,90 & 1.53 & 485,31 & & & 12,00 & 83,30 & & 8 & & 2,00 & 0,56 & 140,65 \\
\hline & 408,69 & 1400 & 67,76 & 7,40 & 390 & $2.096,39$ & 664,91 & 1.4 & 2, & 16,50 & 114,12 & 362,97 & 110 & & 2,00 & 0,77 & 192,70 \\
\hline & 2 & & & 7, & & & & & 2 & & & & & & 2,00 & 0,42 & 112,48 \\
\hline ão da Serra & 240,64 & 14,00 & 3 & 7,40 & 3, & $1.234,39$ & 391,51 & 6 & 2 , & 9,00 & 67,20 & 213,72 & 64,84 & 13 & 2,00 & 0,42 & 113,46 \\
\hline & 368,55 & 14,00 & 6 & 7,40 & 3, & $1.8 \mathrm{~s}$ & 599,61 & & 2 , & 15,00 & 102,92 & & 99,30 & & 2,00 & 0,70 & 173,77 \\
\hline Sa & 290,71 & 14,00 & 48,20 & 7,40 & 3,90 & $1.491,21$ & 472,97 & $1.016,05$ & 2,00 & 12,00 & 81,18 & 258,19 & 78,33 & 184,00 & 2,00 & 0,56 & 137,07 \\
\hline Santc & 137,04 & 14,0 & 2 & 7,40 & 3,90 & & 222,96 & & 2, & 6 & 38,27 & & 36 & & 2,00 & 0,28 & 64,61 \\
\hline & 221,19 & 14,00 & 36,67 & 7,40 & 3,90 & $1.134,59$ & 359,86 & & 2 , & 9,00 & 61,76 & 196,44 & 59,59 & 138,00 & 2,00 & 0,42 & 104,29 \\
\hline & & & & & & & & & & & 24,06 & & 23,22 & & 2,00 & 0,14 & 40,63 \\
\hline & $3.151,55$ & 110,60 & 522,54 & 58,46 & 30,81 & $16.165,97$ & $5.127,39$ & $11.014,81$ & 15,80 & 123,00 & 880,05 & $2.798,97$ & 849,12 & $1.886,00$ & 15,80 & 5,74 & $1.485,96$ \\
\hline São Luís do Paraitinga & $1.889,20$ & & & 7,40 & 3,90 & $9.690,72$ & $3.073,62$ & $6.602,85$ & 2, & 73,50 & 527,55 & $1.677,85$ & 509,01 & $1.127,00$ & 2,00 & 3,43 & 890,76 \\
\hline Silveiras & 122,31 & 14,00 & 20,28 & 7,40 & 3,90 & 627,40 & 198,99 & 427,48 & 2,00 & 4,50 & 34,15 & 108,63 & 32,95 & 69,00 & 2,00 & 0,21 & 57,67 \\
\hline & $1.700,30$ & 49,6 & 281 & 25,90 & 13,65 & $8.721,77$ & $2.766,30$ & $5.942,64$ & 7,0 & 66,00 & 474,80 & $1.510,08$ & 458,11 & $1.012,00$ & 7,00 & 3,08 & 801,70 \\
\hline Tremembé & $1.783,82$ & 14,00 & 295,76 & 7,40 & 3,90 & $9.150,16$ & $2.902,17$ & $6.234,53$ & 2,00 & 69,00 & 498,12 & $1.584,25$ & 480,61 & $1.058,00$ & 2,00 & 3,22 & 841,08 \\
\hline
\end{tabular}


Apêndice 9: Comparação das Faltas X Material disponível por cenário.

\begin{tabular}{|c|c|c|c|c|c|c|c|c|c|c|c|c|c|c|c|c|c|c|}
\hline \multirow[b]{2}{*}{ Cenário } & \multirow[b]{2}{*}{ Parâmetro } & \multicolumn{17}{|c|}{ Materiais (kg) } \\
\hline & & Agasalhos & Bota & Camiseta & $\begin{array}{c}\text { Capa de } \\
\text { chuva }\end{array}$ & Capacete & $\begin{array}{l}\text { Cesta } \\
\text { Básica }\end{array}$ & obertor & Colchão & Colete & $\begin{array}{c}\text { Fita } p \\
\text { isolamento }\end{array}$ & $\begin{array}{c}\text { Kit } \\
\text { Higiene }\end{array}$ & $\begin{array}{c}\text { Kit } \\
\text { Limpeza }\end{array}$ & Lençol & $\begin{array}{l}\text { Lona } \\
\text { plástica }\end{array}$ & Luva & Pluviômetro & Tênis \\
\hline \multirow{6}{*}{1} & Demanda Total & $3.855,45$ & 662,20 & 639,25 & 350,02 & 184,47 & $19.776,68$ & $6.272,60$ & $13.474,99$ & 94,60 & 148,50 & $1.076,61$ & $3.424,12$ & $1.038,77$ & $2.277,00$ & 94,60 & 6,93 & $1.817,86$ \\
\hline & Ek & 8,69 & 338,33 & 612,27 & $2.428,43$ & 195,00 & $349.338,00$ & $28.273,08$ & $97.710,51$ & 100,00 & $1.972,50$ & $4.455,37$ & $18.810,16$ & $4.494,97$ & $30.803,57$ & 980,00 & 49,88 & $1.400,43$ \\
\hline & Doações (2 depósitos abertos) & $4.101,25$ & 0,00 & 680,00 & 0,00 & 0,00 & $3.812,50$ & $6.672,50$ & 62,18 & 0,00 & 0,00 & 341,94 & 271,88 & $1.105,00$ & 0,00 & 0,00 & 0,00 & $1.933,75$ \\
\hline & Limite contratual de compras & $1.752,14$ & 72,08 & $1.141,39$ & 978,83 & 149,14 & $5.262,52$ & $5.371,39$ & $8.641,21$ & 149,14 & 392,23 & $3.127,76$ & $1.743,40$ & $5.156,64$ & 399,47 & $1.461,54$ & 21,25 & 918,04 \\
\hline & (Ek + Doaçōes + Compra) - Demanda & $7.666,62$ & $-251,78$ & $1.794,41$ & $3.057,24$ & 159,67 & $338.636,35$ & $34.044,38$ & $92.938,91$ & 154,54 & $2.216,23$ & $6.848,46$ & $17.401,32$ & $9.717,83$ & $28.926,04$ & $2.346,94$ & 64,20 & $2.434,36$ \\
\hline & Faltas (resultados do modelo) & 0,00 & $-251,79$ & 0,00 & 0,00 & 0,00 & 0,00 & 0,00 & 0,00 & 0,00 & 0,00 & 0,00 & 0,00 & 0,00 & 0,00 & 0,00 & 0,00 & 0,00 \\
\hline \multirow{6}{*}{2} & Demanda Total & $13.433,13$ & 662,20 & $2.227,26$ & 350,02 & 184,47 & $68.905,72$ & $21.854,94$ & $46.949,43$ & 94,60 & 523,50 & $3.751,11$ & $11.930,30$ & $3.619,29$ & $8.027,00$ & 94,60 & 24,43 & $6.333,76$ \\
\hline & Ek & $5.668,69$ & 338,33 & 612,27 & $2.428,43$ & 195,00 & $349.338,00$ & $28.273,08$ & $97.710,51$ & 100,00 & $1.972,50$ & $4.455,37$ & $18.810,16$ & $4.494,97$ & $30.803,57$ & 980,00 & 49,88 & $1.400,43$ \\
\hline & Doações (2 depósitos abertos) & $4.101,25$ & 0,00 & 680,00 & 0,00 & 0,00 & $3.812,50$ & $6.672,50$ & 62,18 & 0,00 & 0,00 & 341,94 & 271,88 & $1.105,00$ & 0,00 & 0,00 & 0,00 & $1.933,75$ \\
\hline & Limite contratual de compras & $1.752,14$ & 72,08 & $1.141,39$ & 978,83 & 149,14 & $5.262,52$ & $5.371,39$ & $8.641,21$ & 149,14 & 392,23 & $3.127,76$ & $1.743,40$ & $5.156,64$ & 399,47 & $1.461,54$ & 21,25 & 918,04 \\
\hline & (Ek + Doações + Compra) - Demanda & $-1.911,06$ & $-251,78$ & 206,40 & $3.057,24$ & 159,67 & $289.507,31$ & $18.462,03$ & $59.464,47$ & 154,54 & $1.841,23$ & $4.173,96$ & $8.895,14$ & $7.137,31$ & $23.176,04$ & $2.346,94$ & 46,70 & $-2.081,54$ \\
\hline & Faltas (resultados do modelo) & $-2.460,75$ & $-251,79$ & $-408,00$ & 0,00 & 0,00 & 0,00 & 0,00 & 0,00 & 0,00 & 0,00 & 0,00 & 0,00 & 0,00 & 0,00 & 0,00 & 0,00 & $-2.081,54$ \\
\hline \multirow{6}{*}{3} & Demanda Total & $41.859,83$ & 662,20 & $6.940,49$ & 350,02 & 184,47 & $214.721,39$ & $68.103,55$ & $146.302,05$ & 94,60 & $1.627,50$ & $11.689,06$ & $37.176,76$ & $11.278,30$ & $24.955,00$ & 94,60 & 75,95 & $19.737,02$ \\
\hline & Ek & $5.668,69$ & 338,33 & 612,27 & $2.428,43$ & 195,00 & $349.338,00$ & $28.273,08$ & $97.710,51$ & 100,00 & $1.972,50$ & $4.455,37$ & $18.810,16$ & $4.494,97$ & $30.803,57$ & 980,00 & 49,88 & $1.400,43$ \\
\hline & Doações (2 depósitos abertos) & $4.101,25$ & 0,00 & 680,00 & 0,00 & 0,00 & $3.812,50$ & $6.672,50$ & 62,18 & 0,00 & 0,00 & 341,94 & 271,88 & $1.105,00$ & 0,00 & 0,00 & 0,00 & $1.933,75$ \\
\hline & Limite contratual de compras & $1.752,14$ & 72,08 & $1.141,39$ & 978,83 & 149,14 & $5.262,52$ & $5.371,39$ & $8.641,21$ & 149,14 & 392,23 & $3.127,76$ & $1.743,40$ & $5.156,64$ & 399,47 & $1.461,54$ & 21,25 & 918,04 \\
\hline & (Ek + Doações + Compra) - Demanda & $-30.337,75$ & $-251,78$ & $-4.506,83$ & $3.057,24$ & 159,67 & $143.691,63$ & $-27.786,57$ & $-39.888,14$ & 154,54 & 737,23 & $-3.763,99$ & $-16.351,31$ & $-521,69$ & $6.248,04$ & $2.346,94$ & $-4,82$ & $-15.484,80$ \\
\hline & Faltas (resultados do modelo) & $-30.337,75$ & $-251,79$ & $-4.506,83$ & 0,00 & 0,00 & 0,00 & $-27.786,58$ & $-39.888,14$ & 0,00 & 0,00 & $-3.764,00$ & $-16.351,32$ & $-663,00$ & 0,00 & 0,00 & $-4,82$ & $-15.484,80$ \\
\hline \multirow{6}{*}{4} & Demanda Total & $3.855,45$ & 662,20 & 639,25 & 350,02 & 184,47 & $19.776,68$ & $6.272,60$ & $13.474,99$ & 94,60 & 148,50 & $1.076,61$ & $3.424,12$ & $1.038,77$ & $2.277,00$ & 94,60 & 6,93 & $1.817,86$ \\
\hline & Ek & $5.668,69$ & 338,33 & 612,27 & $2.428,43$ & 195,00 & $349.338,00$ & $28.273,08$ & $97.710,51$ & 100,00 & $1.972,50$ & $4.455,37$ & $18.810,16$ & $4.494,97$ & $30.803,57$ & 980,00 & 49,88 & $1.400,43$ \\
\hline & Doações (2 depósitos abertos) & $41.012,50$ & 0,00 & $6.800,00$ & 0,00 & 0,00 & $38.125,00$ & $66.725,00$ & 621,85 & 0,00 & 0,00 & $3.419,36$ & $2.718,80$ & $11.050,00$ & 0,00 & 0,00 & 0,00 & $19.337,50$ \\
\hline & Limite contratual de compras & $2.978,64$ & 122,54 & $1.940,36$ & $1.664,01$ & 253,53 & $8.946,29$ & $9.131,37$ & $14.690,05$ & 253,53 & 666,79 & $5.317,20$ & $2.963,79$ & $8.766,28$ & 679,10 & $2.484,61$ & 36,13 & $1.560,67$ \\
\hline & (Ek + Doaçōes + Compra) - Demanda & $45.804,37$ & $-201,33$ & $8.713,38$ & $3.742,43$ & 264,06 & $376.632,62$ & $97.856,85$ & $99.547,42$ & 258,93 & $2.490,79$ & $12.115,32$ & $21.068,62$ & $23.272,48$ & $29.205,67$ & $3.370,01$ & 79,07 & $20.480,74$ \\
\hline & Faltas (resultados do modelo) & 0,00 & $-201,33$ & 0,00 & 0,00 & 0,00 & 0,00 & 0,00 & 0,00 & 0,00 & 0,00 & 0,00 & 0,00 & 0,00 & 0,00 & 0,00 & 0,00 & 0,00 \\
\hline
\end{tabular}

Obs.: células sombreadas indicam faltas mesmo quando materiais encontram-se disponíveis. 
Apêndice 9: Comparação Faltas X Material disponível por cenário (cont.).

\begin{tabular}{|c|c|c|c|c|c|c|c|c|c|c|c|c|c|c|c|c|c|c|}
\hline \multirow[b]{2}{*}{ Cenário } & \multirow[b]{2}{*}{ Parâmetro } & \multicolumn{17}{|c|}{ Materiais $(\mathrm{kg})$} \\
\hline & & Agasalhos & Bota & Camiseta & $\begin{array}{l}\text { Capa de } \\
\text { chuva }\end{array}$ & Capacete & $\begin{array}{c}\text { Cesta } \\
\text { Básica } \\
\end{array}$ & Cobertor & Colchão & Colete & $\begin{array}{c}\text { Fita } p \\
\text { isolamento }\end{array}$ & $\begin{array}{c}\text { Kit } \\
\text { Higiene }\end{array}$ & $\begin{array}{c}\text { Kit } \\
\text { Limpeza }\end{array}$ & Lençol & $\begin{array}{l}\text { Lona } \\
\text { plástica }\end{array}$ & Luva & Pluviômetro & Tênis \\
\hline \multirow{6}{*}{ ( } & Demanda Total & $13.433,13$ & 662,20 & $2.227,26$ & 350,02 & 184,47 & $68.905,72$ & $21.854,94$ & $46.949,43$ & 94,60 & 523,50 & $3.751,11$ & $11.930,30$ & $3.619,29$ & $8.027,00$ & 94,60 & 24,43 & $6.333,76$ \\
\hline & Ek & $5.668,69$ & 338,33 & 612,27 & $2.428,43$ & 195,00 & $349.338,00$ & $28.273,08$ & $97.710,51$ & 100,00 & $1.972,50$ & $4.455,37$ & $18.810,16$ & $4.494,97$ & $30.803,57$ & 980,00 & 49,88 & $1.400,43$ \\
\hline & Doações (2 depósitos abertos) & $41.012,50$ & 0,00 & $6.800,00$ & 0,00 & 0,00 & $38.125,00$ & $66.725,00$ & 621,85 & 0,00 & 0,00 & $3.419,36$ & $2.718,80$ & $11.050,00$ & 0,00 & 0,00 & 0,00 & $19.337,50$ \\
\hline & Limite contratual de compras & $2.978,64$ & 122,54 & $1.940,36$ & $1.664,01$ & 253,53 & $8.946,29$ & $9.131,37$ & $14.690,05$ & 253,53 & 666,79 & $5.317,20$ & $2.963,79$ & $8.766,28$ & 679,10 & $2.484,61$ & 36,13 & $1.560,67$ \\
\hline & (Ek + Doaçōes + Compra) - Demanda & $36.226,69$ & $-201,33$ & $7.125,37$ & $3.742,43$ & 264,06 & $327.503,58$ & $82.274,51$ & $66.072,98$ & 258,93 & $2.115,79$ & $9.440,82$ & $12.562,44$ & $20.691,96$ & $23.455,67$ & $3.370,01$ & 61,57 & $15.964,84$ \\
\hline & Faltas (resultados do modelo) & 0,00 & $-201,33$ & 0,00 & 0,00 & 0,00 & 0,00 & 0,00 & 0,00 & 0,00 & 0,00 & 0,00 & 0,00 & 0,00 & 0,00 & 0,00 & 0,00 & 0,00 \\
\hline \multirow{6}{*}{6} & Demanda Total & $41.859,83$ & 662,20 & $6.940,49$ & 350,02 & 184,47 & $214.721,39$ & $68.103,55$ & $146.302,05$ & 94,60 & $1.627,50$ & $11.689,06$ & $37.176,76$ & $11.278,30$ & $24.955,00$ & 94,60 & 75,95 & $19.737,02$ \\
\hline & Ek & $5.668,69$ & 338,33 & 612,27 & $2.428,43$ & 195,00 & $349.338,00$ & $28.273,08$ & $97.710,51$ & 100,00 & $1.972,50$ & $4.455,37$ & $18.810,16$ & $4.494,97$ & $30.803,57$ & 980,00 & 49,88 & $1.400,43$ \\
\hline & Doações (2 depósitos abertos) & $41.012,50$ & 0,00 & $6.800,00$ & 0,00 & 0,00 & $38.125,00$ & $66.725,00$ & 621,85 & 0,00 & 0,00 & $3.419,36$ & $2.718,80$ & $11.050,00$ & 0,00 & 0,00 & 0,00 & $19.337,50$ \\
\hline & Limite contratual de compras & $2.978,64$ & 122,54 & $1.940,36$ & $1.664,01$ & 253,53 & $8.946,29$ & $9.131,37$ & $14.690,05$ & 253,53 & 666,79 & $5.317,20$ & $2.963,79$ & $8.766,28$ & 679,10 & $2.484,61$ & 36,13 & $1.560,67$ \\
\hline & (Ek + Doaçōes + Compra) - Demanda & $7.800,00$ & $-201,33$ & $2.412,14$ & $3.742,43$ & 264,06 & $181.687,90$ & $36.025,90$ & $-33.279,64$ & 258,93 & $1.011,79$ & $1.502,87$ & $-12.684,01$ & $13.032,96$ & $6.527,67$ & $3.370,01$ & 10,05 & $2.561,58$ \\
\hline & Faltas (resultados do modelo) & $-1.889,67$ & $-201,33$ & $-959,42$ & 0,00 & 0,00 & 0,00 & 0,00 & $-33.316,70$ & 0,00 & 0,00 & $-2.255,41$ & $-12.846,05$ & 0,00 & 0,00 & 0,00 & 0,00 & $-3.400,27$ \\
\hline \multirow{6}{*}{7} & Demanda Total & $13.433,13$ & 662,20 & $2.227,26$ & 350,02 & 184,47 & $68.905,72$ & $21.854,94$ & $46.949,43$ & 94,60 & 523,50 & $3.751,11$ & $11.930,30$ & $3.619,29$ & $8.027,00$ & 94,60 & 24,43 & $6.333,76$ \\
\hline & Ek & $5.668,69$ & 338,33 & 612,27 & $2.428,43$ & 195,00 & $349.338,00$ & $28.273,08$ & $97.710,51$ & 100,00 & $1.972,50$ & $4.455,37$ & $18.810,16$ & $4.494,97$ & $30.803,57$ & 980,00 & 49,88 & $1.400,43$ \\
\hline & Doações (2 depósitos abertos) & $41.012,50$ & 0,00 & $6.800,00$ & 0,00 & 0,00 & $38.125,00$ & $66.725,00$ & 621,85 & 0,00 & 0,00 & $3.419,36$ & $2.718,80$ & $11.050,00$ & 0,00 & 0,00 & 0,00 & $19.337,50$ \\
\hline & Limite contratual de compras & $2.978,64$ & 122,54 & $1.940,36$ & $1.664,01$ & 253,53 & $8.946,29$ & $9.131,37$ & $14.690,05$ & 253,53 & 666,79 & $5.317,20$ & $2.963,79$ & $8.766,28$ & 679,10 & $2.484,61$ & 36,13 & $1.560,67$ \\
\hline & (Ek + Doaçōes + Compra) - Demanda & $36.226,69$ & $-201,33$ & $7.125,37$ & $3.742,43$ & 264,06 & $327.503,58$ & $82.274,51$ & $66.072,98$ & 258,93 & $2.115,79$ & $9.440,82$ & $12.562,44$ & $20.691,96$ & $23.455,67$ & $3.370,01$ & 61,57 & $15.964,84$ \\
\hline & Faltas (resultados do modelo) & 0,00 & $-201,33$ & 0,00 & 0,00 & 0,00 & 0,00 & 0,00 & 0,00 & 0,00 & 0,00 & 0,00 & 0,00 & 0,00 & 0,00 & 0,00 & 0,00 & 0,00 \\
\hline \multirow{6}{*}{8} & Demanda Total & $41.859,83$ & 662,20 & $6.940,49$ & 350,02 & 184,47 & $214.721,39$ & $68.103,55$ & $146.302,05$ & 94,60 & $1.627,50$ & $11.689,06$ & $37.176,76$ & $11.278,30$ & $24.955,00$ & 94,60 & 75,95 & $19.737,02$ \\
\hline & Ek & $5.668,69$ & 338,33 & 612,27 & $2.428,43$ & 195,00 & $349.338,00$ & $28.273,08$ & $97.710,51$ & 100,00 & $1.972,50$ & $4.455,37$ & $18.810,16$ & $4.494,97$ & $30.803,57$ & 980,00 & 49,88 & $1.400,43$ \\
\hline & Doações (2 depósitos abertos) & $41.012,50$ & 0,00 & $6.800,00$ & 0,00 & 0,00 & $38.125,00$ & $66.725,00$ & 621,85 & 0,00 & 0,00 & $3.419,36$ & $2.718,80$ & $11.050,00$ & 0,00 & 0,00 & 0,00 & $19.337,50$ \\
\hline & Limite contratual de compras & $2.978,64$ & 122,54 & $1.940,36$ & $1.664,01$ & 253,53 & $8.946,29$ & $9.131,37$ & $14.690,05$ & 253,53 & 666,79 & $5.317,20$ & $2.963,79$ & $8.766,28$ & 679,10 & $2.484,61$ & 36,13 & $1.560,67$ \\
\hline & (Ek + Doaçōes + Compra) - Demanda & $7.800,00$ & $-201,33$ & $2.412,14$ & $3.742,43$ & 264,06 & $181.687,90$ & $36.025,90$ & $-33.279,64$ & 258,93 & $1.011,79$ & $1.502,87$ & $-12.684,01$ & $13.032,96$ & $6.527,67$ & $3.370,01$ & 10,05 & $2.561,58$ \\
\hline & Faltas (resultados do modelo) & $-1.889,67$ & $-201,33$ & $-959,42$ & 0,00 & 0,00 & 0,00 & 0,00 & $-33.316,70$ & 0,00 & 0,00 & $-2.255,41$ & $-12.846,05$ & 0,00 & 0,00 & 0,00 & 0,00 & $-3.400,27$ \\
\hline
\end{tabular}

Obs.: células sombreadas indicam faltas mesmo quando materiais encontram-se disponíveis. 
Apêndice 10: Comparação das faltas nos cenários 7 e 8 com ruptura no depósito de São Paulo.

\begin{tabular}{|c|c|c|c|c|c|c|c|c|c|c|c|c|c|c|c|c|}
\hline & \multirow{2}{*}{$\begin{array}{c}\text { Cená- } \\
\text { rio }\end{array}$} & \multicolumn{15}{|c|}{ Materiais $(\mathrm{kg})$} \\
\hline & & Agasalho & Bota & Camiseta & Capacete & $\begin{array}{l}\text { Cestaa } \\
\text { Básica }\end{array}$ & Cobertor & Colchão & Colete & $\begin{array}{c}\text { Fita } \\
\text { isolamento }\end{array}$ & $\begin{array}{c}\text { Kit } \\
\text { Higiene }\end{array}$ & $\begin{array}{c}\text { Kit } \\
\text { Limpeza }\end{array}$ & Lençol & $\begin{array}{l}\text { Lona } \\
\text { plástica }\end{array}$ & 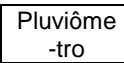 & Tênis \\
\hline \multirow{2}{*}{$\begin{array}{l}\text { Sem ruptura ou ruptura em } \\
\text { depósito do interior }\end{array}$} & 7 & - & 201.33 & - & - & - & - & - & - & - & . & - & - & - & - & - \\
\hline & 8 & \begin{tabular}{|l|}
$1,889.67$ \\
\end{tabular} & 201.33 & 959.42 & - & - & - & $33,316.70$ & - & - & $2,255.41$ & $12,846.05$ & - & - & - & $3,400.27$ \\
\hline \multirow{2}{*}{ Ruptura no depósito SP } & 7 & $4,489.63$ & 370.50 & $1,261.28$ & 86.97 & - & - & - & 44.60 & - & 155.68 & $1,437.70$ & - & - & - & $4,124.30$ \\
\hline & 8 & \begin{tabular}{|l|}
$22,620.48$ \\
\end{tabular} & 370.50 & $3,914.35$ & 86.97 & $24,802.39$ & $27,277.01$ & $82,508.00$ & 44.60 & 641.25 & $6,330.92$ & $23,720.37$ & $4,610.81$ & $9,553.22$ & 24.94 & $11,301.80$ \\
\hline
\end{tabular}

